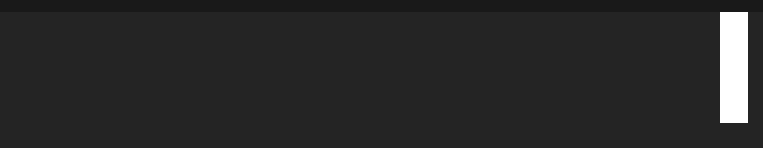

$\odot$

THE WATCHMAN

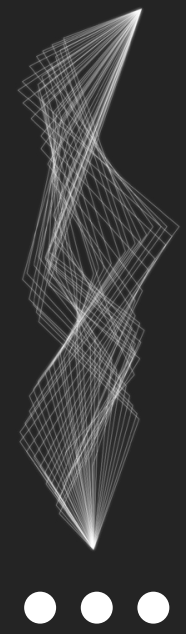

A DIDACTIC REHABILITATIVE ARCHITECTURE 2018 
BY RHIDIAN SCOTT-TOWERS

\section{THE WATCHMAN}

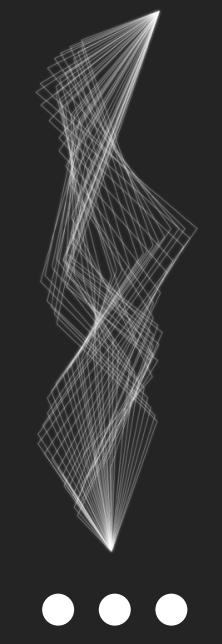

A 120-Point Thesis

submitted to the Victoria University of Wellington in partial fulfilment of the requirements for the degree of Master of Architecture

Victoria University of Wellington School of Architecture 
Little Rose

000

First and foremost I dedicate this research to my little sister Roisin.

Your ability to summon the courage and strength it takes to wake up

in pain every day, and yet somehow express compassion and love in

a world that has been nothing but unfair to you, is utterly incredible.

You inspire me. 
Abstract

\section{0}

Over the course of the last five years, the female prison population in New Zealand has risen more than $56 \%$. As these numbers remain exponentially increasing, the ability to uphold successful facilitation for each and every inmate is weakening. This is largely a result of poor and incorrect implementation of criminal rehabilitation
schemes. Upon release, confusion, fear, and the sheer overwhelm schemes. Upon release, confusion, fear, and the sheer overwhelm
of exposure to the culture contained within modern day society of exposure to the culture contained within modern day society
gives appeal to recidivism, and leads to the escalation of the prison population crisis. In response to this escalating crisis - advancing the search
for alternative means of successful criminal rehabilitation this research explores the enablement of architecture to have a rehabilitative function within a prison chironnent, as well as the reduction of recidivism through didactic architectural experience.

This research proposes that the decommissioned Mount Crawford Prison in Wellington New Zealand can be redesigned to test this opportunity. As a research site, it can be used to test how design
can enhance the rehabilitation process of a prisoner in the cultural transition from incarceration to society.

The research approach integrates Michel Foucault's theory "Of Other Spaces" to address the first principle objective of this research investigation, and develop architecture that encourages prison
inhabitants to reinterpret dystopian experience through the lens of heterotopia: Cathy Ganes theory "Design as Narrative: A theory of heterotopia; Cathy Ganoes theory "Design as Narrative: A theory of
inhabiting space" to address the second principle objective of this research investigation, and develop architecture that establishes a spatial experiential narrative about a person's transforming interpretation of their surroundings; Daniel Merritt Hewetts theory "Architecture and the Productive Implications of Pause" to address the third principle objective of this research investigation, as a means of establishing strategic points of pause along the understanding of heterotopia. Kalervo Oberg's theory of culture shock is also integrated as a means of developing an understanding

of the cultural transition from incarceration to liberation. 


\section{Acknowledgements}

\section{0}

To my supervisor Daniel K. Brown I extend my deepest gratitude. Your wisdom and passionate devotion in the field of architecture is admirable beyond words. I consider myself extremely fortunate
to have received your guidance throughout the process of creating this thesis.

To Dad, from a young age you taught me the importance of understanding how things work. My passion for architecture and inhouttable space stems trom the knowledge you have pase
through years of model making and 'tinkering, thank you.

To Mum, my education would not have been possible without your soul has guided me in the direction of helping others where I can.

To Peter and Linda, thank you for your kindness and hospitality over the past few months. I would not have been able to complete

To Nelson Chan, for the times I fell behind, you were always there to pat me on the back, hand me some Zambrero, and say "Keep going bro."

Last but not least, to the rest of my friends in the class of 2017/18. This year has been a roller-coaster of emotions. We've made it, and I
am so proud of each and every one of you am so proud of each and every one of you. 


\section{Preface}

The title of my thesis is "The Watchman", which is taken from the poem "The Watchman" by Lucy M. Montgomery.

I care no more for glory; all desire

For conquest and for strife is gone from $m$

All eagerness for war, I only care

Some comfort to the wask gs, and to

- L. M. Montgomery, excerpt from "The Watchman"

hroughout my architectural education, I have always valued the importance of poychological thderstand Ing in design. I have taken great pride and interest in how the design of space can trigger emotions and reflections, based upon the psychological context of the occupant.

The criminal mind in particular has, for as long as I remember, been of distinct fascination to me, and from a very young age I had my I also grew up with a natural inclination to help others, combined with a sense of moral obligation to use what knowledge I possessed to make the world a better place.

New Zealand has historically struggled to deal effectively with mental health and wellbeing, and convicted felons often bear currently lies dormant in Miramar, Wellington, and it presents an extraordinary opportunity to explore speculative avenues of criminal rehabilitation through architecture. This thesis hearkens back to my childhood curiosity about the criminal mind and uses

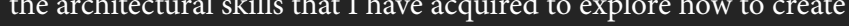
a place and a voice for those who most need it, particularly women convicts on the threshold of being released back into society. 


\section{Contents}

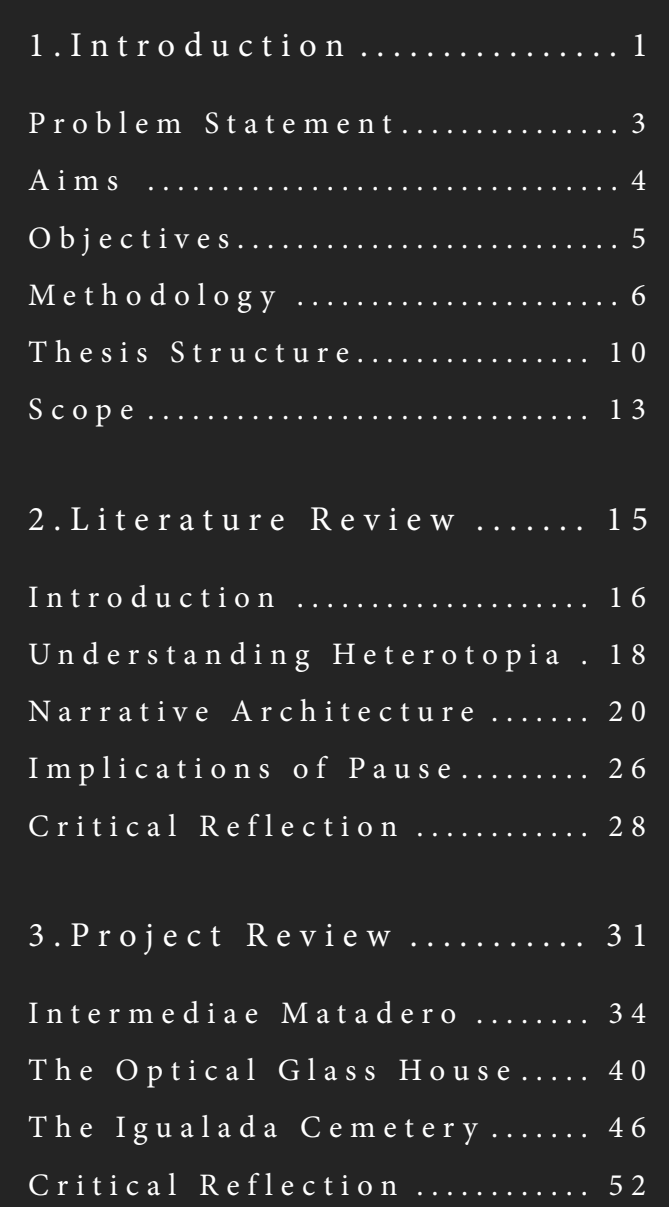

New Zealand Prisons......... 58

Mount Crawford Prison ..... 60

History $\ldots \ldots \ldots \ldots \ldots \ldots \ldots, 62$

Building Analysis ............6 64

Site Visit................... 70

Understanding Heterotopia. 72

Narrative Mapping .......... 77

Pause Mapping .............. 85

Critical Reflection .......... 94

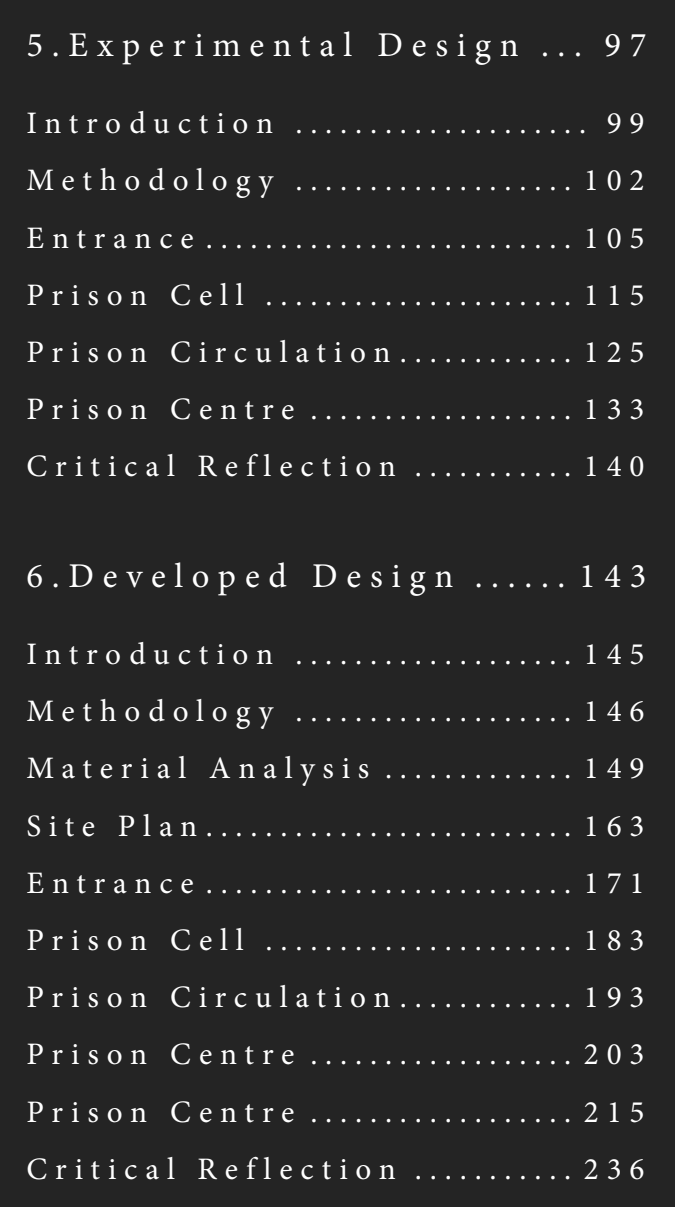

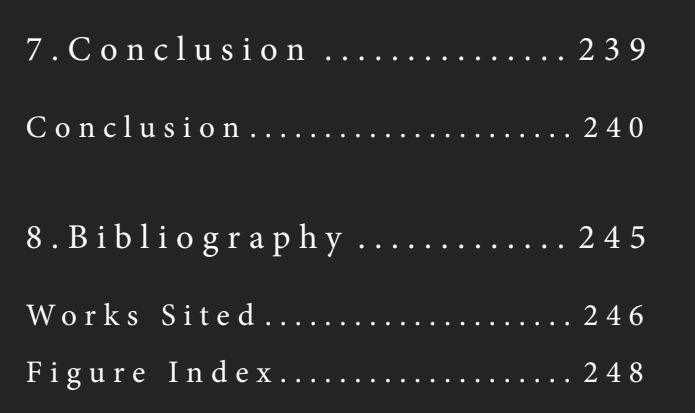

tical Reflection 

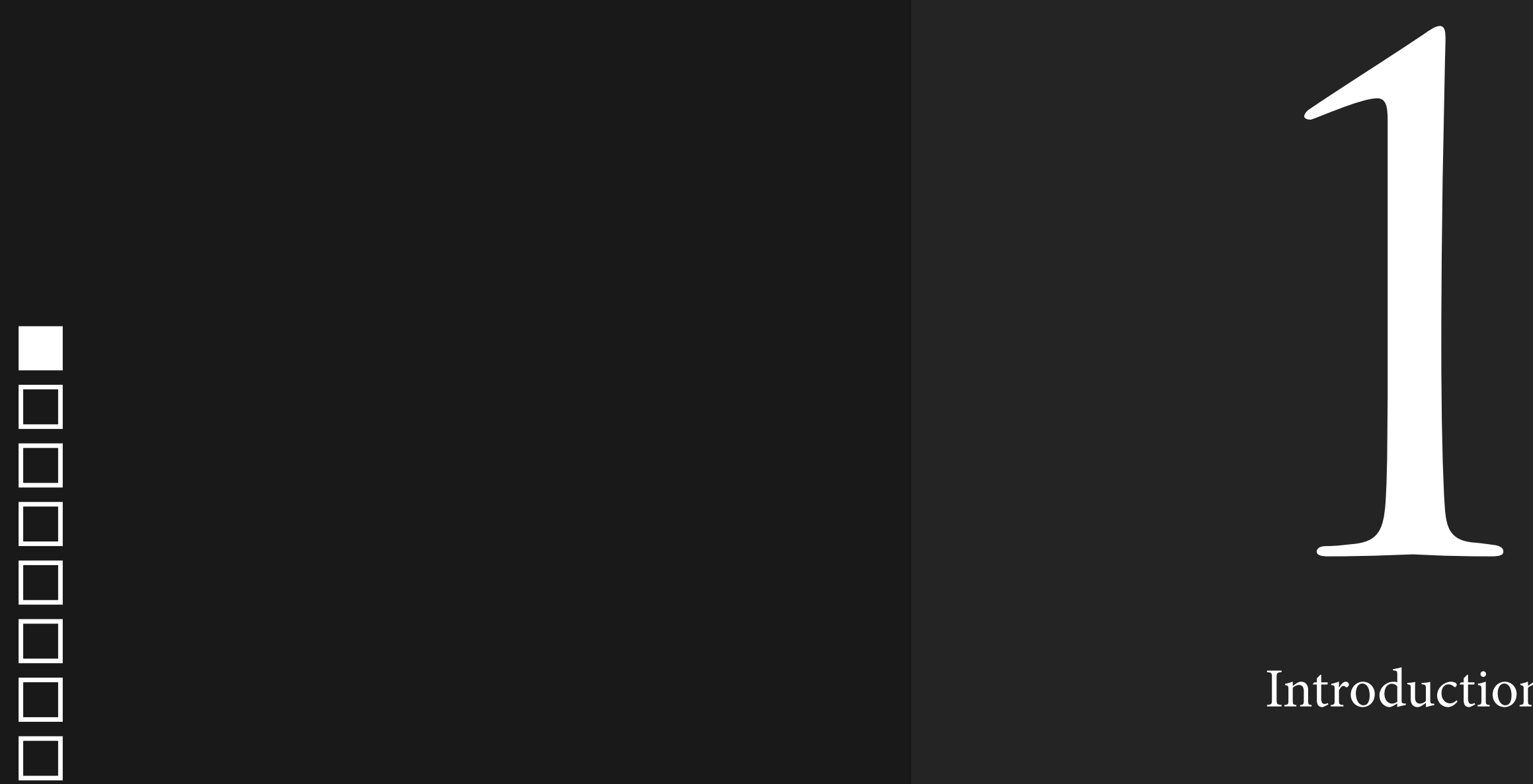

Introduction If you treat an individual as she is, she will remain how she is.
But if you treat her as if she were what she ought to be and could $b e$, she will become what she ought to be and could be.

- Johann Wolfgang von Goethe 


\section{Problem Statement}

\section{0}

In 2013 the murder of a civilian whose killer was on bail at the time of the event, changed the approach to criminal treatment in New Zealand. In a ressonse that ought to have seen a development in
criminal rehabilitation, the New Zealand government instead, hardened the bail laws as the constant calls from the public for "tough on crime" grew louder (Walters, 2018).

Over the course of the last five years, the New Zealand female prison population has risen more than $56 \%$. The national penitentiaries facilitation for each and every inmate is weakened by the sher influx in numbers. This is largely a result of poor, and the sheer implementation of criminal rehabilitation schemes, and the failure to implement qualitative learning within the prison environment. Upon release, confusion, lack of knowledge, and the sheer overwhelm of exposure to the culture contained within modern day society, gives appeal to recidivism. This adds to the escalation

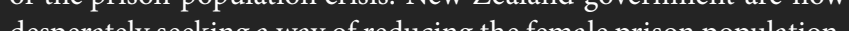
(Wesperately 2018 ).

In response to this escalating crisis - advancing the search for alternative means of successful criminal incarceration - this research proposes, and explores, the enablement of architecture

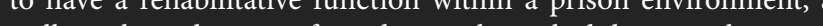
well as, the reduction of recidivism through didactic architectural

Society categorises criminals as deviated individuals and correspondingly separates them from the utopian ideology of a a dystopian understanding of life, as they are restricted to the experience of the prison environment. The constriction of movement and dystopian spatial experience in the prison envis conjunction with a lack of mental stimulation, escalates the inmate's dystopian and deviated understanding of self 


\section{Aims}

\section{0}

- To enable architecture to have a rehabilitative function in a prison environment.

- To help reduce recidivism through didactic architectural experience.

\section{Objectives}

\section{0}

- To use architecture to encourage prison inhabitants to reinterpret dystopian experience through the lens of heterotopia.

-Principal Theorist - Michel Foucault "Of Other Spaces" -Case Study - Intermediae Matadero Madrid by Arturo - To use architecture to establish a spatial experiential narrative
about the prison inhabitants' transforming interpretation of their surroundings, in order to rehabilitate the dystopian mind set.

•Principal Theorist - Cathy Ganoe "Design as Narrative: A -Case of Study - Optical Ghas

- To use architecture to establish strategic points of pause along the journey of the spatial experiential narrative, that enable enhanced derstanding of heterotopia.

- Principal Theorist - Daniel M. Hewett "Architecture and the Productive Implications of Pause Cetery by Enric Miralles and

$$
000
$$

This research proposes the decommissioned Mount Crawford Prison in Wellington New Zealand, as a research site to test design solutions, in the aim of achieving each of the aims and objectives specified. The dystopian experence that correlates with the historical content of the ste proves the opportunity to of dystopian experience. The developed programme will seek to highlight and separate the dystopian experience of the existing site, with the utopian experience of the developed intervention. 


\section{Methodology}

This research investigation adopts Peter Downton's methodology of
research for design to develop a response to the aim of enabling and reducing recidivism through didactic architectural experience.

The term research for design is understood to mean research designing in whatever was the designer(s) regard as useful and this includes research intended to provide information and data that is necessary to successfully conclude the undertaking in question. A good alternative term would be research to enable design (Downton, 2003).

This methodological process is initiated by obtaining a theoretica understanding of the developwert in thecture that engages each

- The first objective of this research investigation aims to use architecture to encourage prison inhabitants to reinterpre dystopian experience through the lens of heterotopia.

Paul-Michel Foucault, otherwise known as Michel Foucault, was a French philosopher, historian of ideas, social theorist and literary critic (Schent, 200). In 1986 he whe the theory "Of Othe Spaces" and cstert their correlating spatial experiences.

Arturo Franco is a Spanish architect and the designer of a transdisciplinary artwork space situated within a former slaughterhouse in Madrid, known as the Intermediae Matadero (ArchDaily, Intermediae Matadero Madrid / Arturo Franco, 2011). with the historic sh partions to create an Antangible relationsh with the historic slaughterhouse, as the wals remain visible $y$ are incapable of being physically interacted with. This creates an exhibit, and spatial separation from the once dystopian experien

Michel Foucault's theory - and its extensive understanding of uropa-dystopia and heterotopia - are used in combination with the findings from the study of the Intermediae Matadero, to establish a theoretical understanding of architecture that explores the first objective. Prison architecture that develops the inmates understanding of dystopian and utopian experience through the lens of heterotopia (or in tangible space, has the potential to development in understanding the culture that exists beyond the prison environment has the potential to reduce the adverse effects of foreign culture shock upon inmate release. This is an avenue of criminal rehabilitation that has not been explored through didactic architectural experience.

- The second objective of this research investigation aims to use architecture to estabish a spatial experiential narrative about surroundings in order to rehabilitte the dystopinn mind set.

Cathy Ganoe was a professor at the Central State Michigan University
established in the Department of Human Environmental studies (Keys, 2007). In 1999 she wrote the theory "Design as Narrative: A theory of inhabiting space" and expressed that an envers should be assessed as unfolding over a period of human time as opposed to a singular experience.

Hiroshi Nakamura is a Japanese architect and the designer of the Optical Glass House in Hiroshima (ArchDaily Optical Glass House / Hiroshi Nakamura \& NAP, 2017). Within the Optical Glass House, nature is fused with architecture and the design is given the physical capability to develop while simultaneously being experienced over the course of human time.

Cathy Ganoe's theory is used in conjunction with the theory of Glass House, to inform the design of a didactic architectural experience that helps inmates to develop their understanding of dystopian experience, and, reinterpret it over the course of human time. Kalervo Oberg was a Canadian anthropologist who first coined the term "culture shock" in 1954 (Oberg, 1954). His descriptive understanding of the process of cultural transtion and the correlating adverse efiects were revolutionary, and will be and informs the transition in theme along the setil experiential journey of the prison. 


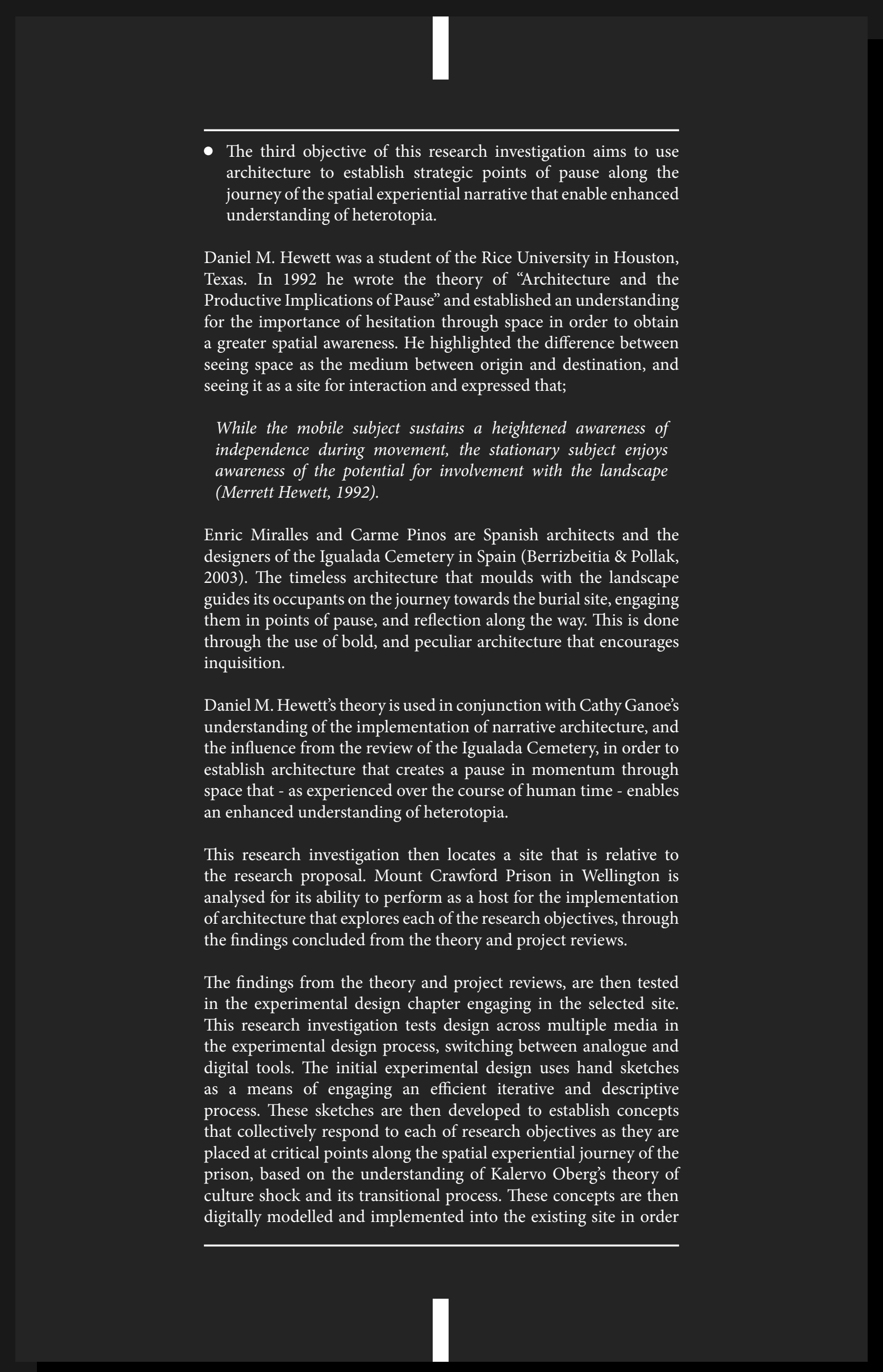

to introduce a scale and location. The experimental design chapter is then critically reflected upon. This critical reflection is used to highight the strenghs and weaknesses of the design experiments

The developed design chapter is informed by the findings of the critical reflection of the experimental design. This chapter engages in a second project review, analysing a new set of cases studies relative to the findings of the experimental design. Physical modeling and
photographic experiments are then used to explore alternative design concepts in the aim of establishing a more successful outcome relative to the real world experience. The design is then developed digitally through the use of $3 \mathrm{D}$ modelling CAD software and photographs, 3D modelling and architectural renders. These imases are created as representations of the developed design ideas that are expressive of didactic architecture that has rehabilitative function in a prison environment, in the aim of reducing recidivism. 


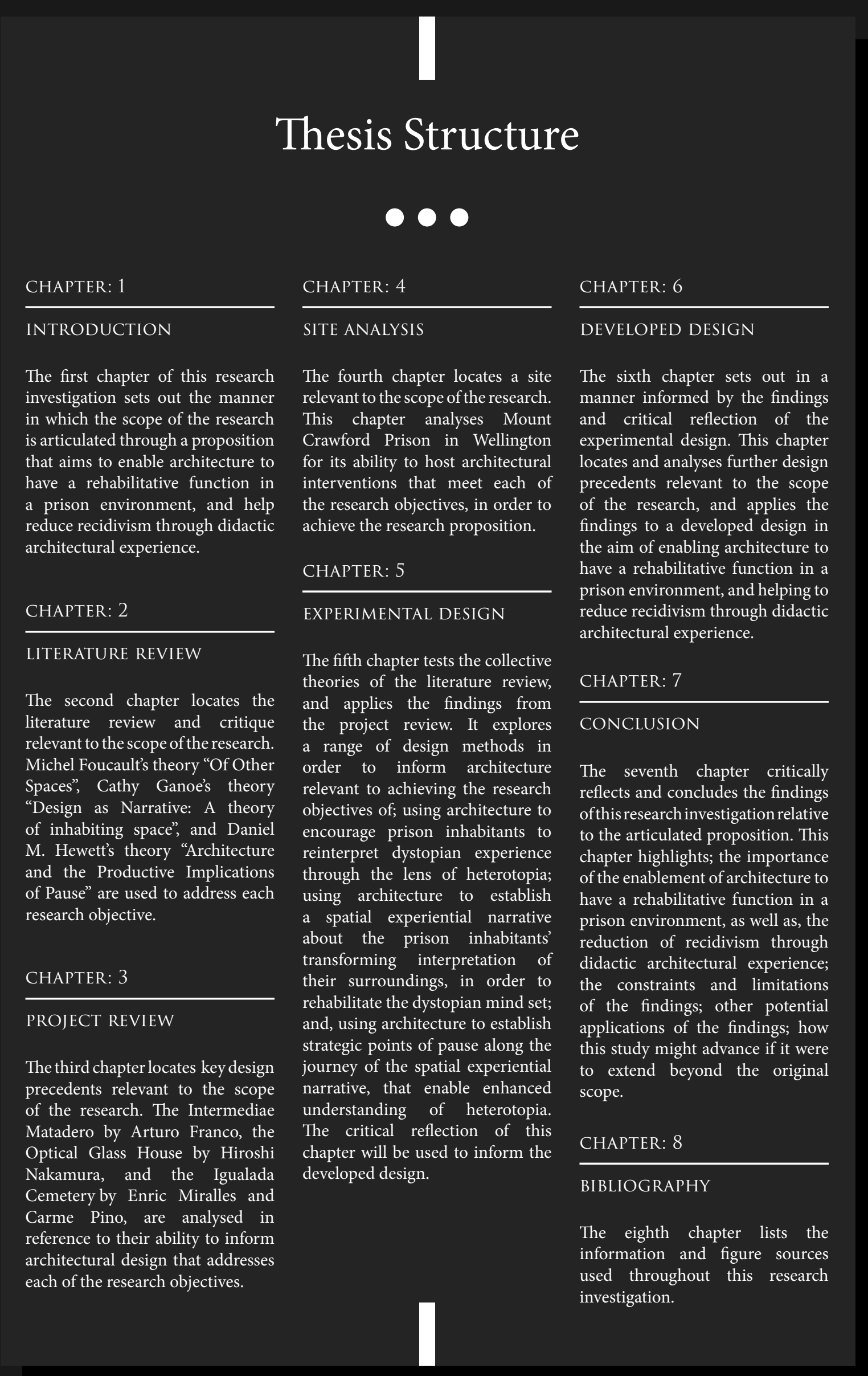

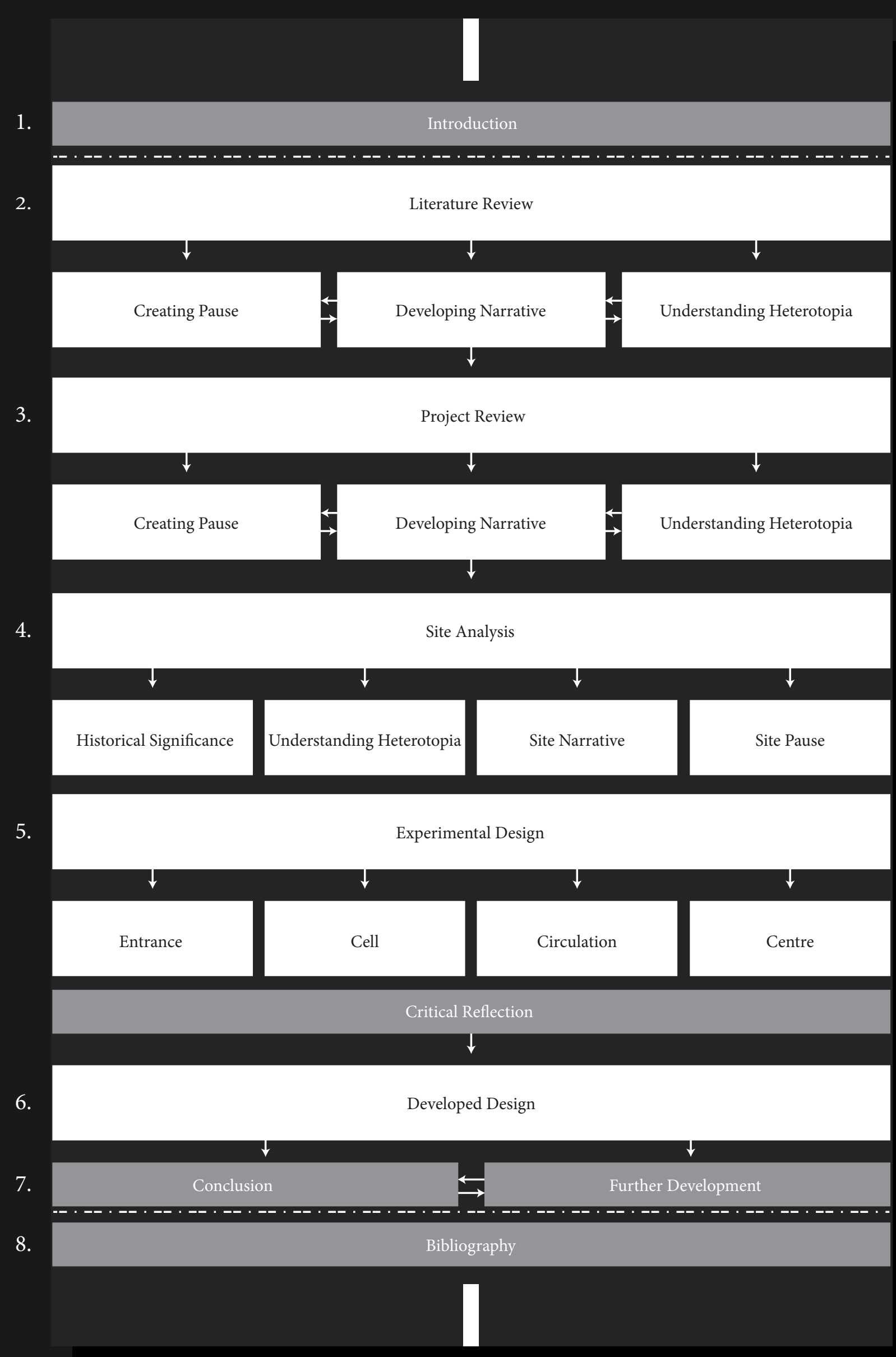




\section{Scope}

000

This research investigation sets out to achieve a theoretical architectural solution, to reduce recidivism among the female prison population in New Zealand. It focuses primarily on the prison environment and to help reduce recidivism through didactic architectural experience.

The sheer scale of the Mount Crawford Prison and the complexity of establishing a criminal rehabilitation program means that certain areas of the design could not be fully addressed such as:

- Development costs and structural analysis,

- Logistical management of guard administration and general services,

- The organisational logistics of the crimina rehabilitation programme.

This research investigation is limited by the inability to freely assess the sie, and test design findings, as it is a restricted area and only one

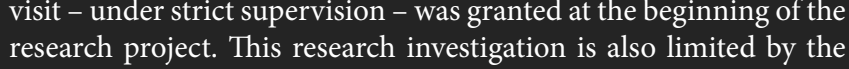
inability to discuss with, and test findings on incarcerated criminals, as well as the time constraint of the original scope. The discipline of architecture may contribute too, but cannot solely, establish a exist beyond the original scope, the collaboration of a multitude of disciplines - in particular psychology criminology and law - over an extended time period, would equally contribute to the outcome of a successful criminal rehabilitation facility.

This research investigation employs a qualitative approach. It is driven by the assumption that the process of cultural transition is relative to the process of chiminal hberation, and therefore, the transition within the criminal rehabilitation facility 

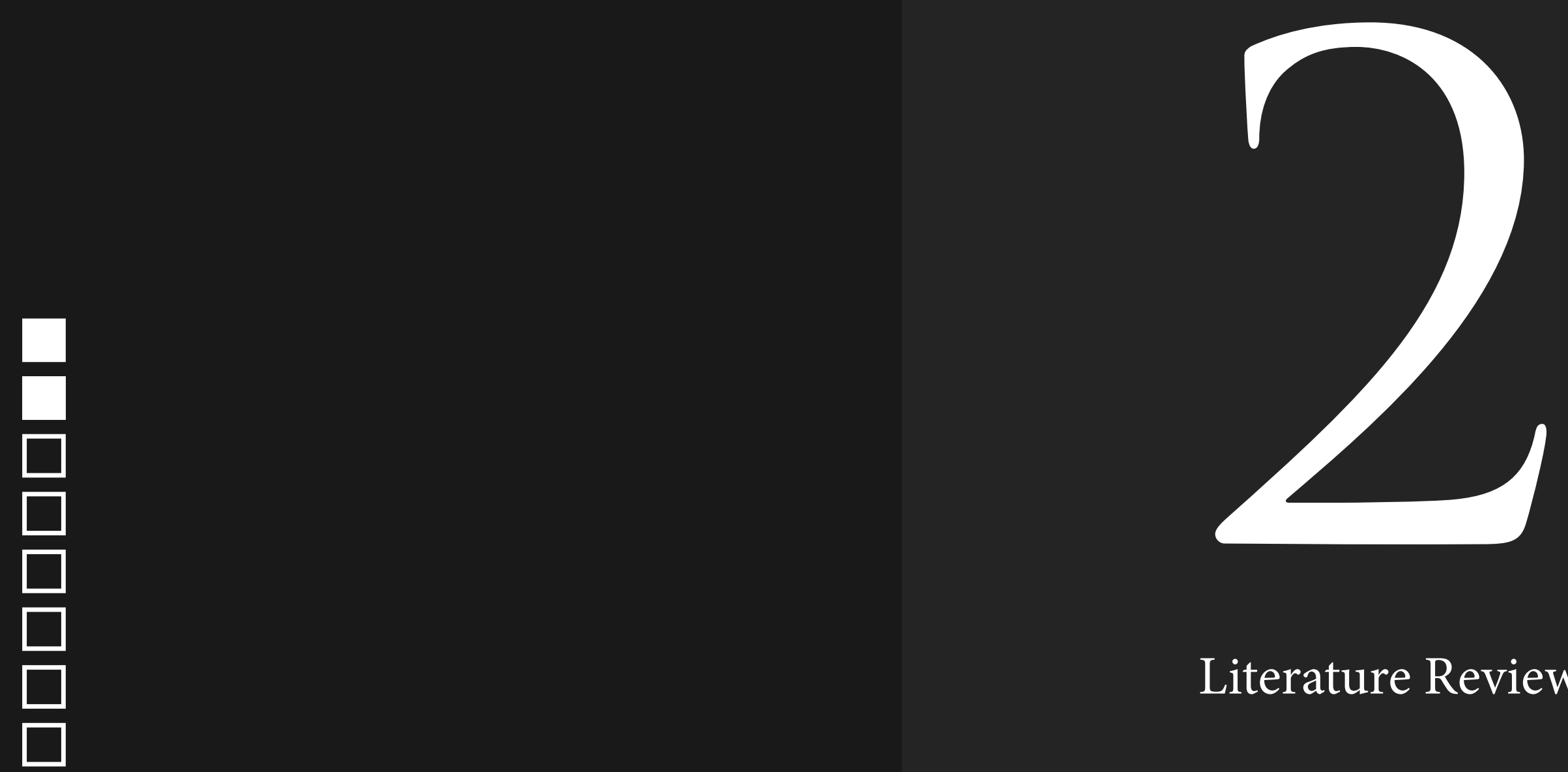

\section{Literature Review}

000

Narrative theory provides an additional framework

that synthesizes the externalsymbolic with the internall phenomenological response to environment through the vehicle of language.

-C. Ganoe, exerpt of Inhabiting Space" 


\section{Introduction}

The principle aims of this research investigation are to test
how architecture environment, and to reduce recidivism through didactic
end architectural experience. This thesis proposes that life in a prison has inherent dystopian qualities that can be overcome and understood lens. The investigation proposes that architecture can help enante this transformative view by establishing a spatial experiential narrative within the daily prison experience, by incorporating strategic points of pause within that spatial experience that help a prisoner reinterpret the dystopian experience into one that helps them transition back into society and a life outside the prison structure.

The research site has an inherent narrative that arises from its histor This brings to light the opportunity to create spatil back to 1927. and real-world comparison in the physical and emotional journey from behind the prison bars into the free world. This thesis proposes that establishing a physical journey to accompany and highlight the mental transitions through culture shock from the depth of prison incarceration to the free world will teach felons about themselves, and help them to develop an understanding of how to behave and deal with the developing word around them. This approach is designed to help mitigate recidvism and reduce prison overflow,
while aiding those who are incarcerated.
This chapter researches different theorists and critically reflects on how their approaches might be integrated together as a means of adree principle objectives of

a) To use architecture to encourage prison inhabitants to reinterpret dystopian experience through the lens of heterotopia;

b) To use architecture to establish a spatial experiential narrative about the prison inhabitants' transforming herpretation of their surround go, in order to rehabilitate the dystopian mind set,

c) To use architecture to establish strategic points of pause along the journey of the spatial experiential narrative, that enable enhanced journey of the spatial experiention
understanding of heterotopis

\section{○० ०}

This chapter considers different perspectives for addressing the aims and objectives of this thesis: Michel Foucault's theory of "Of other experience through the lens of heterotopia: Cathy Genoe's theory of "Design as Narrative: A theory of inhabiting space" and Kalervo Oberg's theory of "Culture Shock" as a means of establishing a spatial experiential narrative about a person's transforming interpretation of their surroundings; Daniel Merritt Hewett's theory of "Architecture and the productive implications of pause" as a
means of establishing strategic points of pause that enable enhanced understanding through the use of architecture.

Theory relating to these perspectives is assimilated around the idea of curating a unique approach to criminal rechbilittion, idea of curating a unique approach to criminal rehabilitation,
through a didactic architecture, and the idea that the narrative of criminal rehabilitation in relation to the demeanour of their prison world, is comparable to that of the narrative of culture shock and therefore similar means of coping can be tested and applied. This approach will be used to help them attain heightened self narrative and enhanced connections with past, present and future identities.
Architecture will be designed and tested to parallel the mental developmental journey of culture shock ond pitice curiosity about spatial configurations that highlight the past, present and future stages of culture shock. Each stage will be designed with the aim of creating an understanding of constantly developing space to reflect that of understanding the relevance of a constantly developing mindset.

The theoretical perspectives, when integrated into design experiments, will be used to test solutions that address the primary this can be applied in a rehabilitative manner. 


\section{Understanding Heterotopia}

Research Objective 1: To use architecture to encourage
prison inhabitants to reinterpret dystopian experience

through the lens of heterotop

\section{In "Of Other Spaces" Michel Foucault describes} heterotopia as:

Utopias are sites with no real place. They are sites that have a general relation of direct inverted analogy with the real space of society. They present society itself as
perfected form, or else a society turned upside dow perfected form, or else a society turned upside down
but in any case these utopias are fundamentally unreal spaces.

There are also, probably in every culture, in every
civilization, real places - places that do exist and that are formed in the very founding of society which are something like counter-sites, a kind of effectively enacted utopia in which the real sites, an other real sites that can be found whin the culture. are simullaneously represented, contested, and even though it may be possible to indicate the location in reality. Because these places are absolutely different from all the sites that they reflect and speak about, I shall call them by way of contrast to utopias, heterotopias (Foucault, 1986).

Foucault's theory gives understanding to space no that is contained within it. Foucault refers to erios in particular, as 'heterotopias of deviation' due to their inhabitants being deviations of what is considered 'normal' in society. Other examples of heterotopias of deviation could be: psychiatric hospitals, rest homes and even preschools due to the fact that occupants are unable to take care of themselves, requiring assistance which is considered a deviated way of hing. Typically however Foucault's theory sheds a new light on the interpretation of all spatial types that are outside the normative for an adult functioning well in society.
Foucault's theory explores the idea that there is more Foucaults theory explores the idea that there is more
to just physically occupying a space, to truly enter a heterotopia is to become a part of the ethos of that space. This is something that is individual to the prisoners within a prison, a psychologival place that cannot be accessed by any prison guard or social worker as they do not live within the heterotopia of This thesis therefore sugests that instead of relying on guards and social workers to implicate schems of rehabilitation, the prison itself can help provide a narrative of rehabilitation and provides the means to understand ulterior heterotopias.

Design research experiments dealing with interpretation of space are an important part of the mental development. This research investigation to apply Foucault's theory of interpretation of space
to help adjust the mindset of felons incarcerated in rehabilitation scheme, and highlight the opportunity to reinterpret and rediscover themselves in the heterotopia of liberated society prior to being physically immersed

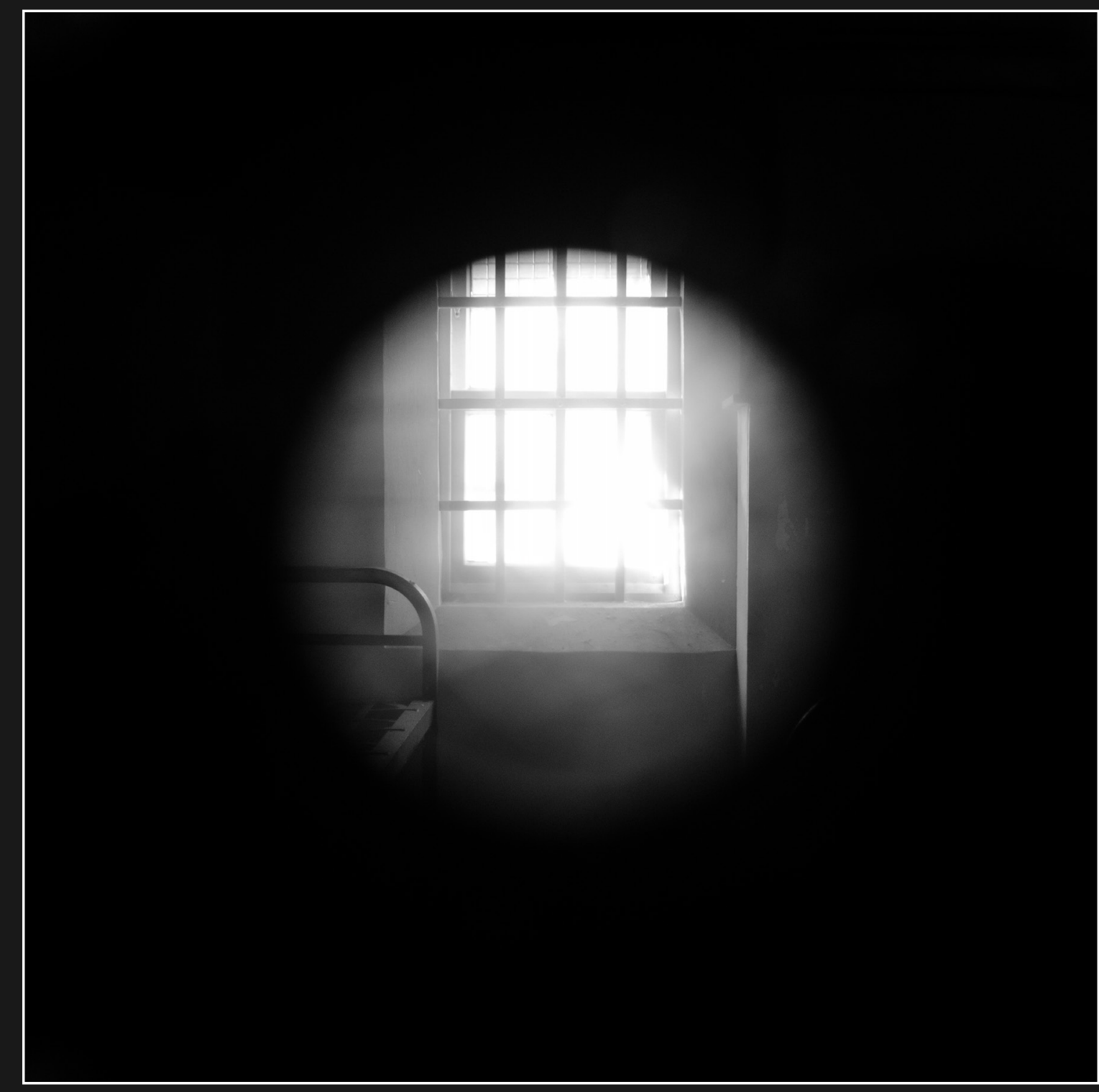




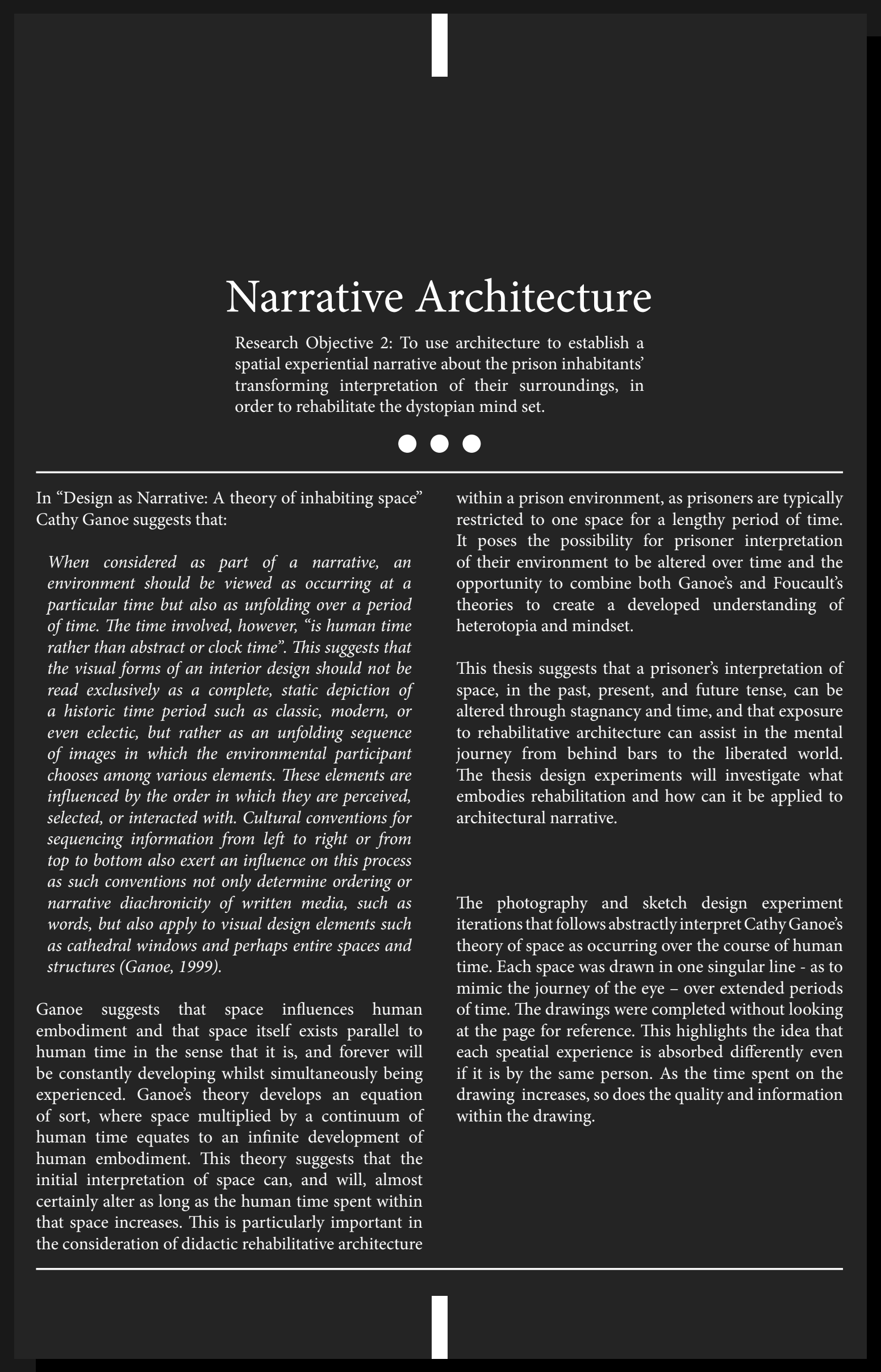
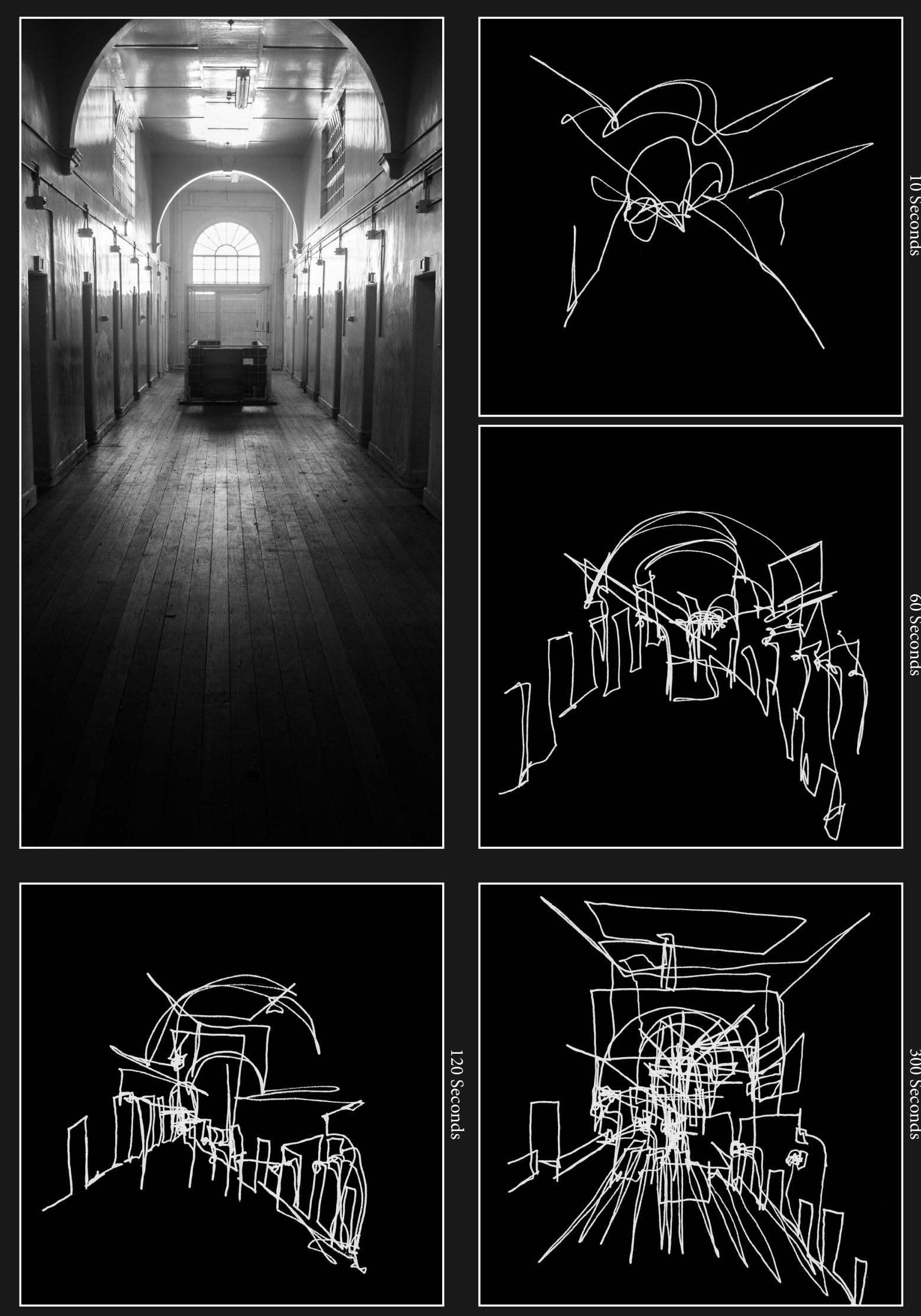

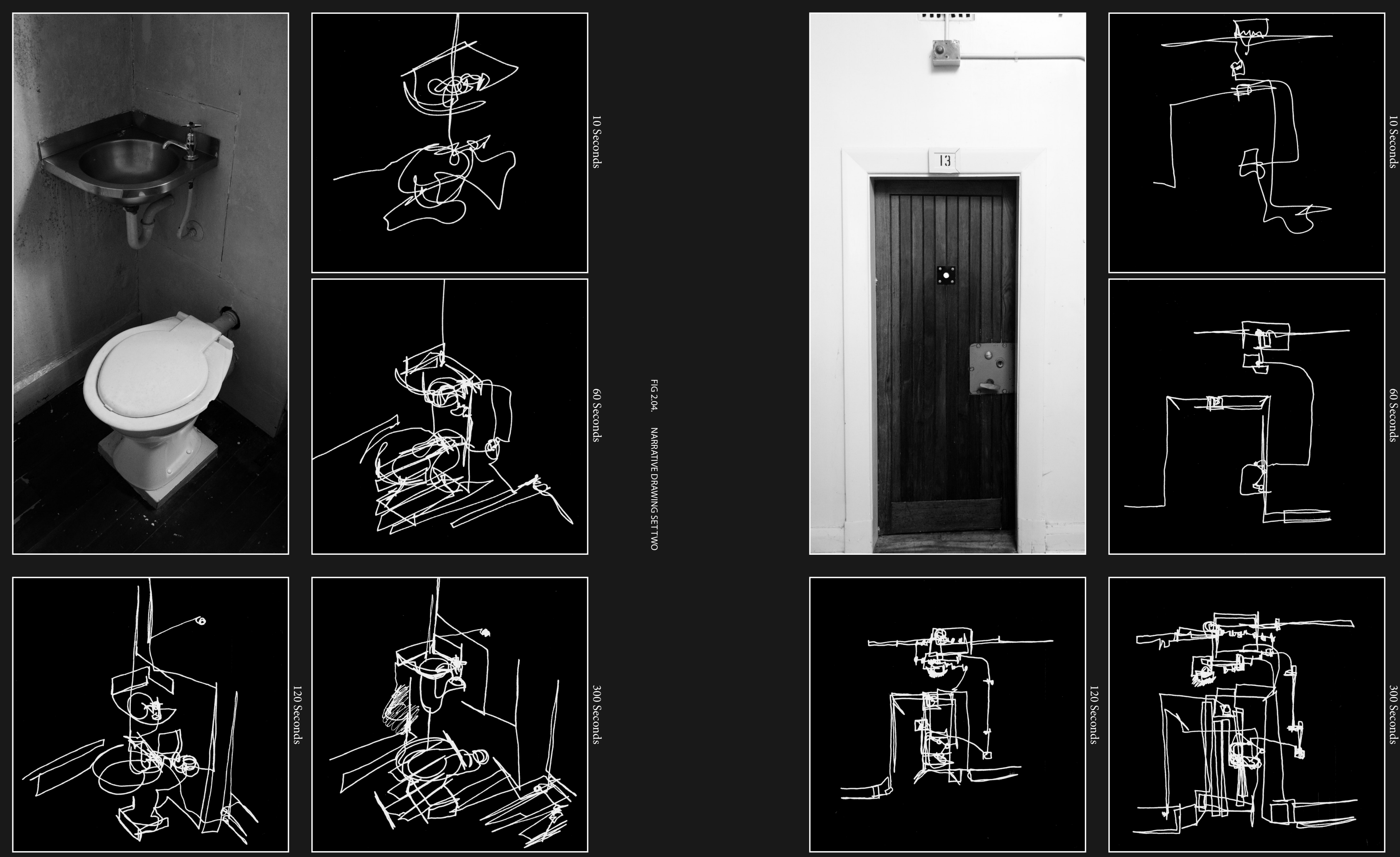


\section{Narrative Architecture}

Research Objective 2: To use architecture to establish a spatial experiential narrative about the prison inhabitants transforming interpretation of their sur
order to rehabilitate the dystopian mind set.

\section{0}

In 1954, anthropologist Kalervo Oberg coined the term

Culture shock is precipitated by the anxiety that results from losing all our familiar signs and symbots of social intercourse. These signs or cues include the thousand and one ways in which we orient ourselves to the situations of daily life: when to shake hand and what to say when we meet people, when and how to give tips, how to give orders to servants, how refuse invitations, when to take statements seriousty and when not. Now these cues which may be words gestures, facial expressions, customs, or norms are acquired by all of us in the course of growing up and are as much a part of our culure as the language we speak or the beliefs we accept. All of us depend for ou peace of mind and our efficiency on hunareds of these

Oberg's theory of Culture Shock suggests that when an ndividual is immersed in a foreign culture almost al these familiar cues are removed, and they experience a series of developmental phases in the process of a

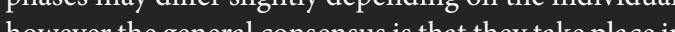
the order that follows:

1) Honeymoon Phase - During this phase individuals may be fascinated by their new surroundings and take pleasure in exploring and discovering their new environment. This phase may last anywhere from a few days to several weeks and if not returned to their home
before this phase ends, the individual will traverse onto

the next developmental stage.

2) Regression Phase - This phase is generally one of and a longing for fariarity. Home assumes tremendous importance and frustration evidently grows out of the genuire difficulty the individual experiences in the proces of adjusting. While people of the host environment may offer assistance daning this phase they are often the same experiential viewpoint as the individul in an unfamiliar environment. This second phase is in a sense, a phase of crisis. If the individual overcom this phase they move on to accepting their new surroundings and becoming a part of its ethos. If they do not, they return home, or in the case of ex-convict. they recommit to return to prison as they have come

3) Adjustment Phase - During this phase individuals have been immersed in the new environment long enough to see it for its differences and appreciate them. They have begun to integrate themselves. They have (t) they still bere diffities, they the by, and althoug stride as opposed to becoming fruse thed with the Typically in this phase individuals take on a superior attitude to the people of the host colvtry. $A$ sente of humour returns and jokes are often made about people and even one's own difficulties. At this point the ndividual has begun to embrace the new culture and is now on their way to recovery. nnother very important element of this phase is that dividuals begin to offer their assistance and what off positions. This in turn gives confidence in ability to both parties and if applied in a prison environmen would encourage inmates within the heterotopia of deviation to assist each other through these microheterotopias.

4) Acceptance Phase - This phase is considered the nal phase as individuals now operate freely and once considered foreign social cues now naturally ecome part of fluent everyday social interaction. Gone is anxiety that resulted from losing all familia attachment to the new culture is formed (Oberg, 1954).

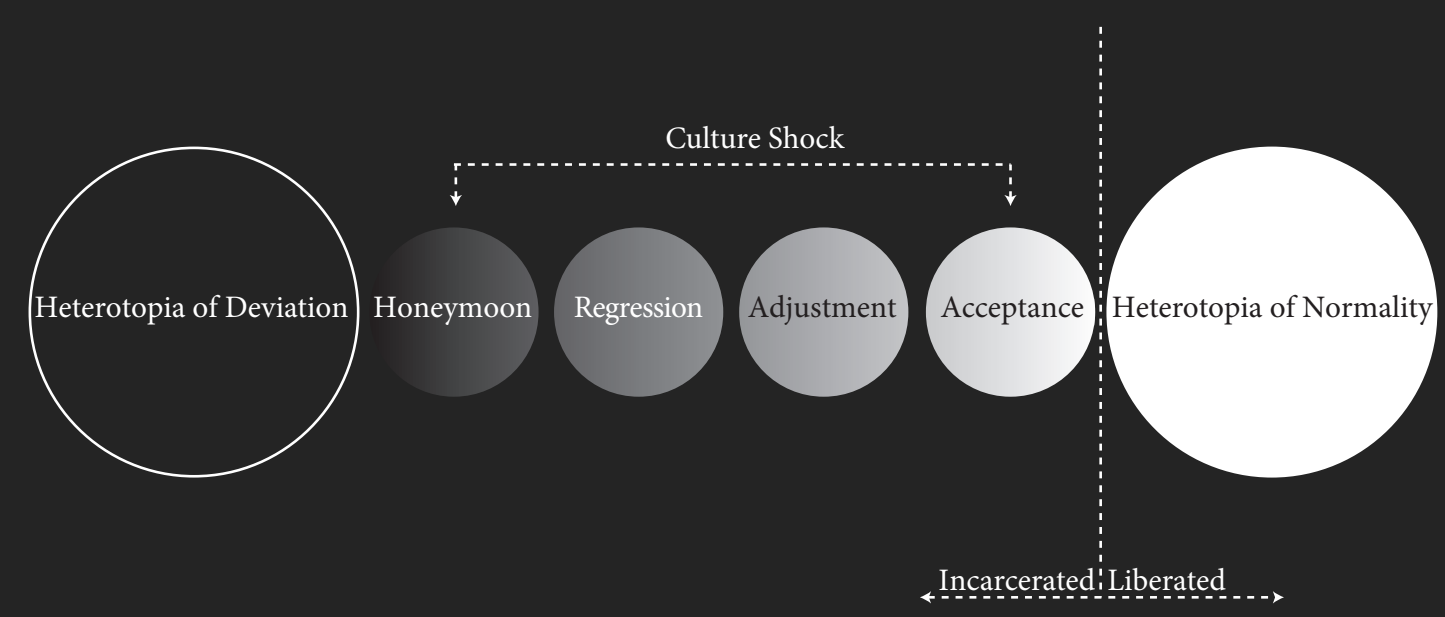

IncarceratediLiberated

No one is born with the knowledge of culture; culture learning Typically poople bave a way of accepting their native culture as both the best and the only way of doing things. This attitude is known as ethnocentrism - an evaluation of other cultures according to preconceptons originating in the standards and

Oberg suggests that the most effective way of reducing culture shock is to remove ethnocentric attitudes as possible prior to entering it. In light of Oberg's on this thesis proposes the design of prison architecture that didactically teaches inmates about freign cultural spaces prior to them entering into 
Implications of Pause

Research Objective 3: To use architecture to establish strategic points of pause along the journey of the spatial
experiential narrative, that enable enhanced understanding of heterotopia.

000

In "Architecture and the productive implications of pause" Daniel Merritt Hewett argues that: architecture designed to inspire curiosity about space, Rope knots tied in the floor challenge the impenetrable edge between air and concrete and slow the movement throughout the space as one attempts to understand their relationship. This pause in momentum creates spatial understanding where once there was none. Points of pause typically arise in the presence of peculiarity and tuconventional design where

Hewett's theory establishes that stationary time spent in any environment leads to a greater awareness and potential involvement. Hewett's and Ganoe's theories complement each other beautifully in the striving for greater understanding of space, as they both refer space as a continuum of experience. When considered in tandem within a prison environment these theories desired focal points throughout the design. When used in conjunction with Fouceult's the ory of interpetation of space, points of pause can be established, that hel one develop a better an understanding of spat awareness and heterotopias outside that of oneself.

The photographic design experements that follow are bstract examples by the author of cases where pause might be encouraged. Each image exhibits an out
of the ordinary experience influenced by change in colour, pattern, orientation and conventional location. They inspire queries into their relationship with the surrounding objects or foundations that otherwise would not be considered.

Hewett's theory explores what happens to ourspatar
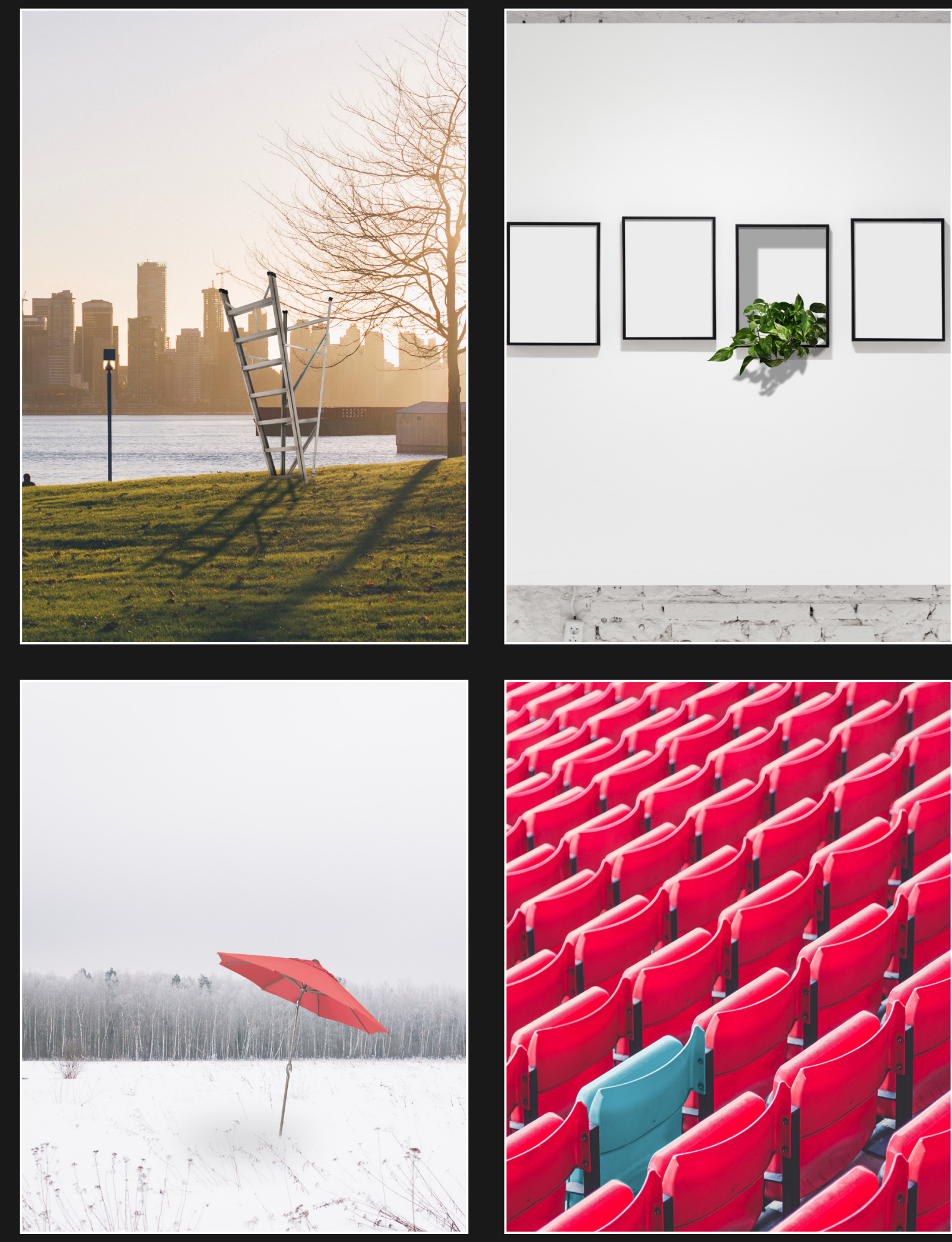
awareness when a pause is introduced. He uses Mary
Miss's project "Knots in a Room" as an example of 


\section{Critical Reflection}

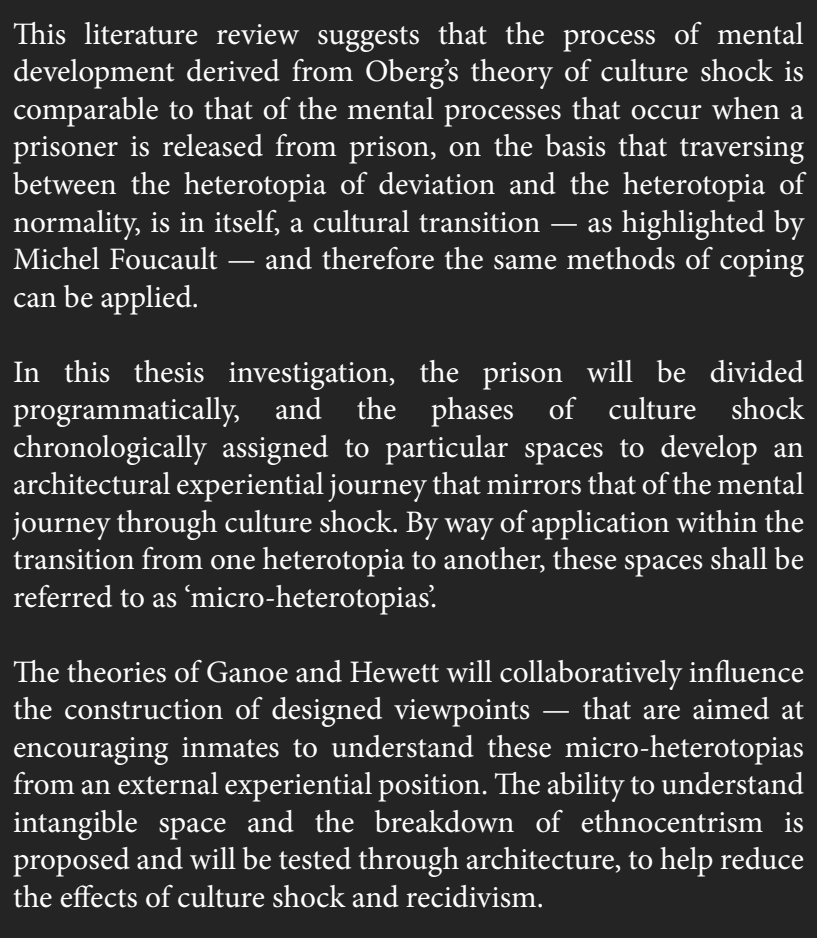



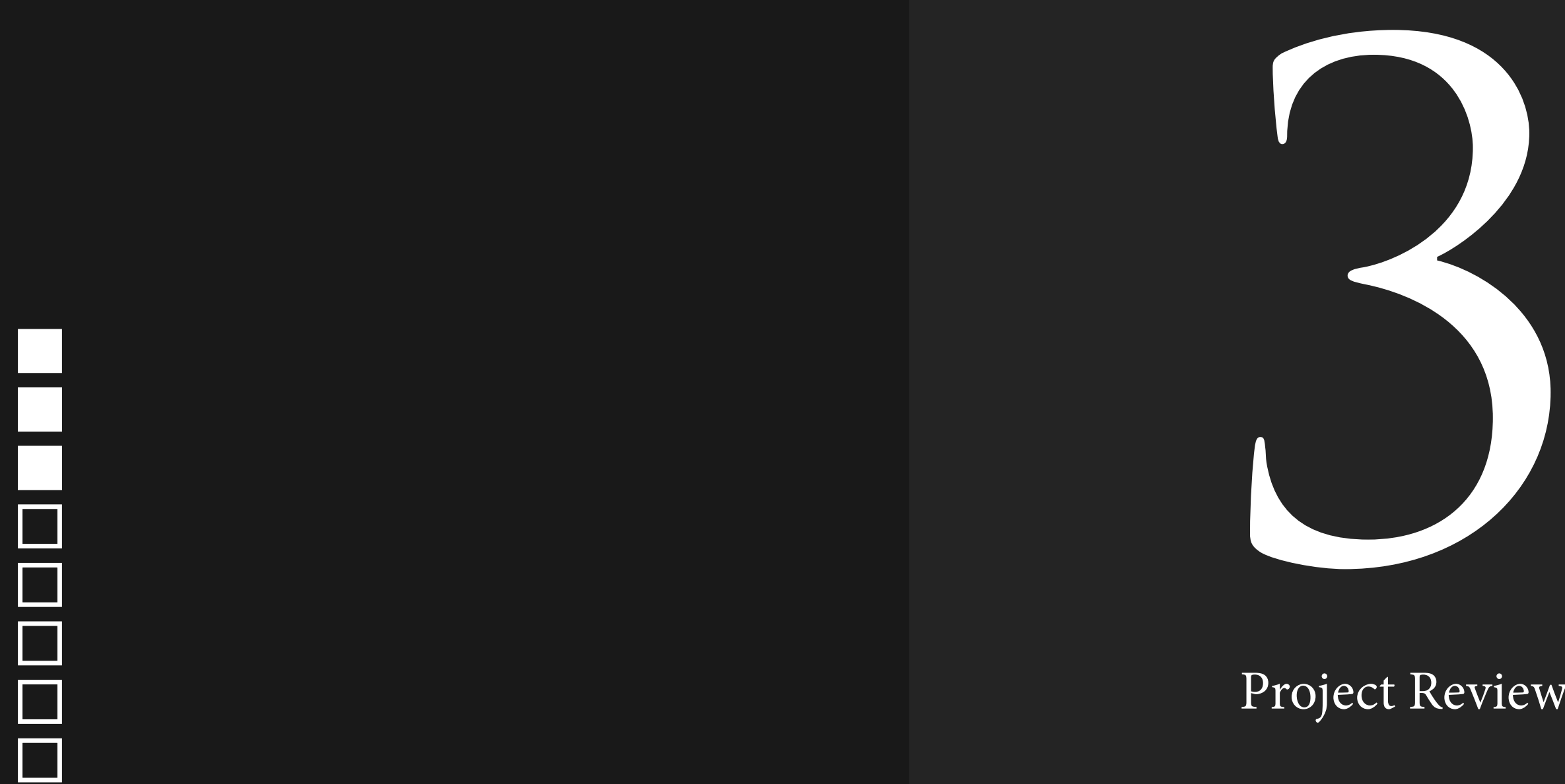

Project Review

We are at a moment, I believe, when our experience of the world is less that of a long life developing through time than that of $a$ network that connects points and intersects with its own skein.

- M. Foucault, excerpt from "Of Other Spaces" 


\title{
I
}

\author{
Introduction
}

This chapter examines case studies around the world where the theories of Michel Foucault, Cathy Ganoe, and Daniel Hewett can be recognised. It discusses their ability to function around the ideas of these principle theorists and draws out aspects that critically relate to thlied within a prison reshbilitaion environment to achieve the overall ains of this reseach investigation.

The first case study looks at the Intermediae Matadero in Madrid, where Michel Foucaults theory of "Of Other Spaces" can be recognised in the restoration of a historic building aimed at The second case study looks at The Optical Glass House in Japan, where Cathy Ganoe's theory of in a design that tells the story of safety and growth thech manipulation of flow and focal points and human time within

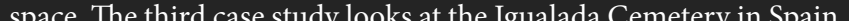
where Daniel M. Hewetts theory of "The Productive Implications of Pause" is recognised in the way in which the architecture highlights point of interest through peculiarity in design.

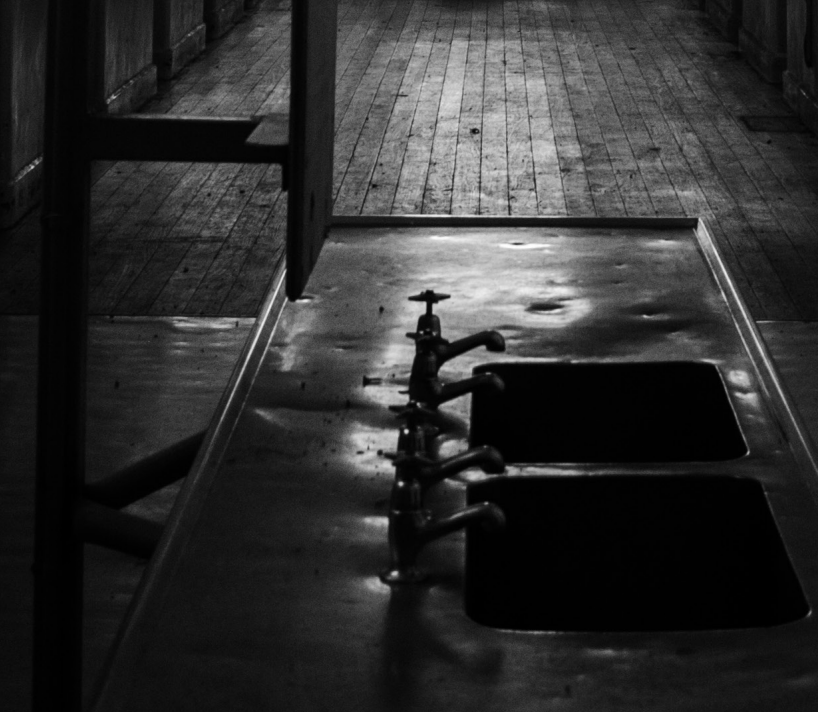


Intermediae Matadero

Architect: Arturo Franco

City: Madrid, Spain

Year: 2007

000

The Matadero complex in Madrid, Spain is an Arts Centre slaughterhouse began in 1911 and became an icon, recognised as one of the most singular industrial establishments of the 20th century Spanish Architecture. The Slaughterhouse was comprised of 48 buildings and spanned a total of 165,415 square meters. In 2007 the first of many developments began in the Matadero complex and the Intermediae Matadero Madrid was opened with the focus of creating a collaborative transdisciplinary artwork space (de Legazpi,

The project was born within the scope of the old slaughterhouse is that of the glass enclosed work space within (figure 3.09). While this space functions as a collaborative transdisciplinary artwork space it simultaneously exhibits the context of which it is situated within, It creates a visible yet inaccessible relationship with the preexisting building, freezing it in time and preserving its history. The
intermediae Matadero Madrid displays a beautiful collaboration of contemporary architecture with 20 th century Spanish aratecture contemporary architecture with and century Spanish architecture and glass enclosed by the old warn brick create an architectural language and emphasise the history of the site. 


\section{Understanding Heterotopia}

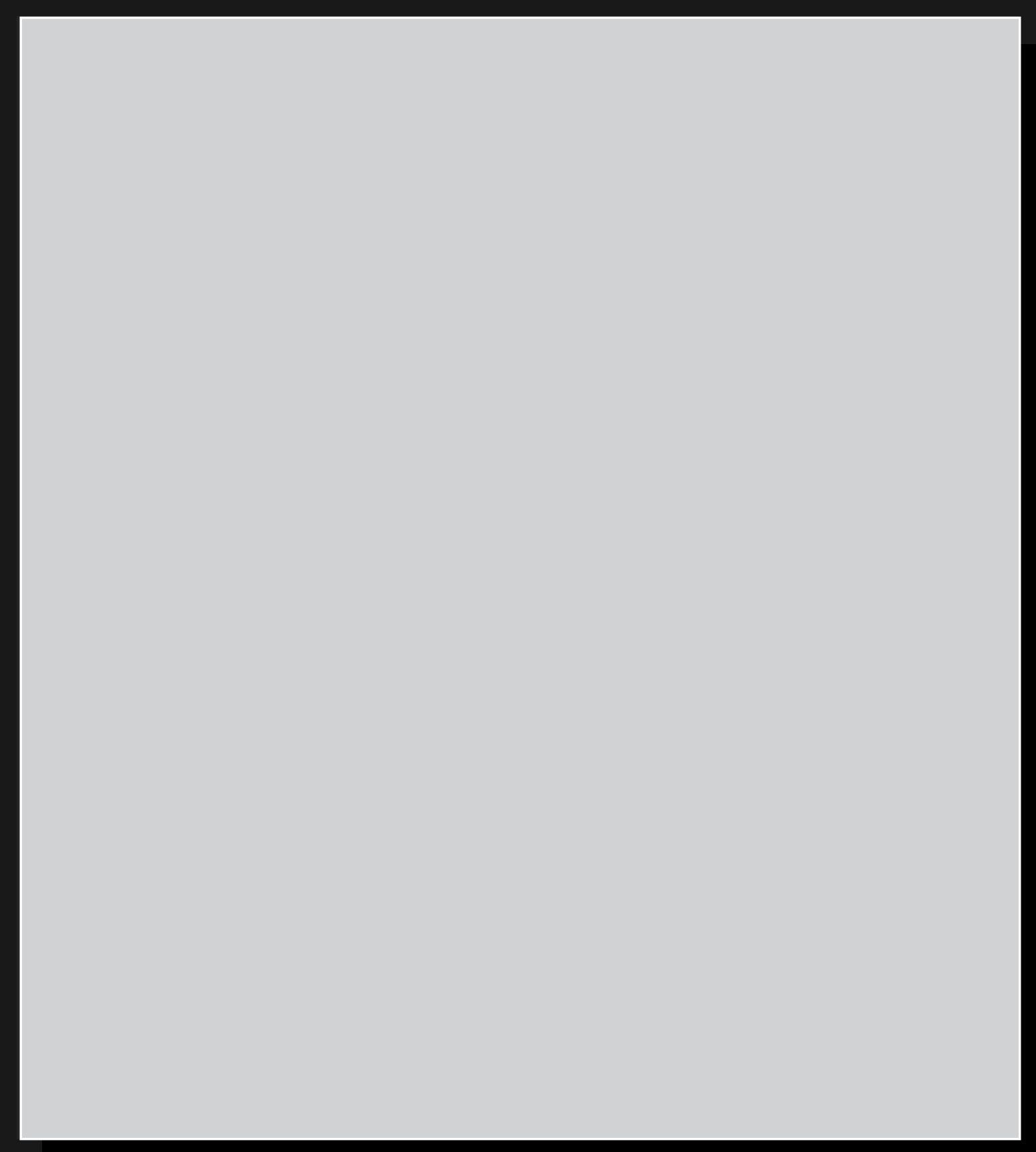

Understanding Heterotopia - The glass enclosed work space
within Intermediae Matadero Madrid (figure 3.10) sheds light within Intermediae Matadero Madrid (figure 3.10 ) sheds light
on the ability of architecture to encourage the reinterpretation of on the ability of architecture to encourage the reinterpretation of
dystopian experience through the lens of heterotopia. It does so by While the slaughterhouse walls remain visible they are incapable of being physically interacted with and an exhibit of sorts is created. A slaughterhouse is perhaps the most aggressive encompassment of dystopia imaginable and although no intervention is capable of altering the past experiences within a building, the glass enclosed work space removes the occupant from any tangible interaction with the existing building and displays it for how it functions outside of

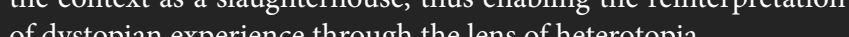

Human experience within the glass work space gives understanding to Michel Foucault's theory - where he describes heterotopias as places outside of all places - as the walls of the historic slaughterhouse exist only in reflection, in the sense that they lie behind the glass in an intangible space outside of anything physically accessible, yet their location can be described. When interpreted from the viewpoint of Cathy Ganoe in her theory describing space space or heterotopia (which in this case are the interior walls of the slaughterhouse) is developed as it is humanly perceived.

The distinction between the tangible and intangible space is exaggeraled through contrast in material and style. From the viewpoint inside the glass work space - tangible space is comprised of contemporary architctur phe intangible space and highlight its early 20th century composition. 


\section{Application}

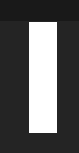

The first major objective of this thesis is: to use architecture to encourage prison inhabitants to reinterpret dystopian experience
through the lens of heterotopia The Intermediae Matadero Madrid displays architectural techniques that develop an understanding of intangible space that was once host to dystopian experience.

The idea of enclosing the occupant within glass to showcase the prison cell. This would freeze in time and expose any graffiti and emotion expressed on the cell walls by its previous occupants. In enlightenment of the collaborative theories of Foucault and Ganoe, one could assume that over the course of human time experienced within the new cell, the prisoner would develop an understanding of the prison for what tis - ander - a place of prin deviated individuals - and learn to appreciate it for its repurposed rehabilitative qualities.

The architecture now possesses the ability to didactically teach its occupants to reinterpret dystopian space through the lens of heterotopia or intangibility.

As Kalervo Obergs theory of Culture Shock suggests; the most effective way of dealing with the shock of becoming immersed in a foreign culture is to develop prior knowledge of its cues and the ability to didactically teach its occupants to reinthat possesses space through the lens of heterotopia or intangibility - when applied to criminal rehabilitation, provides criminals with ability to understand the intangible space that exists outside the prison walls prior to being released into it. It proposes that this understanding will reduce the adverse effects of culture shock and in turn reduce recidivism. 
I

The Optical Glass House

Architect: Hiroshi Nakamura

City: Hiroshima, Japan

Year: 2012

000

The Optical Glass house is satiated among tall buildings and the bustling metropolis of downtown the intentions of creating tranquillity and peace among an otherwise frantic cityscape.

Its most striking feature when viewed from the roadside is the glass brick facade measuring $8.6 \mathrm{~m} 2$ allowing a partial but not complete
view of its lush interior (ArchDaily Optical Glass House / Hiroshi Nakamura \& NAP, 2017). Once inside, this glass facade works to draw the occupant away from the chaos by obscuring the view to the exterior, only allowing fragmented light within.

The interior itself is design primarily about the centre point, of which room in the house and is the key to $c$ gis garden is visible form every the focal point away from the busy city outside. Flowing water and its ambient sound is used in conjunction with the greenery to put emphasis and focus on the spatial connection with nature, and further draw the occupant away from the city.

This beautiful display of nature in conjunction with thoughtful architectural design is successful in spiritually removing the is possible through didactic architecture and the manipulation of focus. 
Narrative Architecture

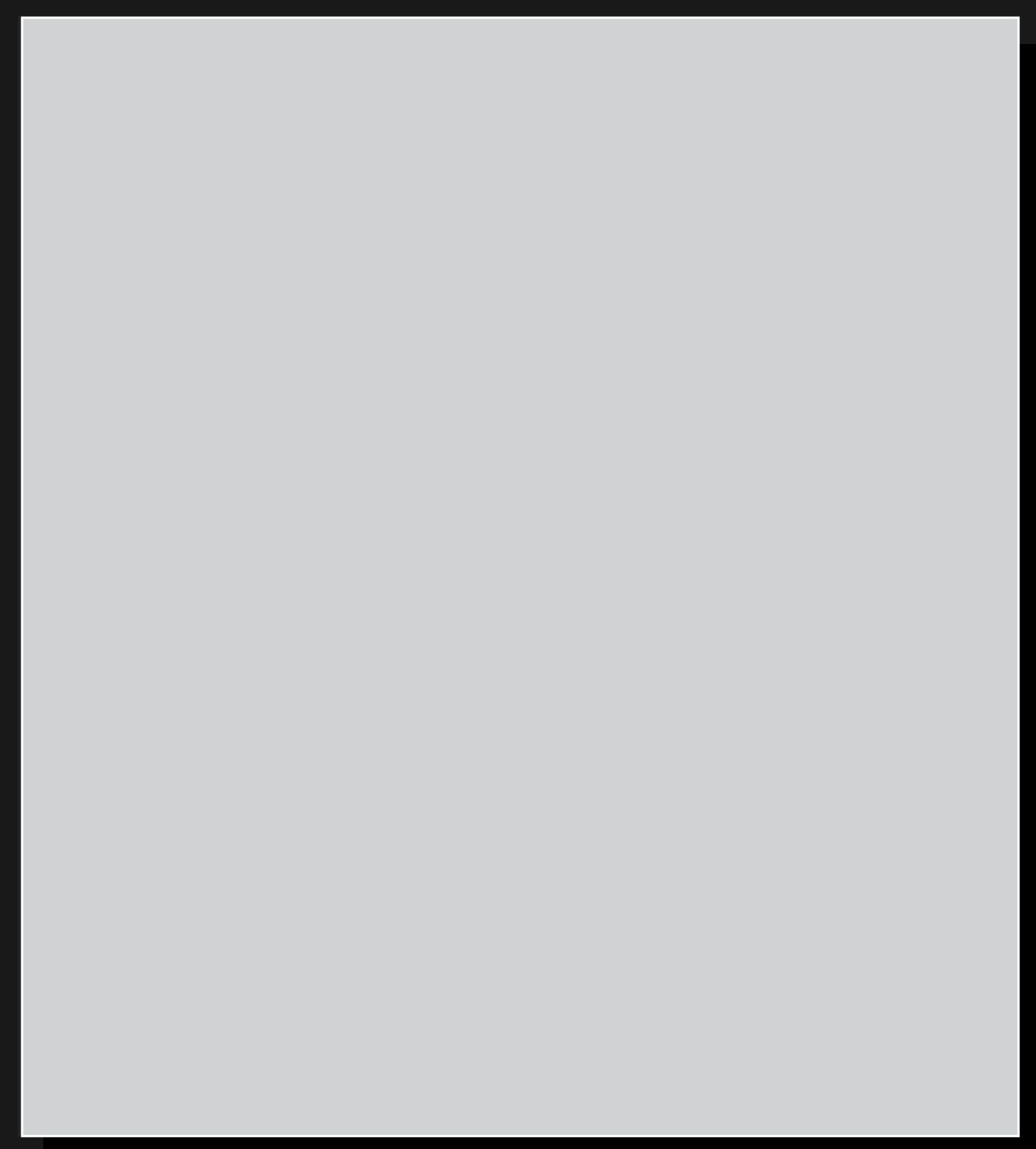

\section{1}

The Optical Glass House tells the narrative of sefety securty and the ability to grow within a restricted environment. It does so by providing the essentials for nature to flourish amidst a typically hostile environment the way a mother would to a child. It possesses the ability to didactically impose responsibility upon any of its occupants through the configuration of occupiable space around a focal point. The nurturing responsibility for the nature growing

This technique can be seen in to the right (figure 3.13) where the bathroom wall is substituted for glass and obscuring features such as the mirrors are reduced to a practical yet minimal size. The material palette remains very basic as to not to attract from the focal intentions of this space which exceed beyond its physically traversable boundaries.

Figure 3.13 shows the opaque glass bricks and the relationship they provide with the exterior. They expose the world to nature as if it of filtering what is necessary to grow - which in this case is warmth and sunlight. The act of filtering out negative qualities reinforces the narrative of growth and nurture within a hostile context. The glass bricks also provide enough natural ight to give the sense of being outside whilst simultaneously removing the distraction of the outside world to enhance the focal point of the design.

Cathy Ganoe's theory of inhabiting space and understanding it as occurring over time is radicalised in the Optical Glass House. capability to grow architecture and the design is given the physical experienced as noticeably developing over time. As the garden grows it becomes more equal to the architecture in relation to its permanence. What were once small delicate sprouts will become fruitful gardens. As this happens the responsibily of the architecture to protect and act as a guarding igure to its gardens will change as conjunction with its ability to nurture. 


\section{Application}

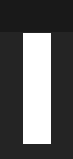

The Optical Glass House sheds light on the architectural ability to estabish a spatial experiential narrative about a persons
transforming interpretation of their surroundings. As the site is experienced in human time the relationship between nature and experienced in human time the relationship between nature and
architecture develops and can be appreciated for what it has been, what it is, and what it will become. As the relationship between the architecture and the garden transforms from one of caring and nurture to one of spatial equilibrium and comparative strength, the interpretation of the archinecture transforms from an appreciation of the ability to provide the essentials for growth, to an appreciation

This transforming interpretation will be applied in the prison environment, to encourage prisoners - over the course of human time - to transform their interpretation of the prison as a restrictive environment to an environment that provides their needs to mentally develop and remove themselves form the heterotopia of deviation.

The use of controlled focal points and spatial qualities such as contrasts everything that surrounds it. It alludes to a space foreign to the typical experience within a busy city and draws attention to its ability to give life to nature that would otherwise struggle within the exterior context. What is perceived from the exterior differs extremely to the spatial experience within.

This idea of contrasting interior spatial experience with exterior perception will be used in the design of prison. The prison interior behind the prison walls to create as much normality as possible and develop a rehabilitative self narrative. 


\section{I \\ The Igualada Cemetery}

Architect: Enric Miralles and Carme Pinos

City: Igualada, Spain

Year: 1994

000

The Igualada Cemetery was completed in 1994 by Spanish architect Enric Miralles and Carme Pinos. It was designed with the intentions of becoming a cemetery, but also a place to explore poetic ideas and develop an understanding and acceptance of the cycle of life, creating a link between the past, present, and future. The project
can be appreciated for its poetic nature across the alternate scales of interior, landscape, and architecture. It carves a powerful path through the landscape as a metophor for the river of life, whilst simultaneously creating delicacy and intimacy around the deceased. The intention of the design is to draw the bereaved down into the landscape - along the river of life - to arrive at a city of the dead. The city of the dead represents a between place where the living and the dead are brought closer together (Zabalbeascoa, 1996).

The materials used in the construction of the Igualada Cemetery were chosen due to their ability to appear timeless. Sand stone rises forms the winding pathway towards the burial site. Tall rusted steel poles protrude from the ground acting as gates, and abstractly mimic the crosses of Calvary and their symbolism. 


\section{Establishing Points of Pause}

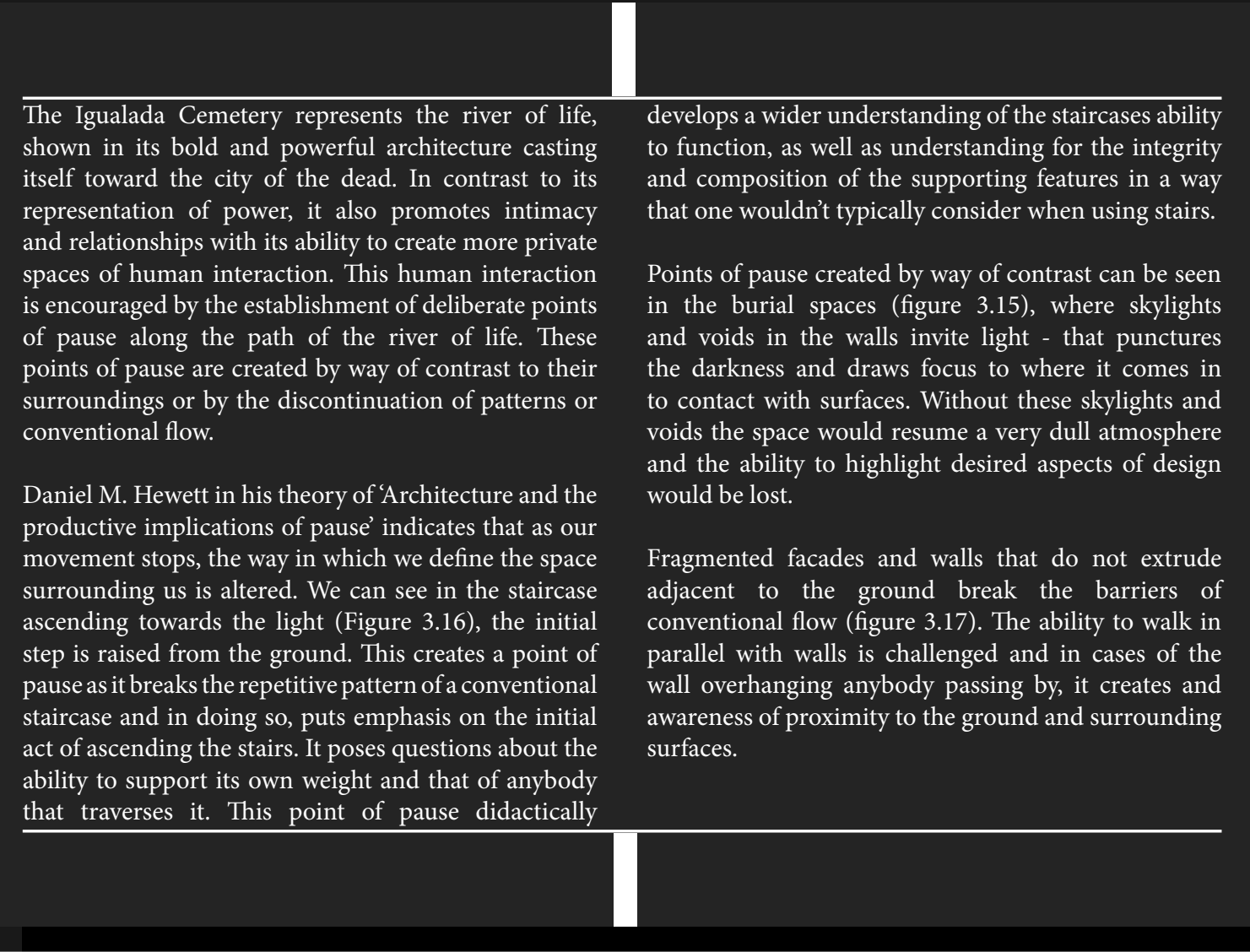

shown in its bold and powerful architecture casting representation of power, it also promotes intimacy spaces of human interaction. This human interaction of pouraged by the establishment of deliberate point points of pause are created by way of contrast to the (n)

Daniel M. Hewett in his theory of 'Architecture and the movere implications of pause' indicates that as comes in dajacent to the ground break the barriers of parallel with walls is challenged and in cases of the wareness of proximity to the ground and surrounding

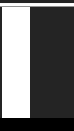




\section{Application}

\section{I}

The Igualada Cemetery sheds light on the plausibility of the third strategic points of pause along the journey of the spatial experiential narrative, that enable enhanced understanding of heterotopia. The cemetery displays techniques that emphasise pause in momentum in desired locations in order develop a wider understanding of how they function and how they relate to their surrounding.

These techniques may be applied in a rehabilitative prison understanding of desired focal points. As inmates are typically restricted to a designated space for a prolonged period of time - this thesis proposes the collaboration of Hewett's and Ganoe's theories, and techniques used in the Igualada Cemetery and The Optical Glass House, to develop points of pause, that focus attention to spaces aimed at transforming dystopian interpretation. 


\section{Critical Reflection}

\section{0}

The Intermediae Matadero, Optical Glass House, and Igualada

cemetery each express qualities of didactic architecture. This is

achieved through the manipulation of conventional movement,

material and sensual experience. Each case study gives examples

they may reinterpreted to perform in a rehbilitice how

These findings, alongside the theories discussed in chapter two of
this research investigation, create a set of design precedents and this research investigation, create a set of design precedents and
framework that can be used to inform the initial experimental design. 
$\square$
$\square$
$\square$
$\square$
$\square$
$\square$

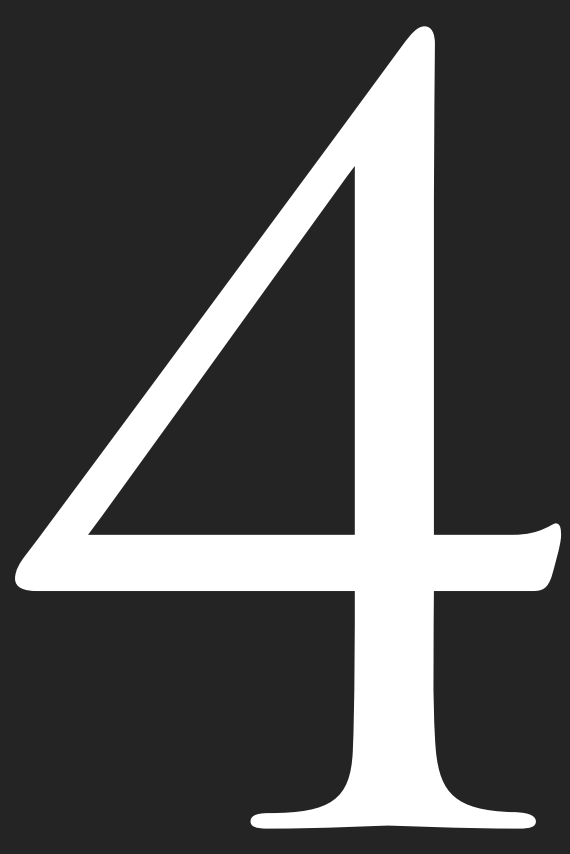

Site Analysis

000

To move through space is to change. Individuals and communities have always moved for change; within and over their own cultural borders. Yet, it is only by not moving, by breaking an ongoing migration, inat certain critical advantage cultural springs from the constructive engagement between a people and their chosen site. Architecture, as an assembly of transitory constructions and spaces, is a primary instrument through which such an interaction may occur.

- D. M. Hewett, excerpt from "Architecture and the Productive Implications of Pause' 
Introduction

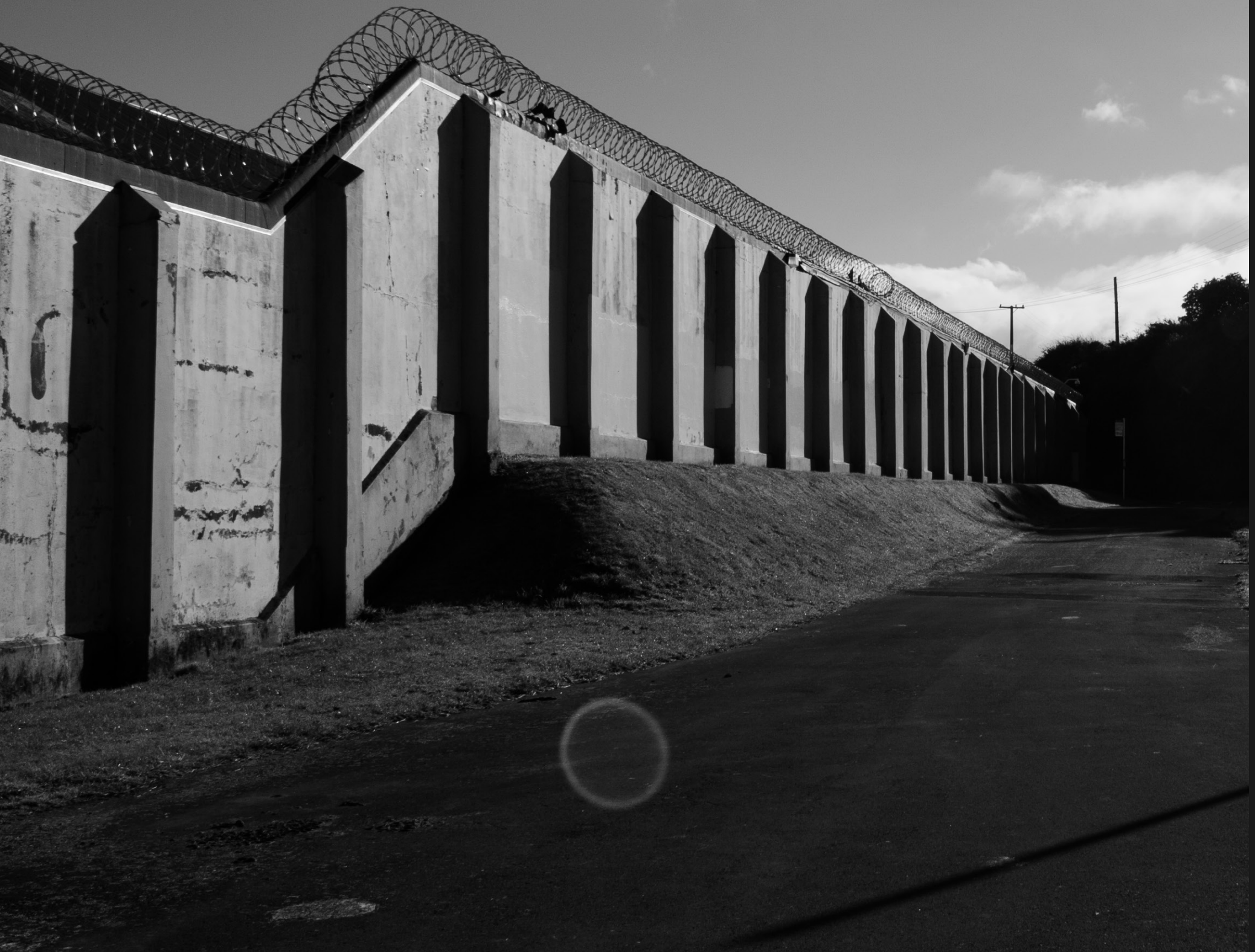

This chapter examines incarceration facilities within New Zealand in relation to their location, capacity and gender orientation. It introduces and justifes the selection of Mount Crawiord Prison as the site for this investigation and analyses qualities of site that can ative process.

The outcome of the analysis of the site will help determine how the site conditions, in particular how the site might be interpreted as a heterotopia, opportunities for narrative, and strategic locations for establishing points of pause. 


\section{New Zealand Prisons}

There are currently a total of seventeen prisons nationwide within
New Zealand; of these seventeen, fourteen are male and three are
female. In order of capacity the female prisons are:
Auckland Women's Corrections Facility
Capacity: 462
Arohata Women's Prison, Wellington
Capacity: 154
Christchurch Women's Corrections Facility
Capacity: 134
Total Capacity: 750
While the population of female inmates only contributes to a small
percentage of the total population of incarcerated criminals in New
Zealand, the lack of capacity for female prisoners has resulted in an
overcrowding crisis (Corrections, Women in Prison, 2018) (Vance,
2017).

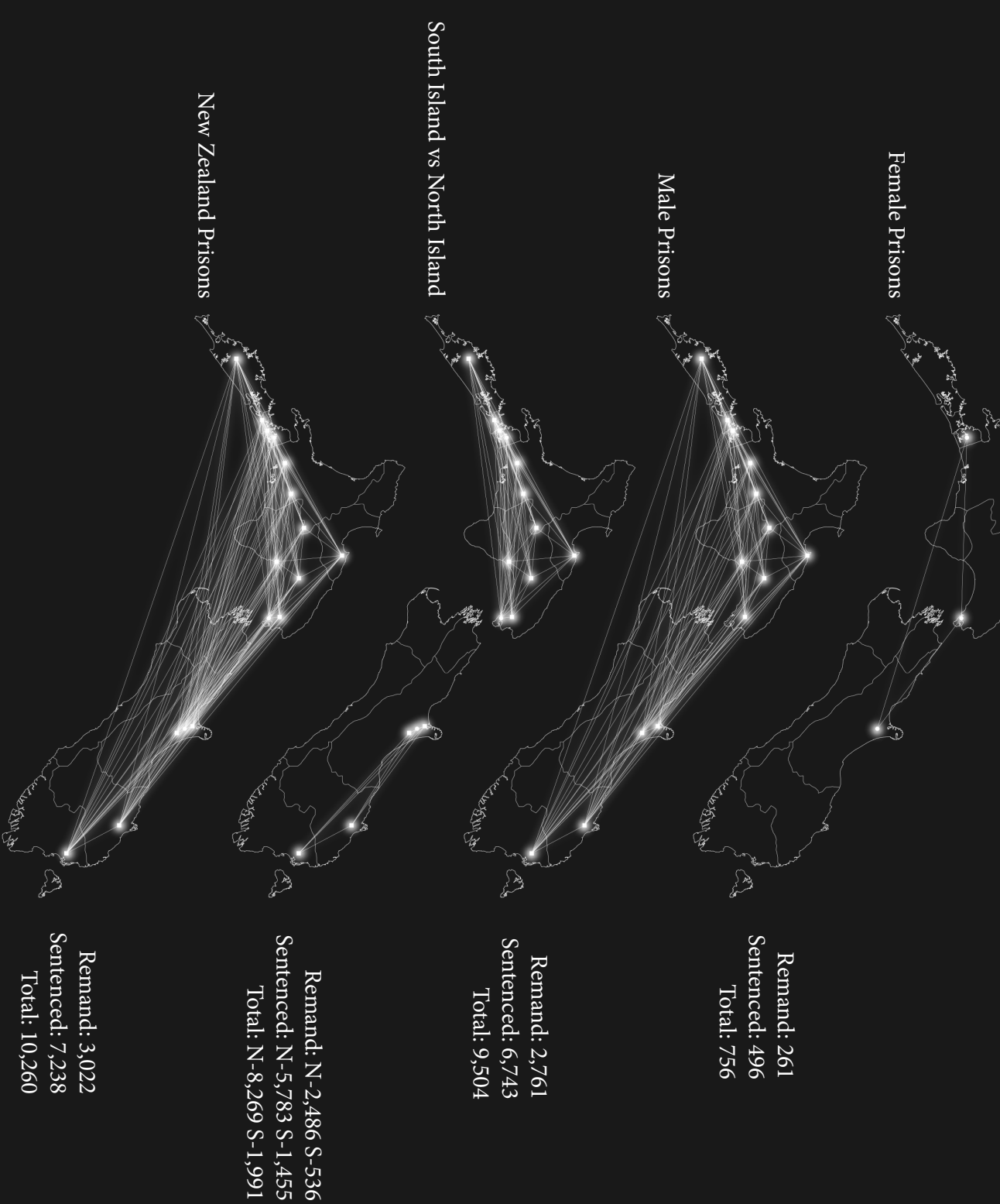




\section{Mount Crawford Prison}
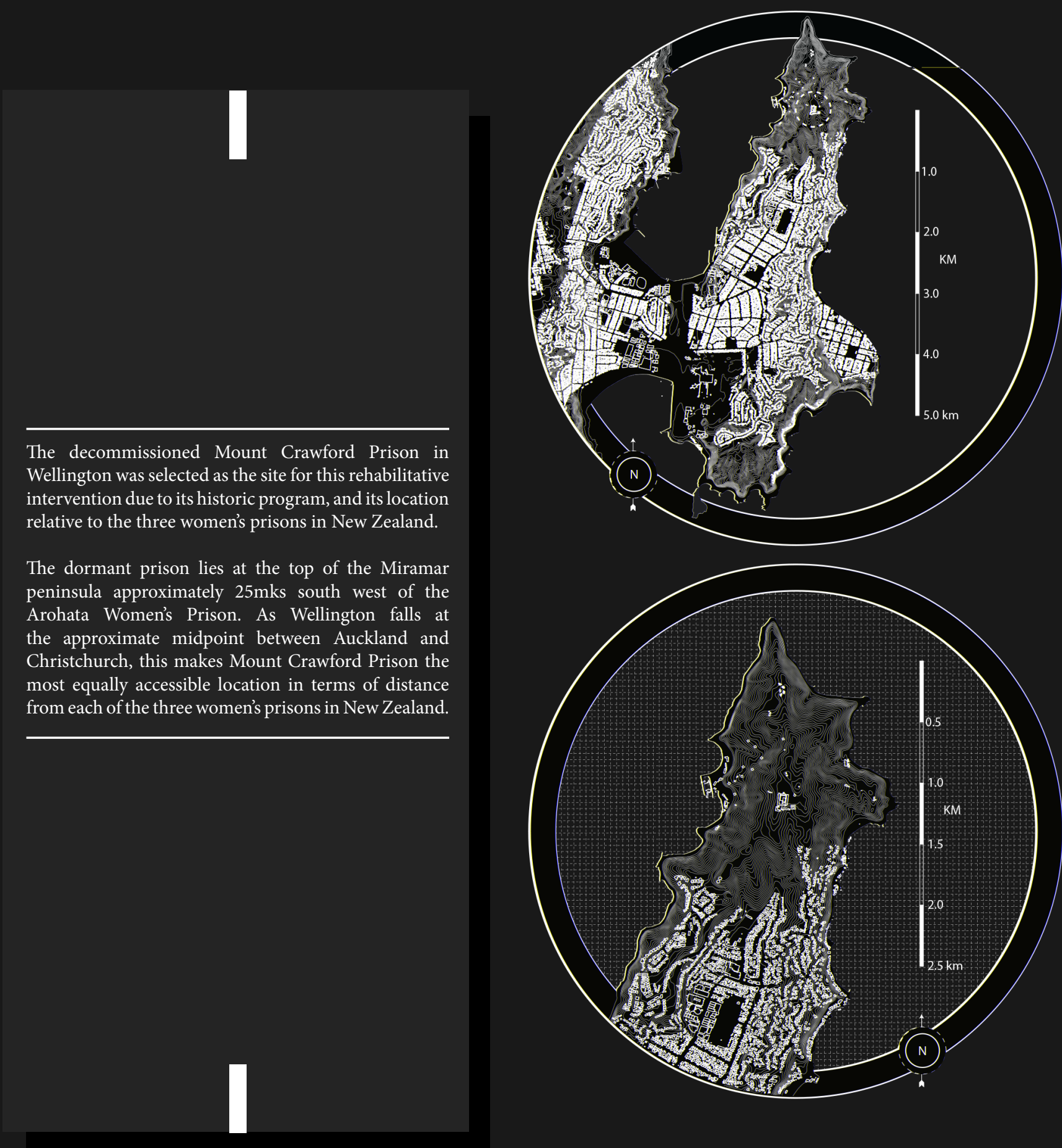
History

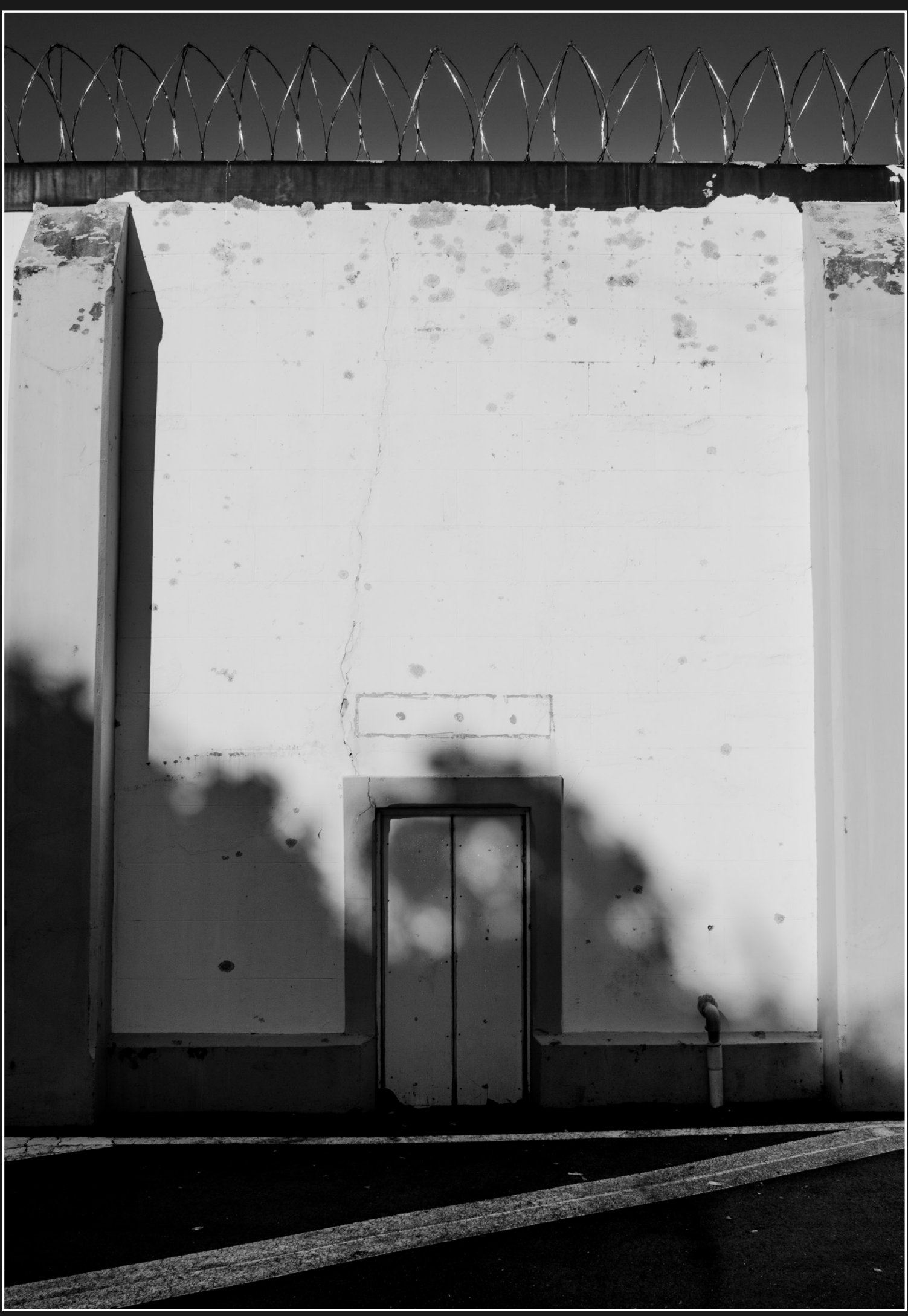

The construction of Mount Crawford Prison began in 1915 and was built predominantly by convicted felons sentenced to work on the site. The Prison site was selected due to its strict accessibility and isolation from suburban Miramar. Considered a revolution of its time, the prison was fitted with communal areas, exercise yards, and (acted

The incarceration facility as we know it today was opened in 1927 rehabilitation as of of becoming a reformative facility focused on heavily contrasted by the sentencing laws in practice during the early 1900 s as death by hanging was still an enforced measure of punishment served to extreme cases of criminal activity. This meant that Mount Crawford Prison had to accompany criminals ranging on desth row - and the activities associated with them. During the on death row - and the activities associated with them. During the
1930 's there were four high profile murderers executed within the prison. These executions took place in the gallows set up in the north eastern corner of the prison and the diseased were removed from the site through a purpose built door in the northern wall (figure 4.22). In 2008 the prison was closed due to the deterioration of the building however in 2009 it was reinstated as wellington prison due In 2012 Mout Critow prison was closed for the hast time as it was deemed unsutable for the modern dy increcertion schemes and laws in place (Corrections, Wellington Prison, 2017). 


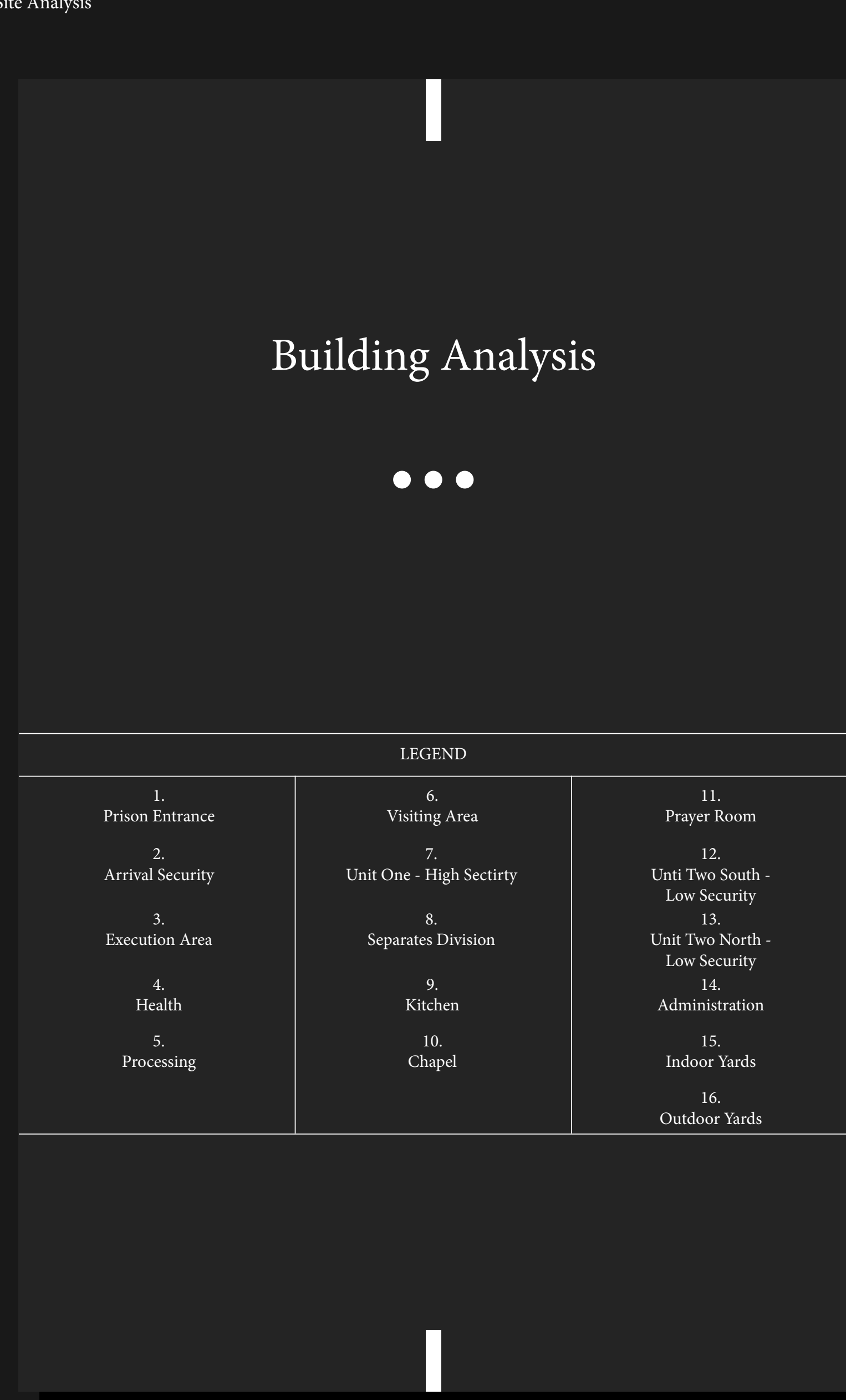

(3) (4)

(2)

(14)

(13)

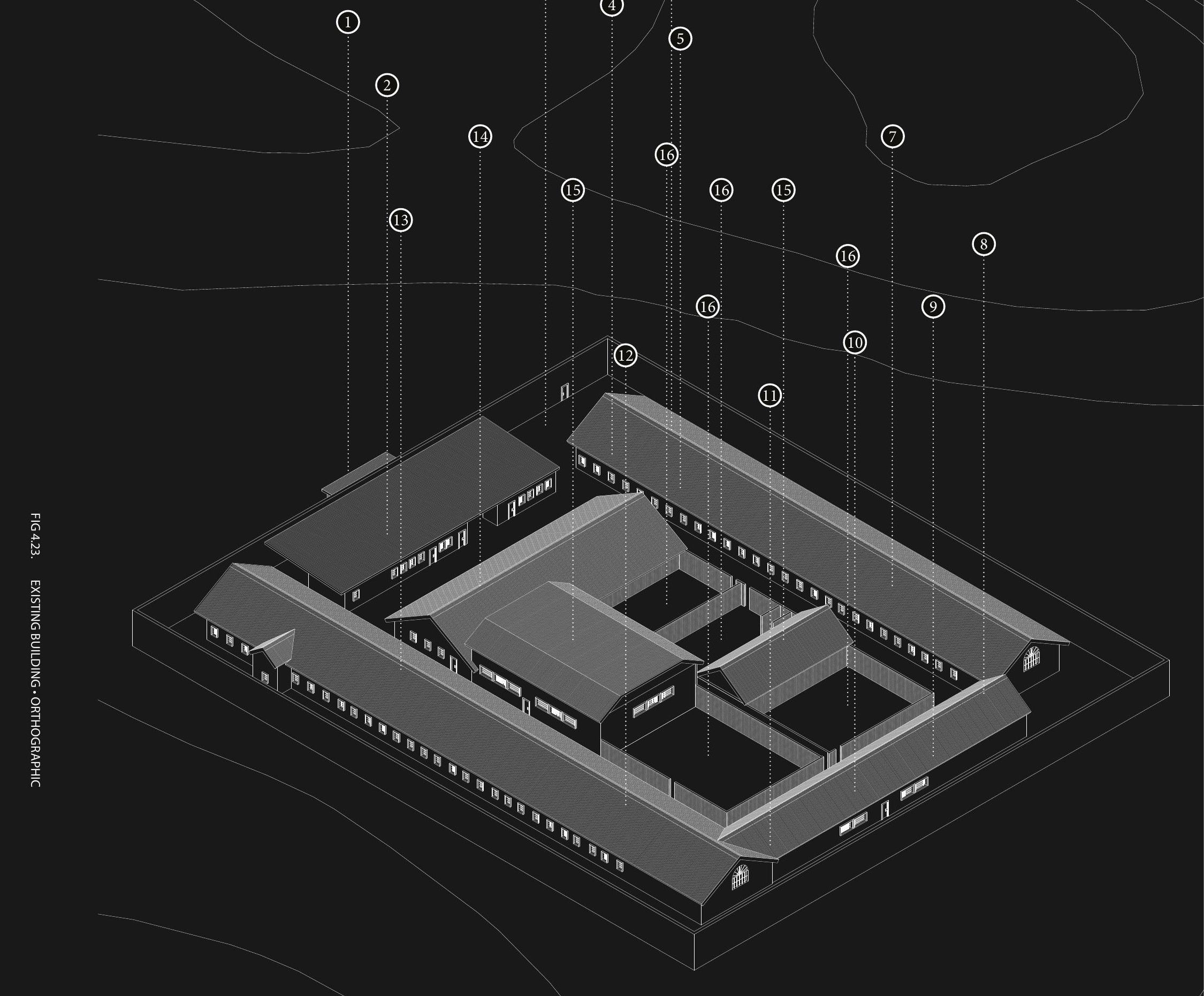




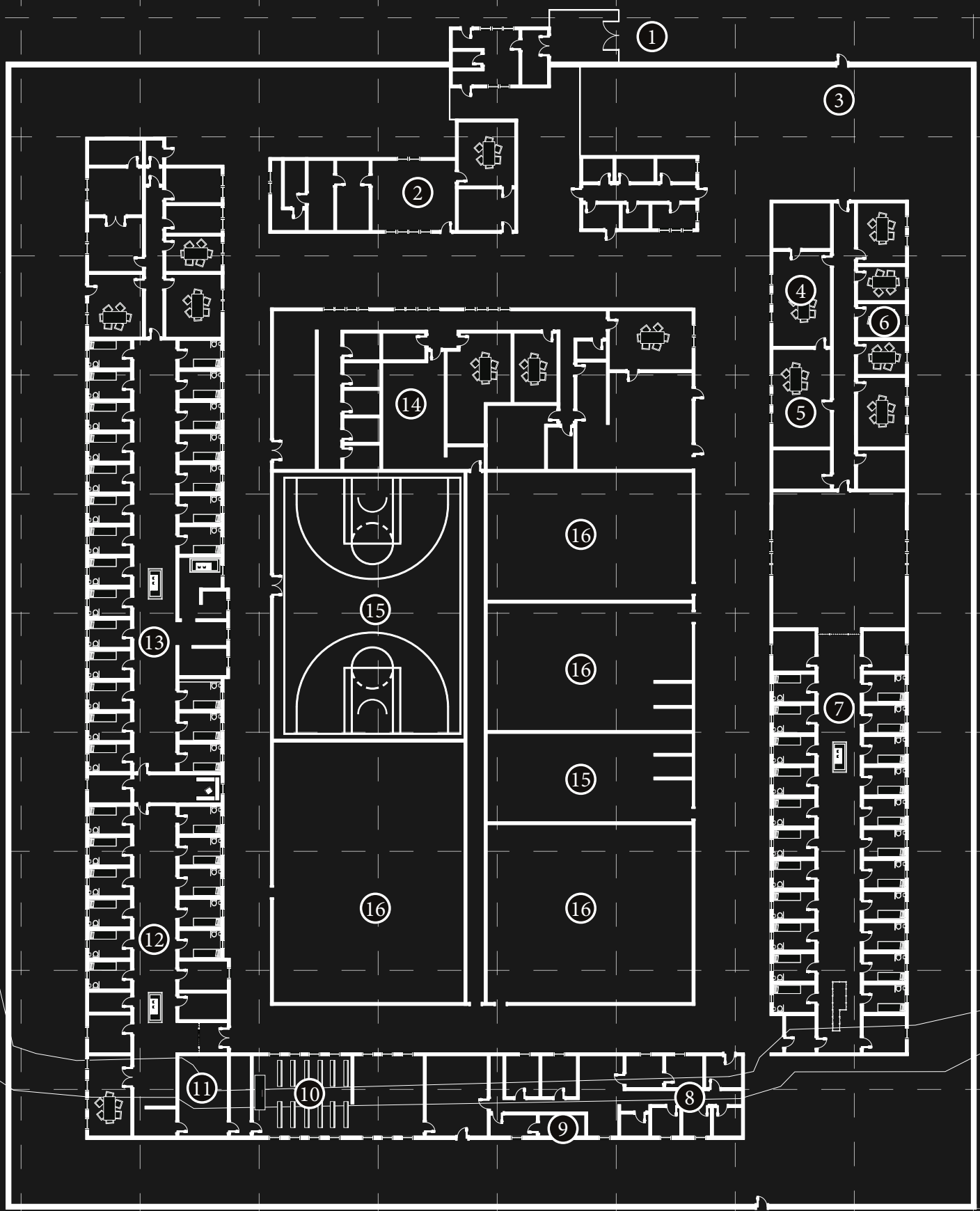

\section{Building Analysis}

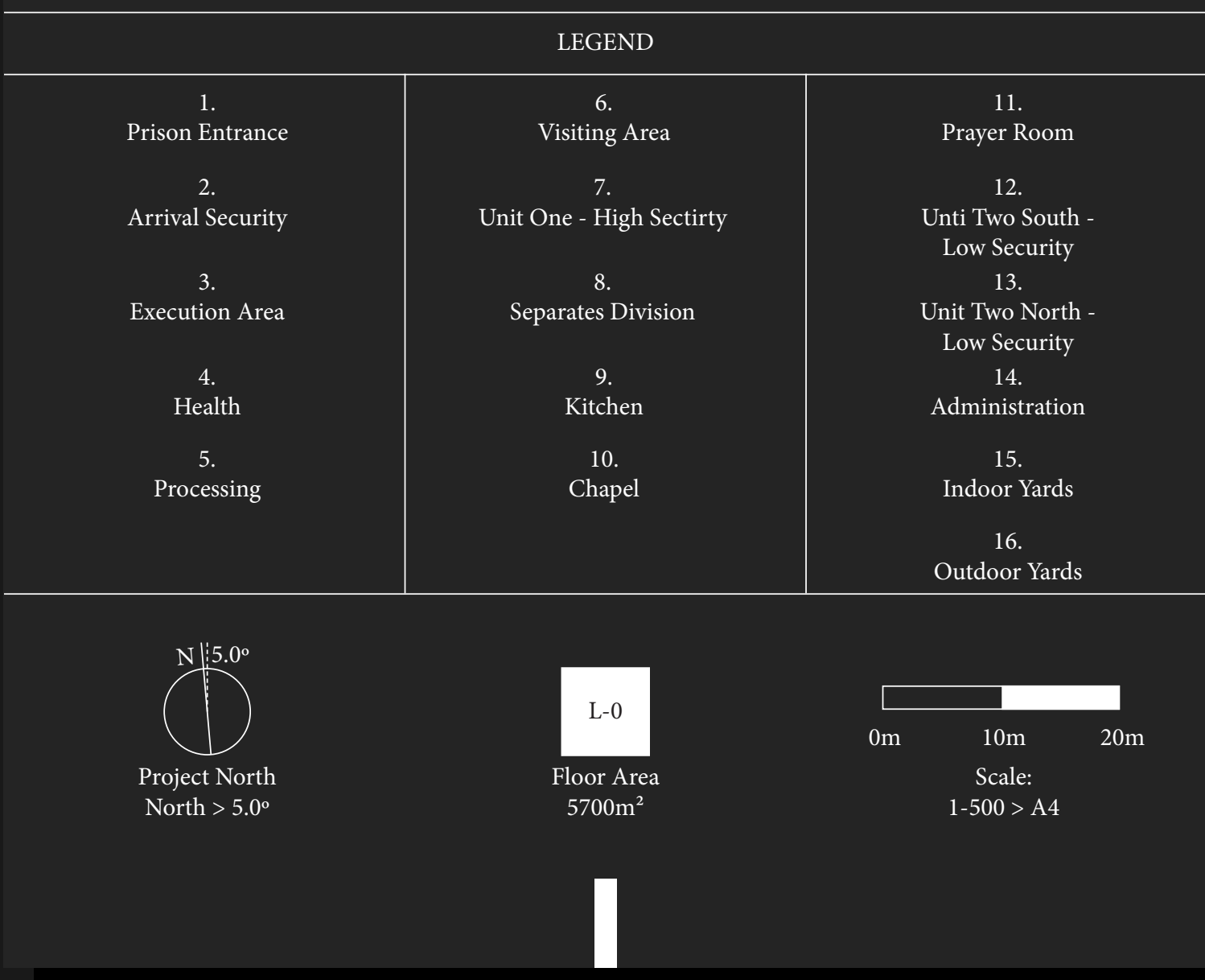



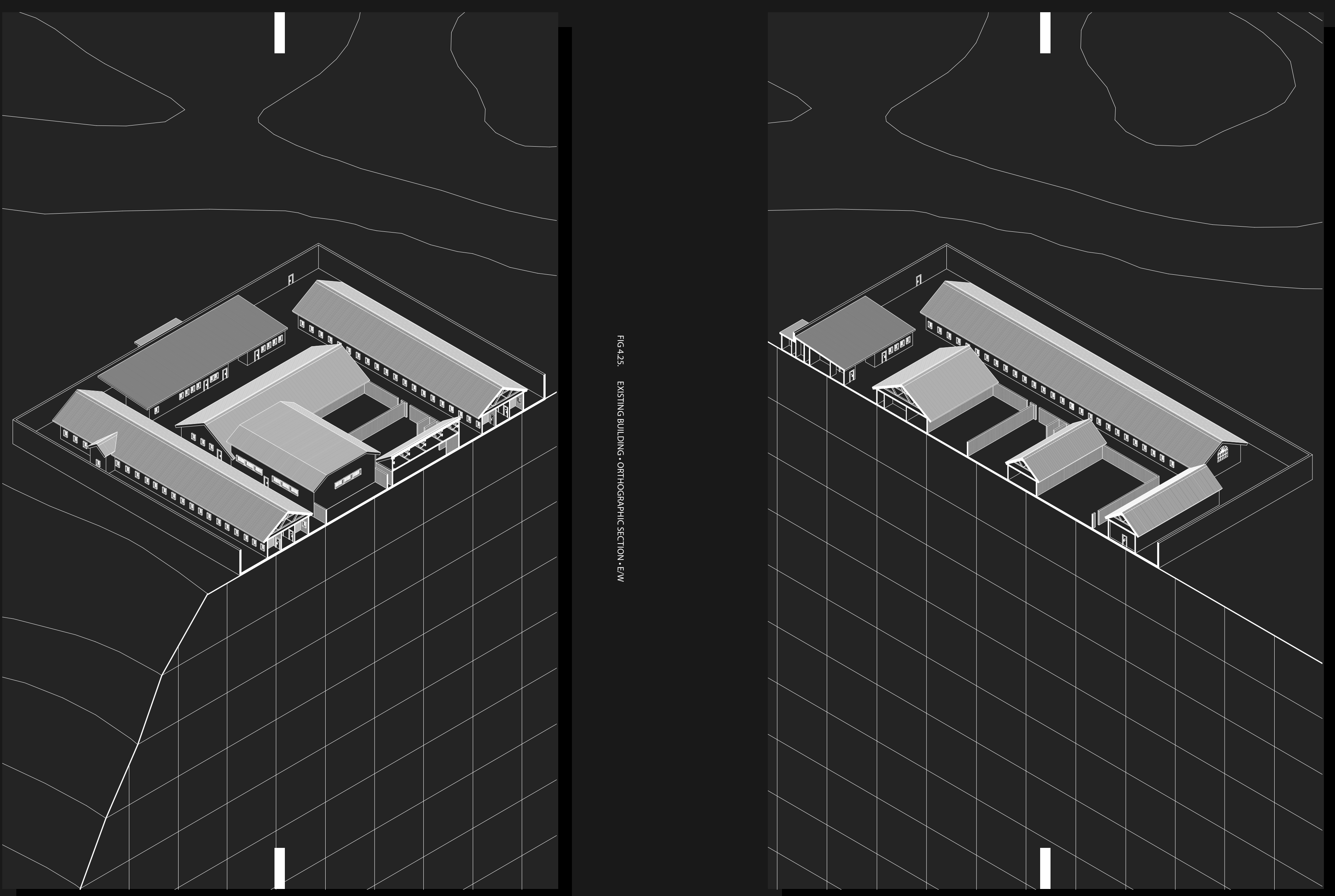
Site Visit

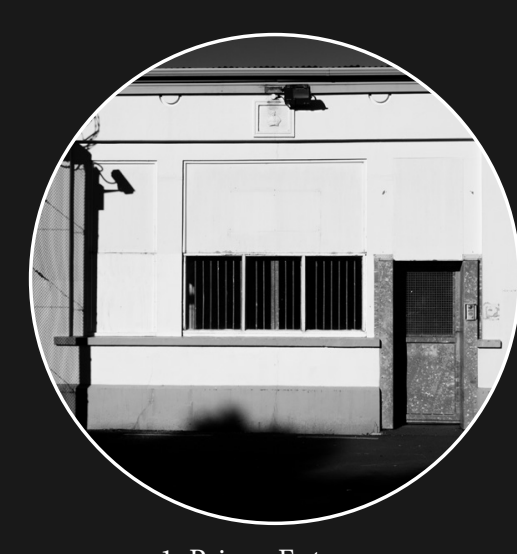

1. Prison Entrance

:

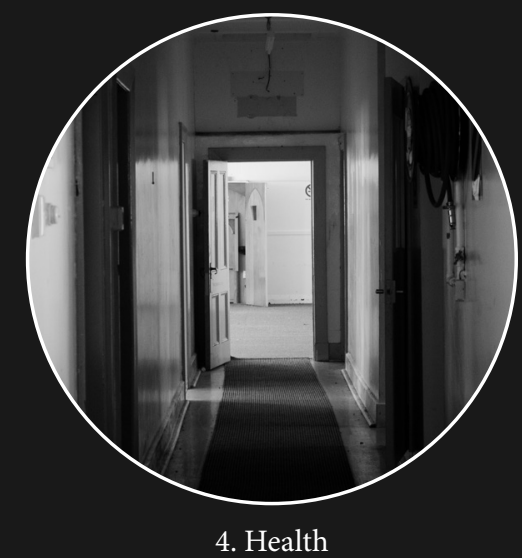

13
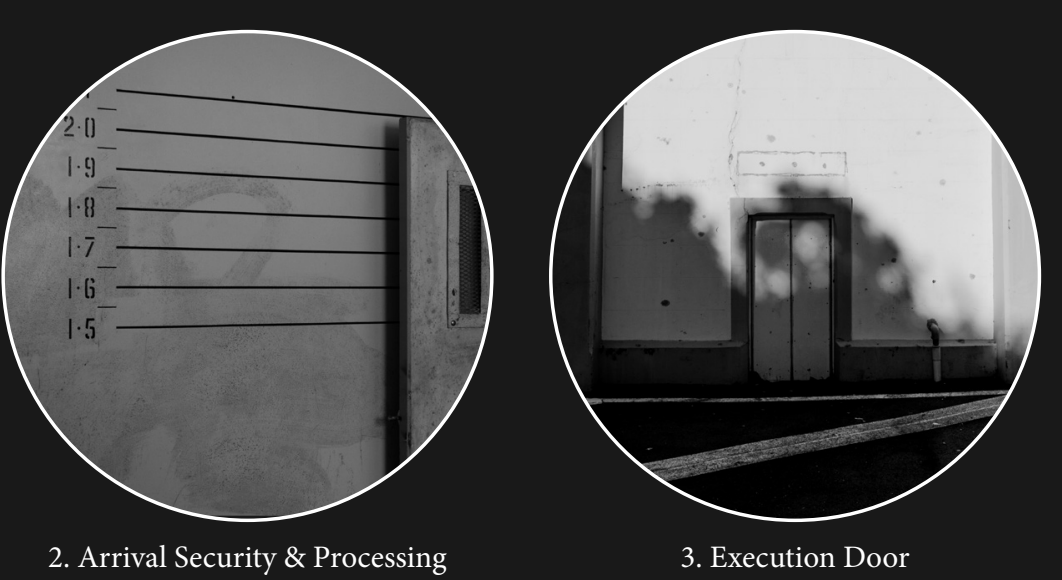

1)

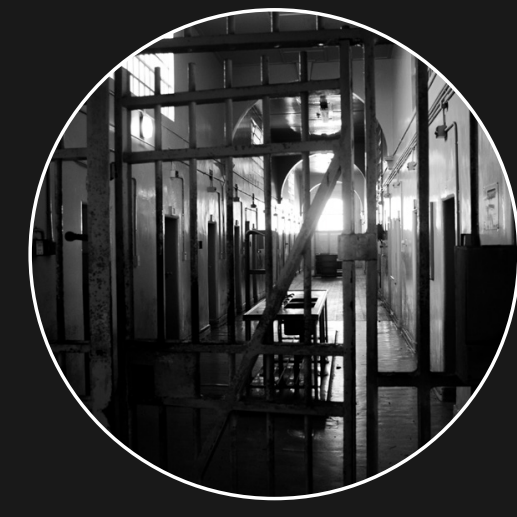

5. Unit One - High Security

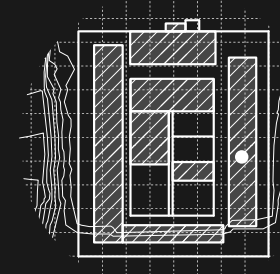

(1)
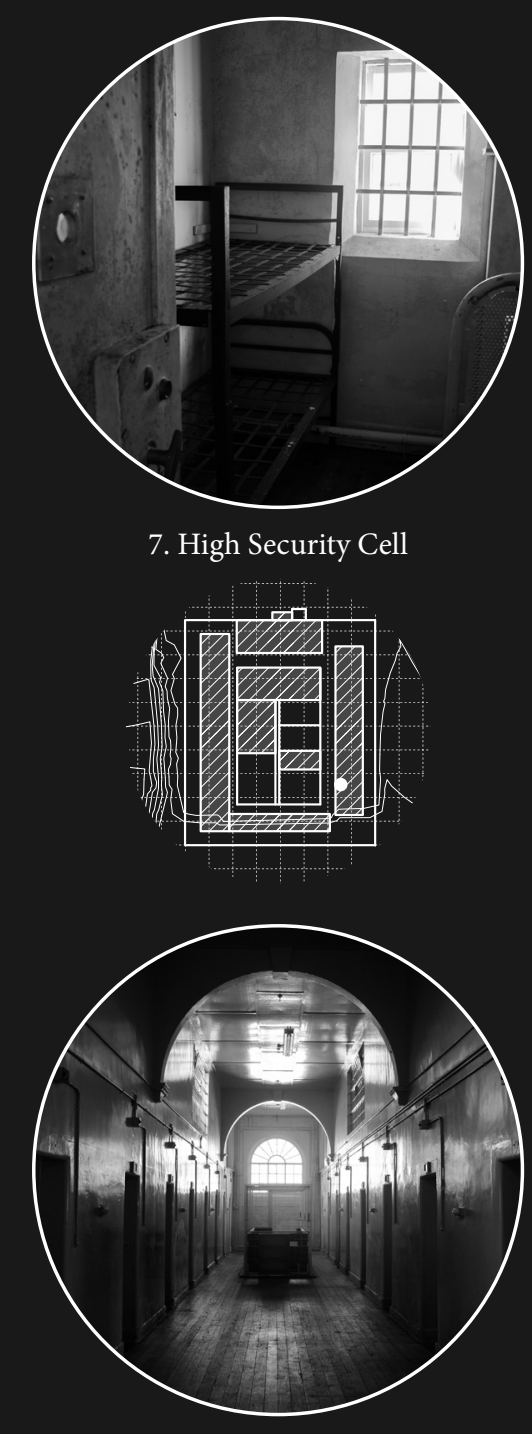

10. Unit Two - Low Security

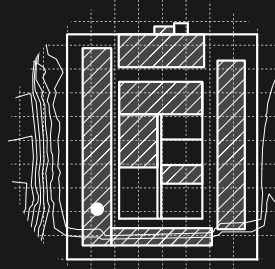

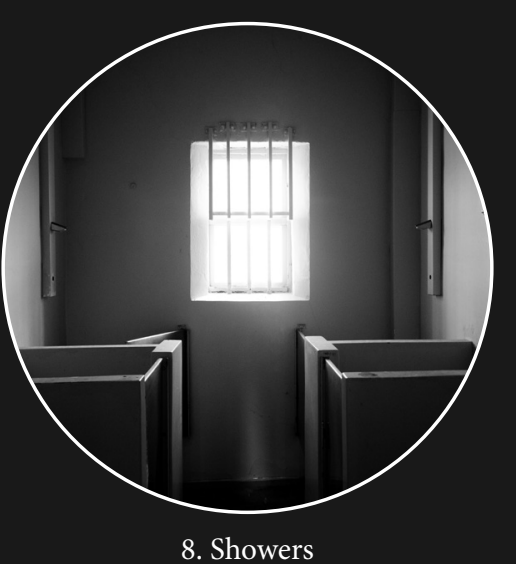
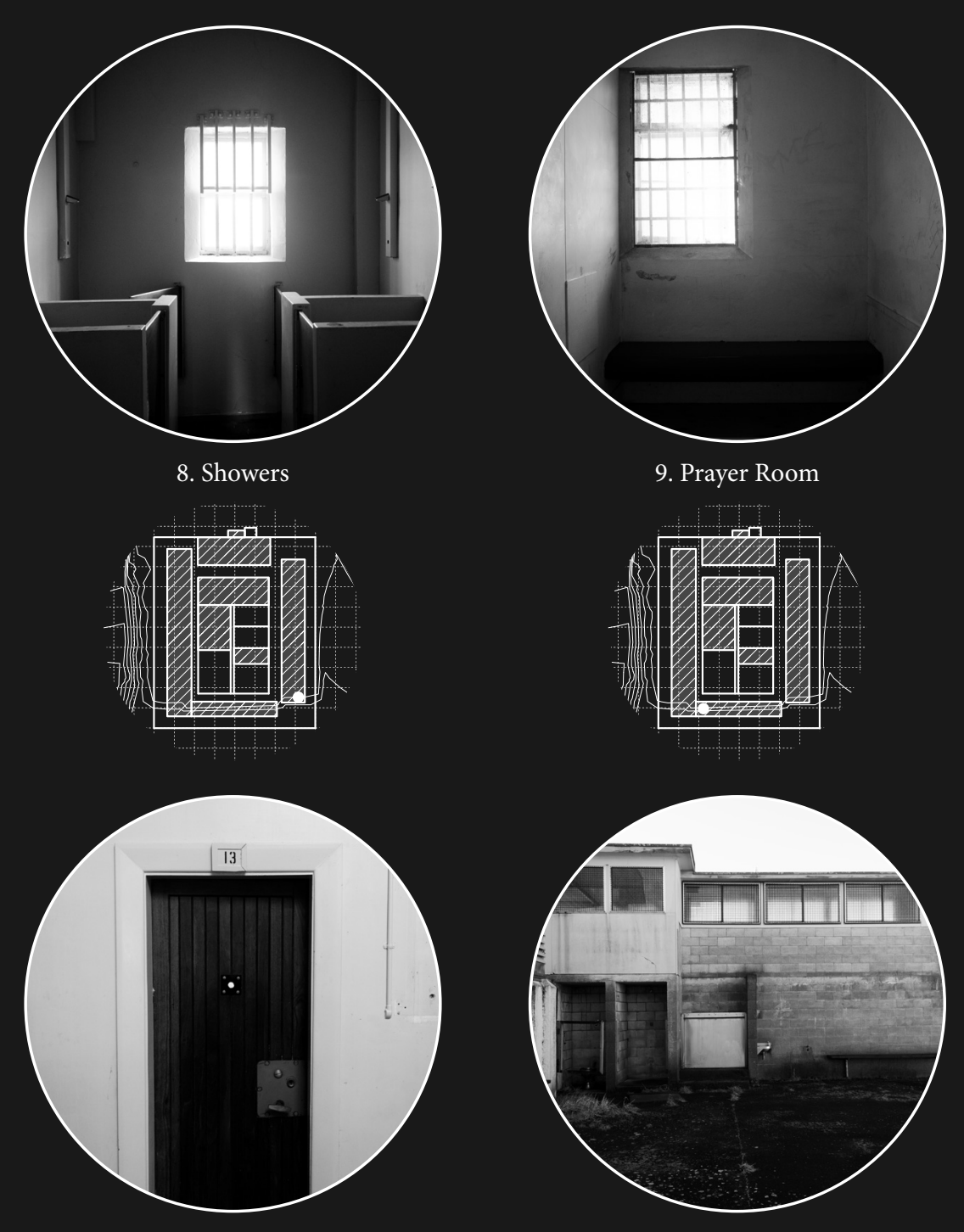

11. Low Security Cell Door
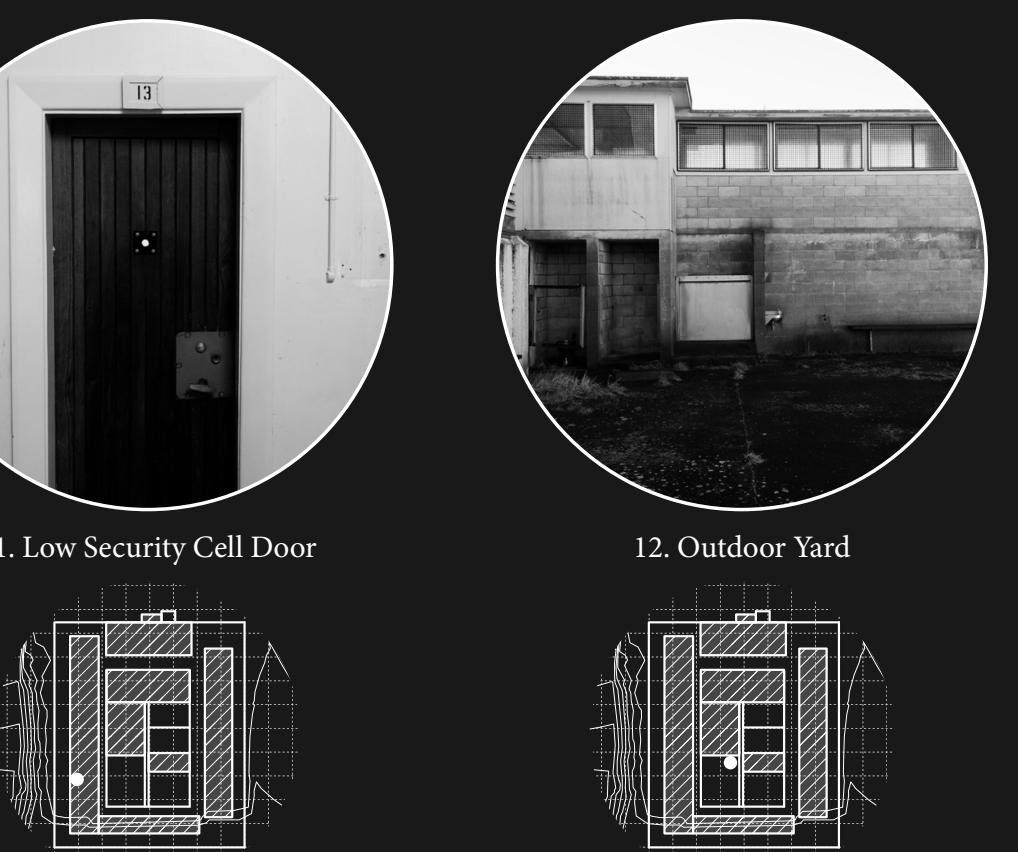
Understanding Heterotopia
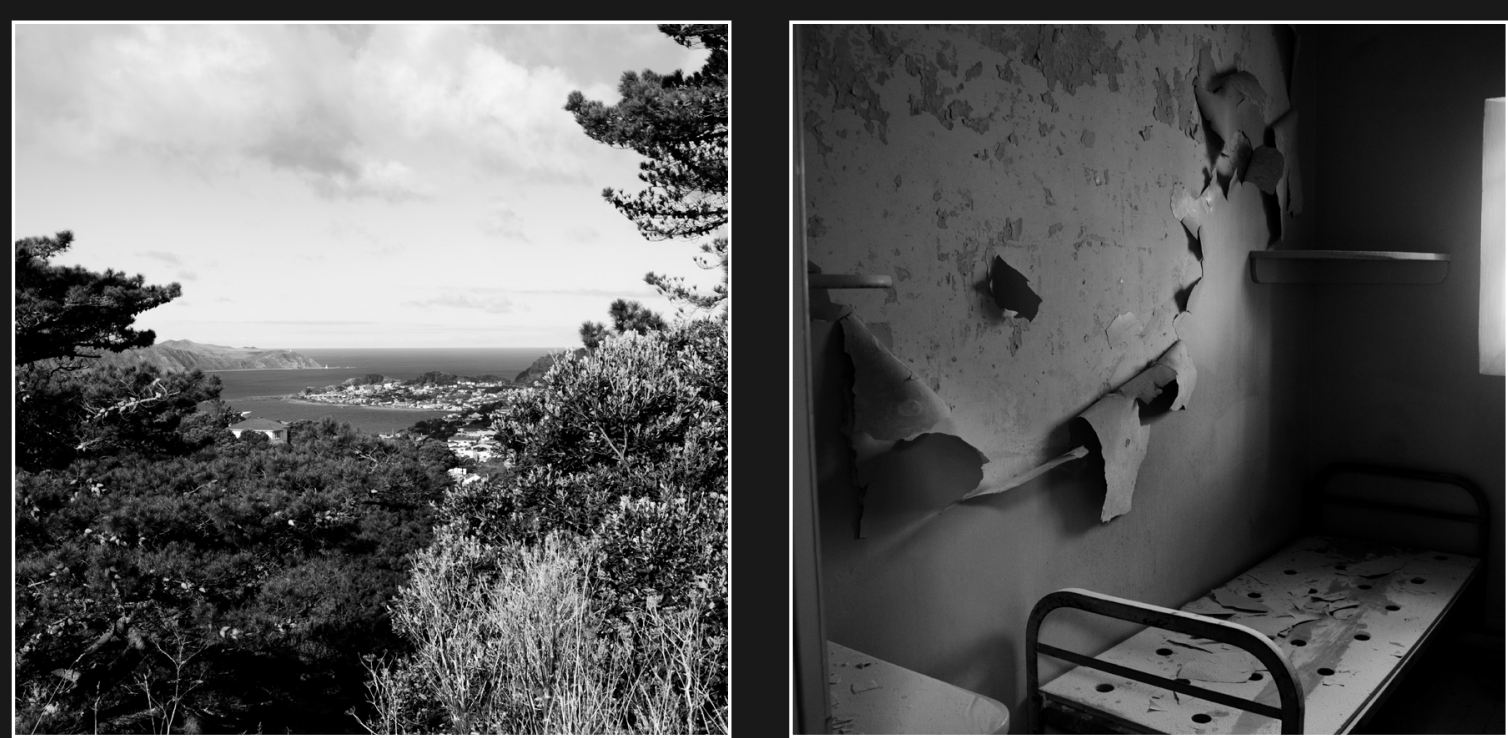

The first objective of this research investigation is to use architecture to encourage prison inhabitants to reinterpret dystopian experience through the lens of heterotopia

The reinterpretation of dystopian experience through the lens of of the site that exhibit its past in comparion to its present thecte prime example of this would be the preservation of the prison cell prime example of this wese walls bare generations of abuse and graffiti from their past and those confined within them (figure 4.28). As an exhibit they would express the history of incarceration for its negative qualities, and shed light on the positive aspects of the rehabilitative facility that this thesis proposes for Mount Crawford Prison.
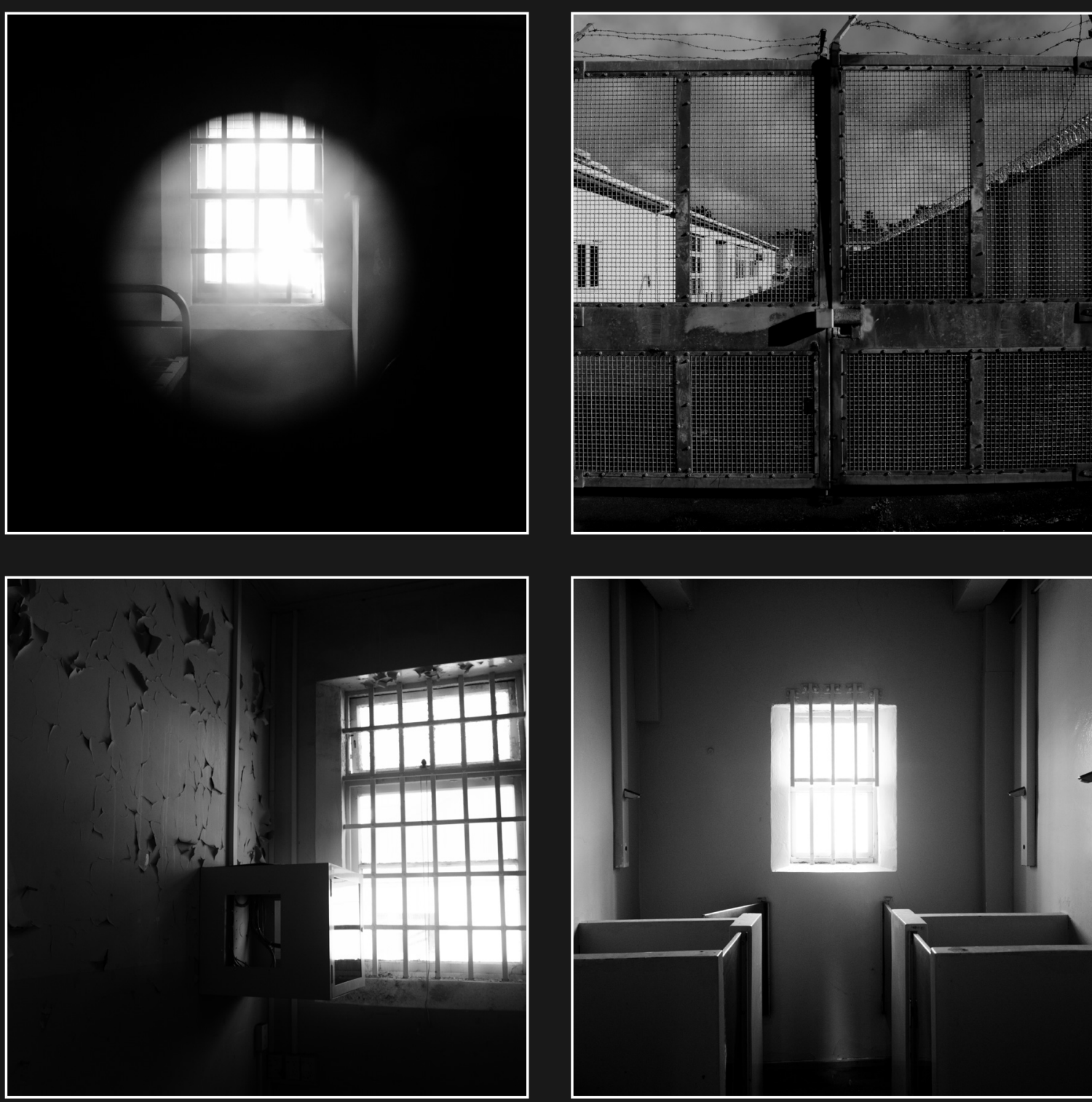

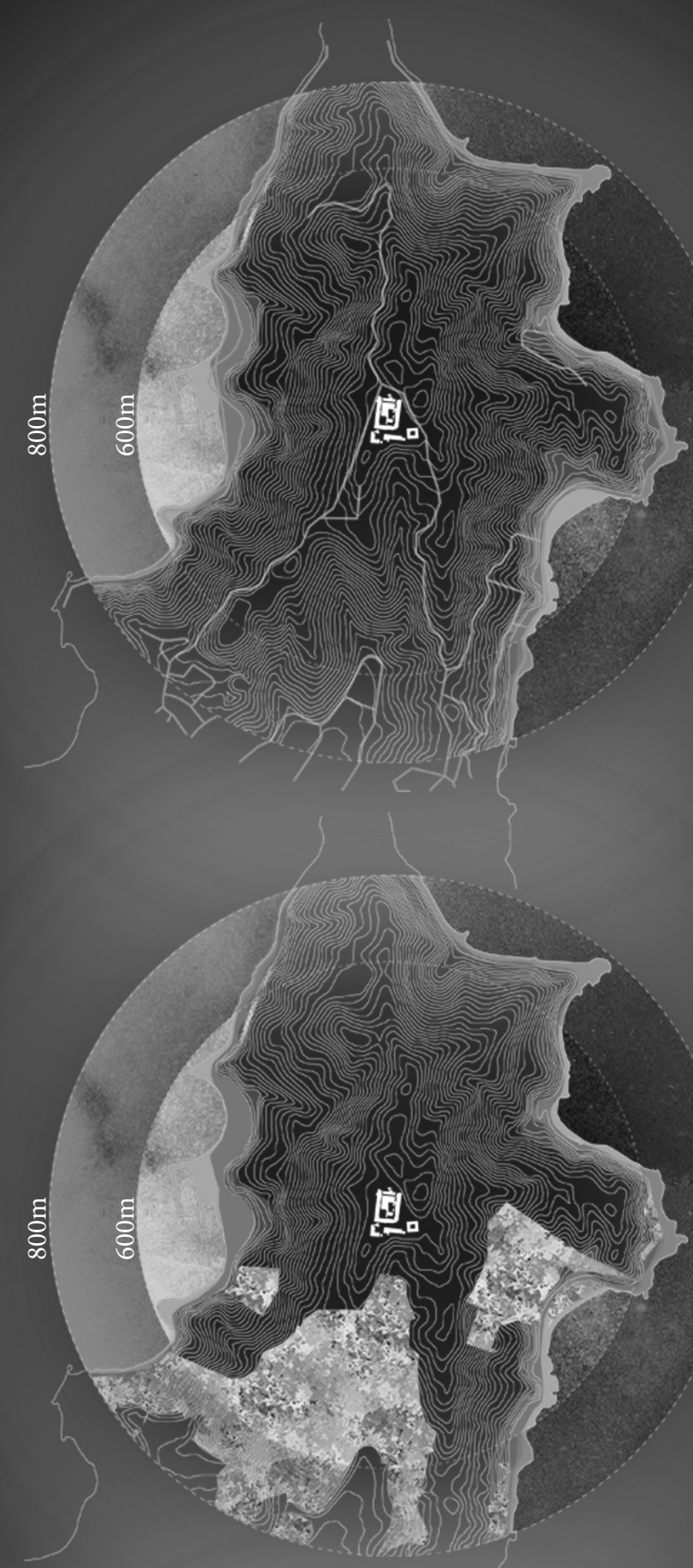

\section{Adjacencies}

\section{0}

This series of images (figure 4.29) illustrate the location of Mount
Crawford Prison and its adiacent features. The land surrounding the site is comprised mostly of horticultural farms as its slope makes it difficult to build on. The lack of adjacent buildings provides Mount Crawford Prison with views of the surrounding harbours; in the development of understandig heterotopic space, points of pause a developing heterotopic understanding of the world outside of a developing heterotopic understanding of the world outside of
priosn.

1. Access routes to the site by road.

2. Nearby reserves and parks.

3. Neighbouring buildings.

03

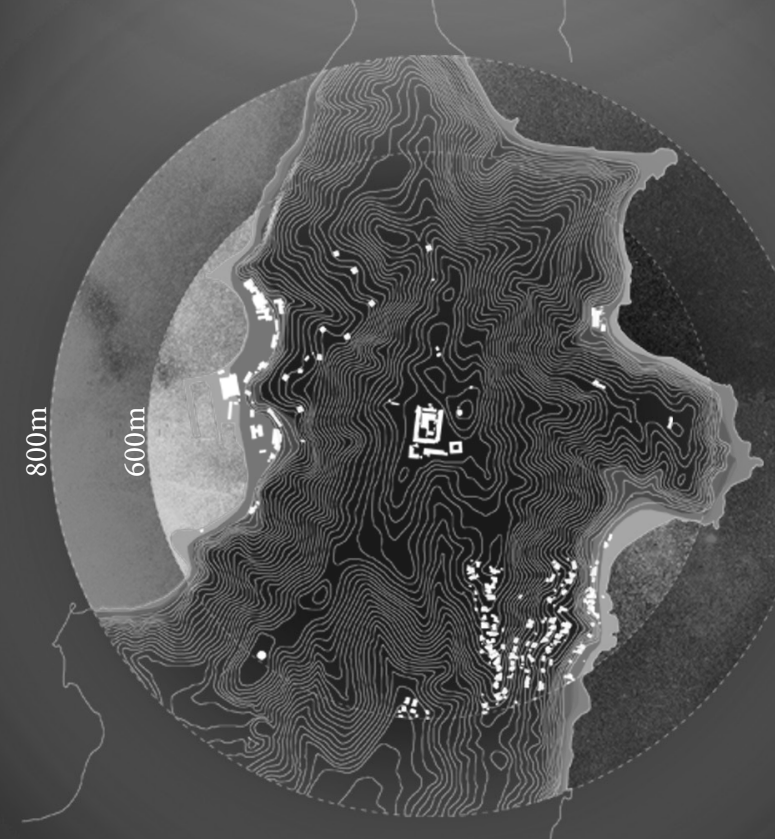




\section{Narrative Mapping}

\section{0}

This research investigation looks to analyse and map the individual journeys of each inmate in the circulation of Mount Crawford Prison, through the developmental phases of culture shock. This is carried out in order to gather data to inform the experimental design, as it looks to establish a spatial experiential narrative about the prison mhabiants' transforming interpretation of the mind set.

The strict control of movement throughout Mount Crawford Prison limits the spatial experience of each inmate, therefore it is critical to the development of the spatial experiential narrative to understand the individual inmates' movement throughout the site as they transition through the phases of culture shock. 

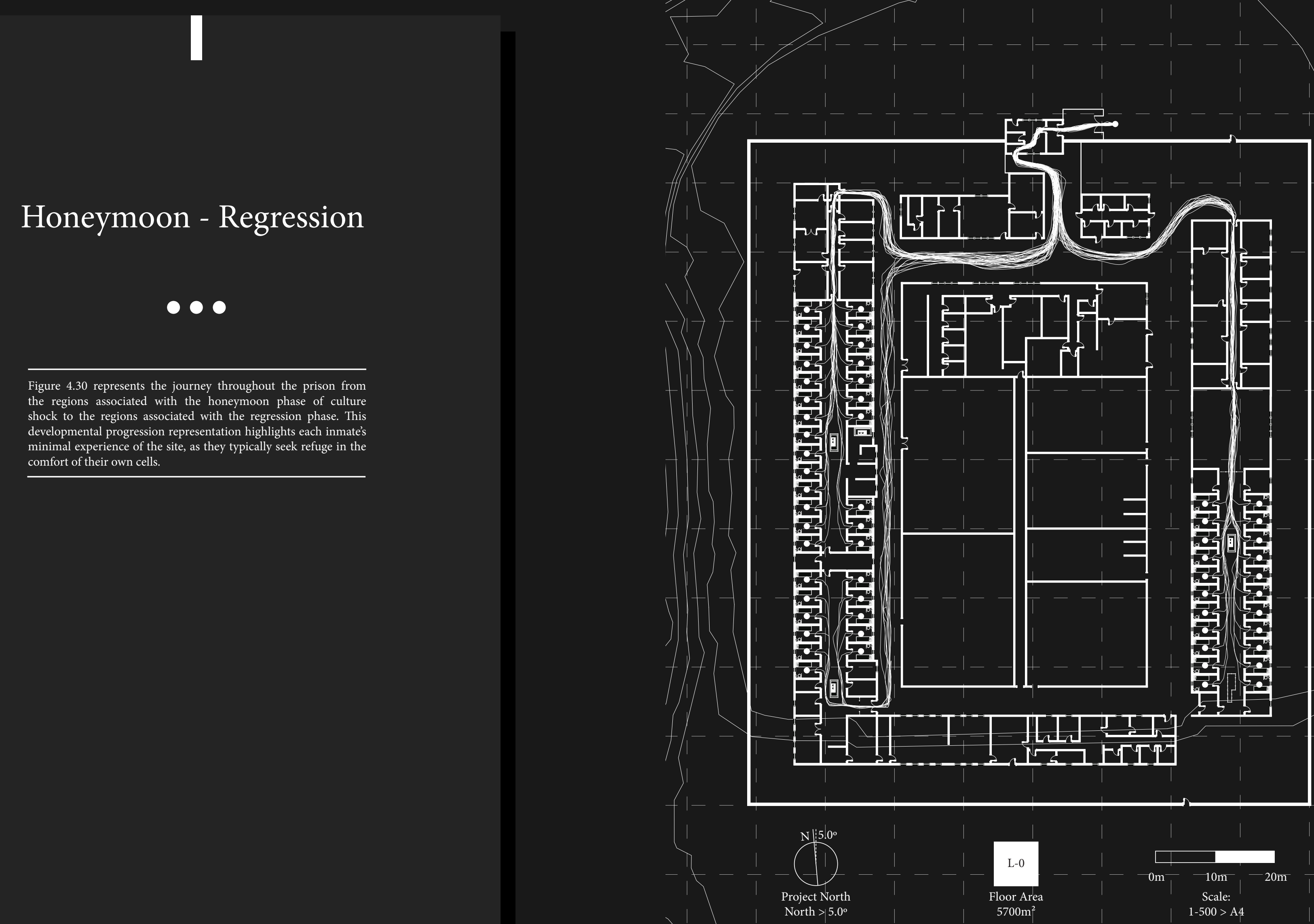

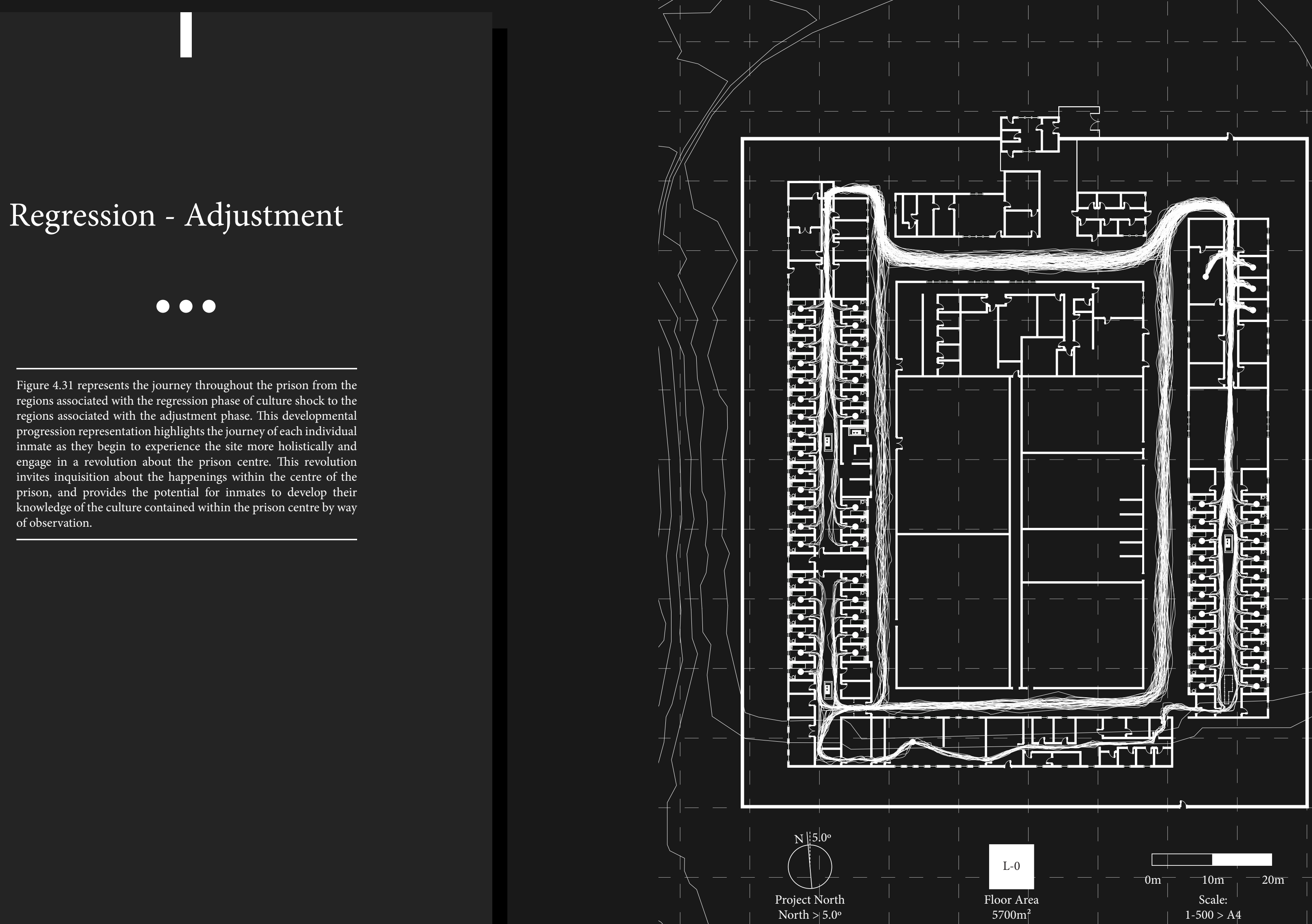
Adjustment - Acceptance

Figure 4.32 represents the journey throughout the prison form the regions associated with the adjustment phase of culture shock to the regions associated with the acceptance phase. This developmental progression representation highlights that while each inmates journey may difier slightly, hiey mantann a revolution about the prison centre, engaing in the highest levcls of socil intercorse.

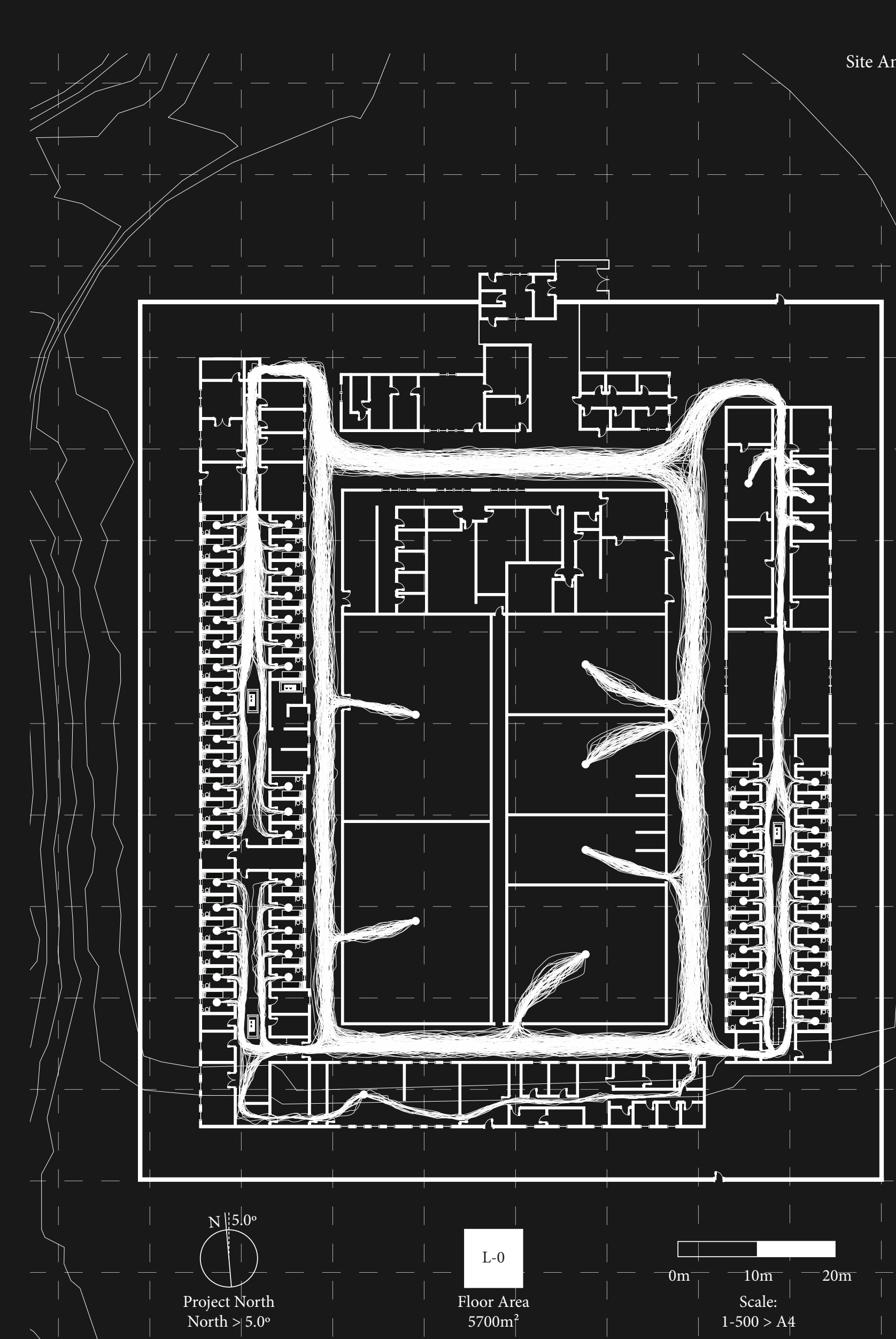




\section{Pause Mapping}

\section{0}

The circulation of Mount Crawford Prison engages inmates in a numerous series of pause upon a daily basis by way of destination locations. The first of these is experienced only once and is situated within the entrance to the site. This is where inmates begin the process of cultural
adaptation, as it is the first experience within
the walls of the foreign culture. At this point. the walls of the forcign culture. At this point, guards and processing officers who do not shre the same heterotopic identity as the inmates therefore social cues and tendencies of the foreign culture are not yet experienced. This lack of social intercourse allows for the opporting for new inmates to develop an understanding of the phystal properties of in prior to expereecing of

Perhaps the most recognisable destination point of pause by way of quantity is located within the prison cells where inmates eat, sleep, and find confort in solation. These points of pause are located in spaces of minimal socia intercourse and provide a much more intimate setting. Envo pats wh intercourse are particularly important in regard
to the regression phase of culture shock. They provide a setting where one can mentally remove themselves temporarily form the foreign culture and find comfort in their own familiar company.

phase of culture shoc themselves in the on goings within the foreign culture by way of gesture, conversation or simply observation.

Social intercourse continues to increase in destinations of pause such as the chapel, health
care vicinities and the visiting quarters. These destinutions and the visting quarters. These destinations are subject to spiritual values,
medical requirements or the visitation of family and loved ones and are seemingly vulnerable experiences - as inmates are required to reveal more of themselves within the foreign culture. The frequency of pause within these locations is relative to the comfort of the inmate within the environment - it increases as the adaptation phase of the spectrum to the acceptnce end-

The pinnacle of social intercourse within Mount Crawford Prison is located within the central division, of which the rest of the site revolves around. This central hub plays host to six ef activity you two of of pause in the form way of association to the developmental phy of culture shock and the level of understases of social cues and tendencies with in this area inmates occupying this space have accepted the foreign culture and have begun to embrace it as

As the journey throughout the site develops it is apparent that social intercourse increases a
the distance from the cell grows. The walkways the distance from the cell grows. The walkways
surrounding the prison yards play host to numerous journeys from one destination to another and yet not one destination lies within. This revolution around the centre of the site engages the opportunity for social interaction. however does not impose it. These walkways provide the ideal platform for the adaptation 
Honeymoon Phase

The following series of drawings represent the time spent in locations throughout the prison chatecto the developmental stage of culture shock or the inmat, Whate hes represent high frequency journeys while the red lines represent low frequency journeys.

Figure 4.33 represents the Honeymoon Phase of culture shock. majority of the site remains unexplored and the level of integration to the foreign culture remains minimal.

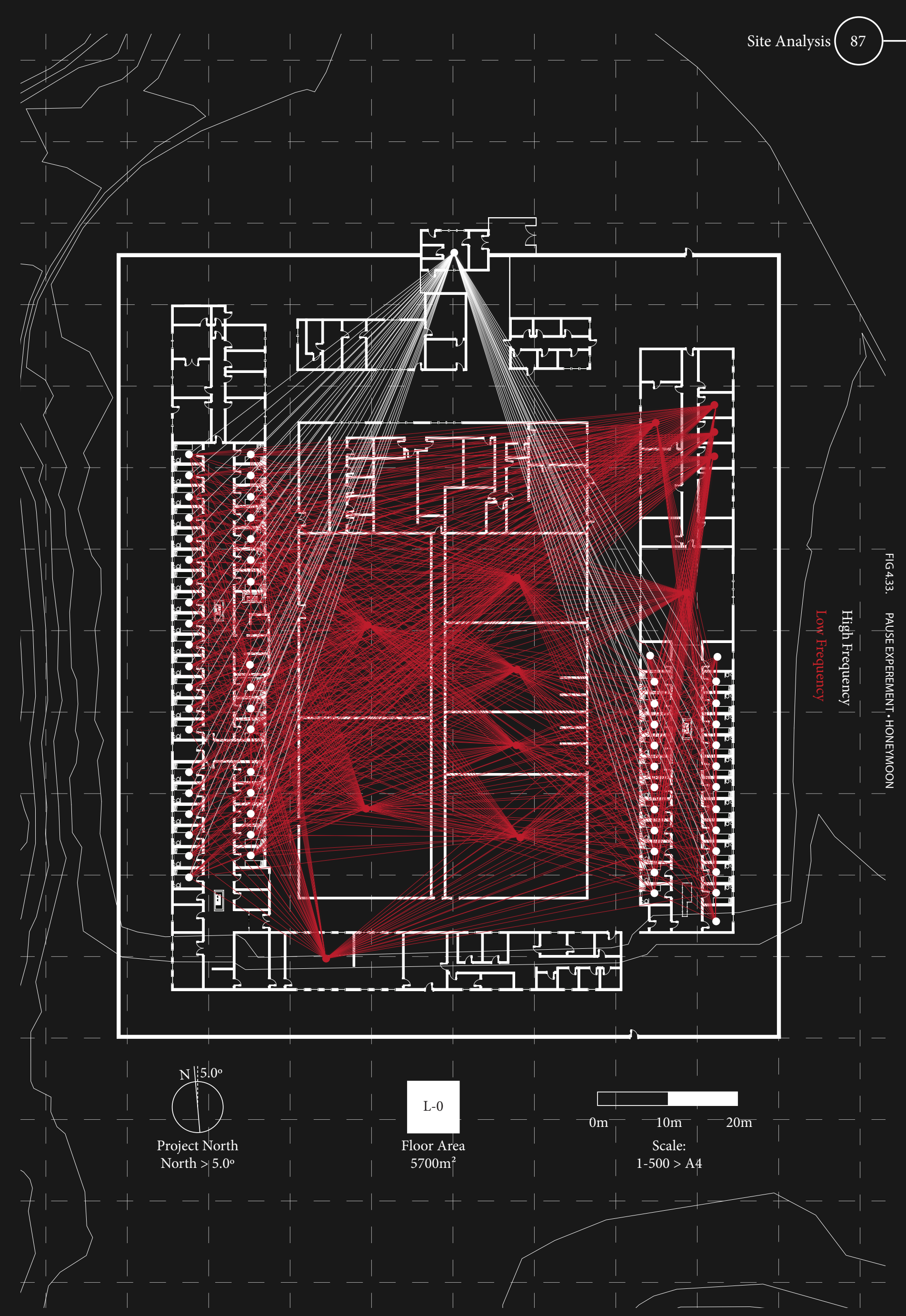


Regression Phase

Figure 4.34 represents the Regression Phase of culture shock Typically, inmates in this stage of culture shock have begun to reject the foreign culture and seek comfort in their own company in isolation. Social intercourse is avoided through prolonged periods of time spent in the individual's prison cel.

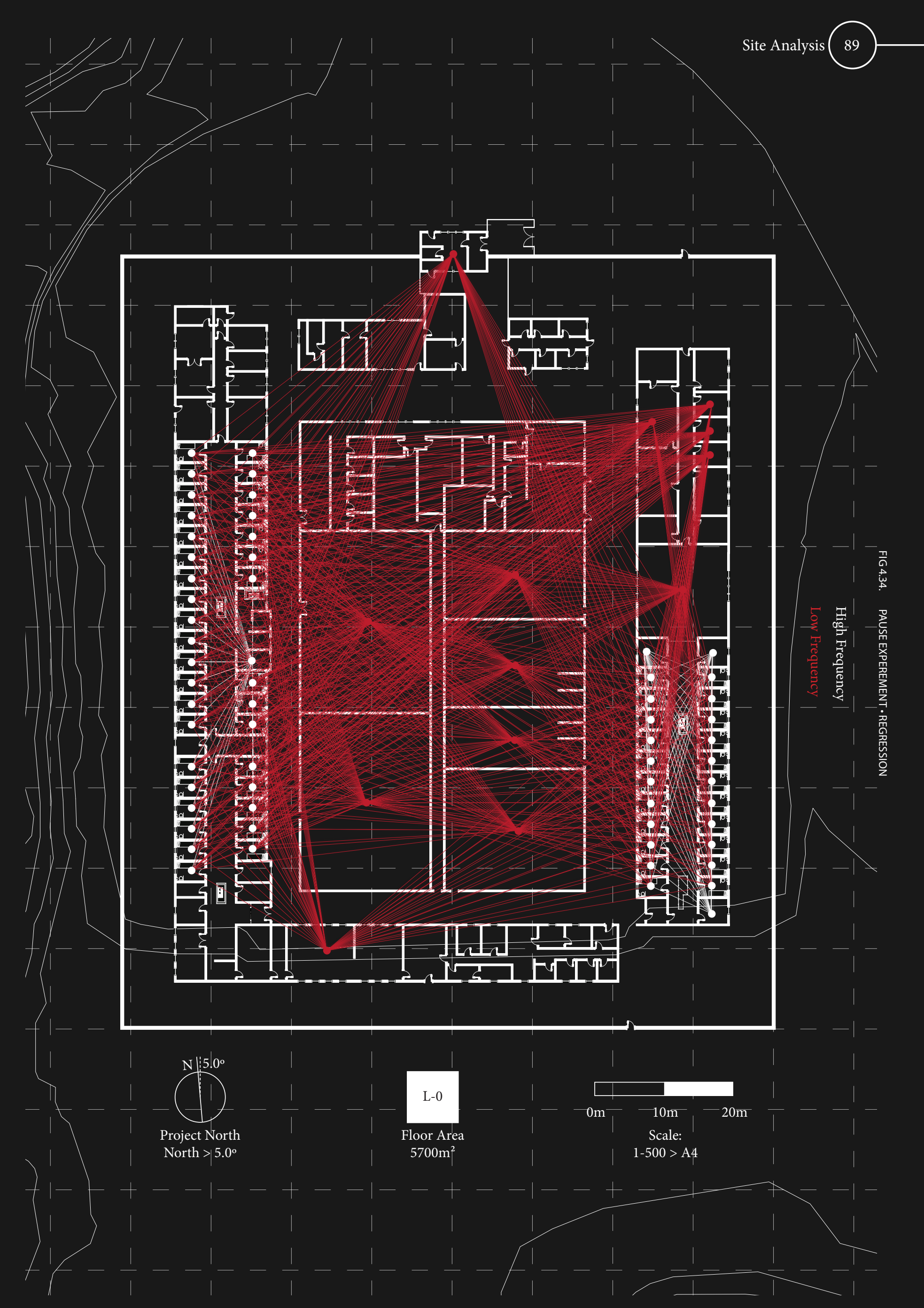



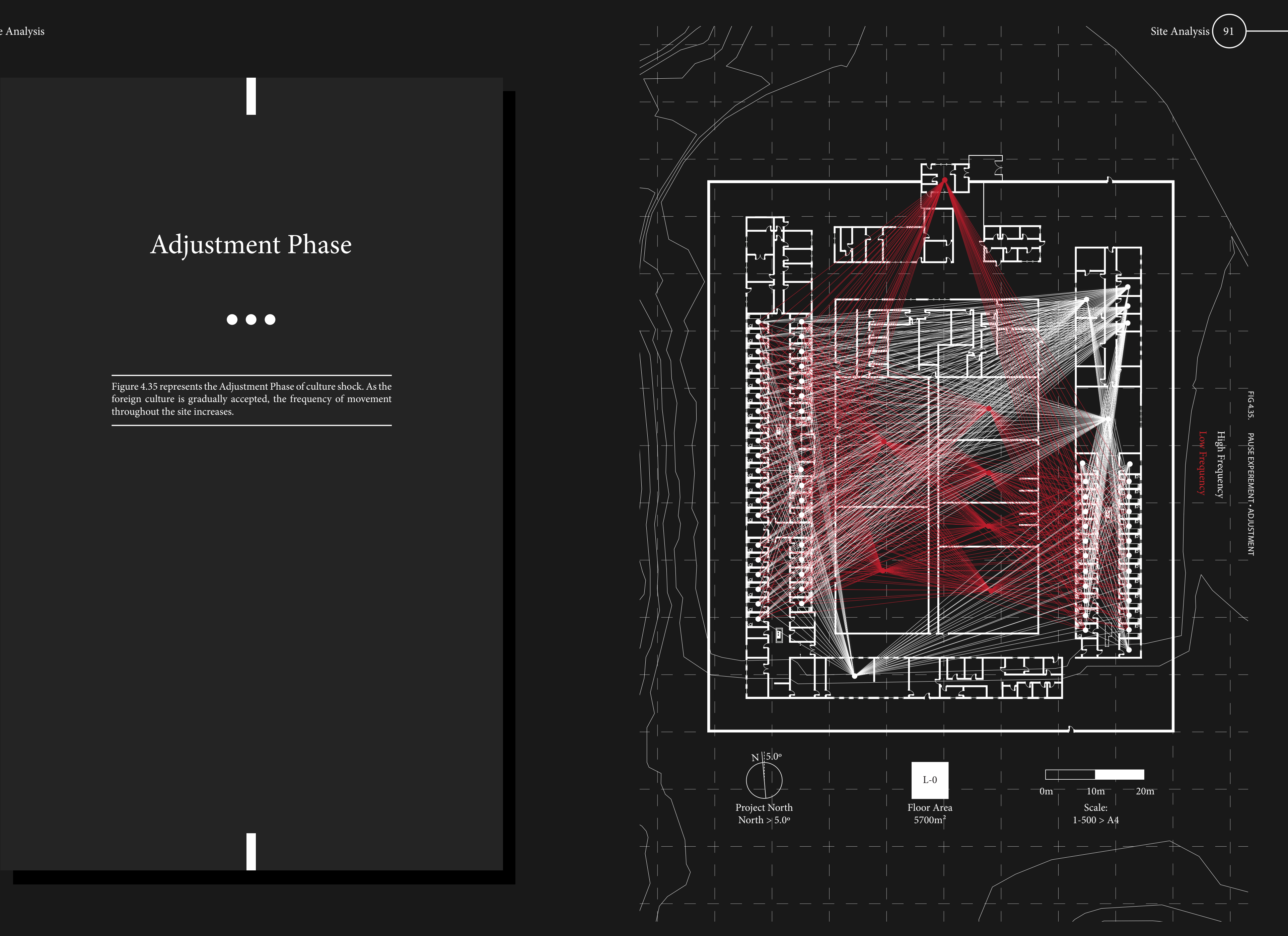
Acceptance Phase

Figure 4.36 represents the Acceptance Phase of culture shock experience the site and culture entirely at a series of high frequency journeys.

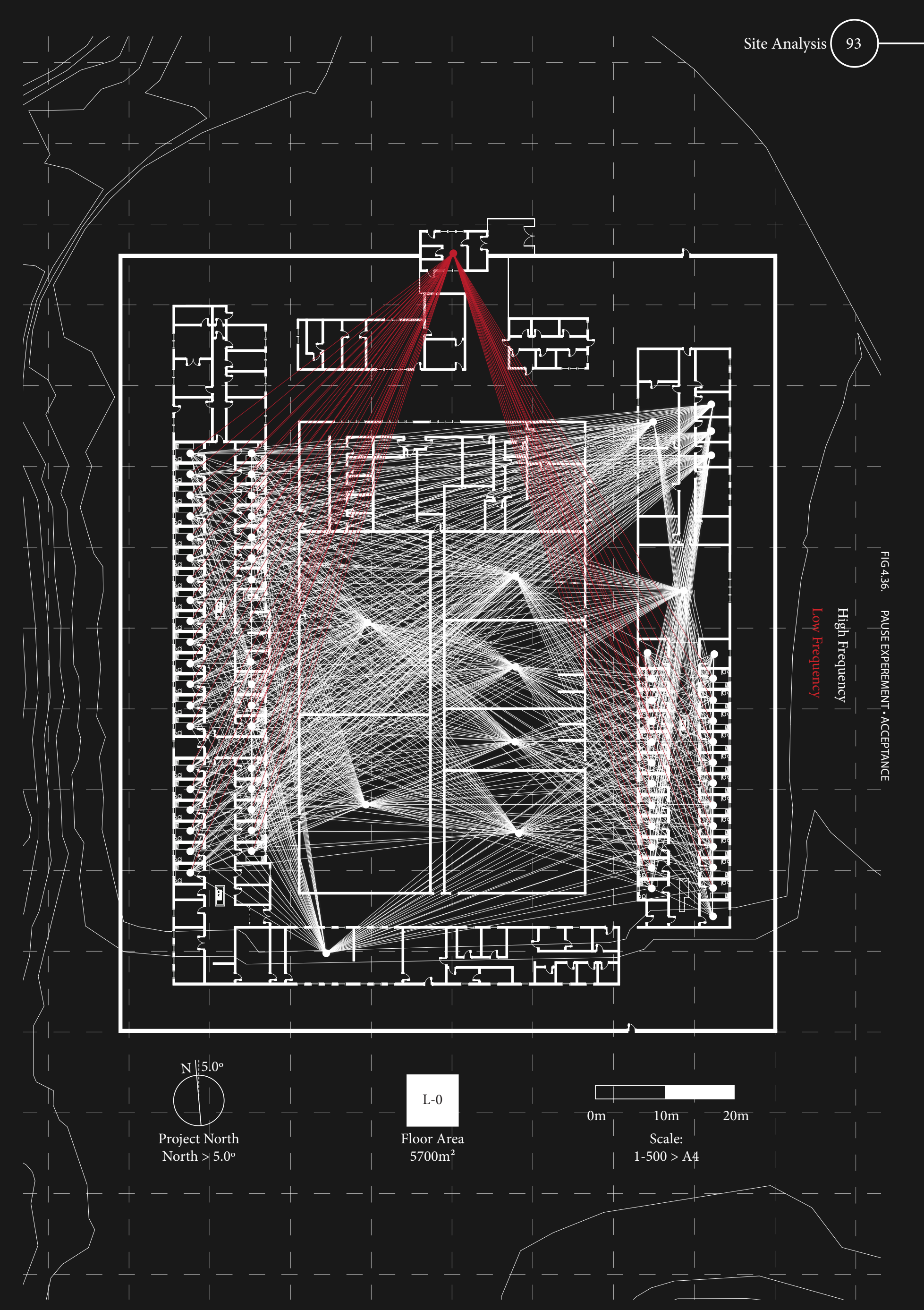




\section{Critical Reflection}

In the aim of the enablement of architecture to have a rehabilitative
function in a prison environment, in conjunction with, the
reduction of recidivism through didactic architectural experience,
Mount Crawford Prison provides a strong foundation to test the
objectives of this research investigation.
The dystopian experience of previous inmates is present
throughout the site is it exposes grafifit and wear. This provides
the opportunity for the developed architecture to establish an
experiential separation between the dystopian heritage of the site
and the utopian rehabilitative intervention. This will be carried out
in the experimental design in the exploration of encouraging prison
inhabitants to reinterpret dystopian experience through the lens of
heterotopia.
The strict control of flow throughout the site provides the
opportunity for architecture to establish a spatial experiential
narrative about the prison inhabitants' transforming interpretation
of their surroundings, in order to rehabilitate their dystopian
mind set. As each transitioning phase of culture shock sees the
further exploration of the site and its cultural environment, the
experimental design will explore architecture that encourages the
development in cultural integration.
The existing site establishes a series of points of pause that are based
on destination, however, neglects the importance of pause in the
journey from origin to destination. The centre of the prison plays
host to the most advanced phase of cultural integration, therefore,
it is critical to the inmates developmental understanding of culture
to provide them with the opportunity to observe this space in their
journey from origin to destination. The experimental design will
explore the establishment of points of pause along the journey of the
spatial experiential narrative, which enable enhanced understanding
of foreign culture through a heterotopic lens.



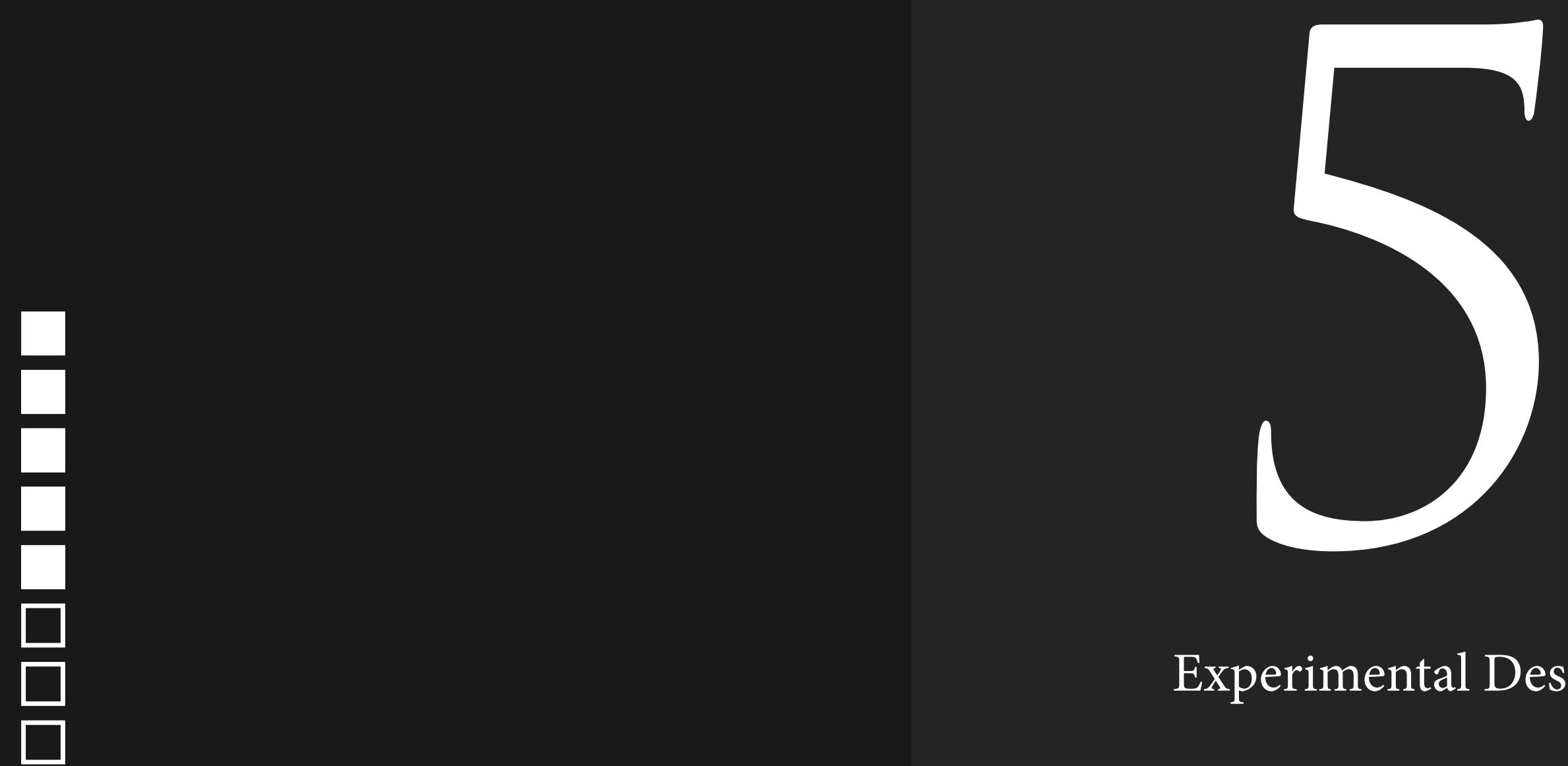

\section{Experimental Design}

000

When considered as part of a narrative, an environment

should be viewed as occurring at a particular time but also as

unfolding over a period of time. The time involved however, is

- C. Ganoe, excerpt from "Design as Narrative: A theory of Inhabiting Interior Space" 
Introduction

This chapter explores methods It begins at the entrance and of - estabishing deliberate develops through the physical ponts of pause within the experiential journey of the
context of the prison and its prison mirroring the mental subdivisions. These points of experiential journey of culture pause focus on establishing shock. The resulting design enhanced understandhy or whe critically analysed on its site in order to help transform enhanced understending of the self-narntive of the inmate dystopic experience. and their interpretations of dystopic experience. dystopian experience. 


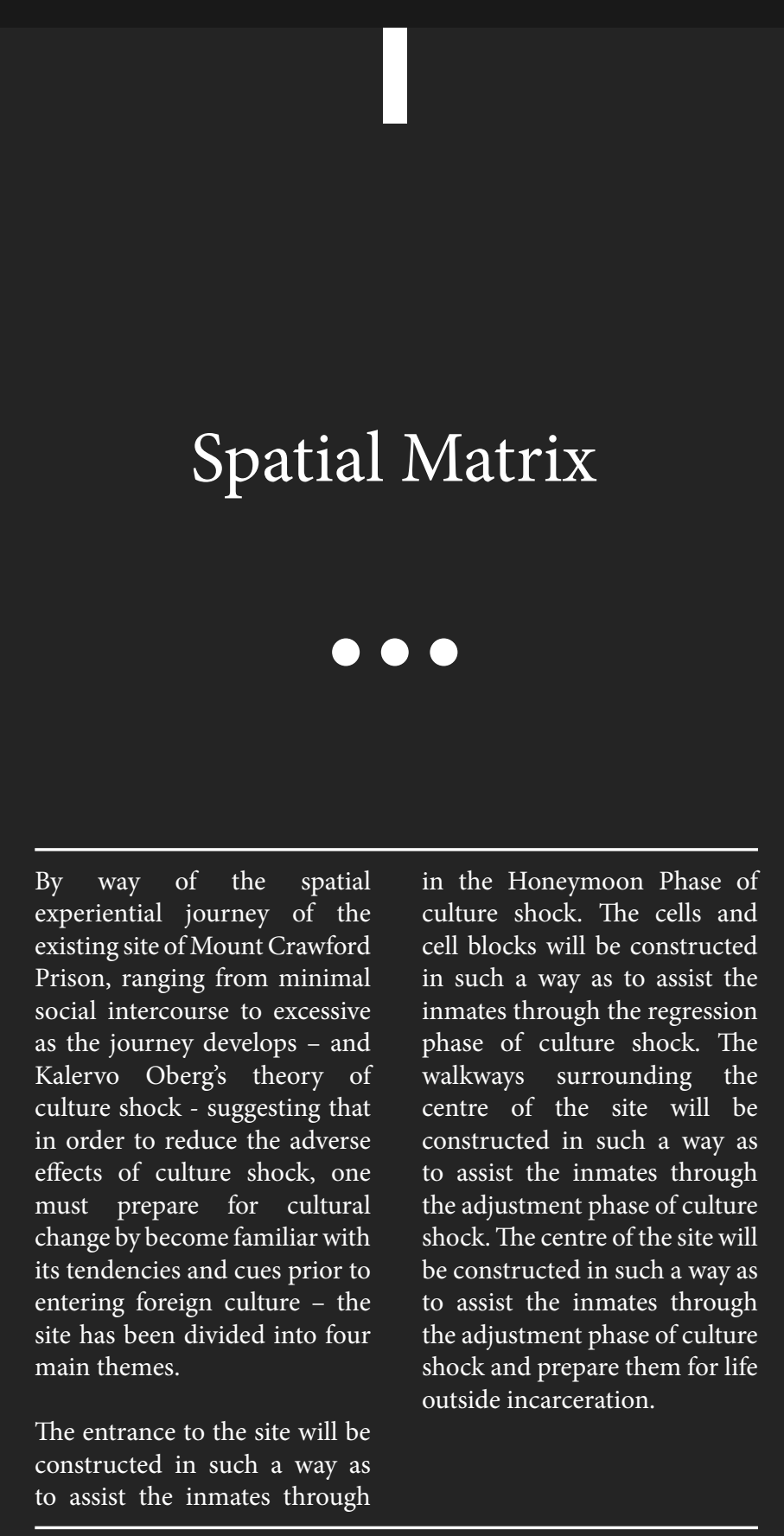

Spatial Matrix

\begin{tabular}{|c|c|}
\hline $\begin{array}{l}\text { By way of the spatial } \\
\text { experiential journey of the } \\
\text { existing site of Mount Crawford } \\
\text { Prison, ranging from minimal } \\
\text { social intercourse to excessive } \\
\text { as the journey develops - and } \\
\text { Kalervo Obergs theory of } \\
\text { culture shock - suggesting that } \\
\text { in order to reduce the adverse } \\
\text { effects of culture shock, one } \\
\text { must prepare for cultural } \\
\text { change by become familiar with } \\
\text { its tendencies and cues prior to } \\
\text { entering foreign culture - the } \\
\text { site has been divided into four } \\
\text { main themes. }\end{array}$ & $\begin{array}{l}\text { in the Honeymoon Phase of } \\
\text { culture shock. The cells and } \\
\text { cell blocks will be constructed } \\
\text { in such a way as to assist the } \\
\text { inmates through the regression } \\
\text { phase of culture shock. The } \\
\text { walkways surrounding the } \\
\text { centre of the site will be } \\
\text { constructed in such a way as } \\
\text { to assist the inmates through } \\
\text { the adjustment phase of culture } \\
\text { shock. The centre of the site will } \\
\text { be constructed in such a way as } \\
\text { to assist the inmates through } \\
\text { the adjustment phase of culture } \\
\text { shock and prepare them for life } \\
\text { outside incarceration. }\end{array}$ \\
\hline & \\
\hline
\end{tabular}

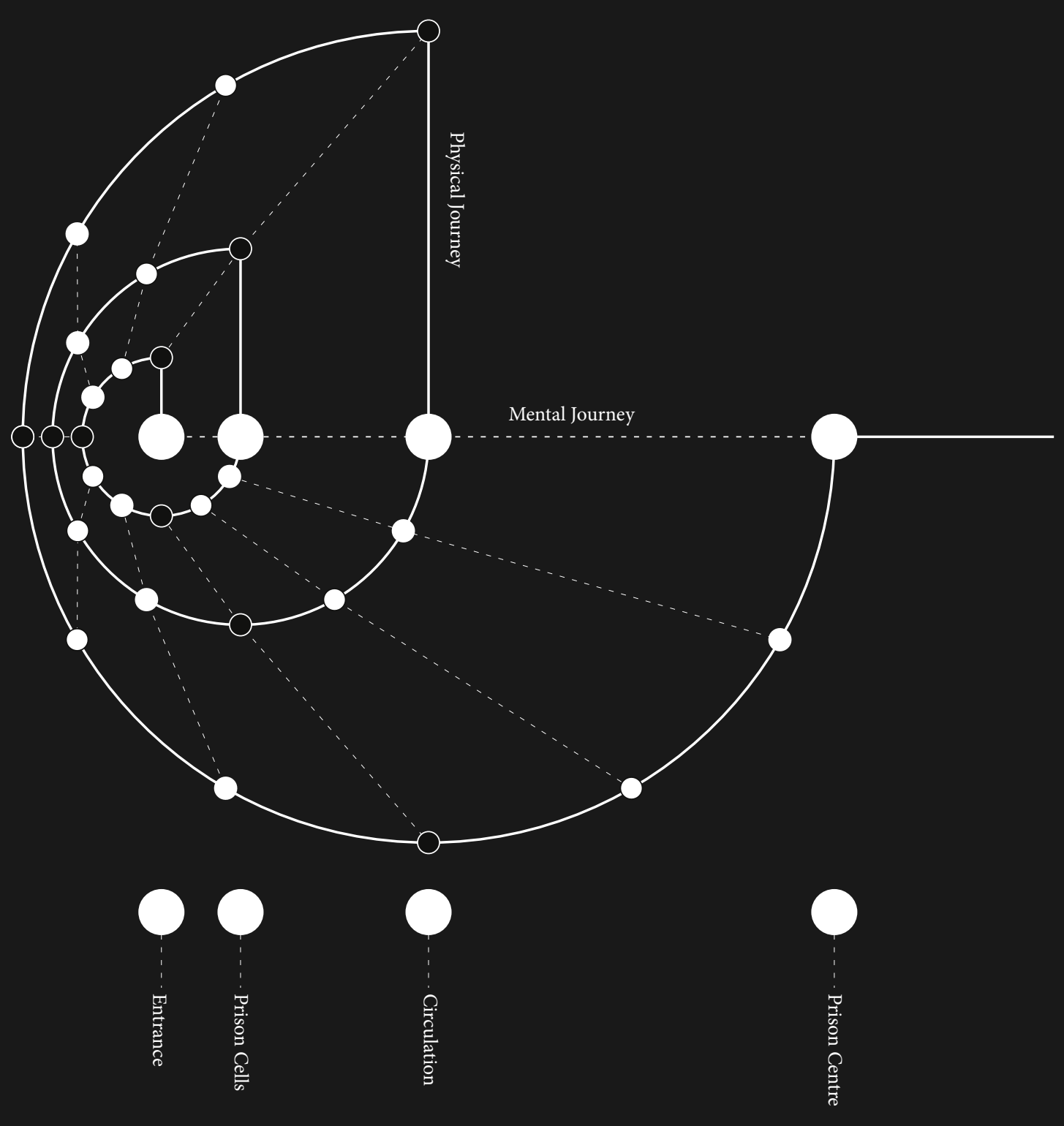




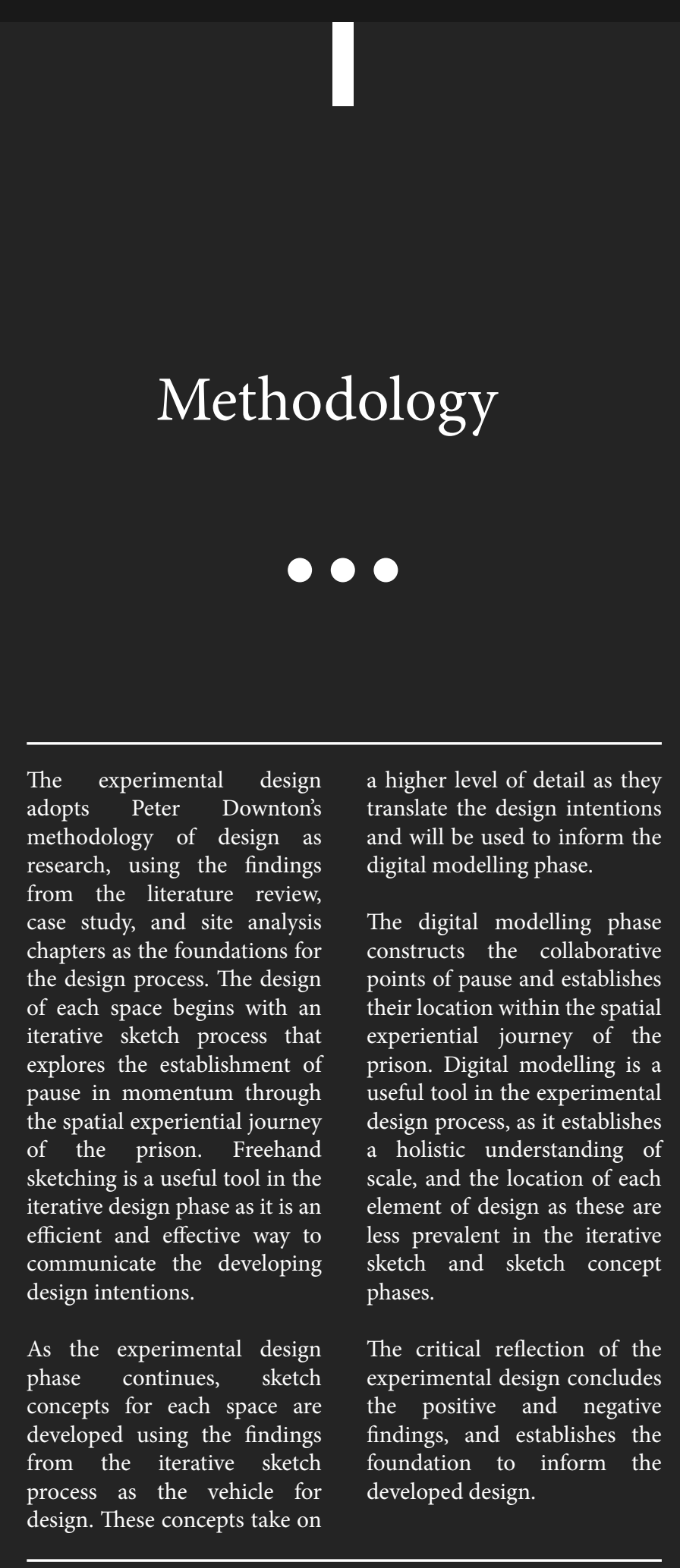

I
4.
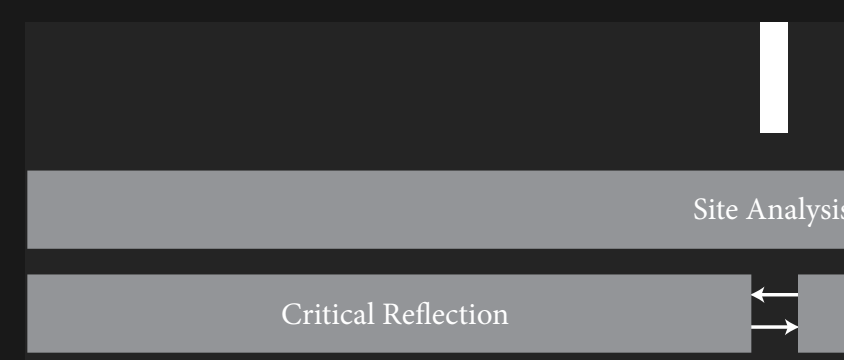

$\Leftrightarrow$

Findings
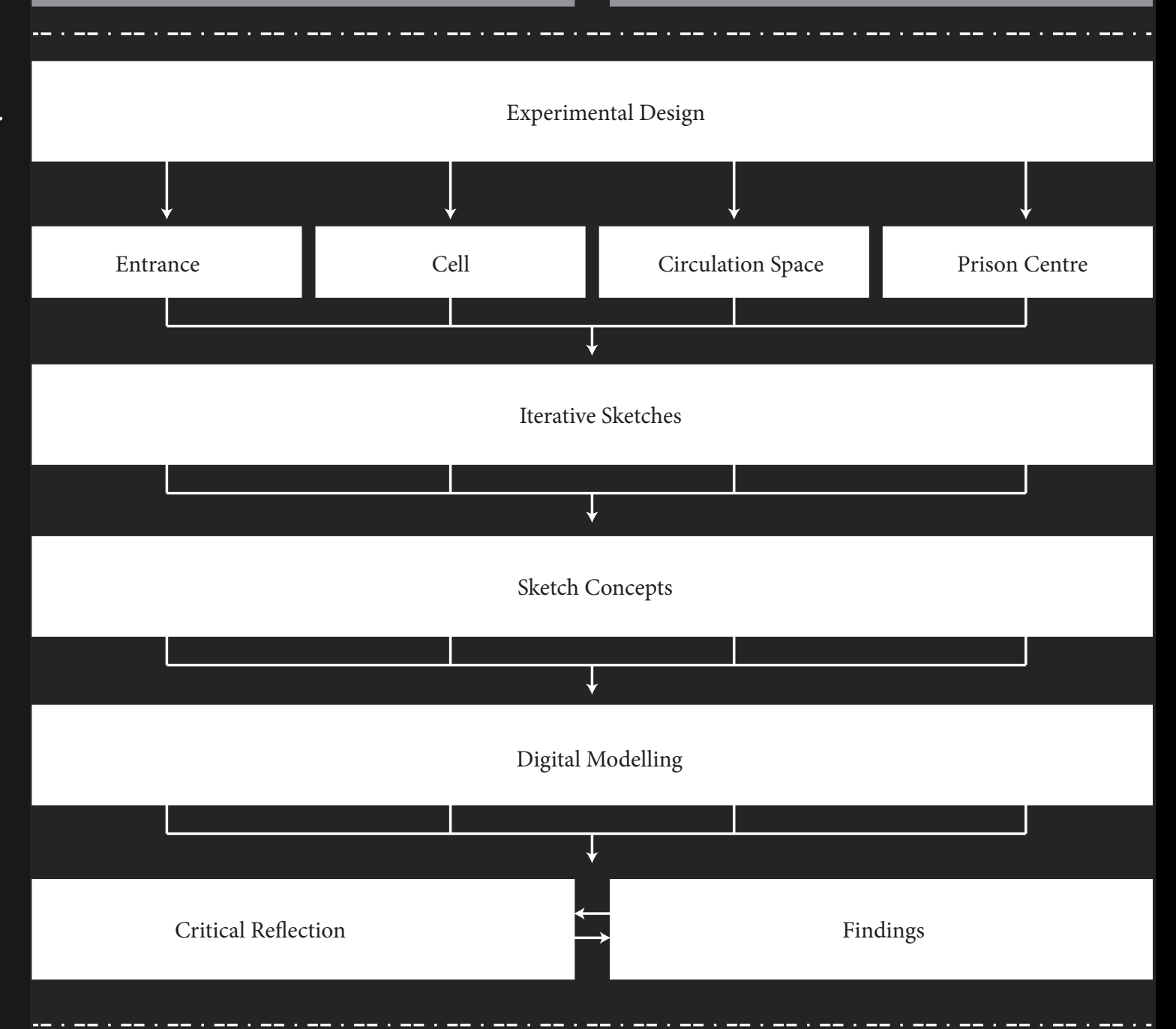

Developed Design

7.

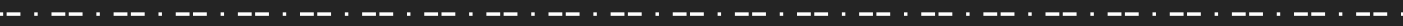

.

Conclusion

8.

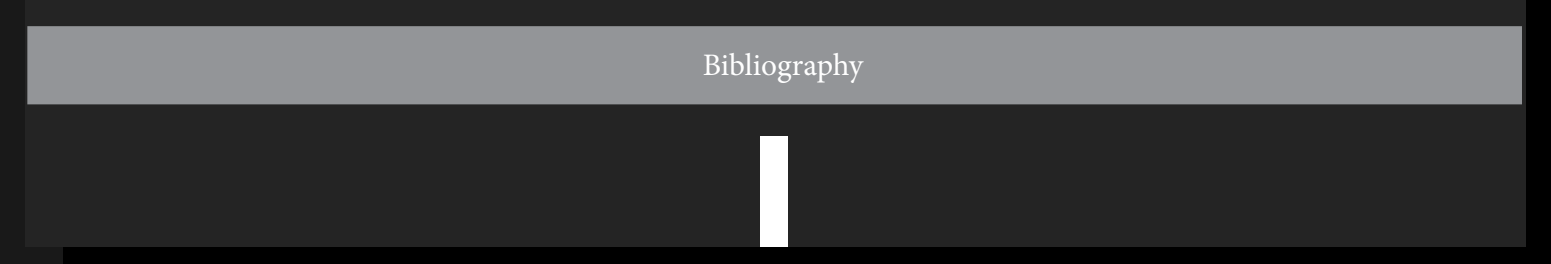




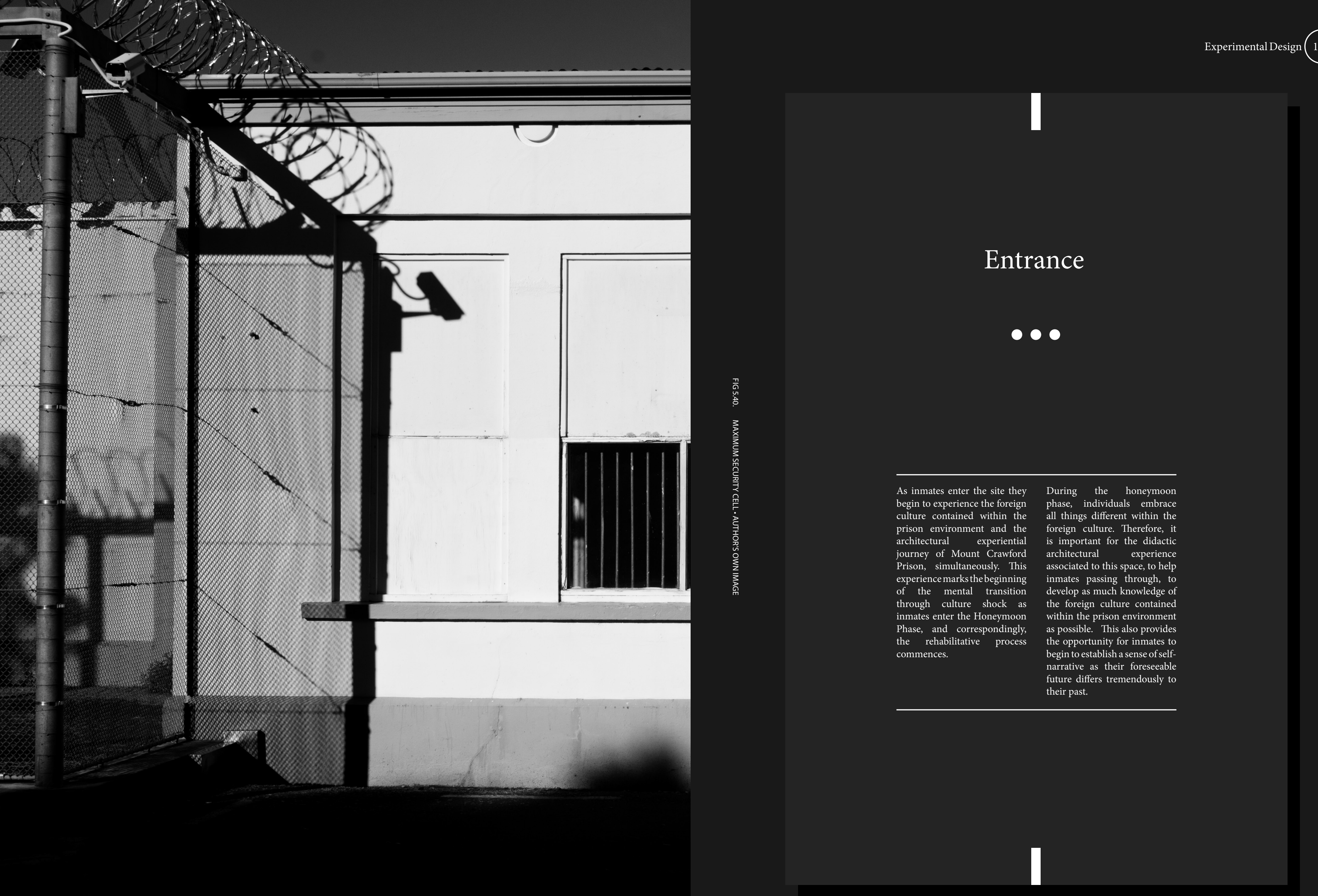




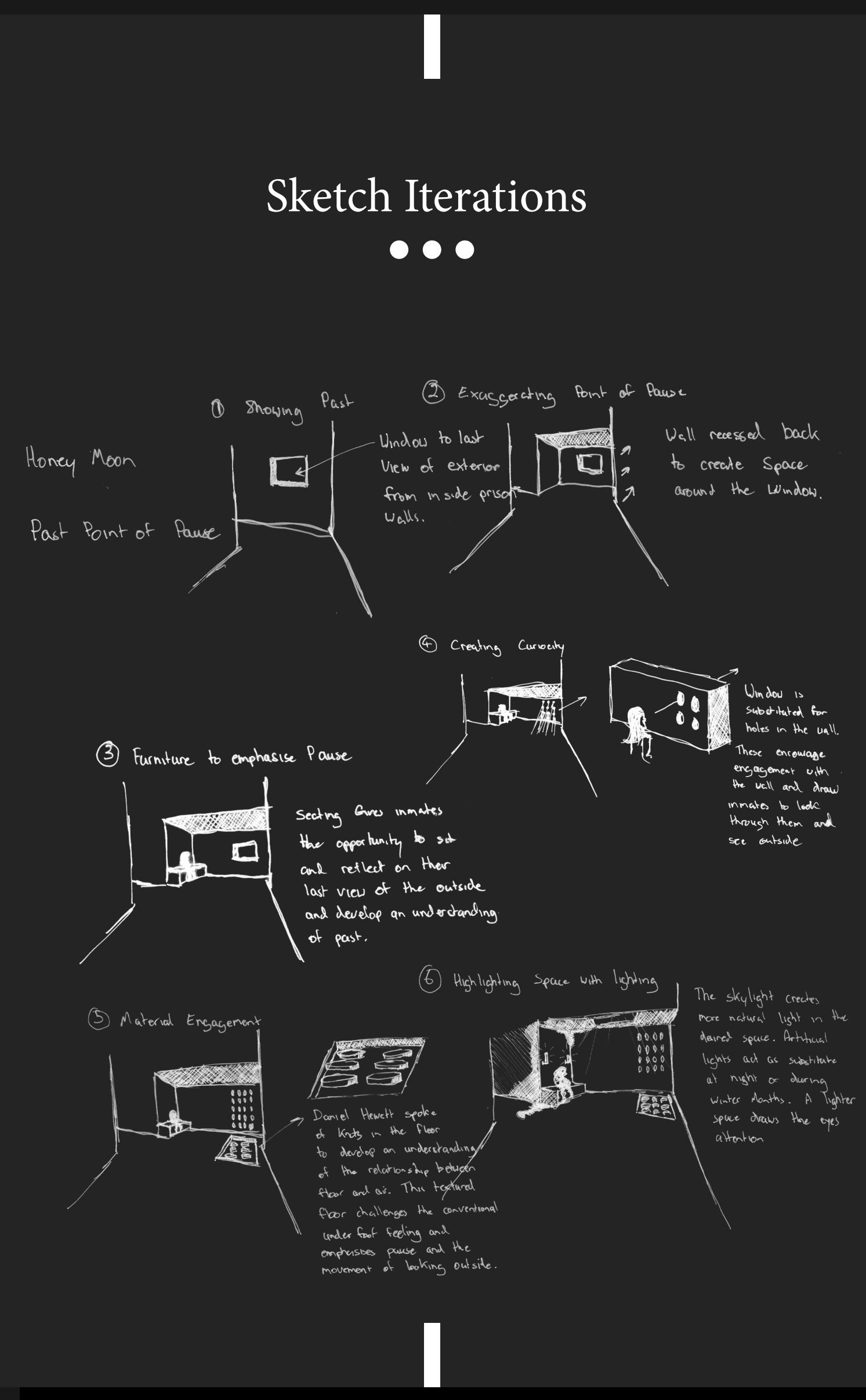

Developed Sketch

000

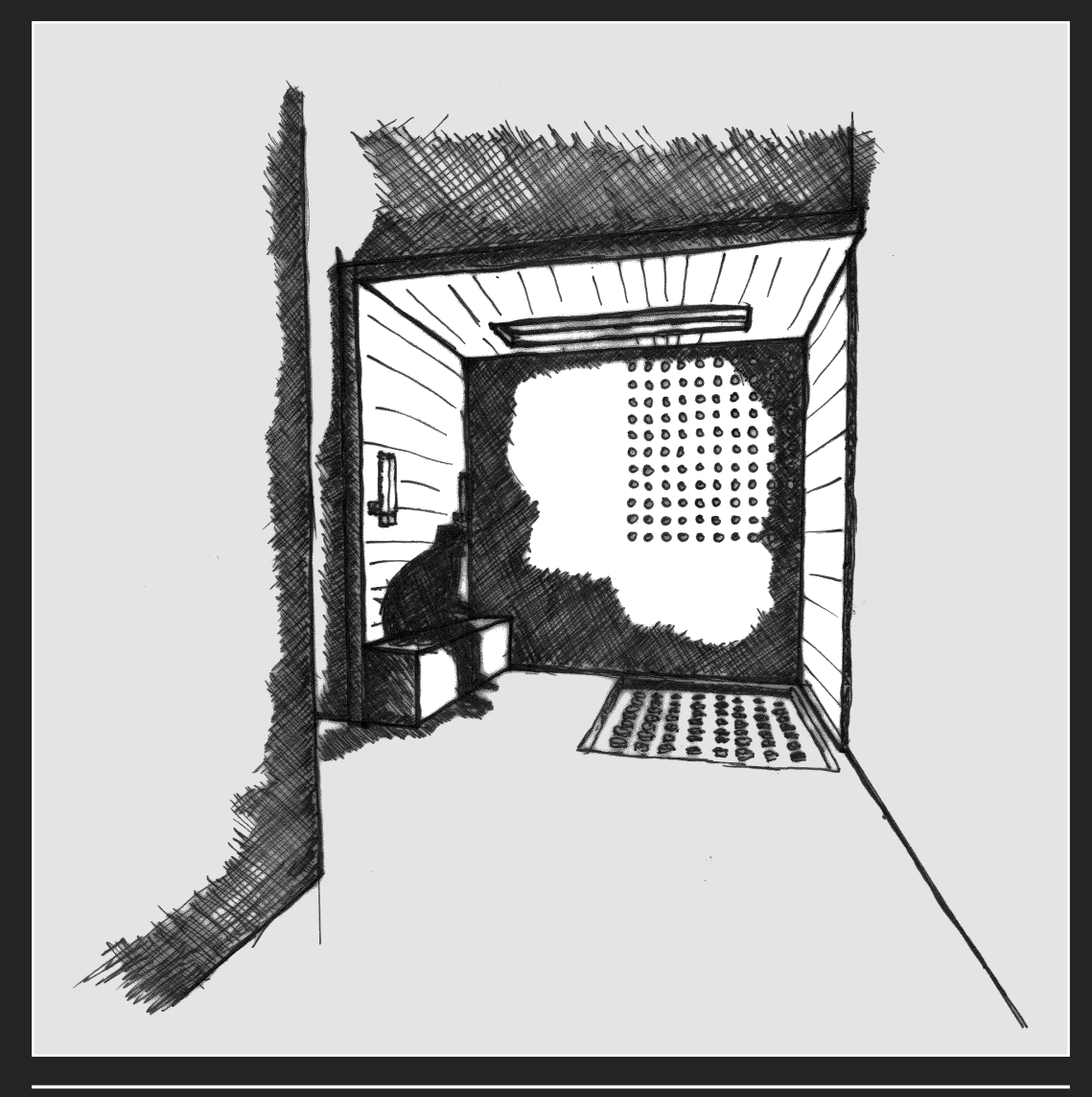

The rehabilitative journey through this curiosity and inquisition about the space intervention begins in the entrance of the and encourage passers-by to approach the site with the design of the first point of wall to look through. This point of pause pause. The design of pause is influenced frames the last view of the outside world by Daniel $M$. Hewett - in his theory from the ground floor of the prison. It Implications of Pause" - and involves heterotopia by way of presenting whet the manipulation of texture, movement once was tangible space as intangible and the window where its conventional and using the association to memories shape is challenged and divided into of the past as a means of developing a series of small circular holes in the understanding. vall. These unconventional voids create 


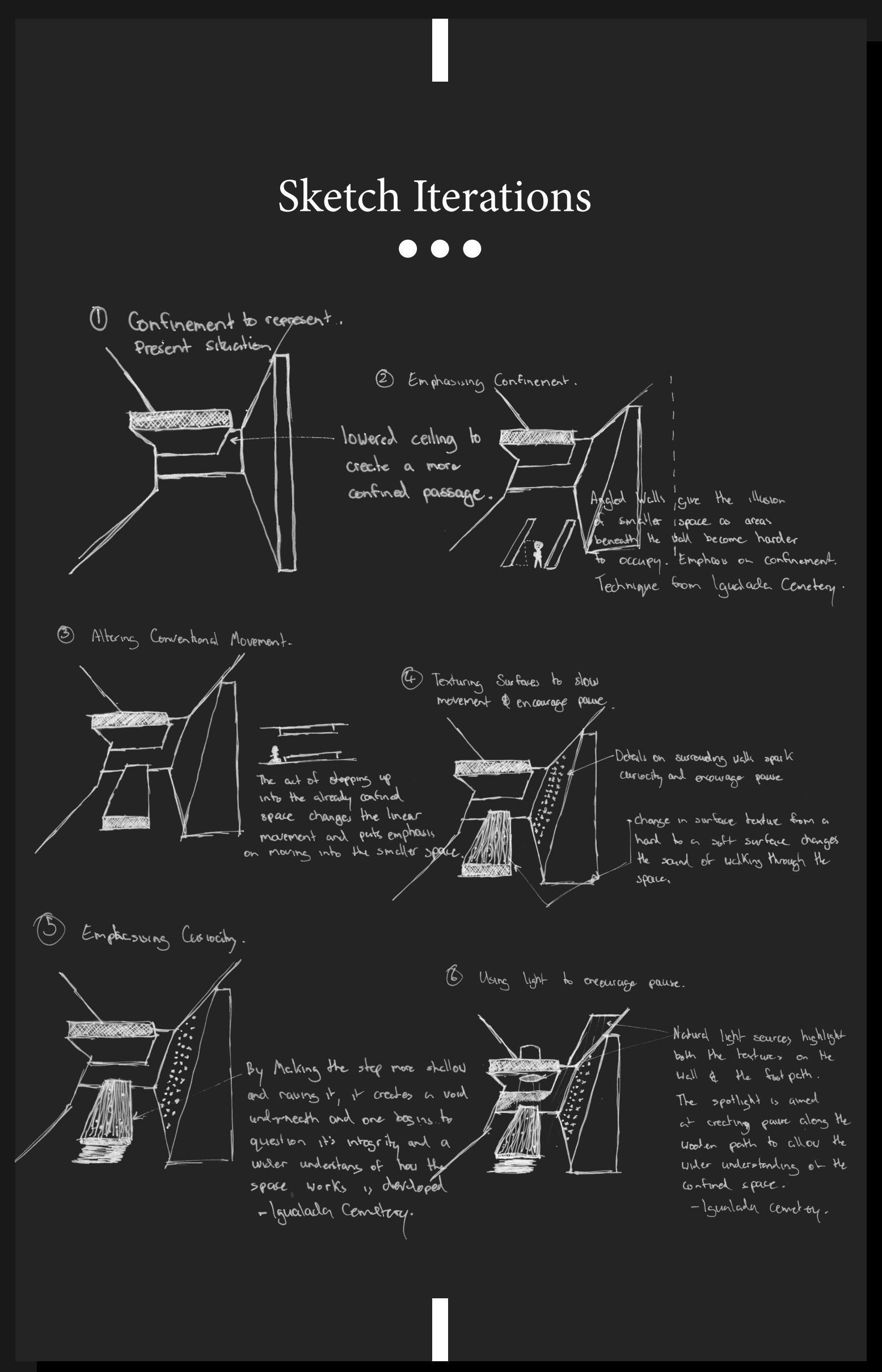

Developed Sketch

000

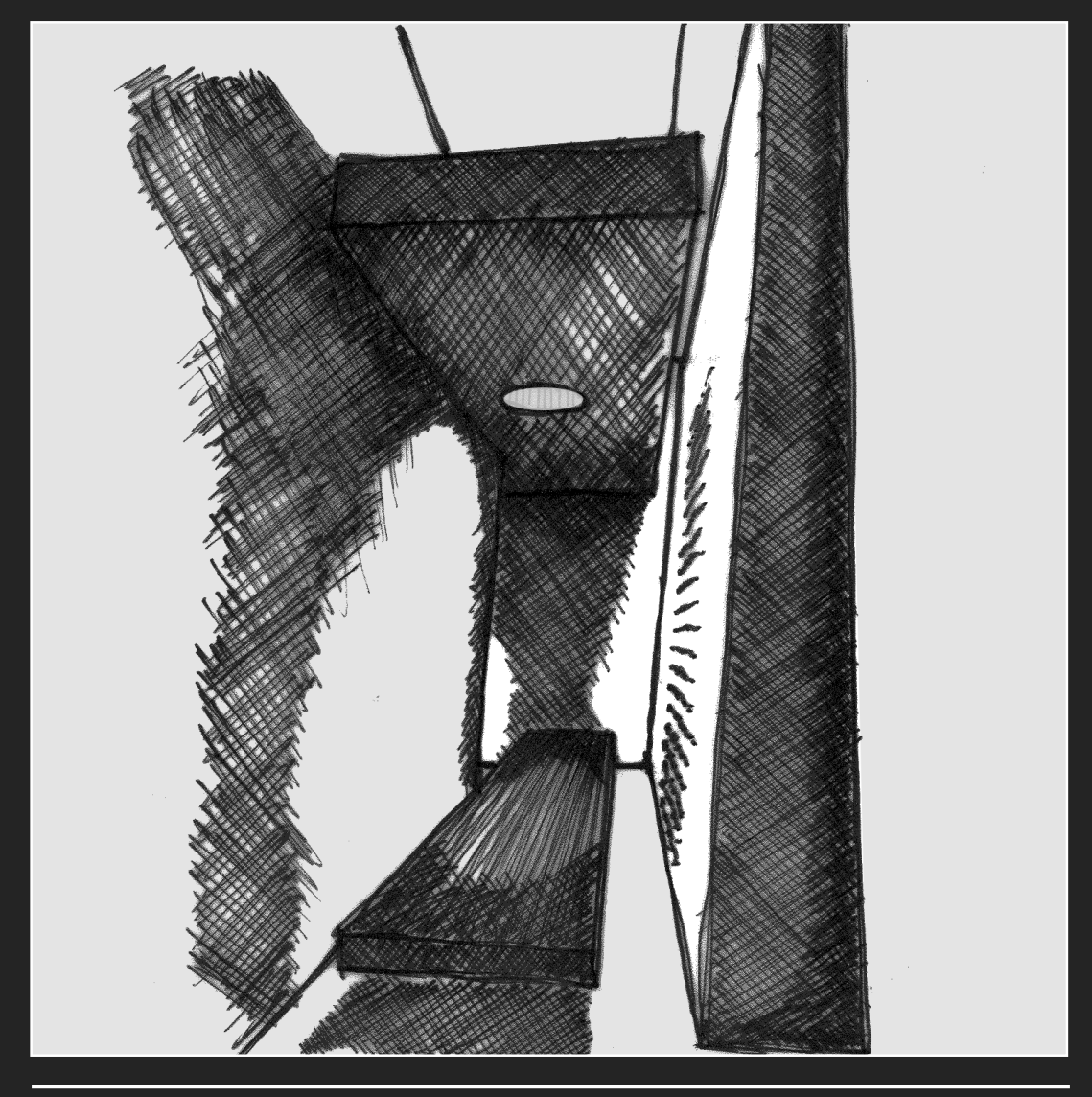

As the journey through the entrance flow through the space is also controlled
through the use of a designated path. continues the influential architecture through the use of a designated path. develops from highlighting the past Self-narrative is developed as this point
- through assisting in developing an of pause is experienced as it tells the Inderstanding for heterotopic space - to story of confinement and the restrictio highlighting the present. This is done $\mathrm{s}$. of morement thet is commonly present the experiential journey of the prison. aim of this point of pause is to help This point of pause uses architecture inmates passing through to develop influenced by the Igualada Cemetery an understanding for the confinement where angling walls give the illusion of of prison and their currentmental and smaller space, to slow movement and physical situation. 


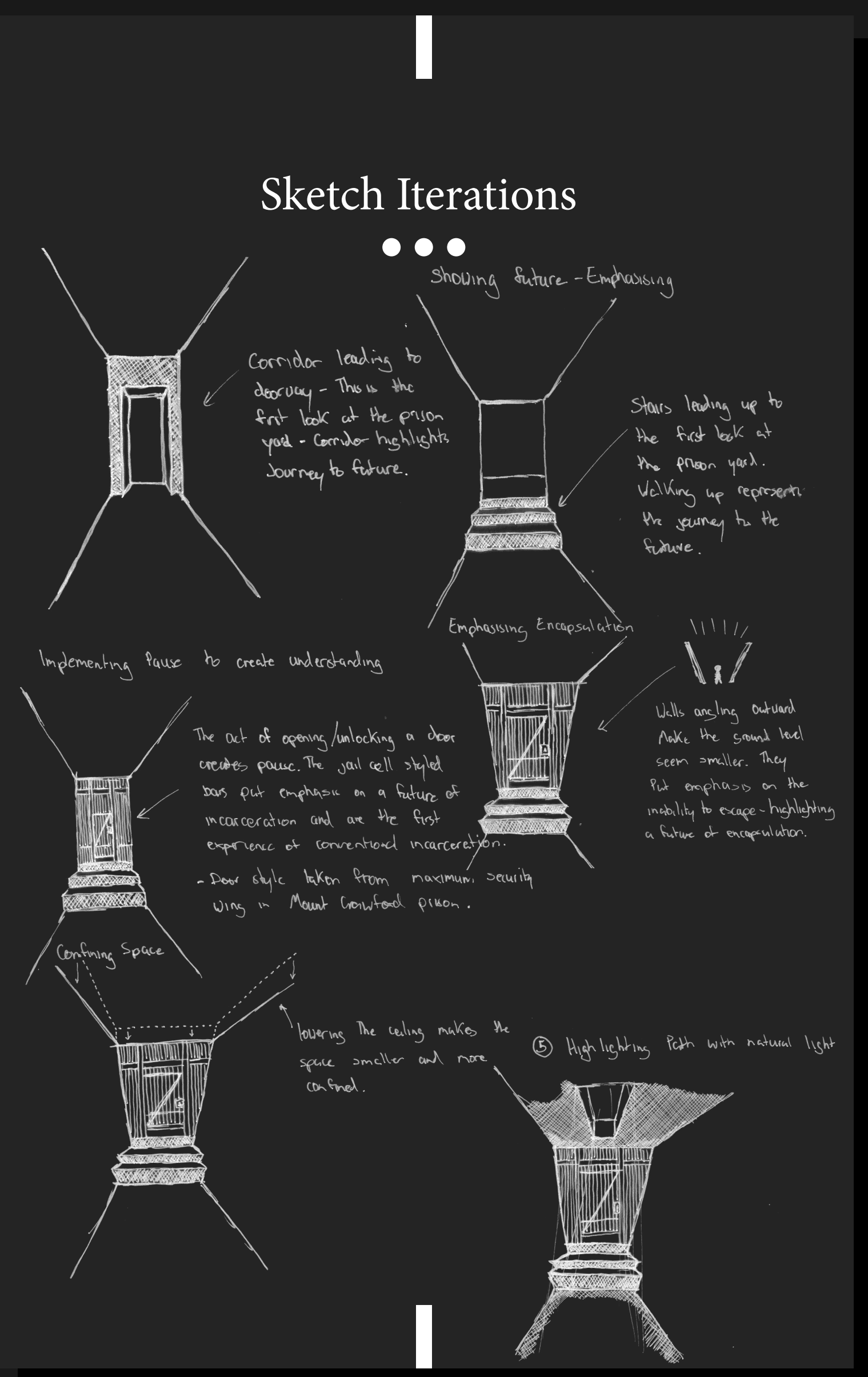

Developed Sketch

000

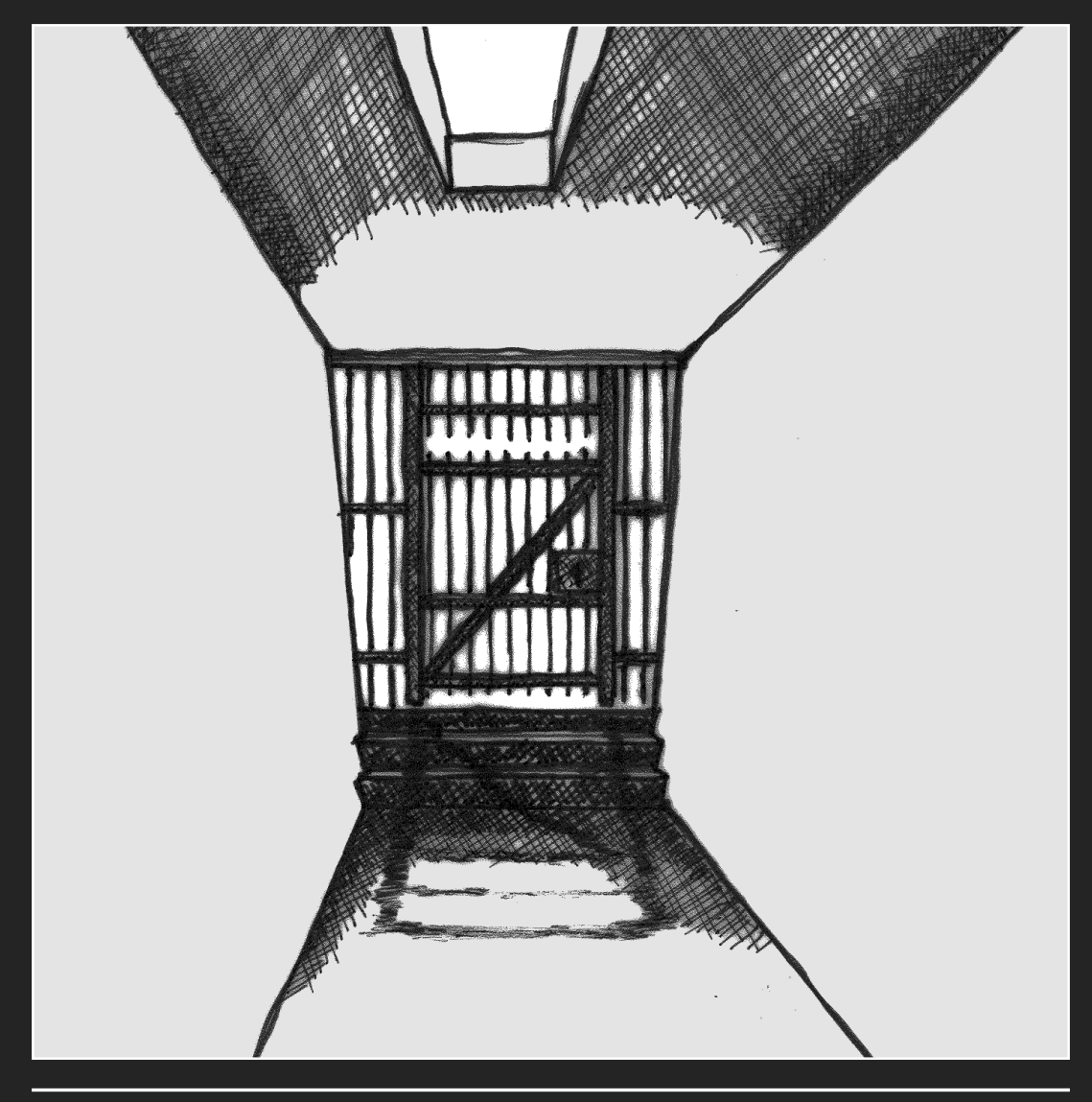

rest of the circulation of the prison. The entrance, and the Honeymoon phase of act of pausing to open the gates creates culture shock draw to an end, the design a hesitation in momentum through the begins to focus attention on helping space and allows inmates passing throug inmates to develop an understanding their foreseeable future and the culture forecourt and develop an un the prison contained within that space. The third for the space as it shifts from intangible to point of pause situates itself around a tangible. This space helps inmates passing doorway that opens up to view life within through develop their self-narrative the prison walls for the first time. The from one of confinement - inflicted by most prominent feature of this point of the architecture in the previous point pause is the large iron gate. This mimics pause - to one of overwhelming cultura the gates that divide the prison cells and - as seen in the site analysis - from the ck begins. 

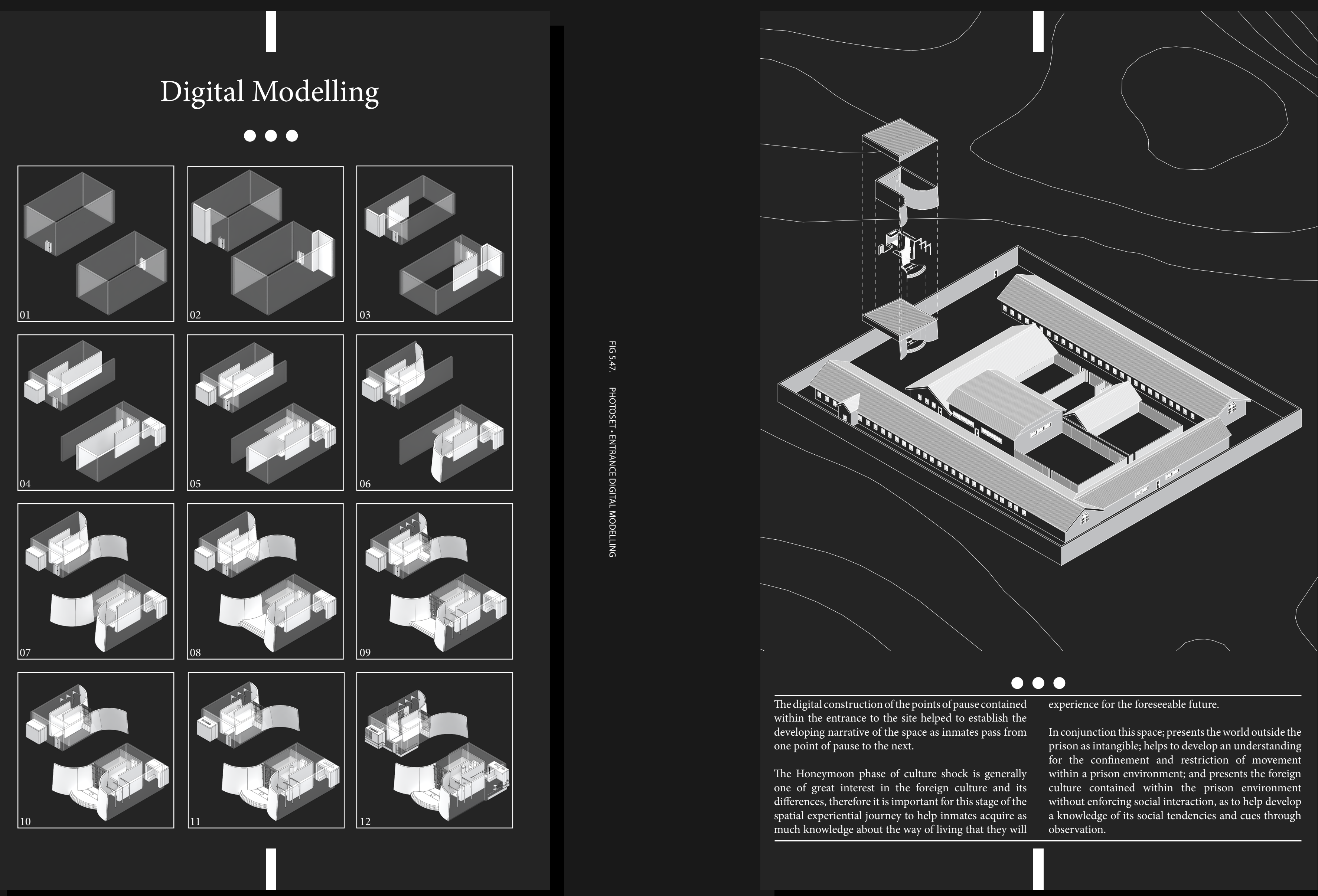
Prison Cell

As the Honeymoon phase cell is a place of prolonged
of culture shock develops pause, the aim of this design is to help inmates reinterpret inmates begin to reject the their dystopian experience of foreign culture contained the prison environment.

within the prison environment

and seek cultural familiarity

The change of mind-set from

in their surroundings. As a dystopian experience to

the prion for minimal social to help inmates mentally

intercourse, it becomes a place transition from the regression of reclusiveness and comfort phase of culture shock to the through the mental journey of adjustment phase and begin to the regression phase of culture accept their foreign culture and ock. As the nature of prison its diversity. 


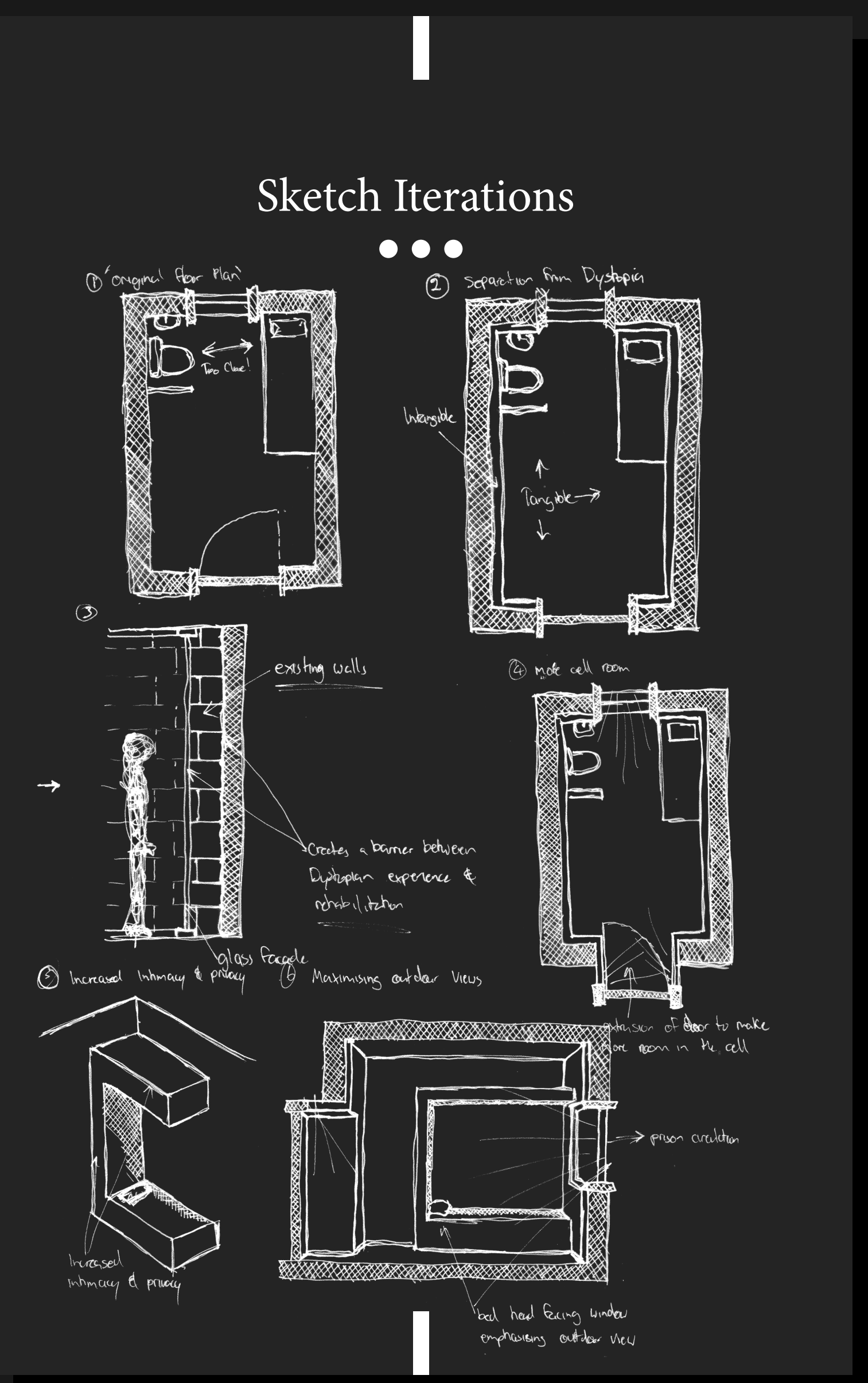

Developed Sketch

000

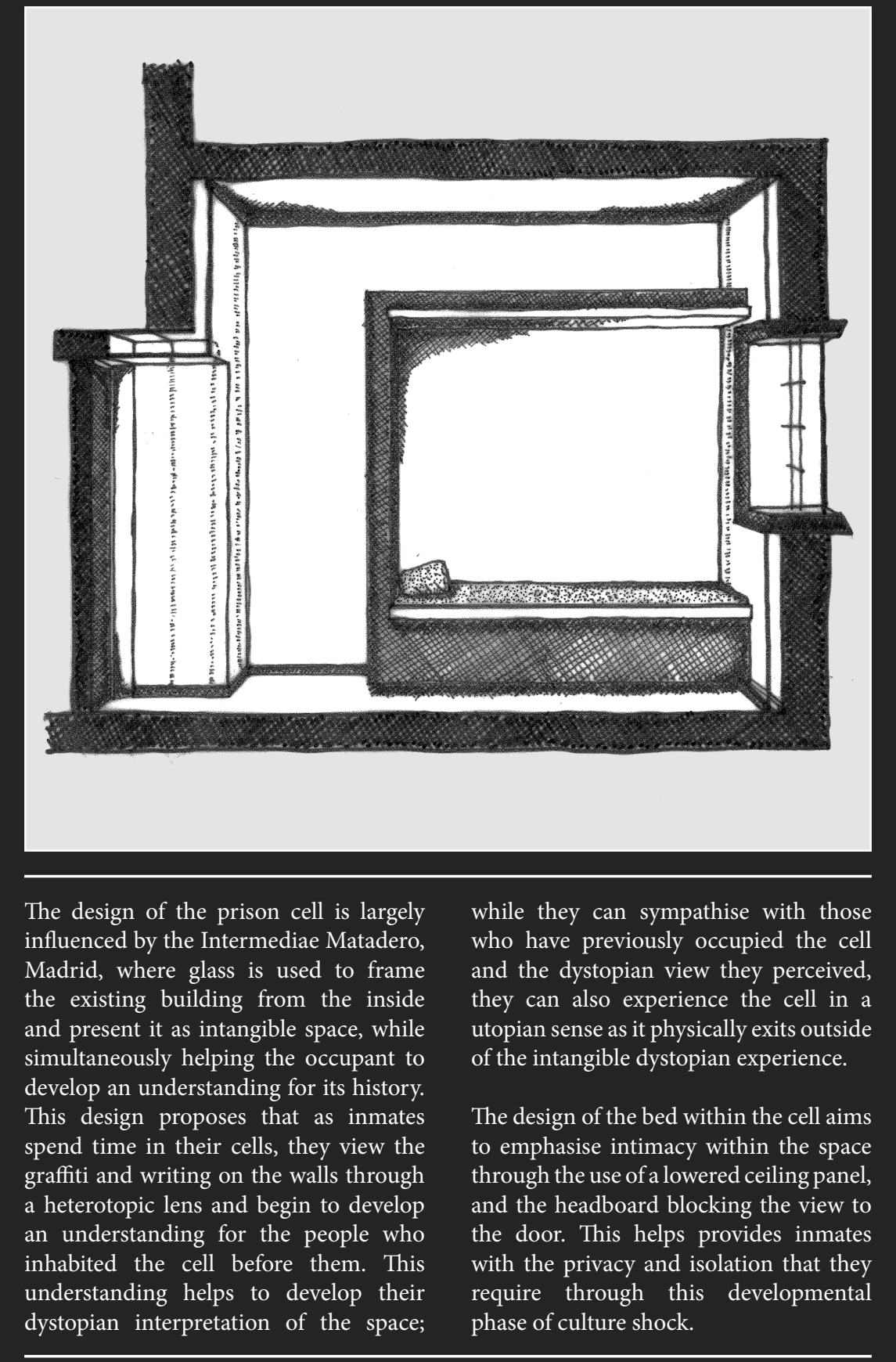

I 


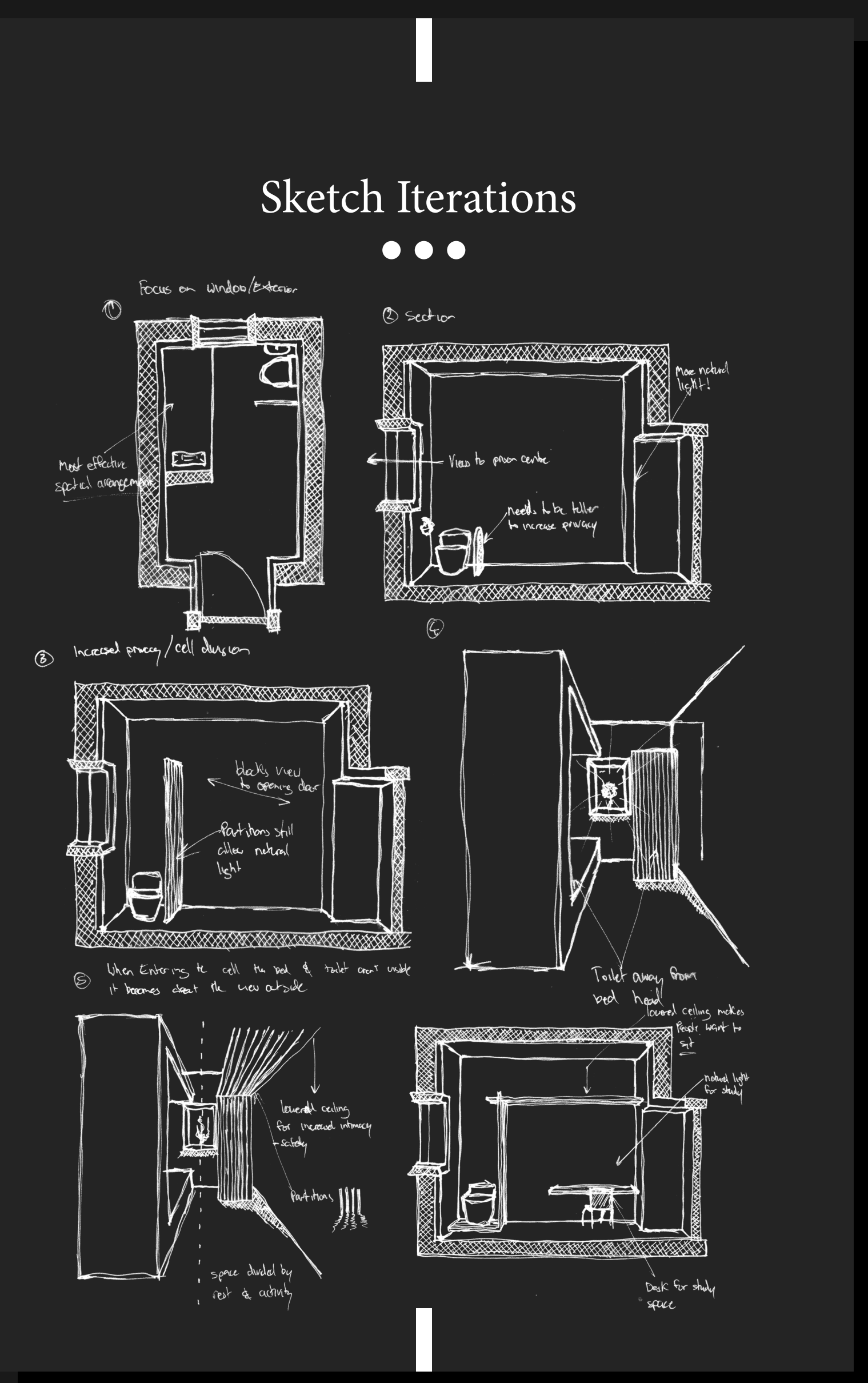

Developed Sketch

$\bullet \bullet \bullet$

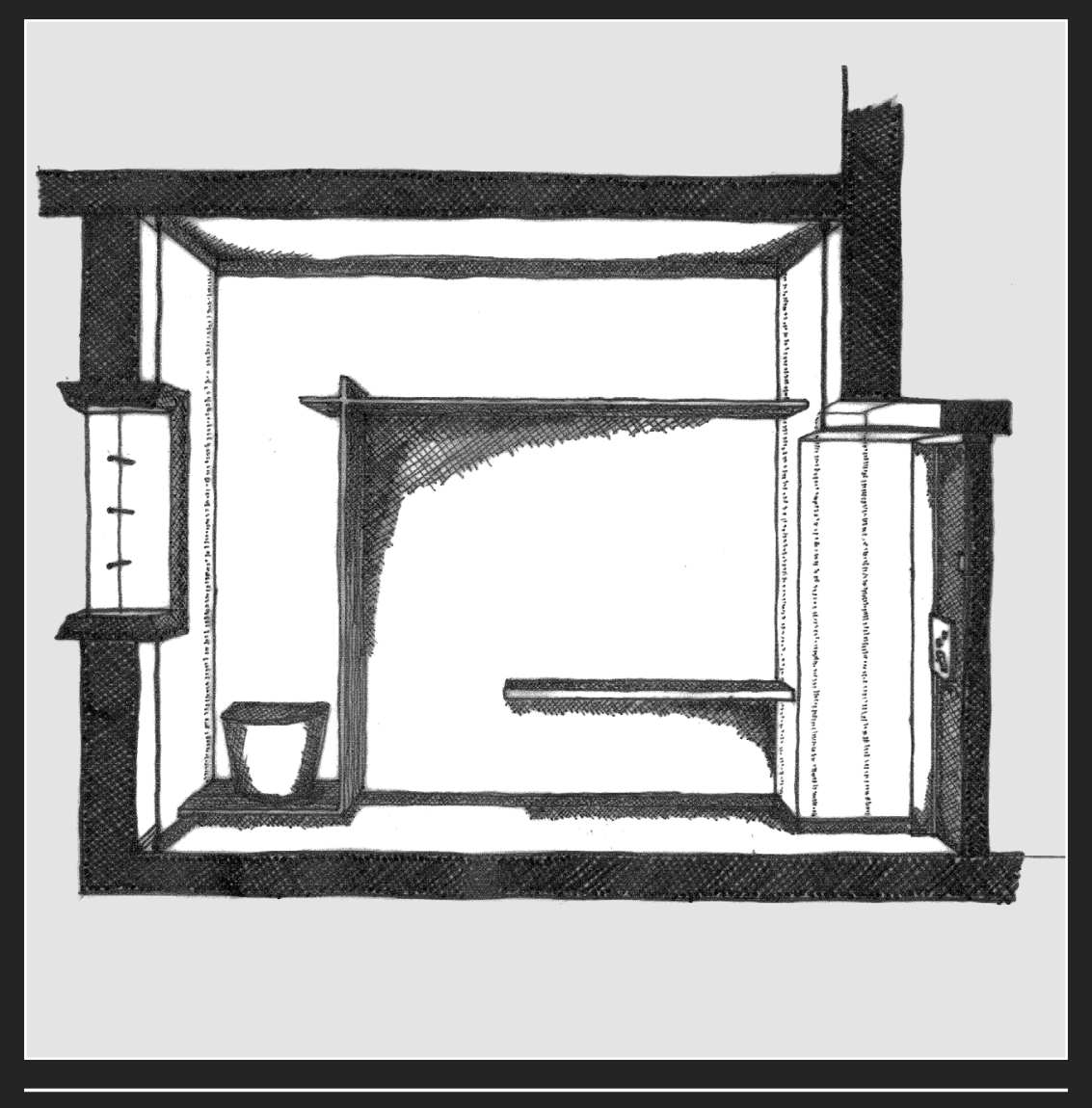

Each cell in Mount Crawford Prison This spatial division as also allows for the is fitted with a toilet. This design stage input of a desk which provides inmates looks to remove that tollet away from the conventional flow through the space familiarity in arts and crafts. through the use of partitions that extrude eye level. 
Developed Sketch 000

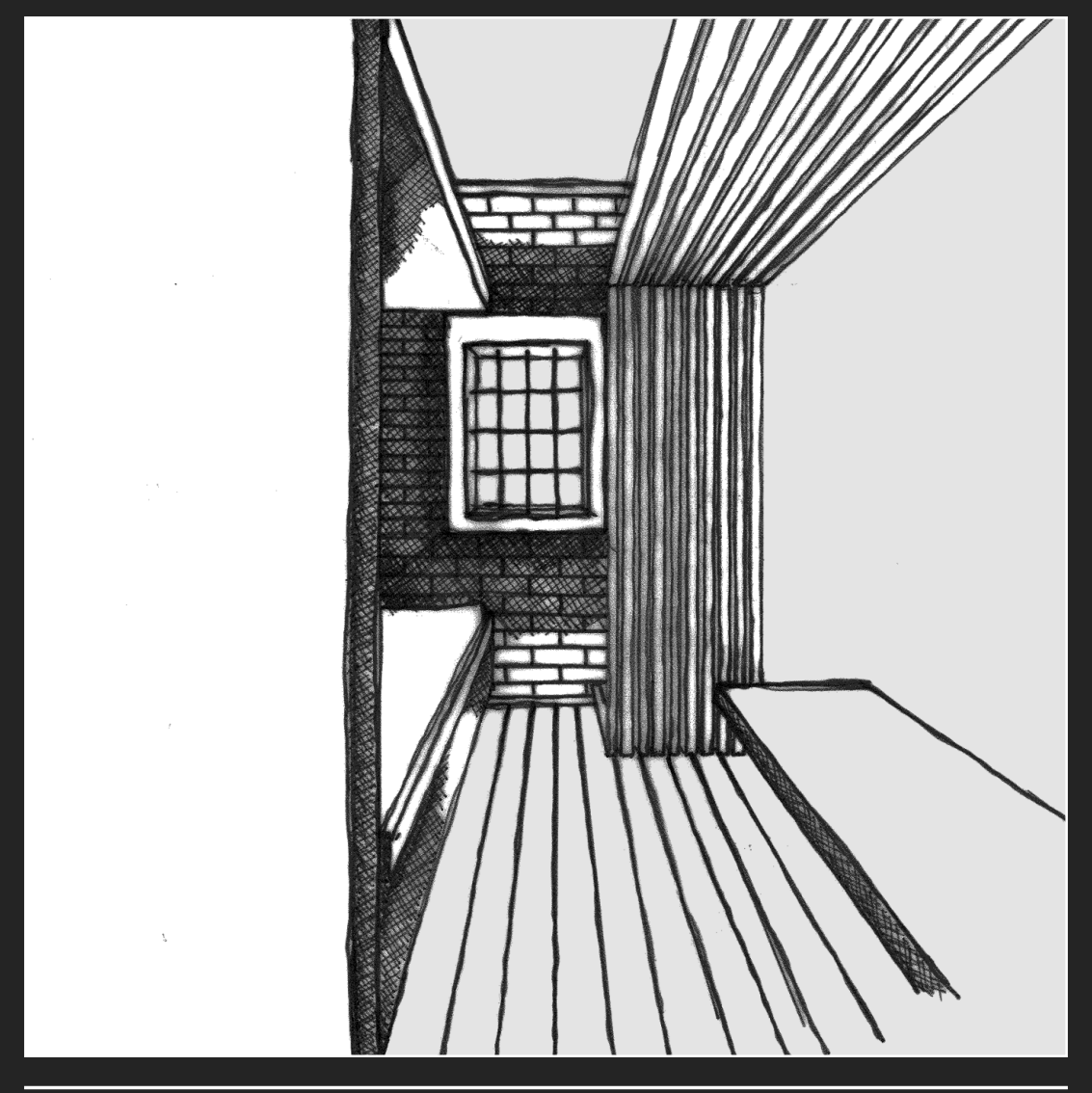

As the spatial experiential journey through the prison reaches the cell; the view through the prison window. It the focus of the design is to establish a does this from a point of minmal social comfortable and familiar setting away interaction in order to reduce the risk from the foreign cultural activites. Thy of the humiliation of not knowing the through the regression phe of culture developed witin the prison alure shock. This setting also aims to provice inmates with the opportunity to develop their understanding of the foreign culture
Developed Sketch

000

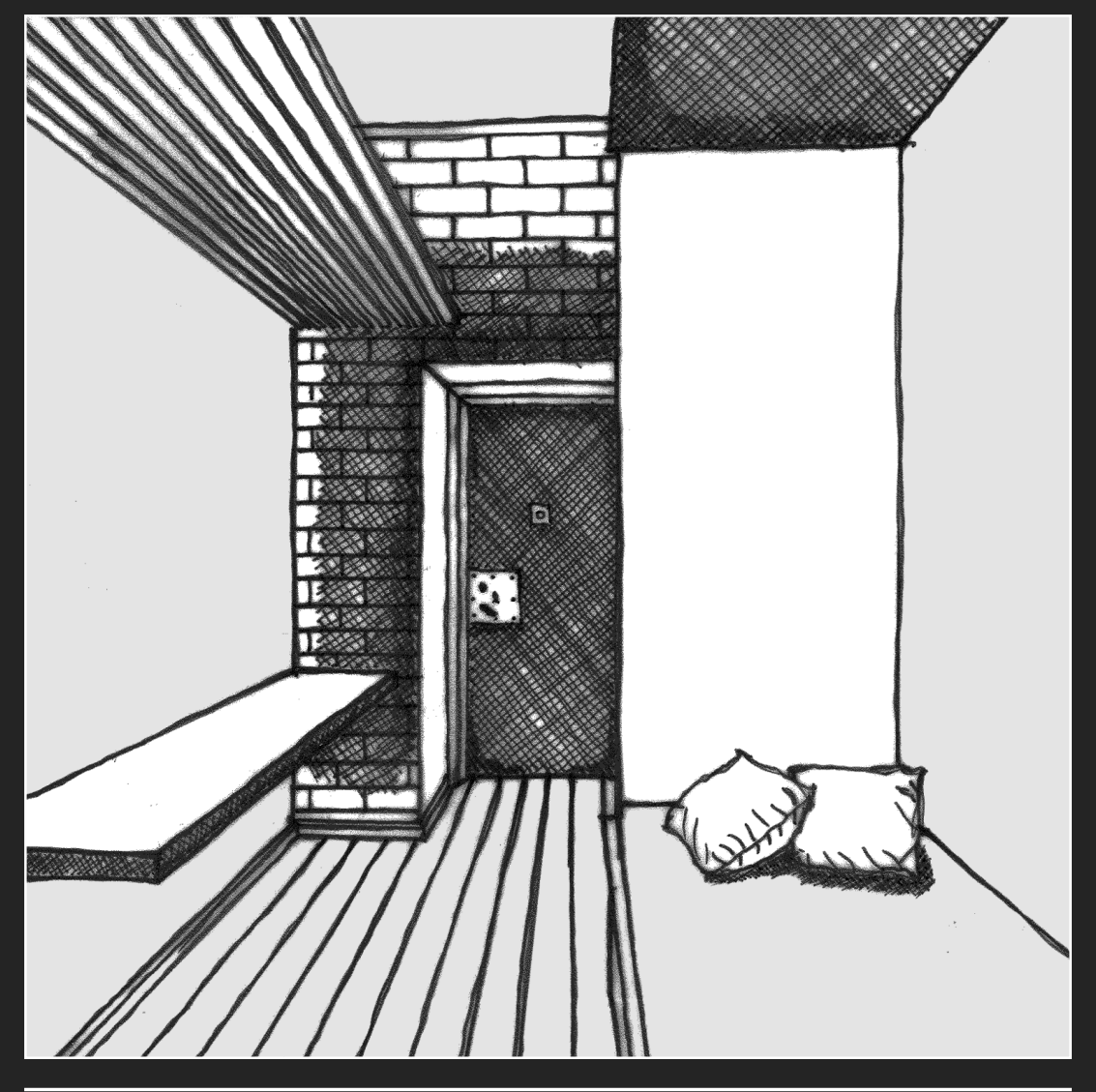

As the understanding of space is

he inmates self-narrative begins to

transform from a dystopian experience

to a utopian experience, and the mental

culture shock to the adjustment phase 

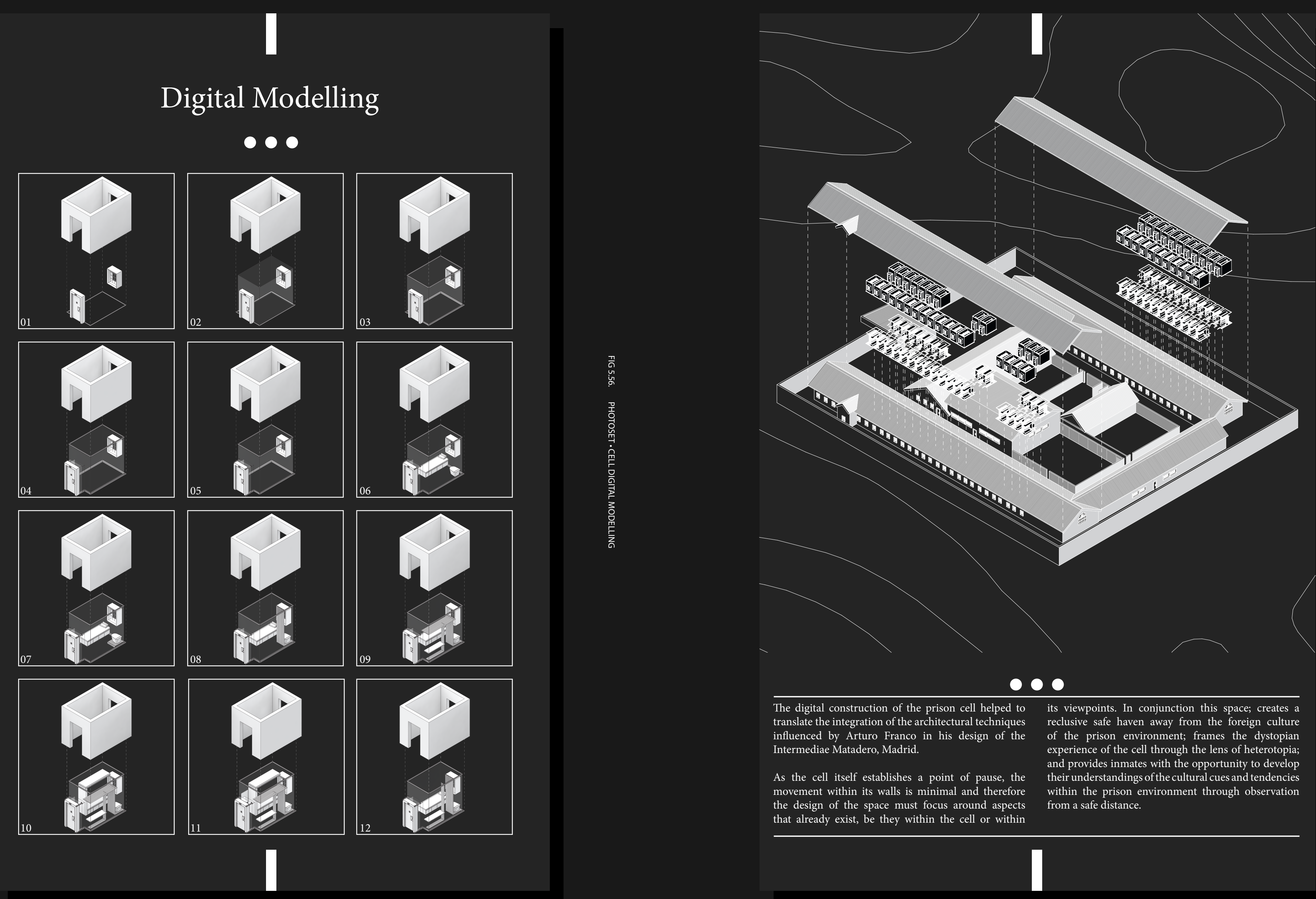


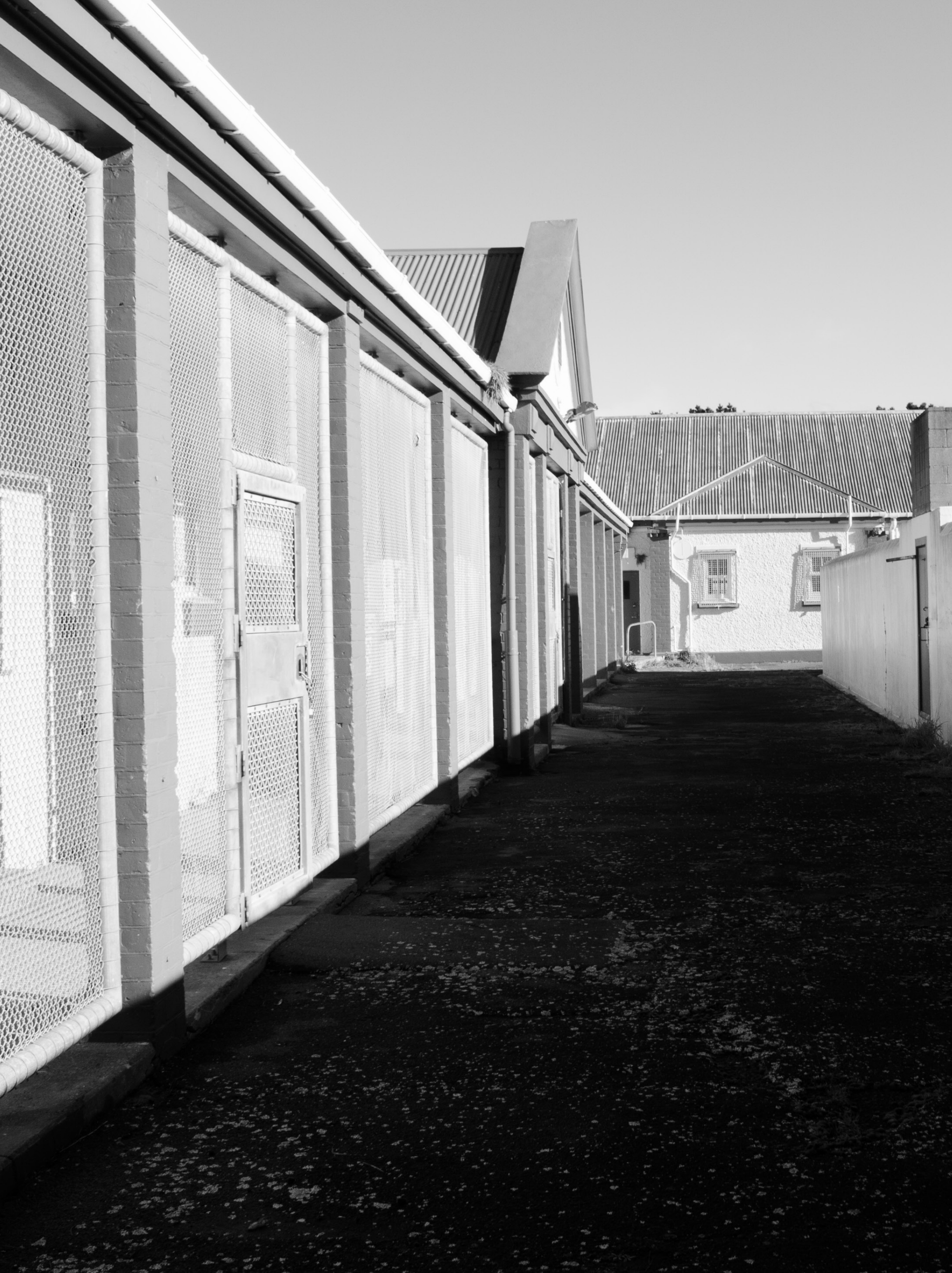

Prison Circulation

The transition from the the opportunity to engage
regression phase into the in social intercourse and regression phase into the in social intercourse and
adjustment phase of culture use the knowledge they shock marks the beginning have previously acquired in integration which this thesis of heterotopia. While these relates to rehabilitation. spaces provide the opportunity Typically Individuals in the for social intercourse they adjustment phase of culture do not enforce it; this allows shock have begun to embrace inmates to gradually integrate own and they have developed contined within the prison enough knowledge of its envirme

cues and tendencies to get
by comfortably. The aim of the design within this stage is to provide inmates with 


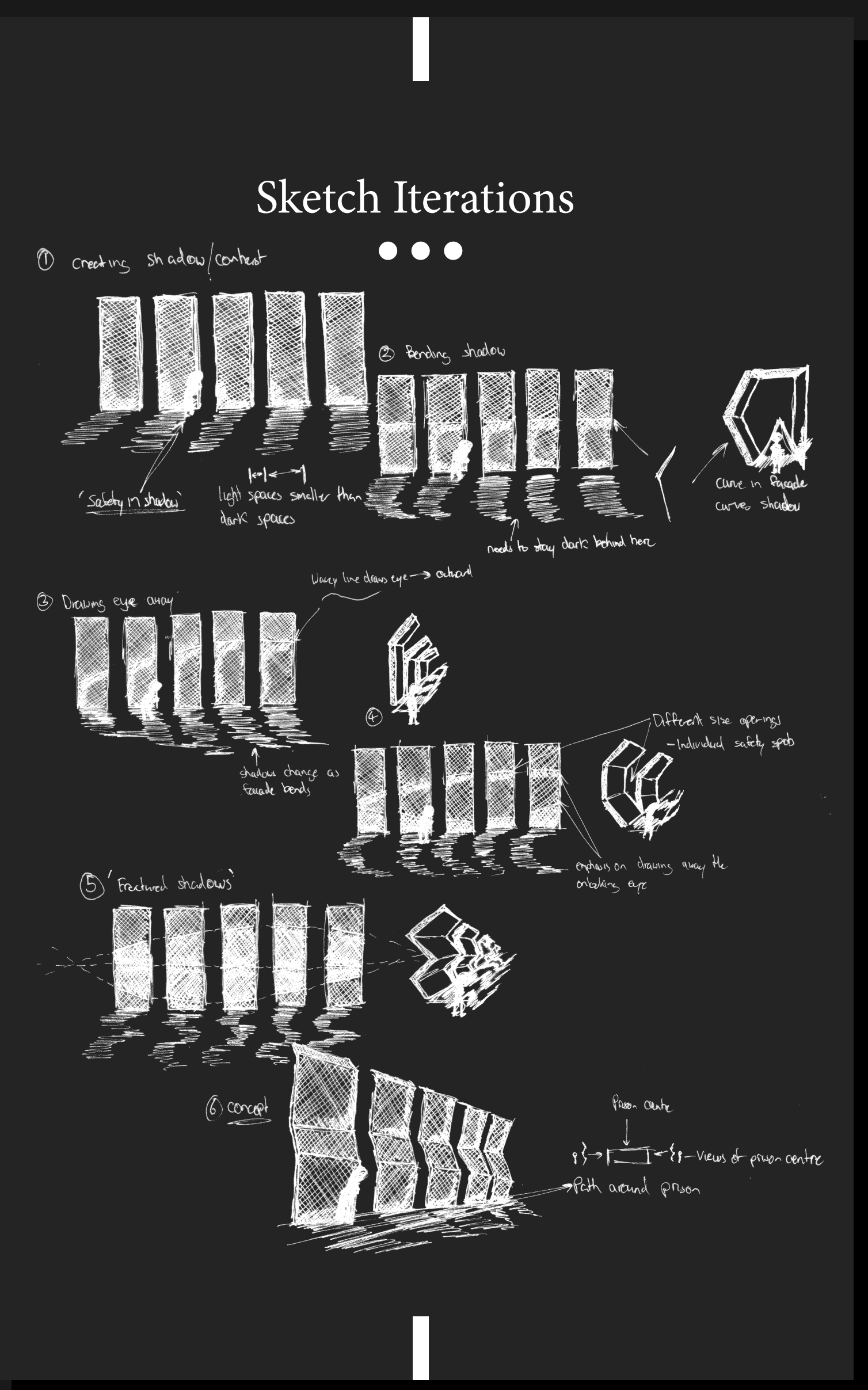

Developed Sketch

$\bullet \circ \bullet$

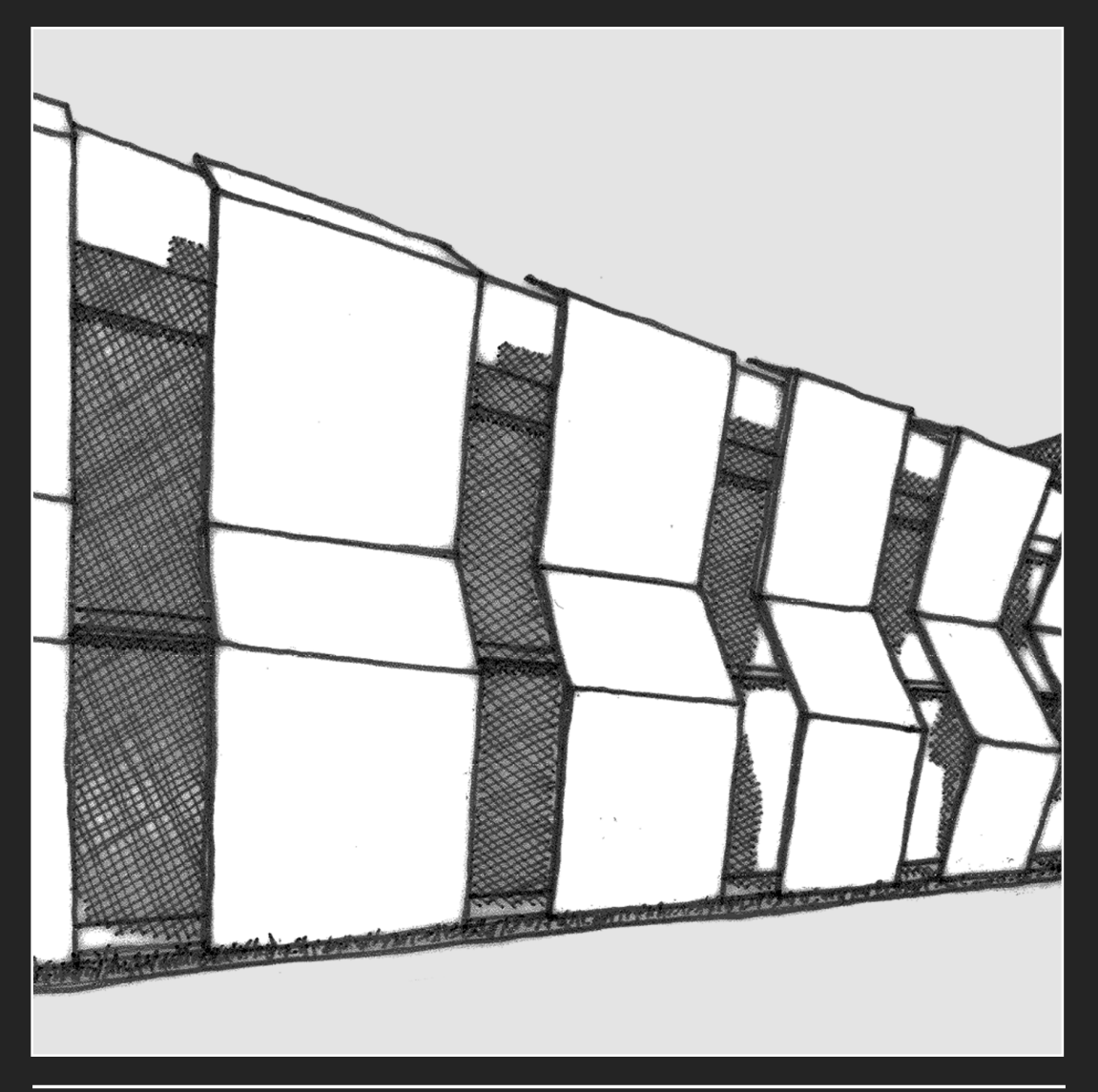

The design of the prison circulation
pause in momentum using contrasting
light as a means of creating a multitude walkway space within the prison. These of safe points of observation of cultur walkways direct the flow between activites, as inmates begin to venture multiple destination points throughout into the social real ws of the prison. The opportunity for social intercourse as the between light and dark spaces was crossing of paths occurs in the journey influenced by the design of the Irulada from one destination to another. They Cemetery where skylights and voids also provide insight into the central on the walls puncture the darkness and hub of the prisons culture through a create experiential conversation between heterotopic lens as they circulate its spaces of light and dark.

boundaries but do not share its physical pace. The façade is designed to create 
Developed Sketch 000

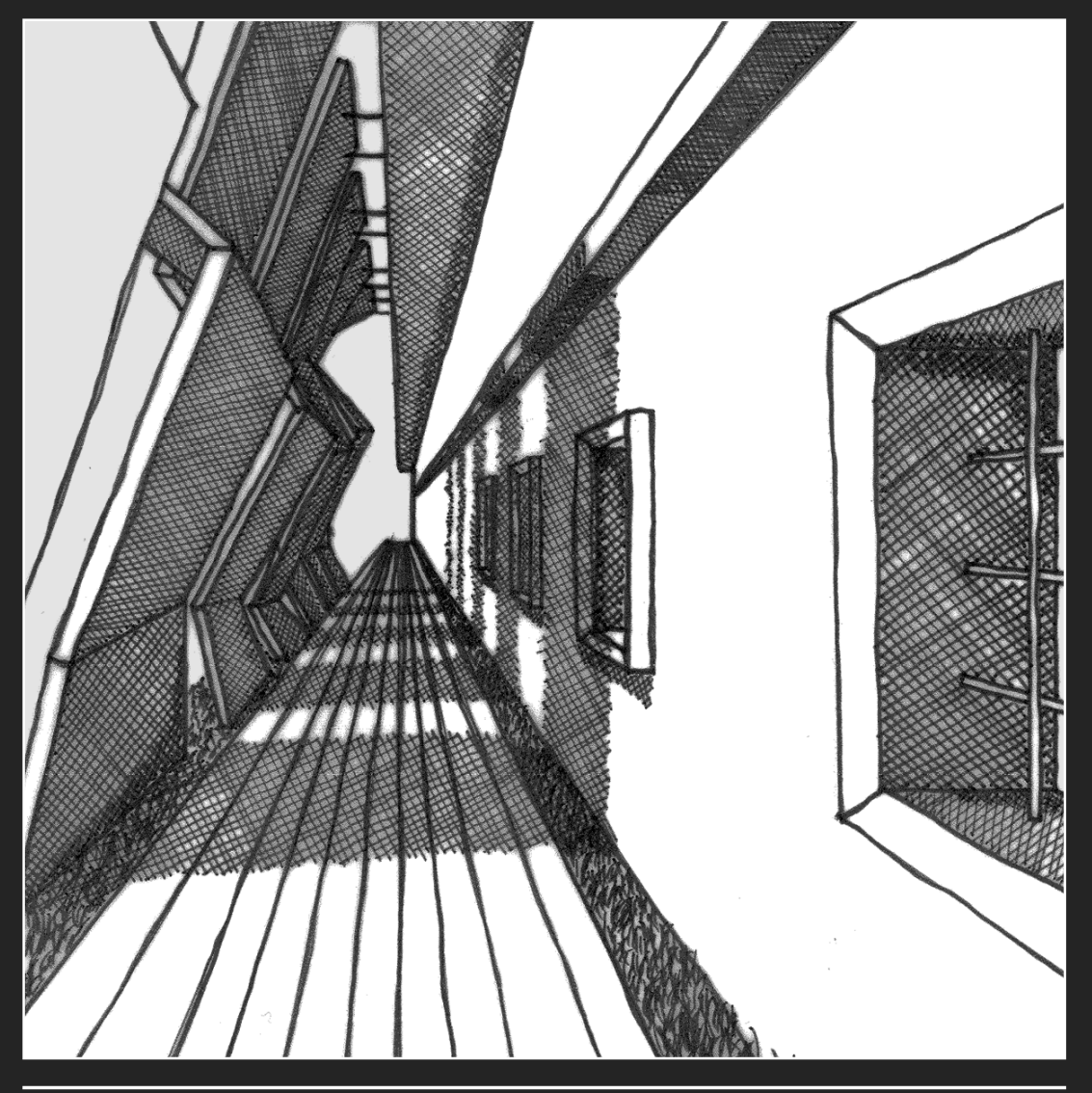

ve, and assist in the The fragmented nature of the façaa the
when observed from the centre of the prison - is designed to draw the eye away from those seeking refuge within the shadows that it casts.

As inmates seek refuge among the The ability to reinterpret dystopian experience helps inmates transform to understand their current ment and physical states they can appreciate
the utopian qualities that exist within them. This is important in the process of rehabilitation as it draws attention to the positive qualities of life instead of the

space begins to transform into a utopian

for its ability to provide the means negative. 

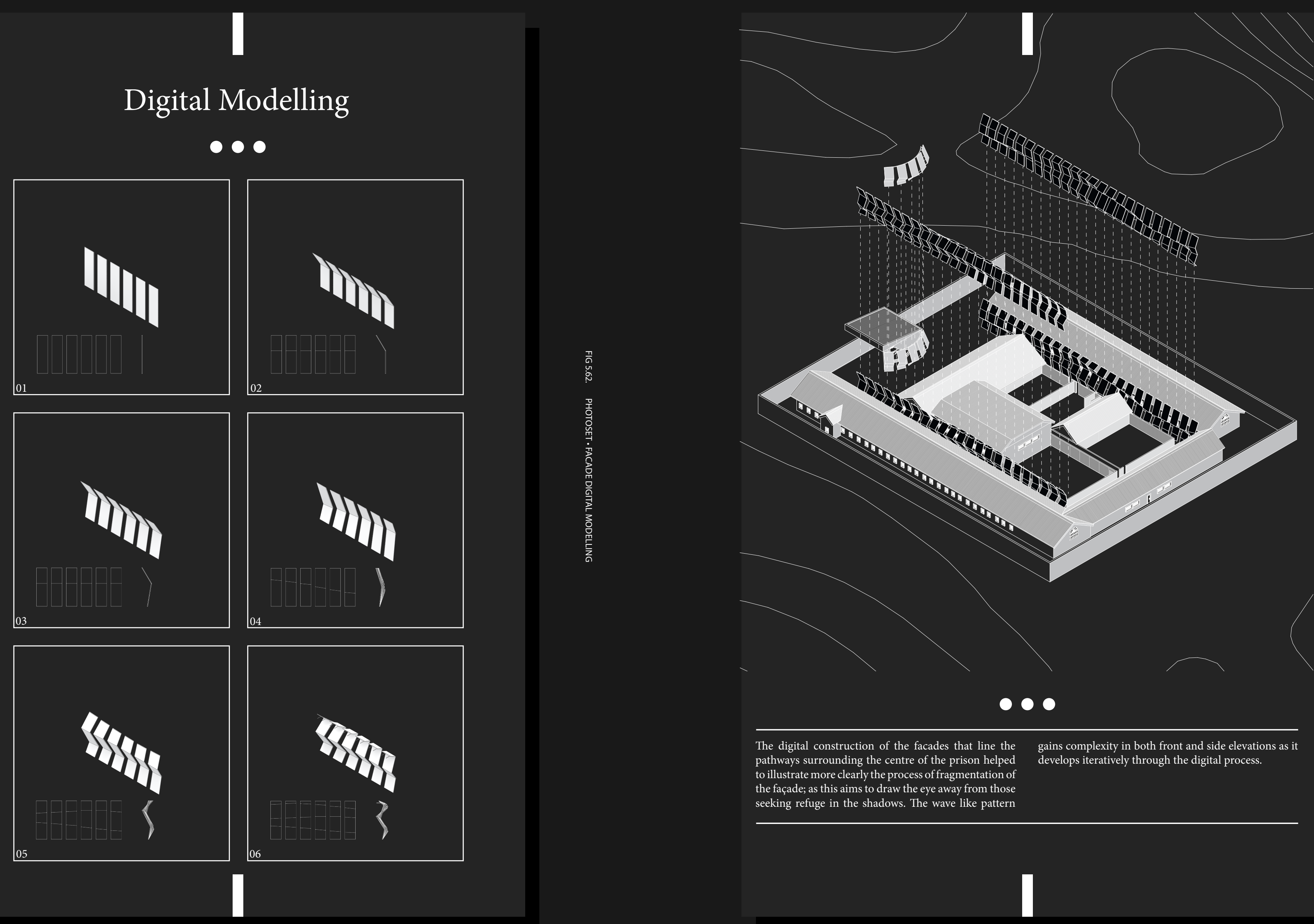


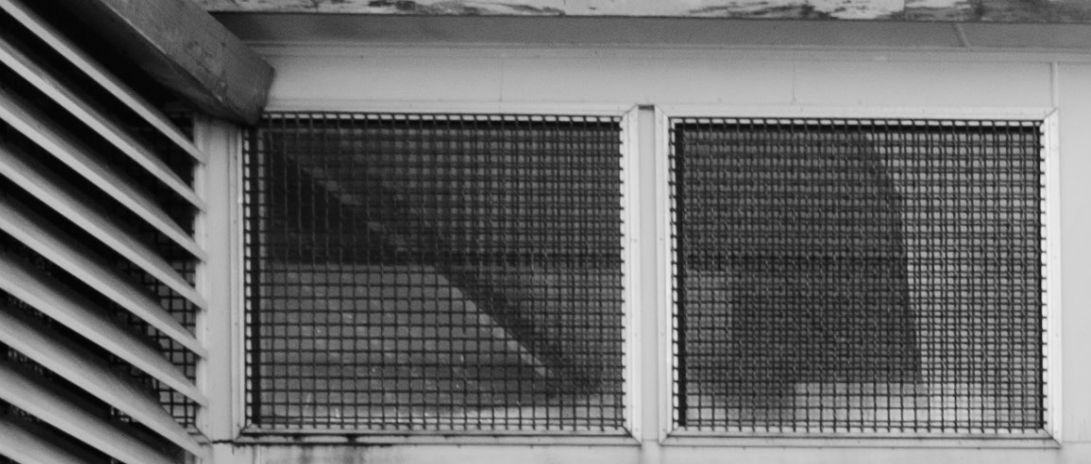

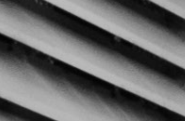

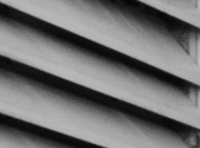 \\ Tin}

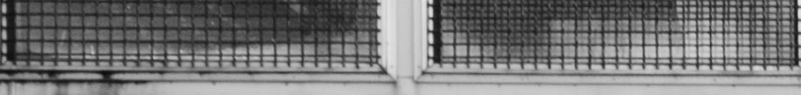

17

8
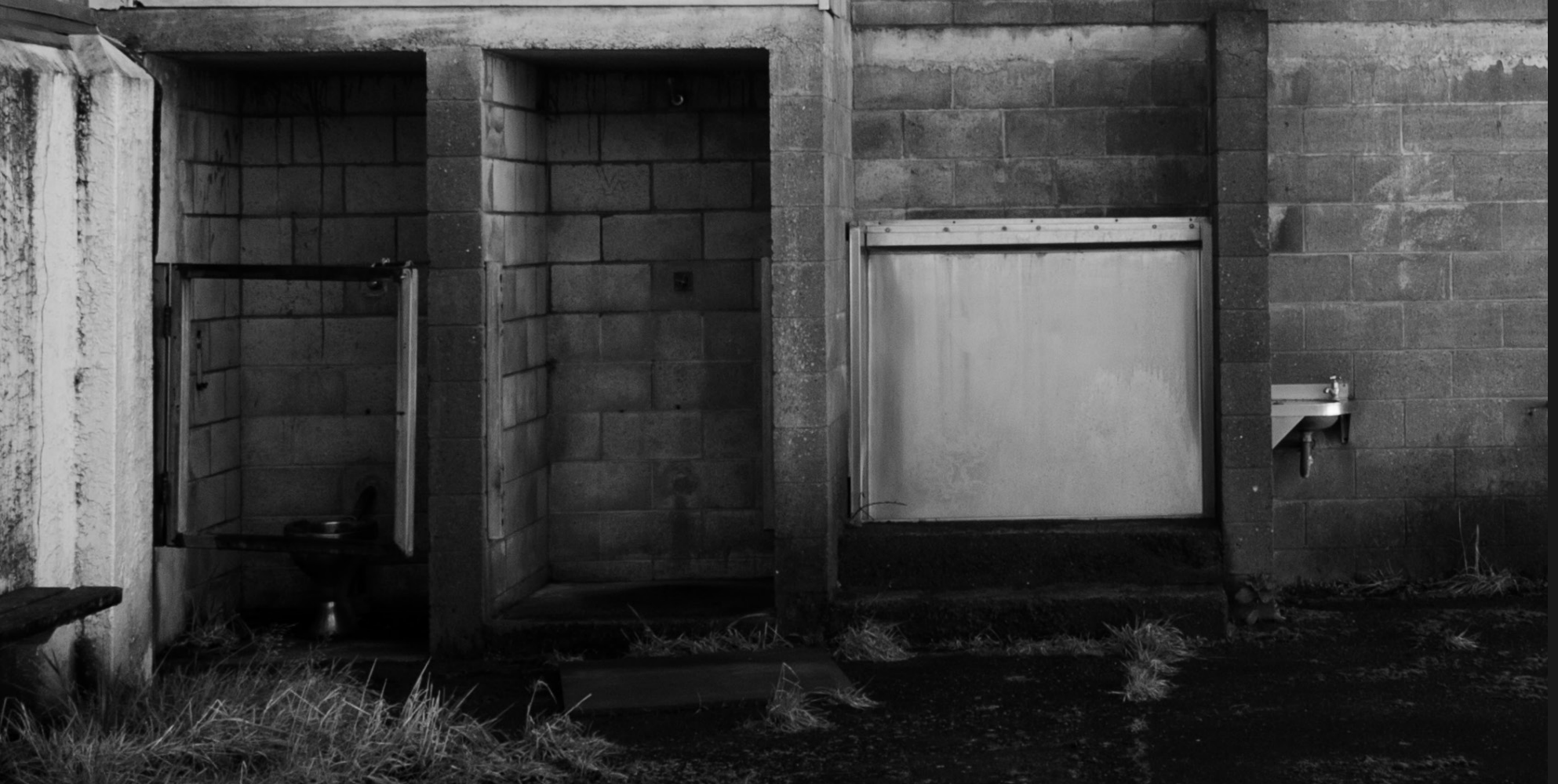

(2)
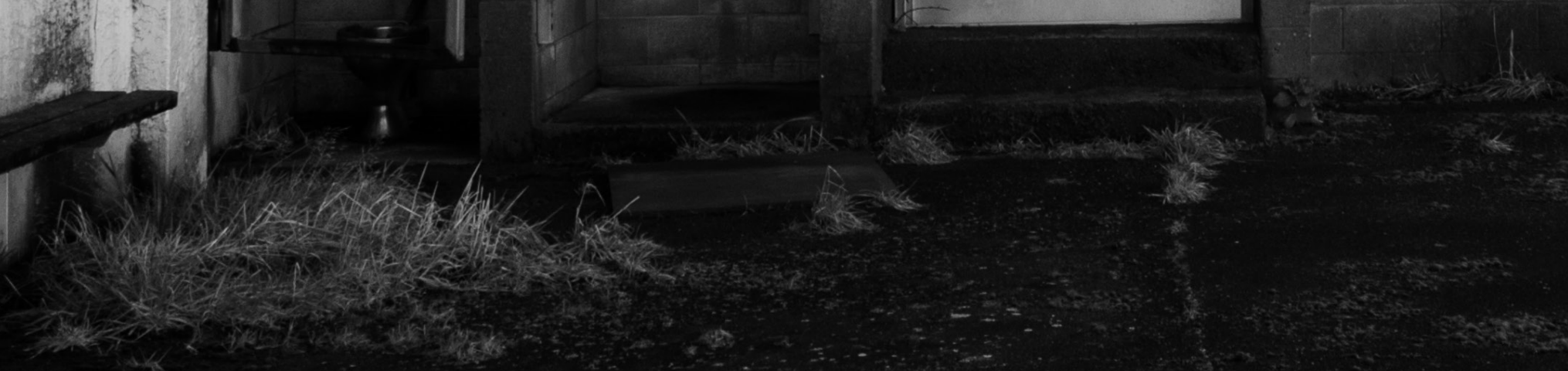

\section{I}

\section{Prison Centre}

$\begin{array}{ll}\text { As the rehabilitative journey } & \text { The aim of the design within } \\ \text { this space is to provide inmates }\end{array}$ develops from the adjustment this space is to provide inmates phase and into the acceptance with the opportunity to learn
phase, the design begins to about the world outside of the focus on implementing social prison walls, as well as develop intercourse within its spaces. the acceptance phase of culture individuals. Kalervo Oberg in shock are typically fluent in his theory of Culture Shock what once was a foreign culture suggest individuals that have and now take part in everyday successfully transitioned into activities with little or no the acceptance phase begin to hesitation at all. look to assist those in similar As discovered in the analysis of experienced: therefore it is the site, the centre of the prison important that the design plays host to a large majority of of these spaces influences social intercourse and therefore inmates to help the rest of the this thesis proposes that the prison community through the design of space intended for process of culture shock. culturally fluent individual take place in this location. 


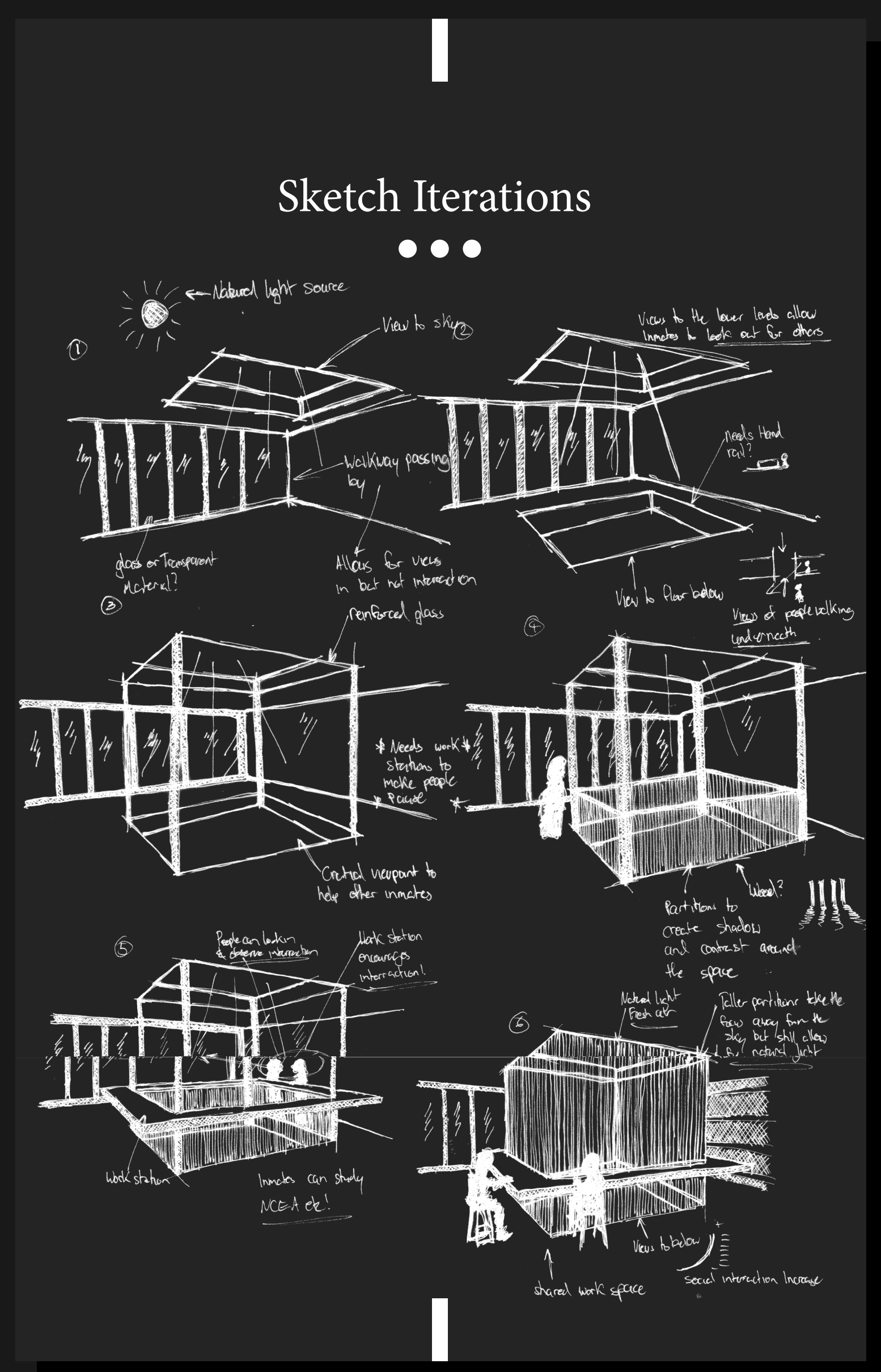

Developed Sketch

000

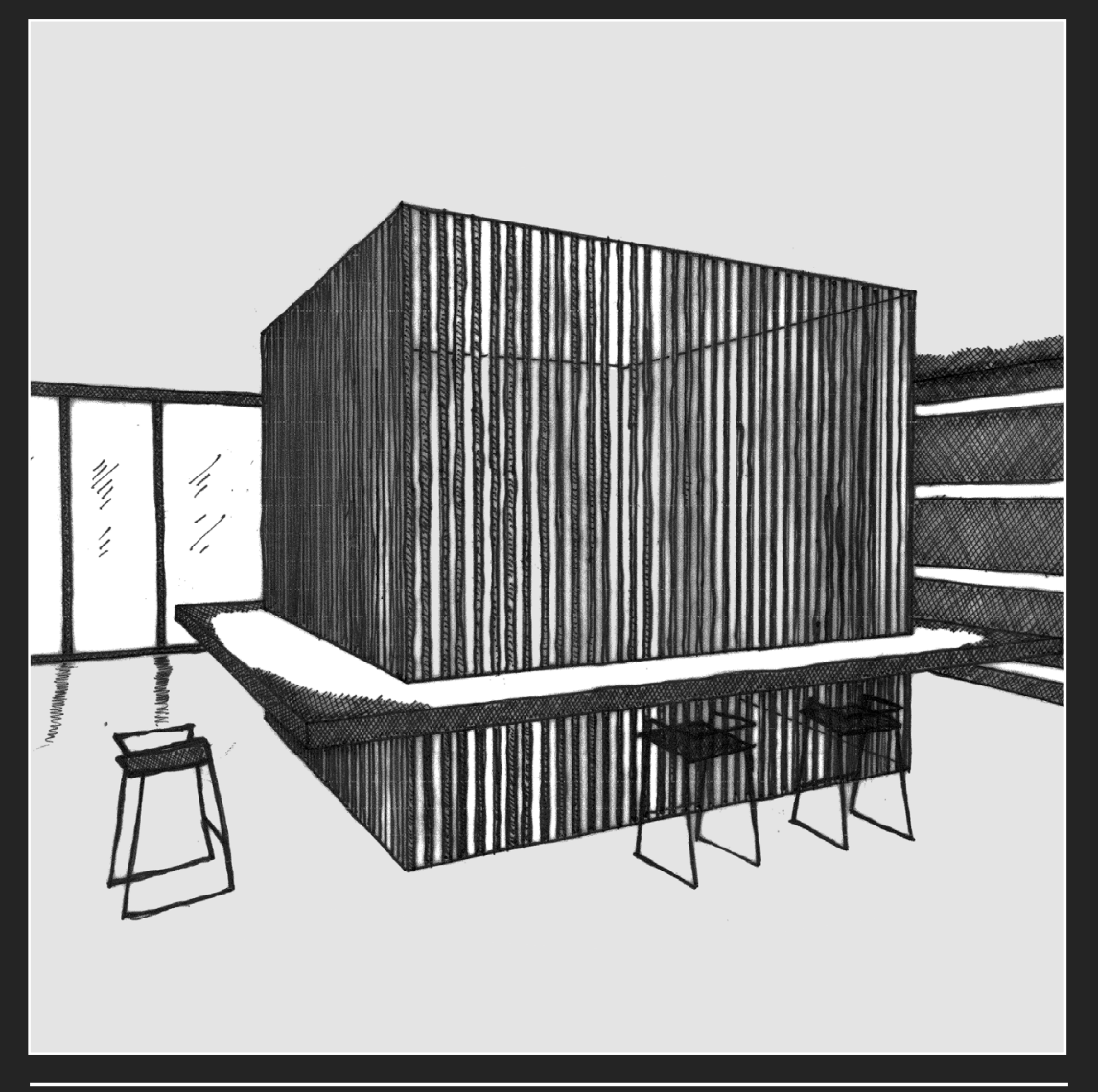

The second point of pause focuses on space around the focus of nurturing life helping inmates to develop their social within a dystopia. It frames a view of the skills and creates a setting for them to prison yard below through a void in the
floorn in the aim of encouraging inmates learn about the world existing outside floor in the aim of encouraging inmates
of prison. The design is influenced by to look to help others who may be of prison. The design is influenced by to look to help others who may be
Hiroshi Nakamura is the way in which he struggling through the process of culture structures the flow of movement through shock. 


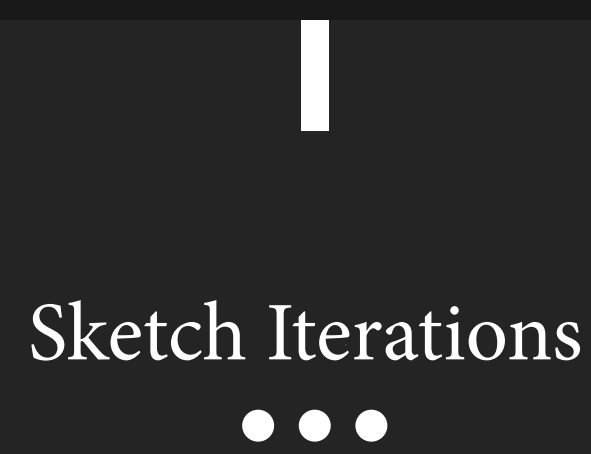

(2) crecting food point

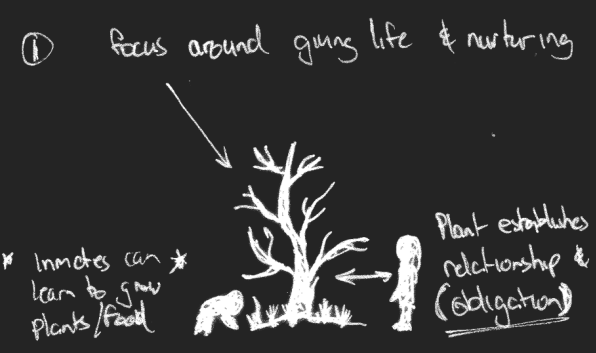

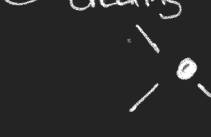

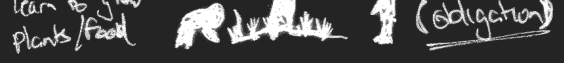

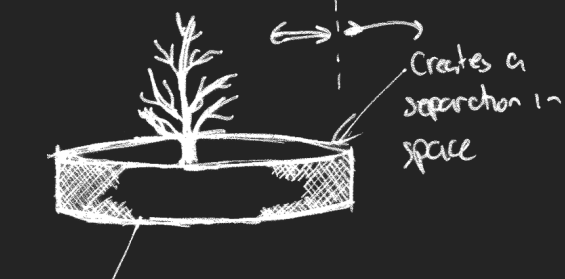

Foed pant of room

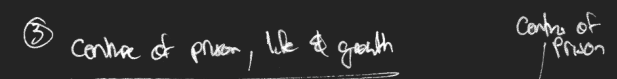

(4) conecting nether with peopte

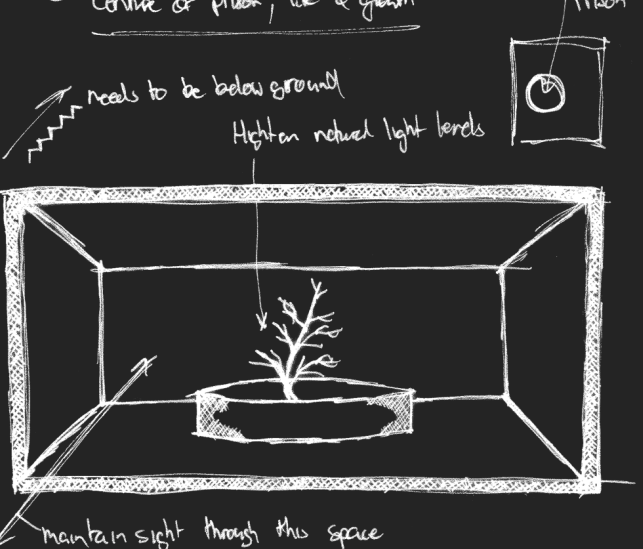

$\$ 2$

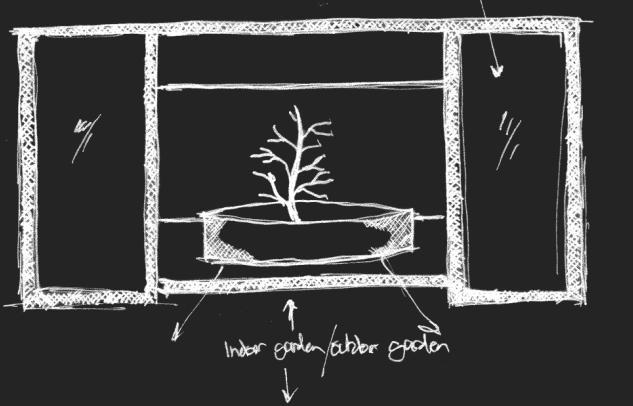

Emphase foul point by lowerng

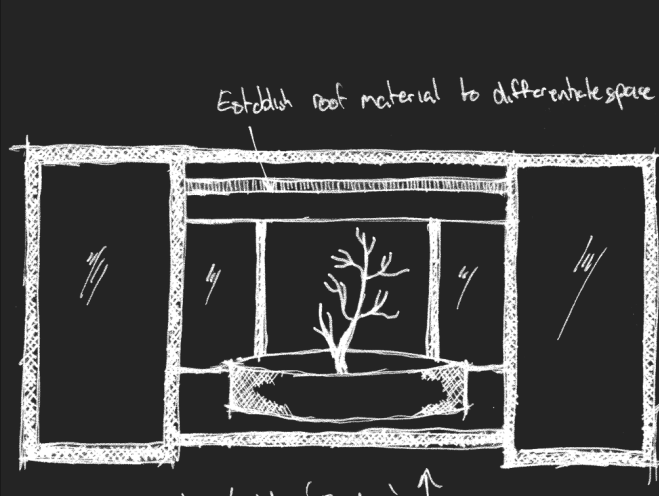

Whar fordator' Freedom '

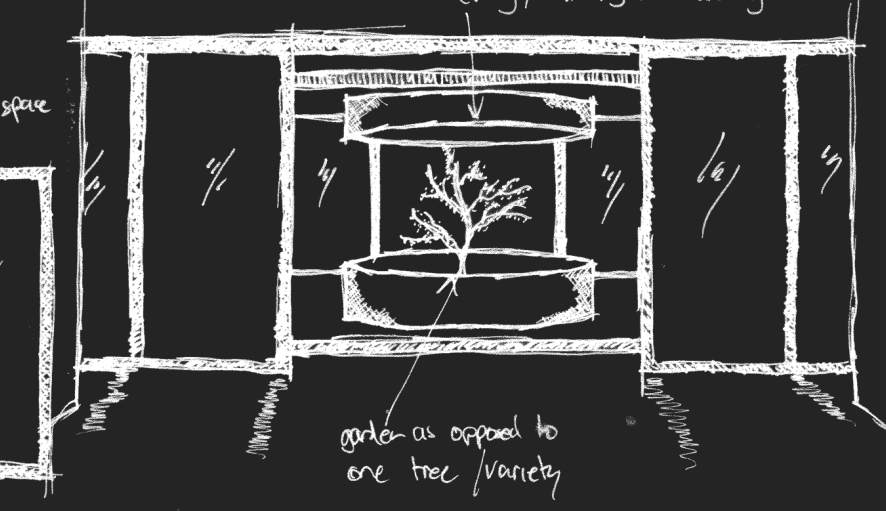

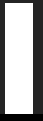

Developed Sketch

000

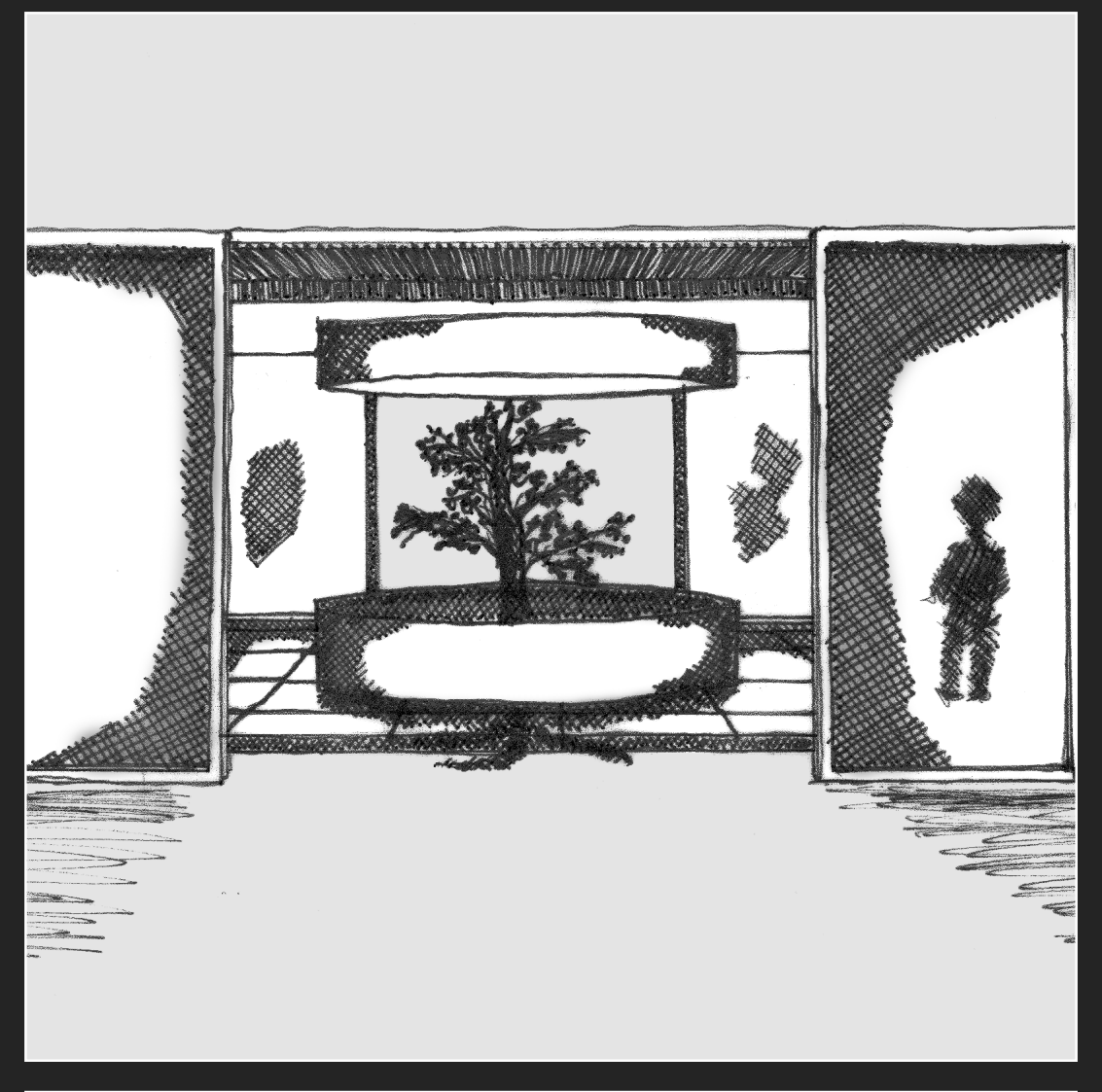

The design of the first point of pause experience through the growth of a within this space is influenced by Hiroshi garden as a focal point within the space. Nakamura in his design of the Optical The aim of this is to allow inmates the Glass House, Japan. The narrative of opportunity to nurture and care for hility for life to thrive in a utopie the histing outside of their own -

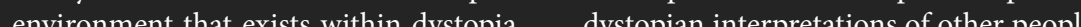
The design of the physical representation of the acceptance phase of culture shock crimes. therefore looks to mimic that utopian 

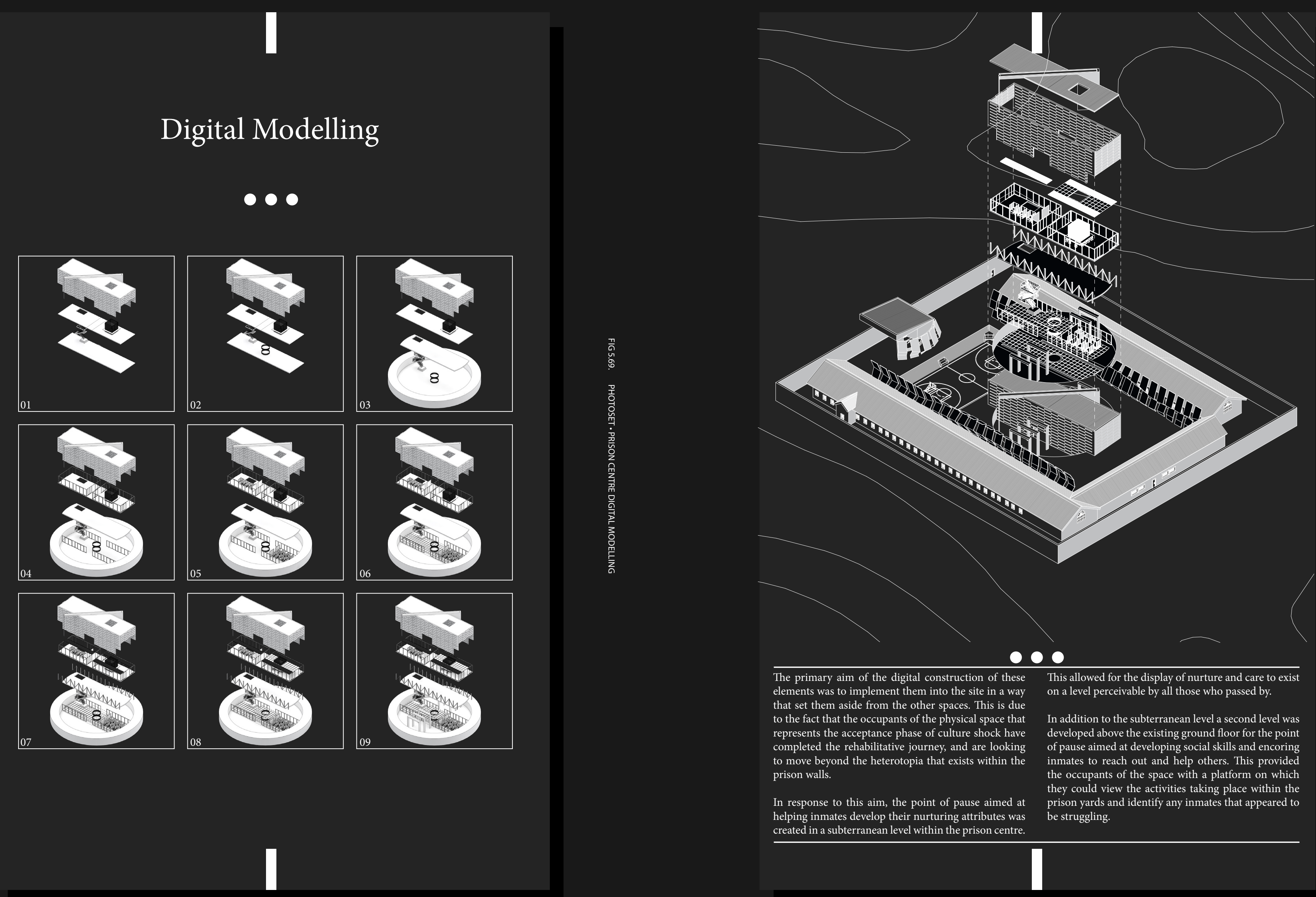
Critical Reflection

000

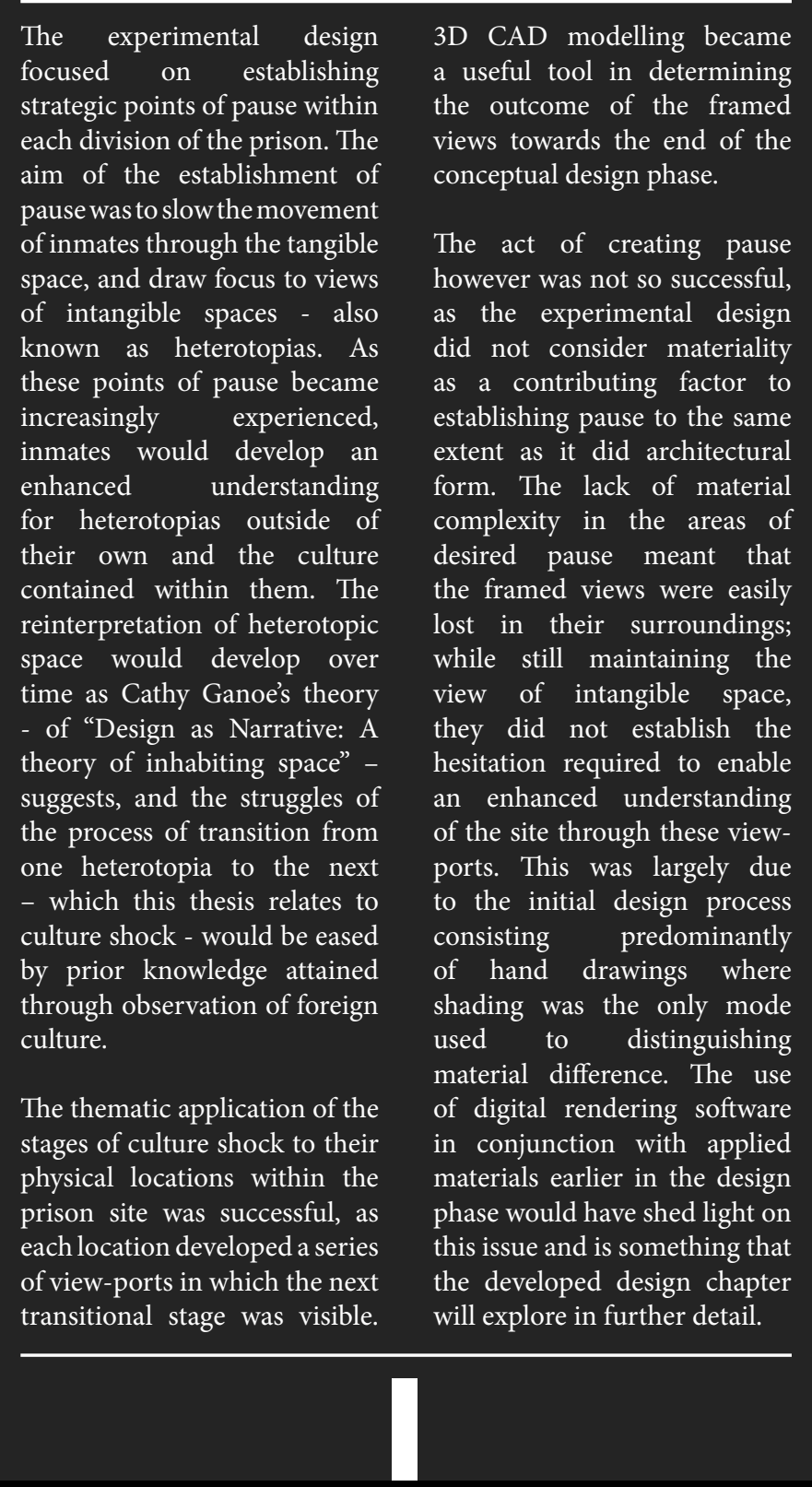

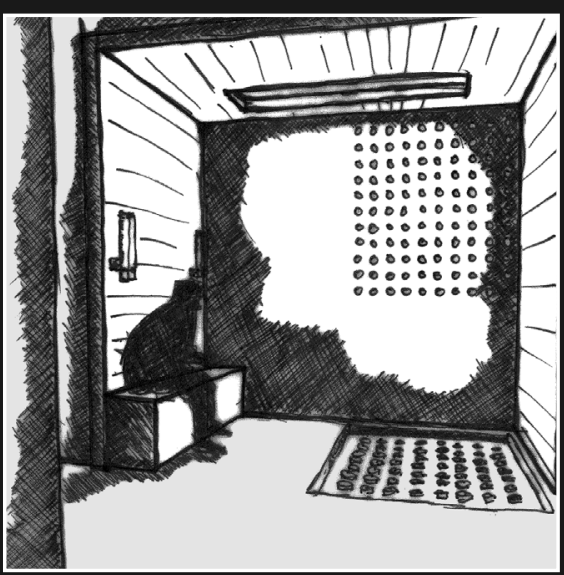
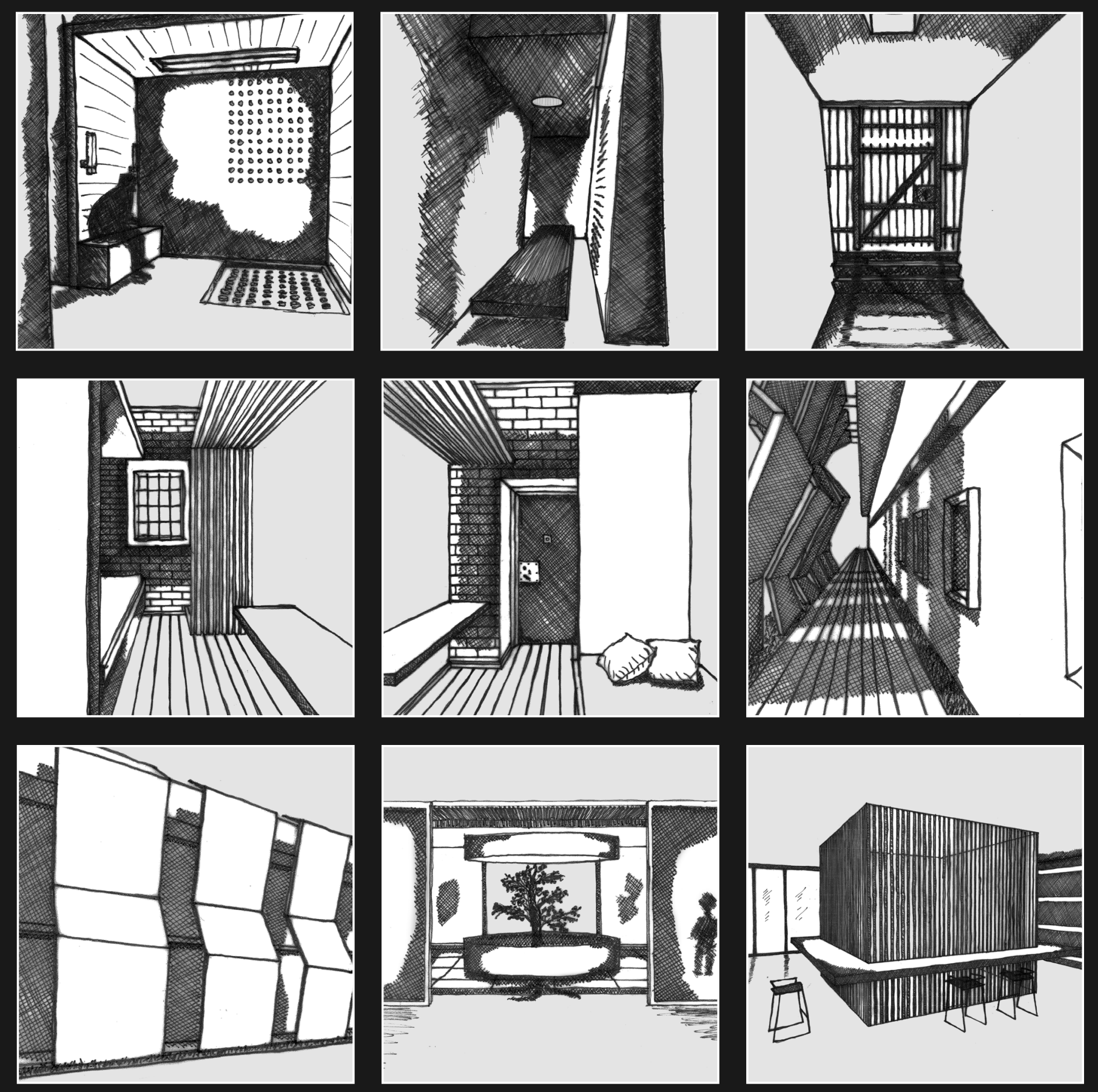


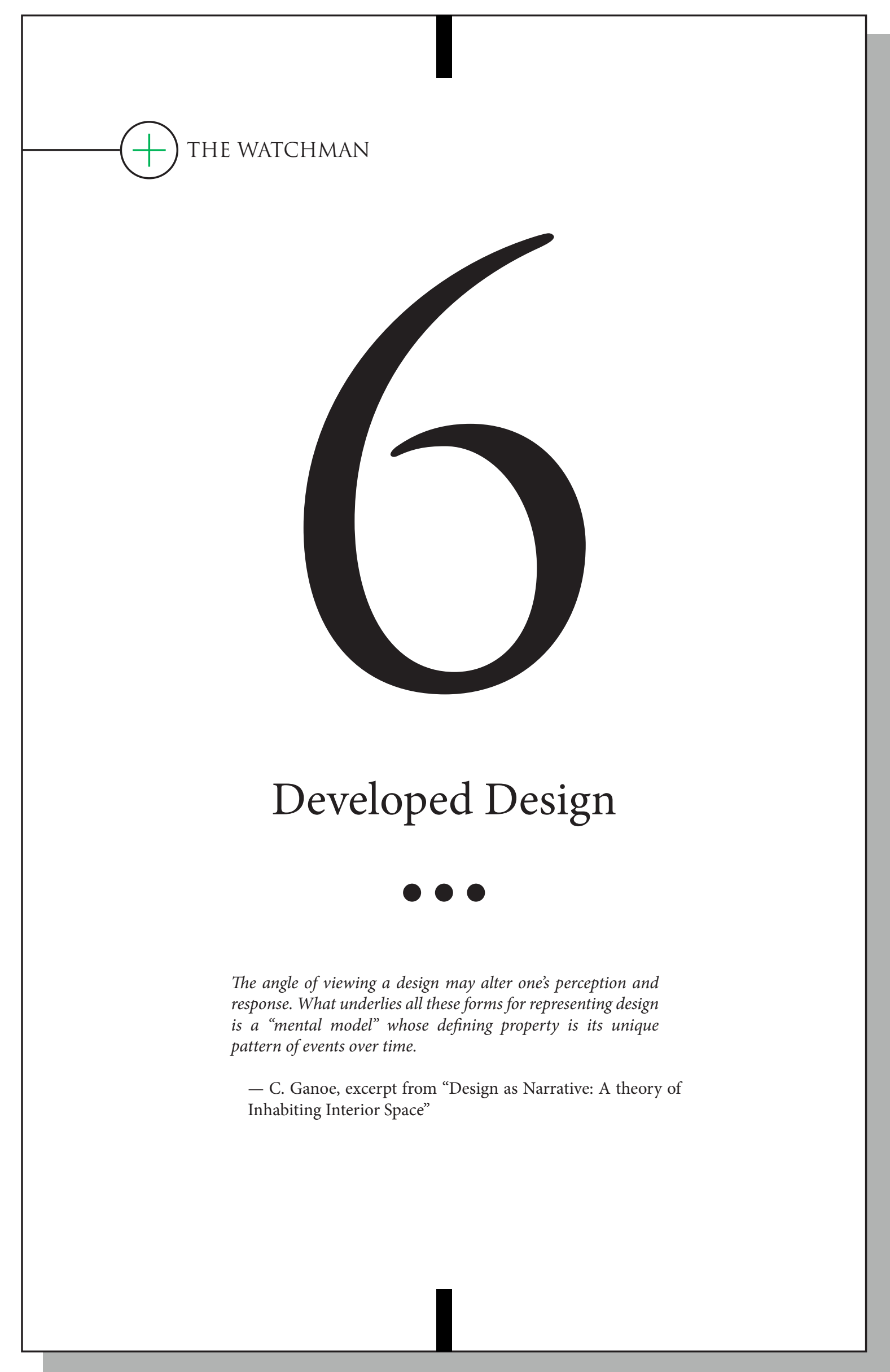




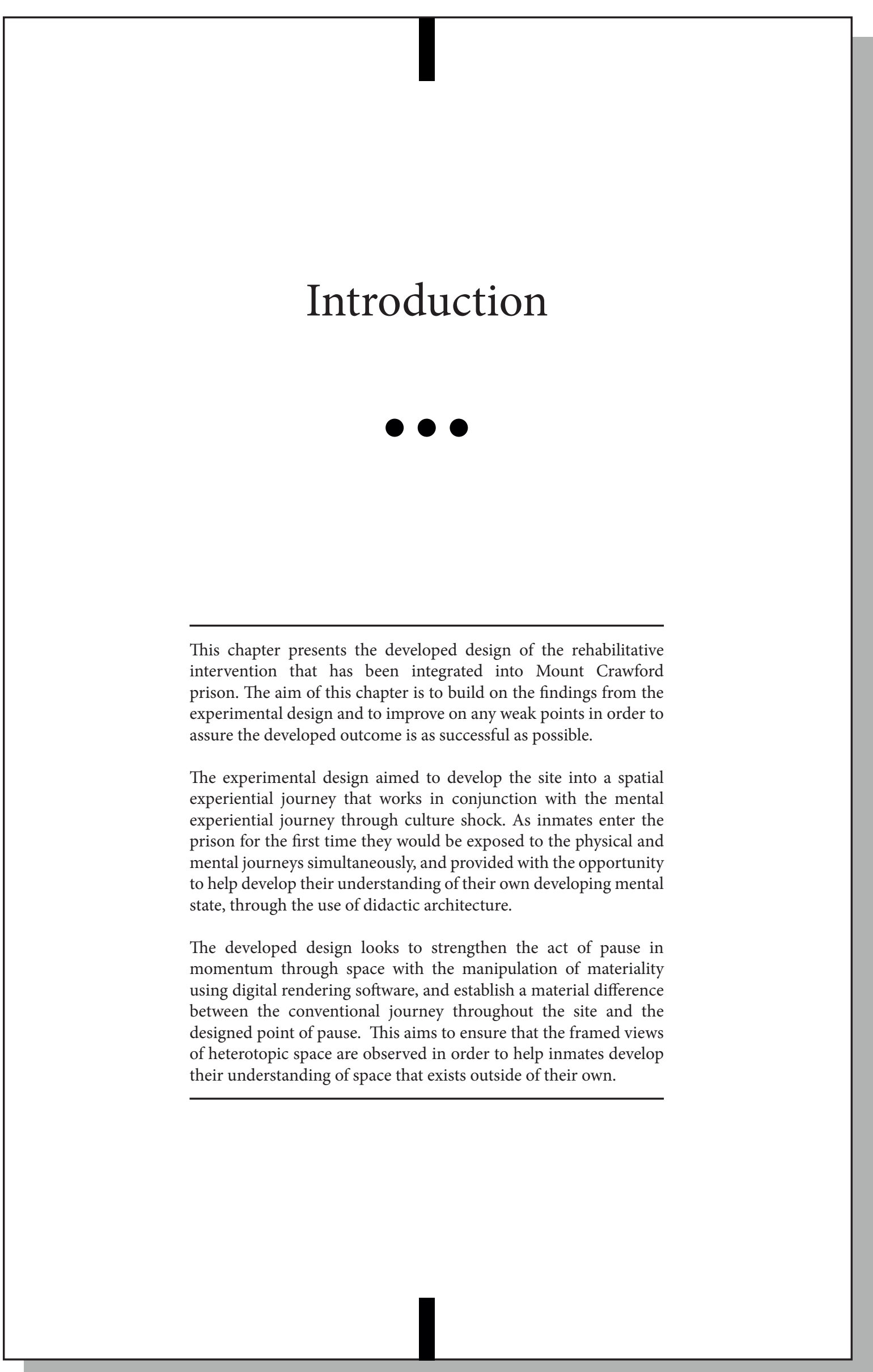

This chapter presents the developed design of the rehabilitative intervention that has been integrated into Mount Crawfor . 作 for undertanding of space that exists outside of their own. 

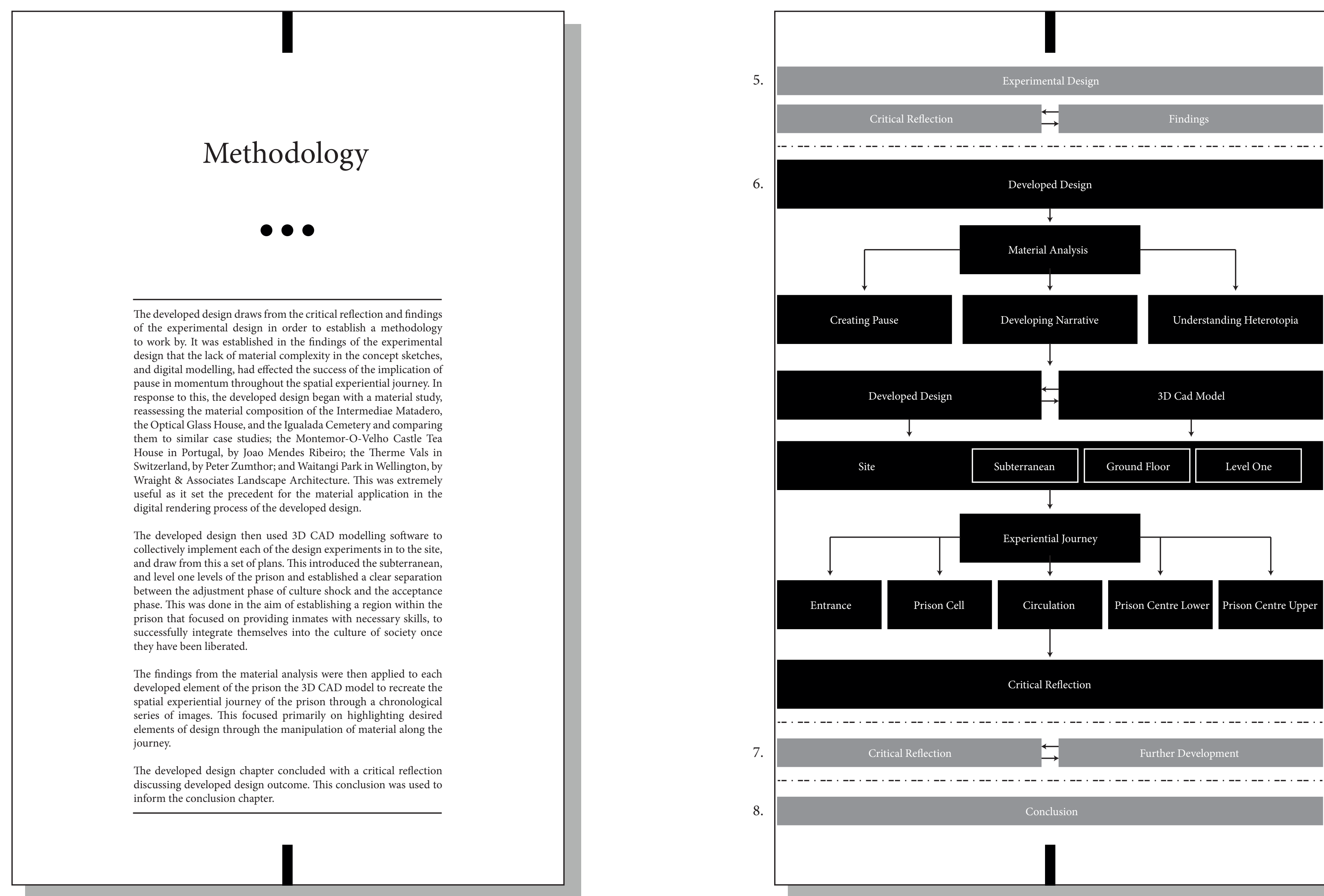

Developed Design

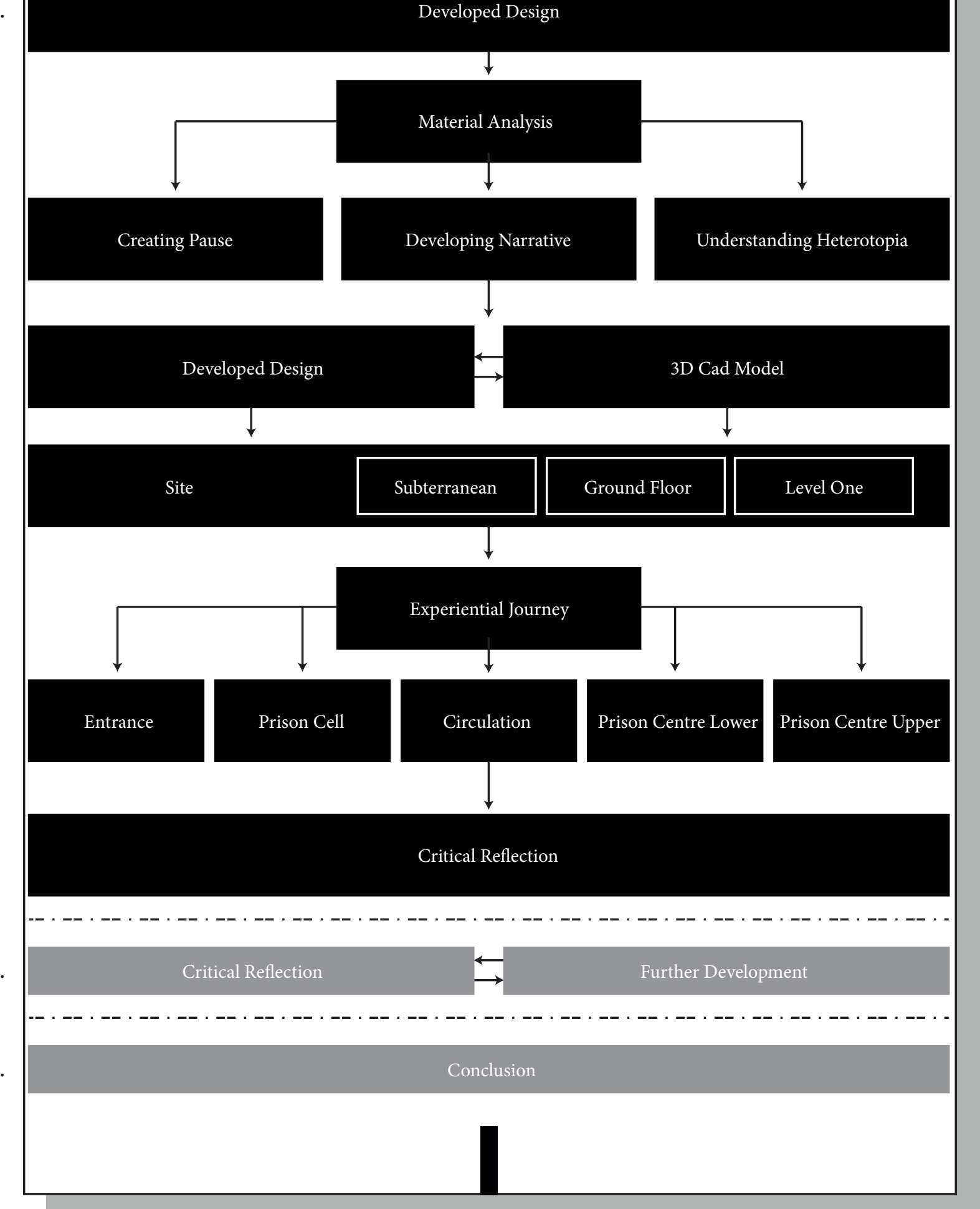




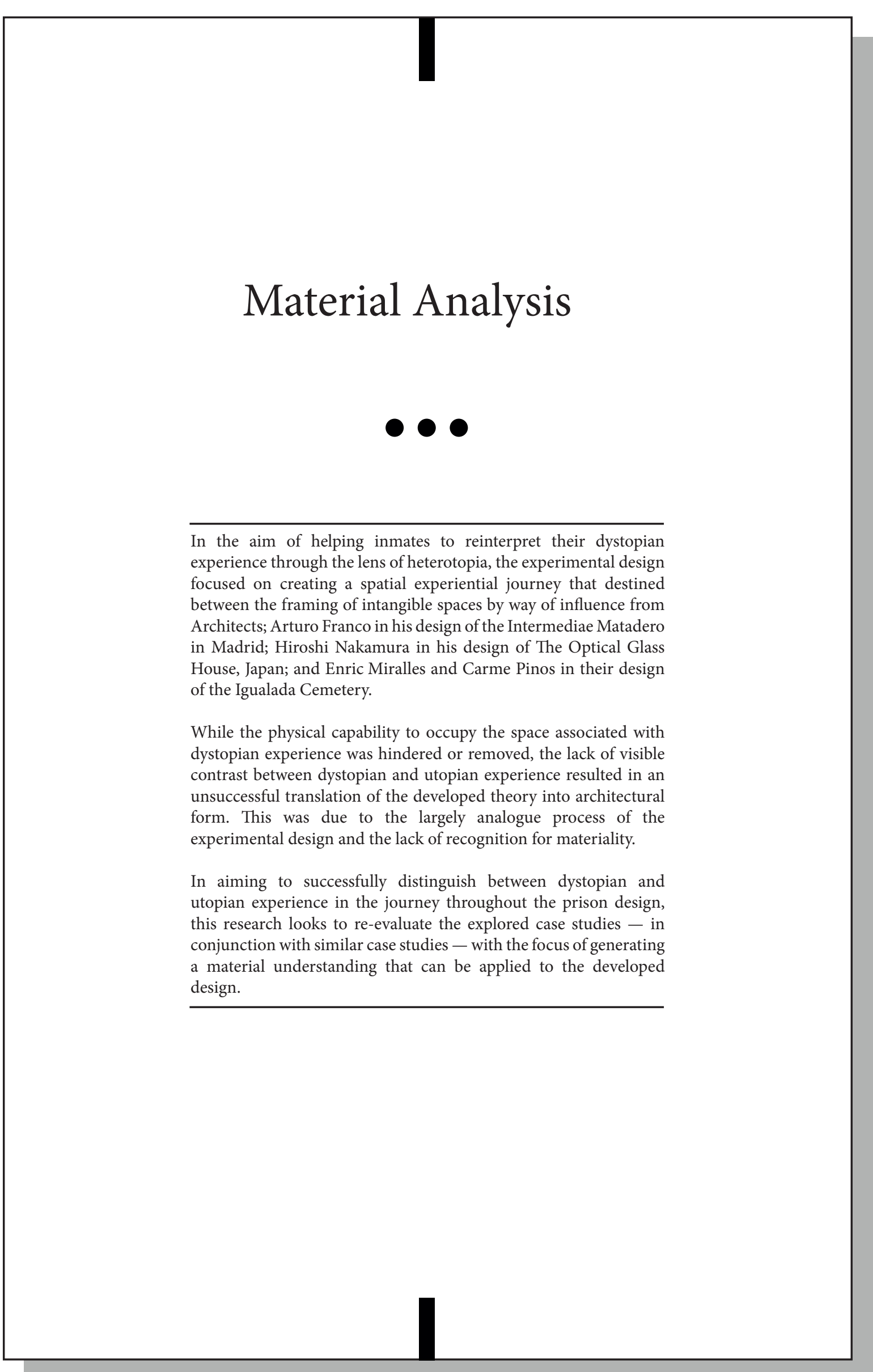

In the aim of helping inmates to reinterpret their dystopian focused on creating a spatial experiential journey that destined

While the physical capability to occupy the space associated $w$ 

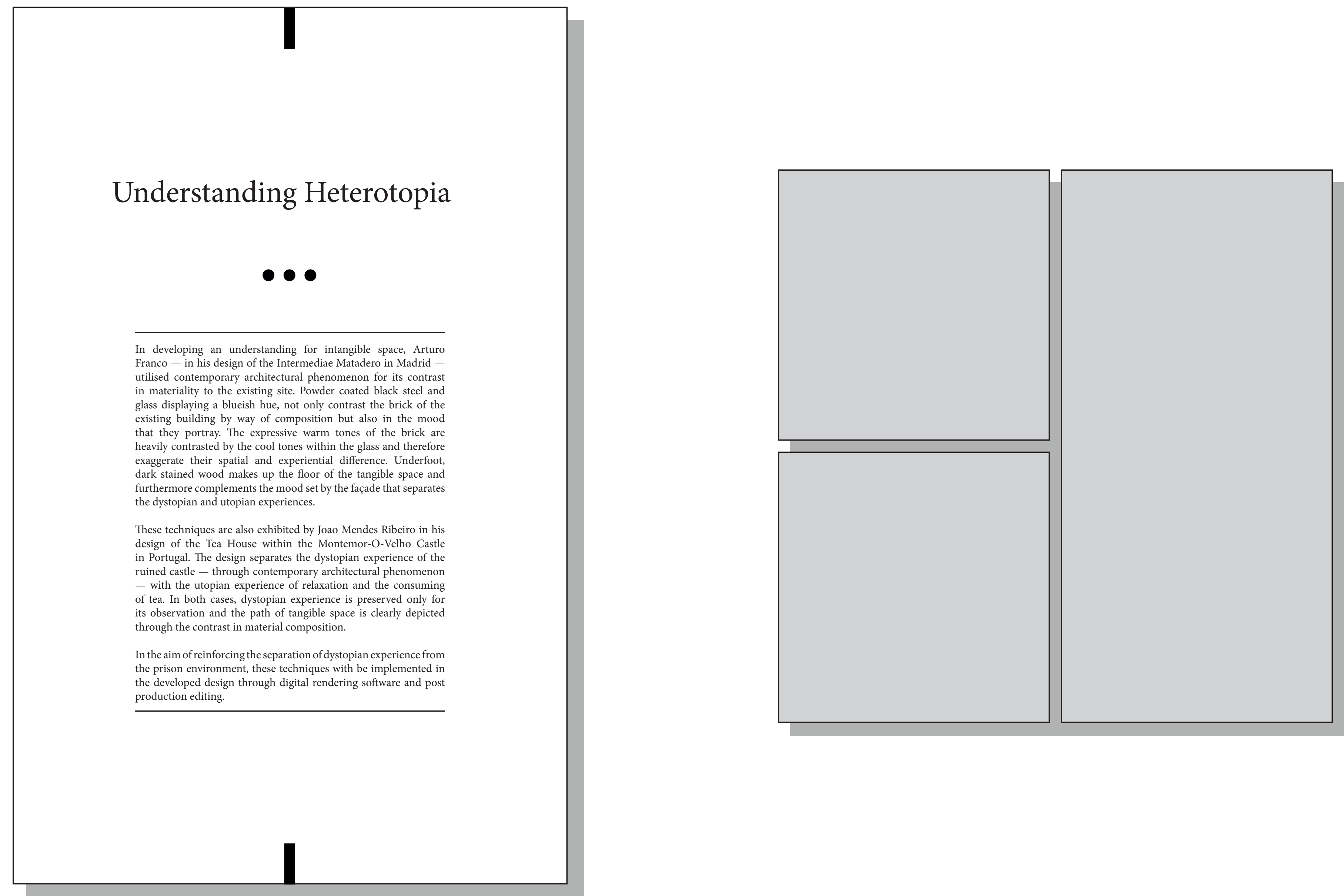

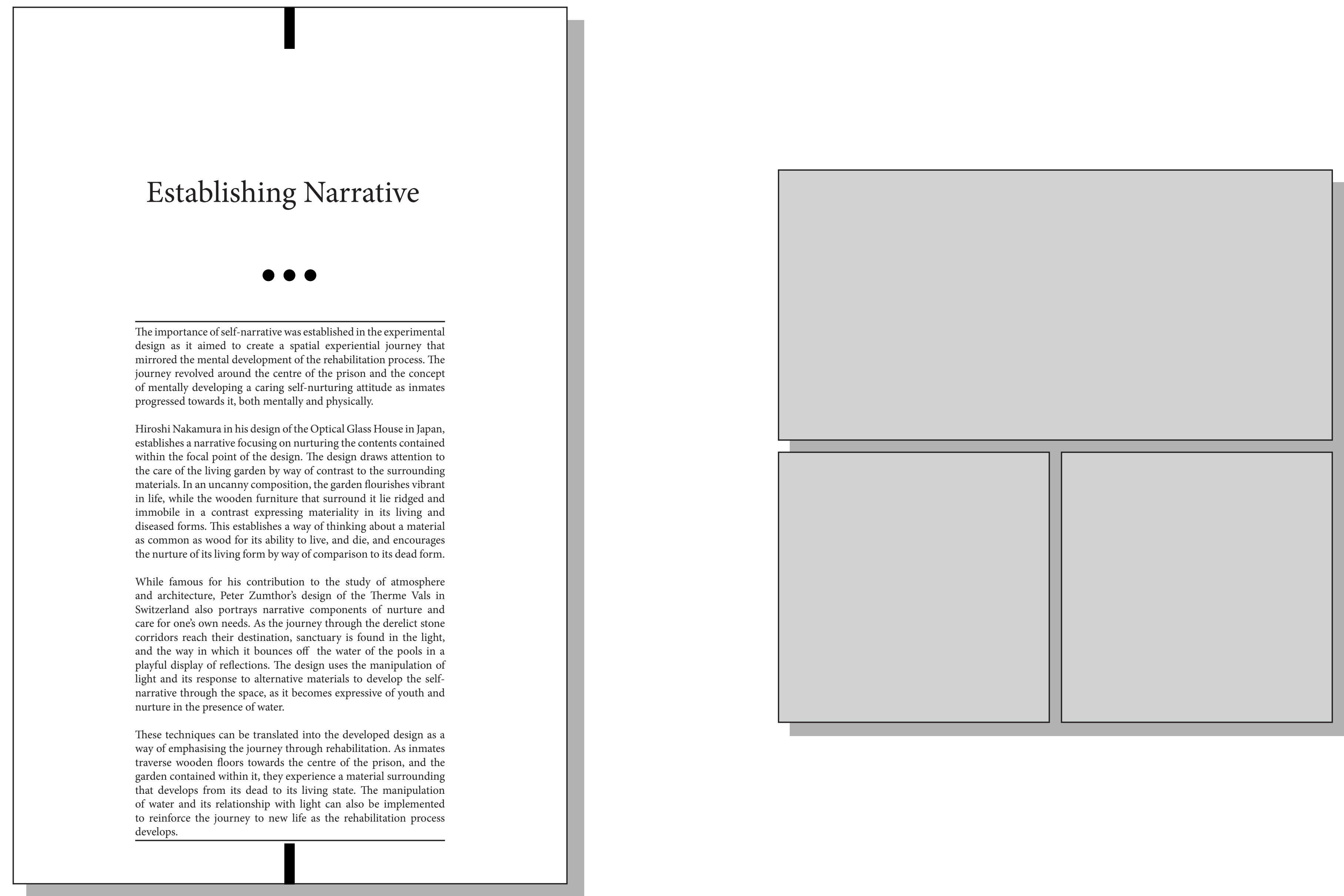

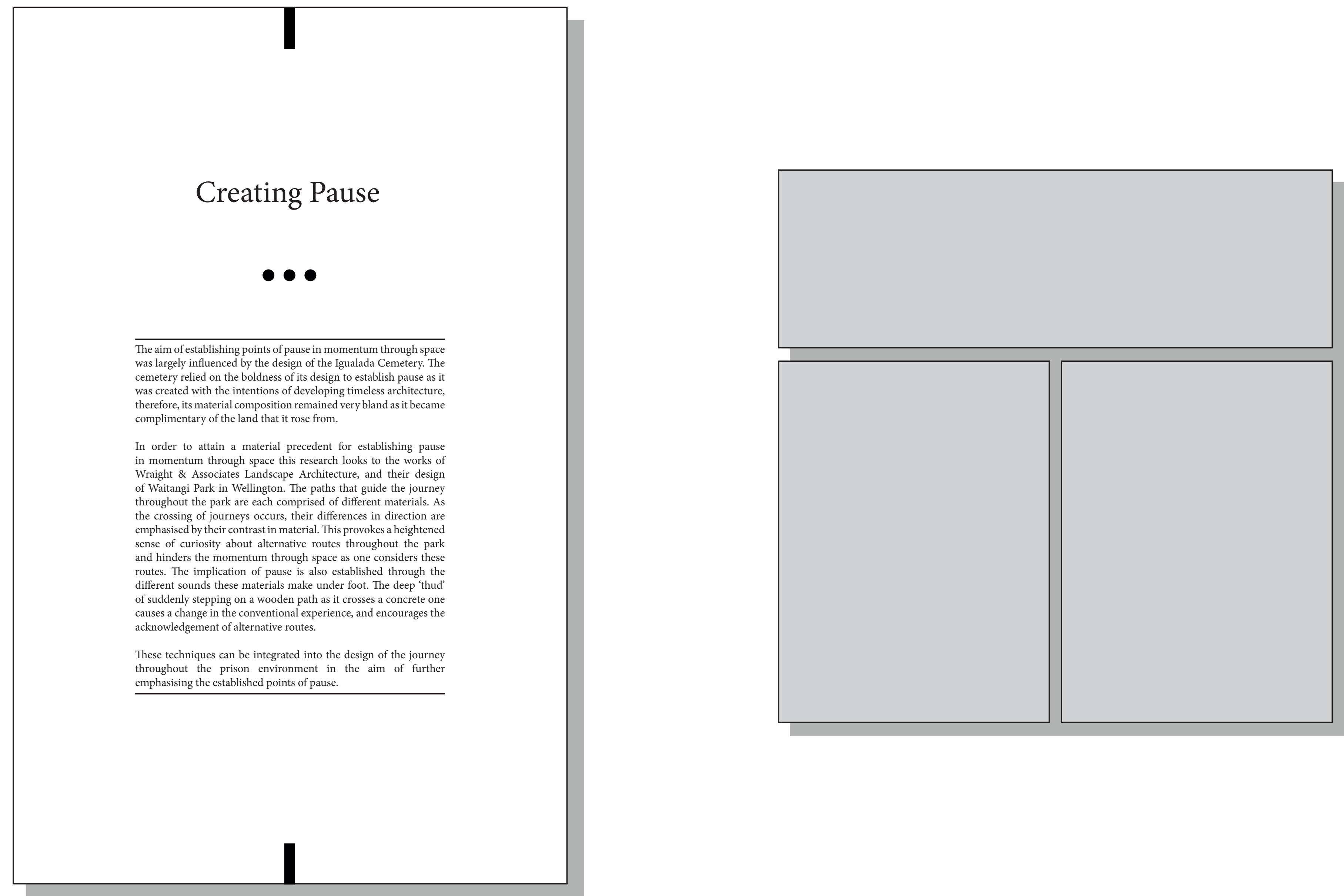

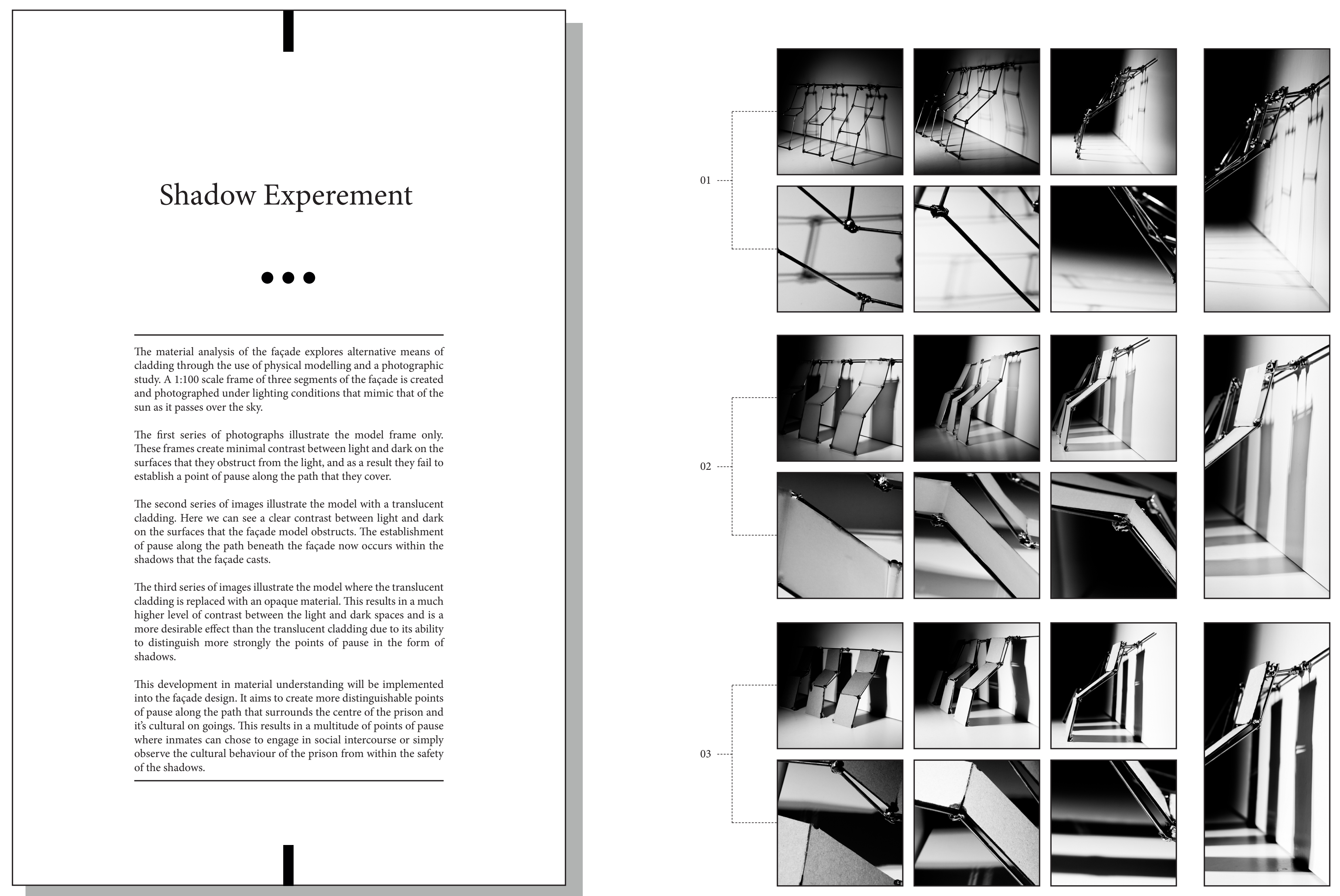


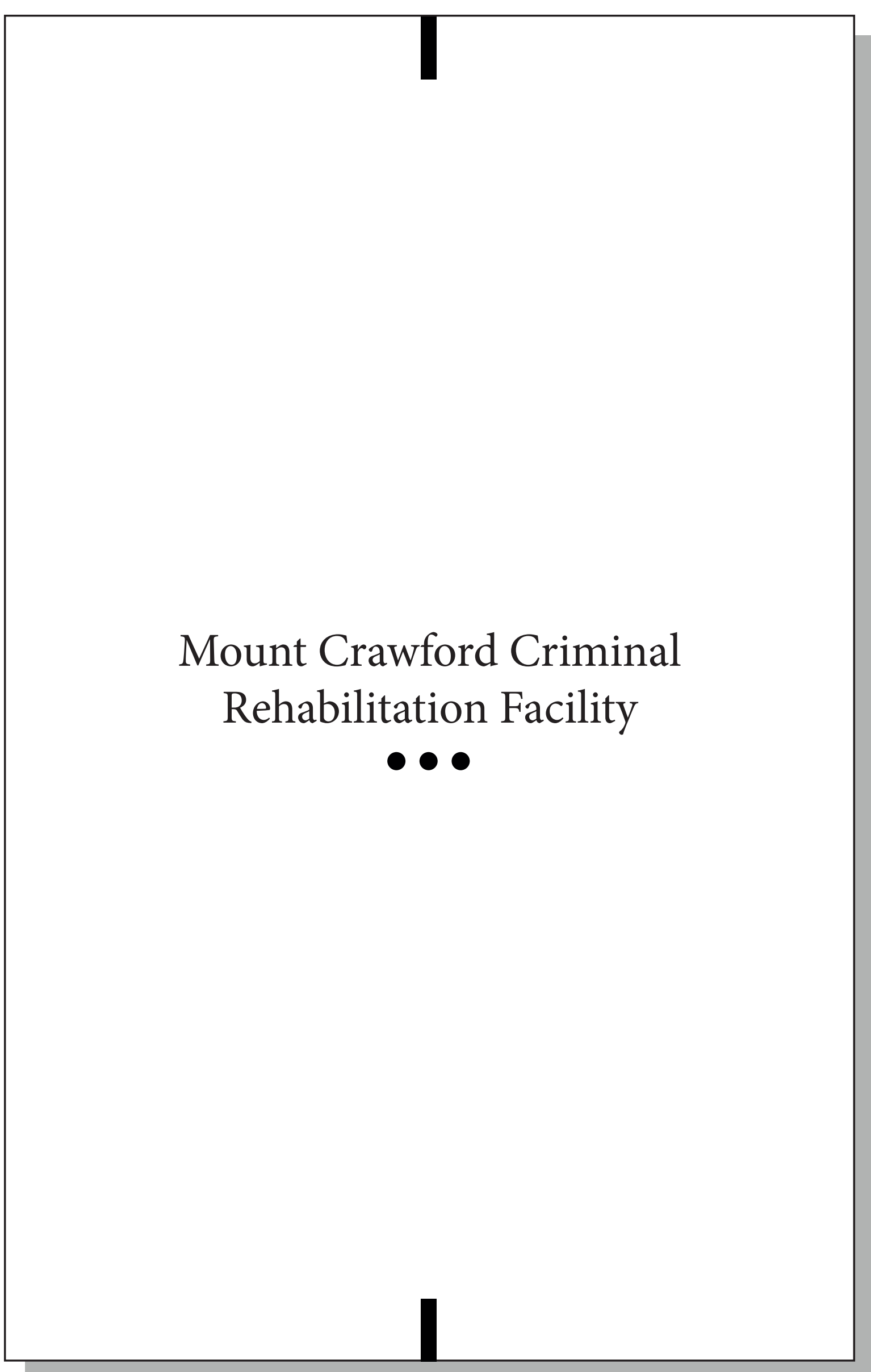



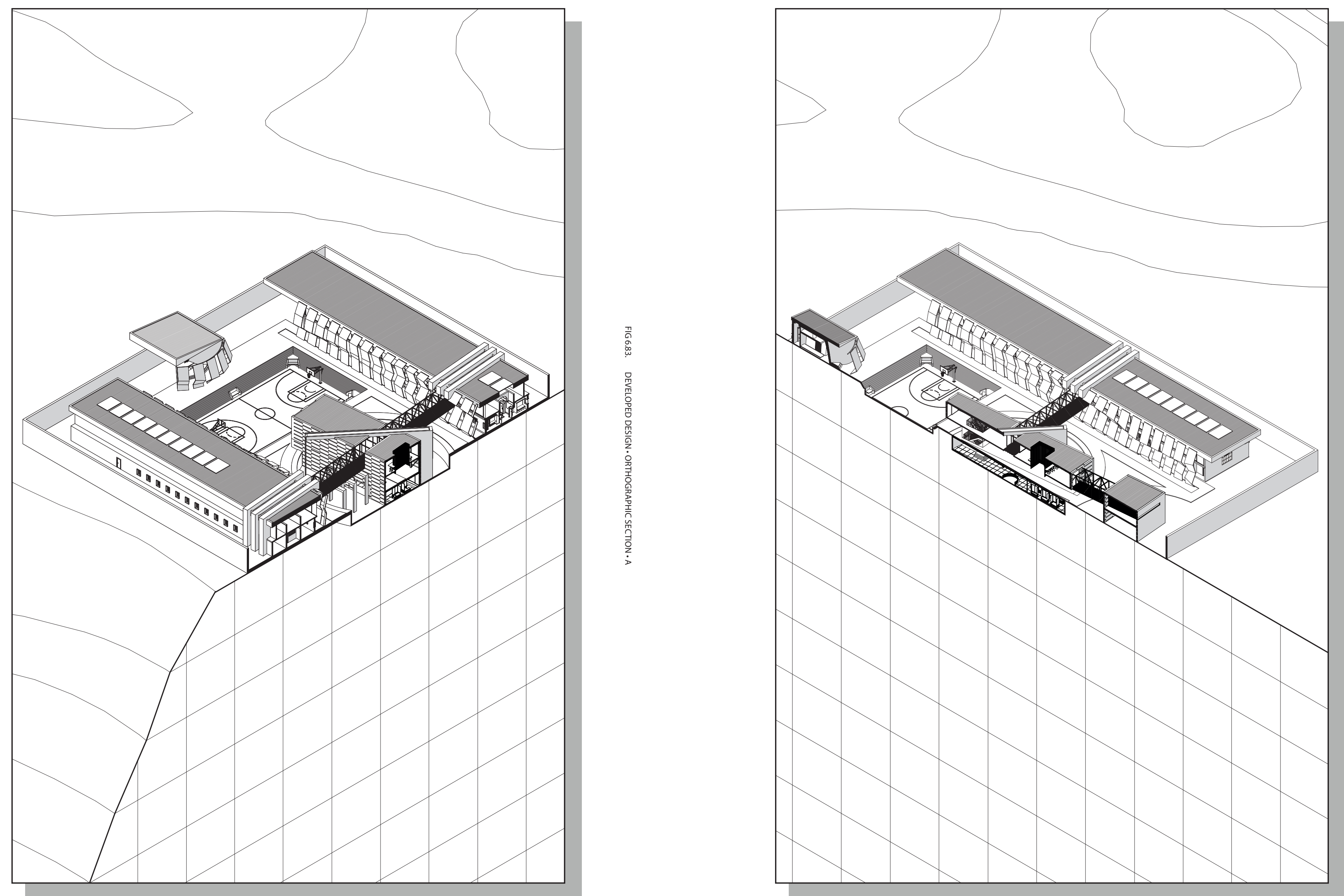


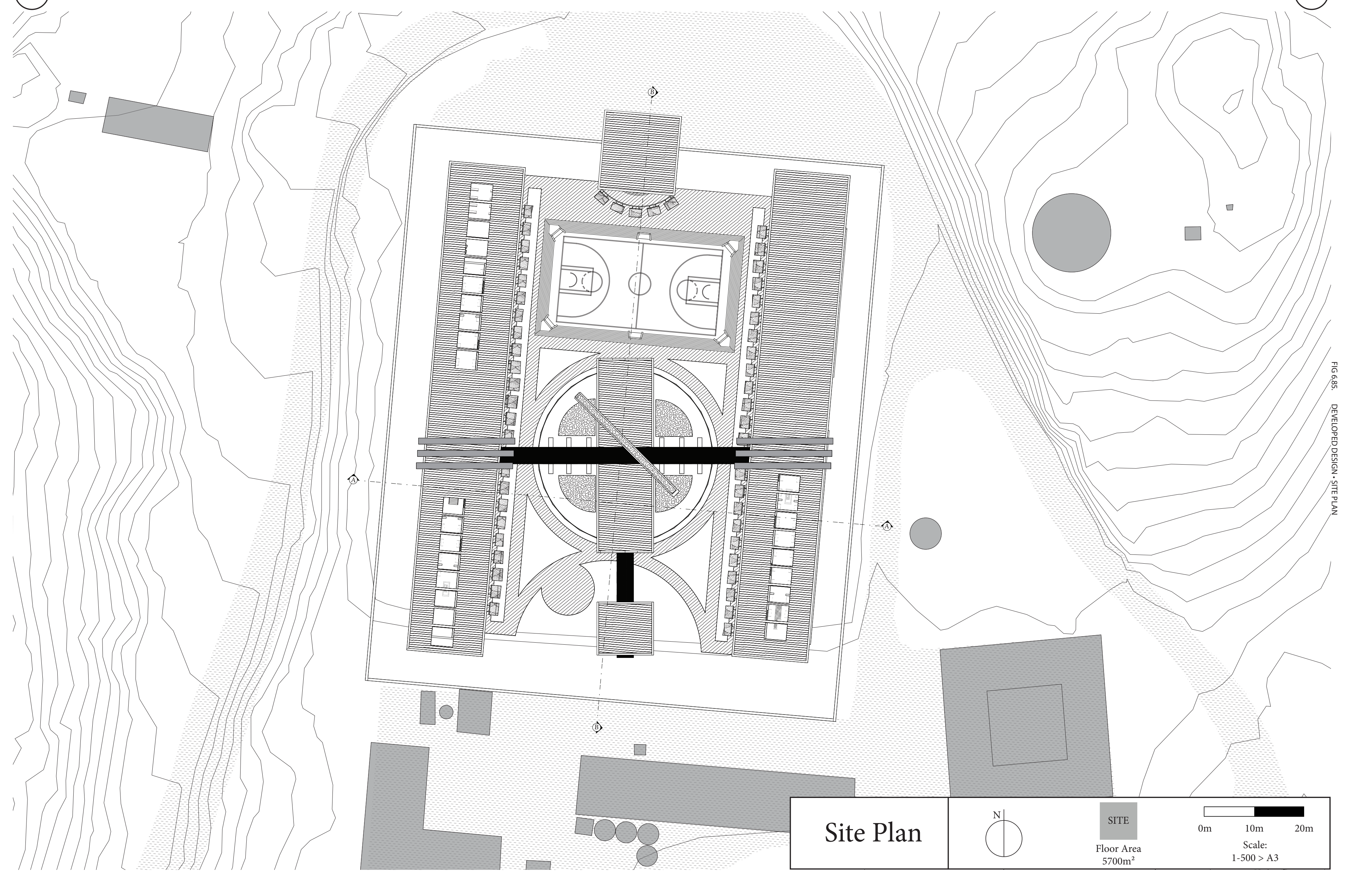



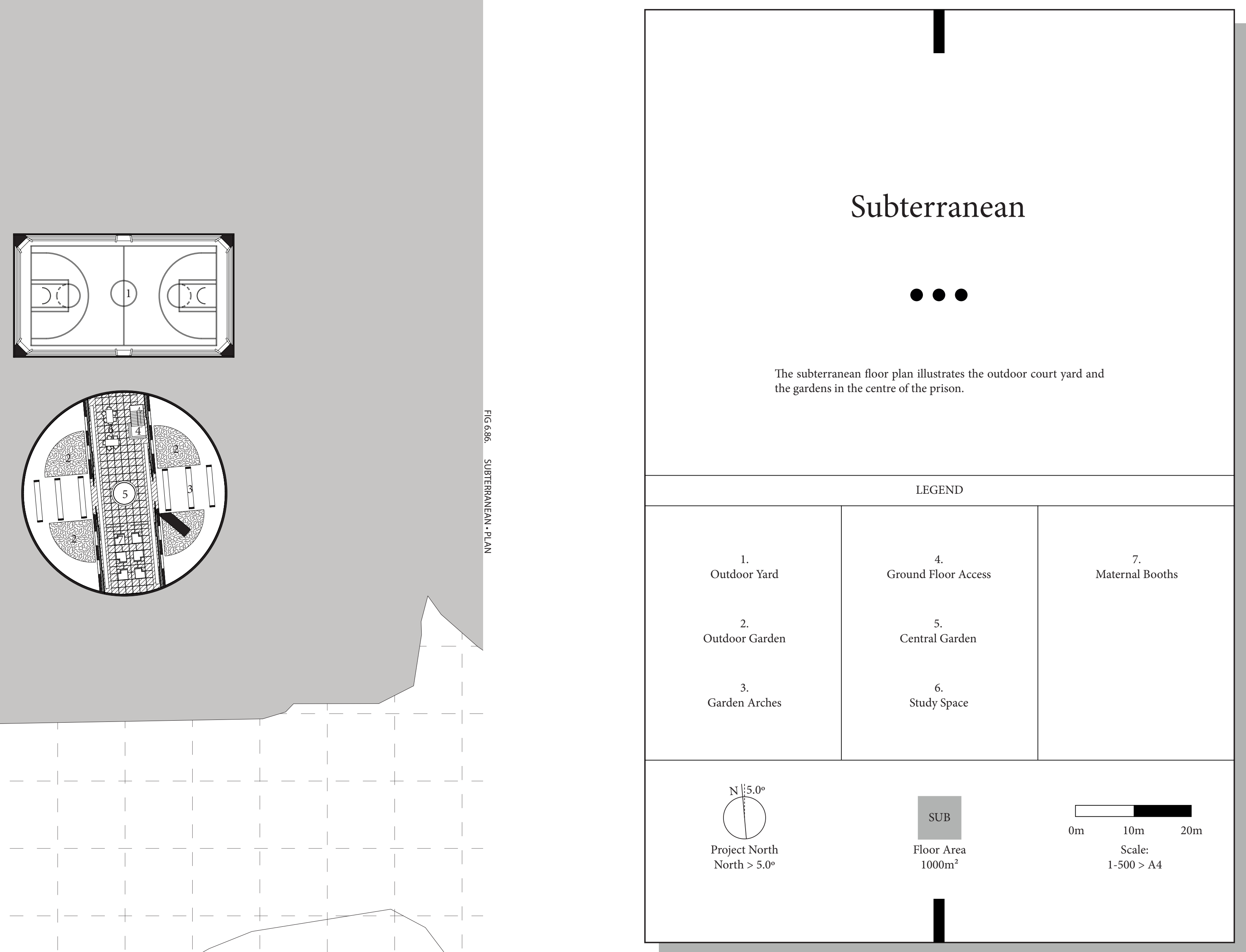


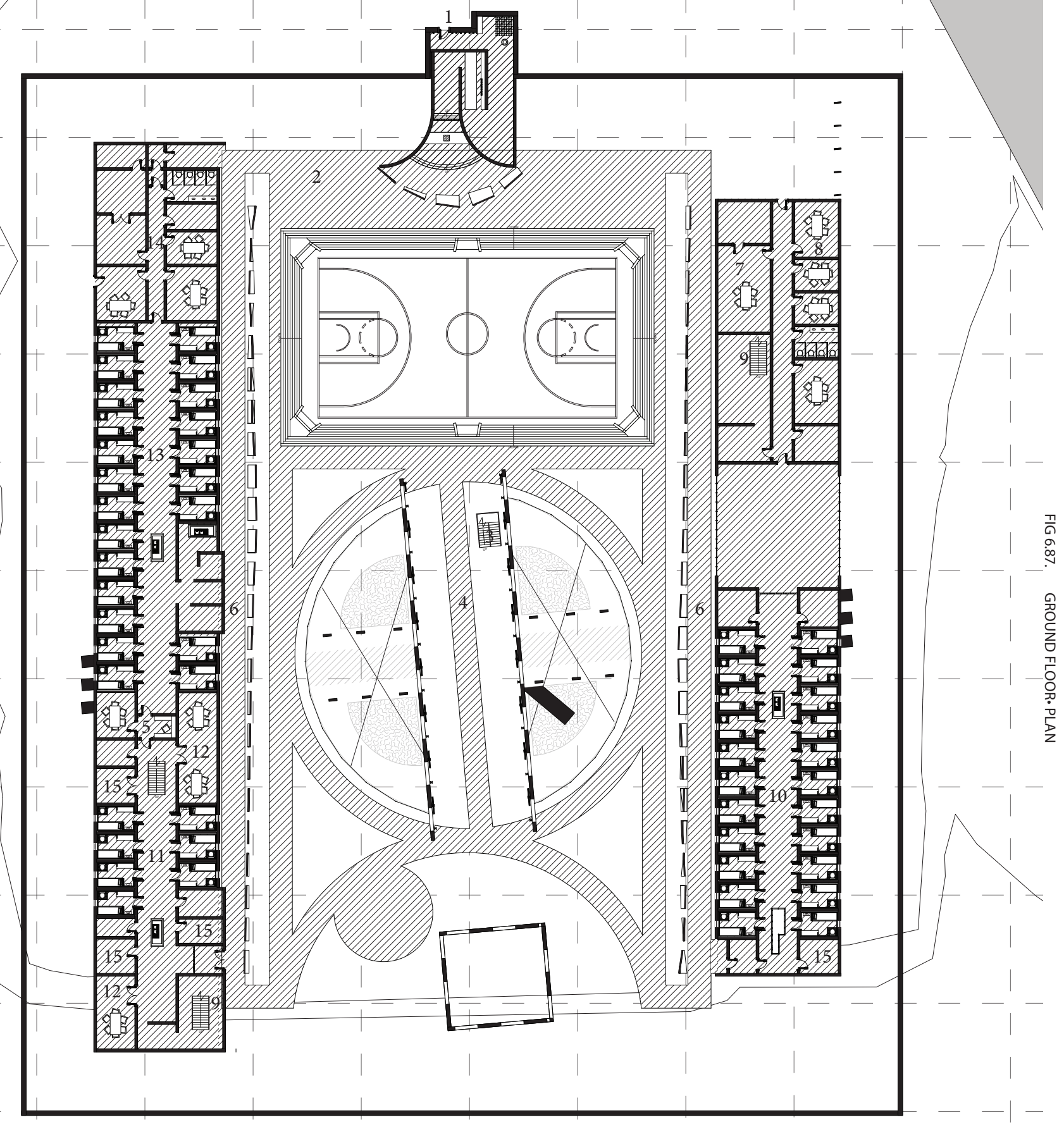

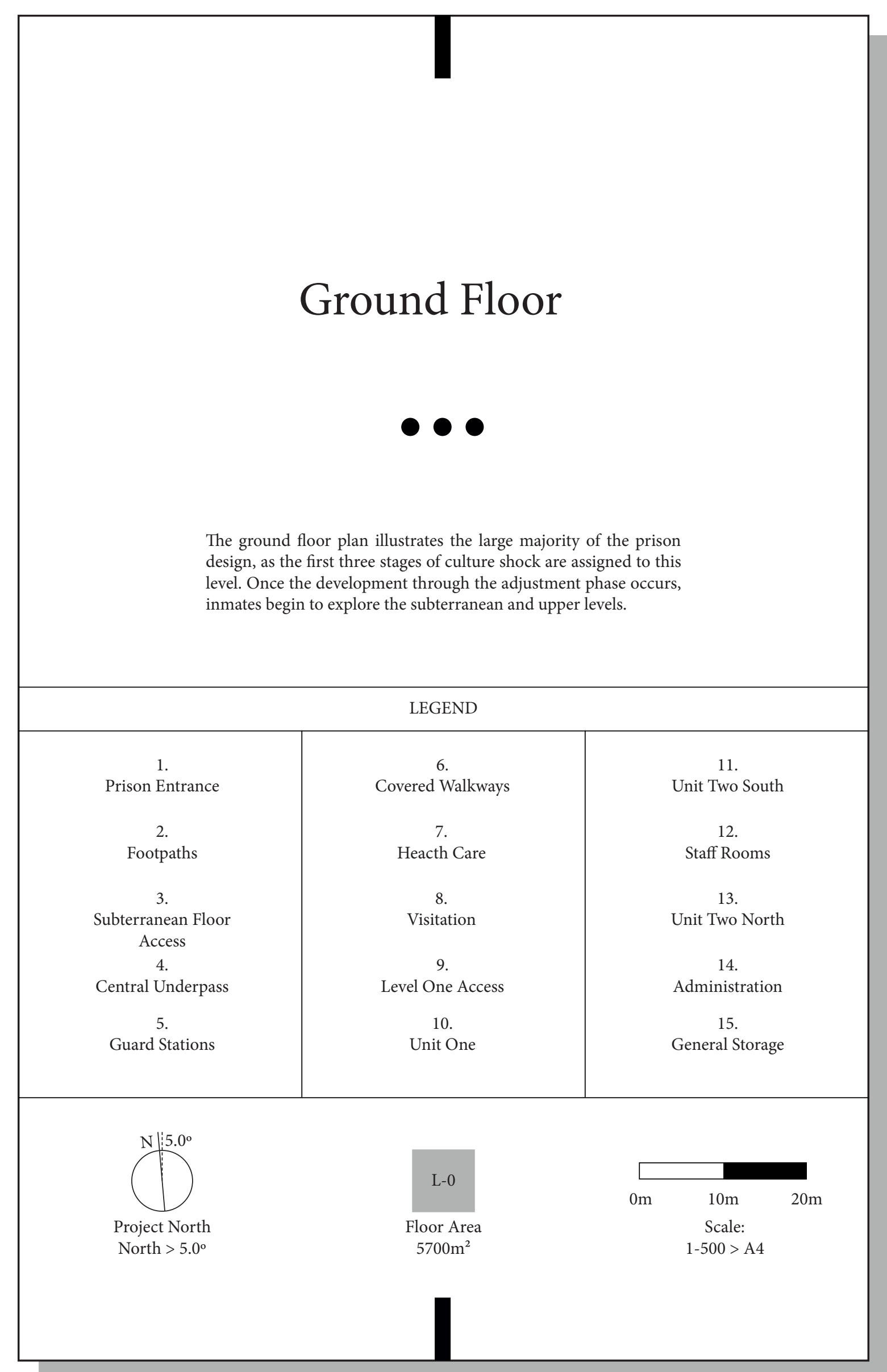




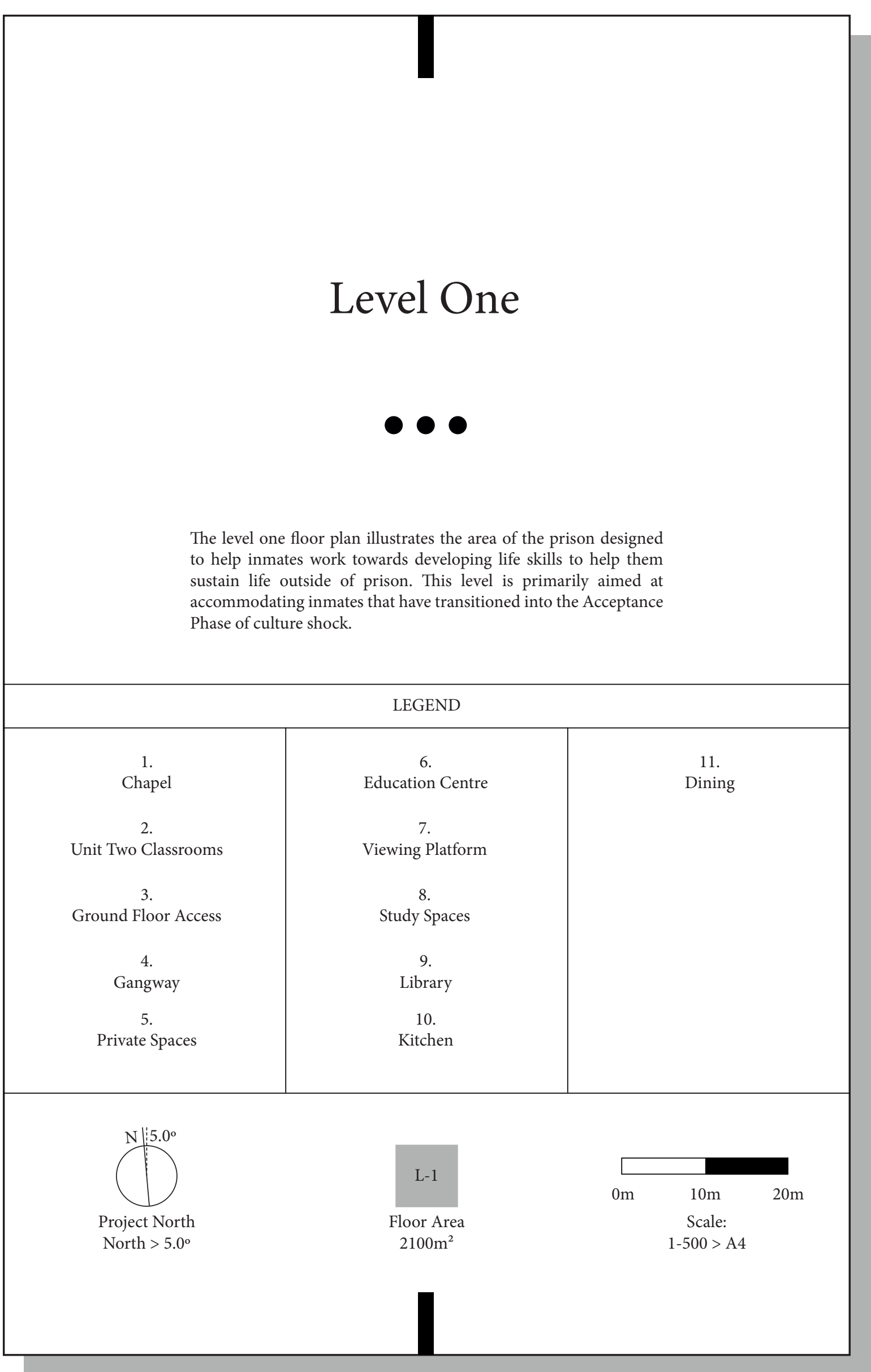


Honeymoon Phase

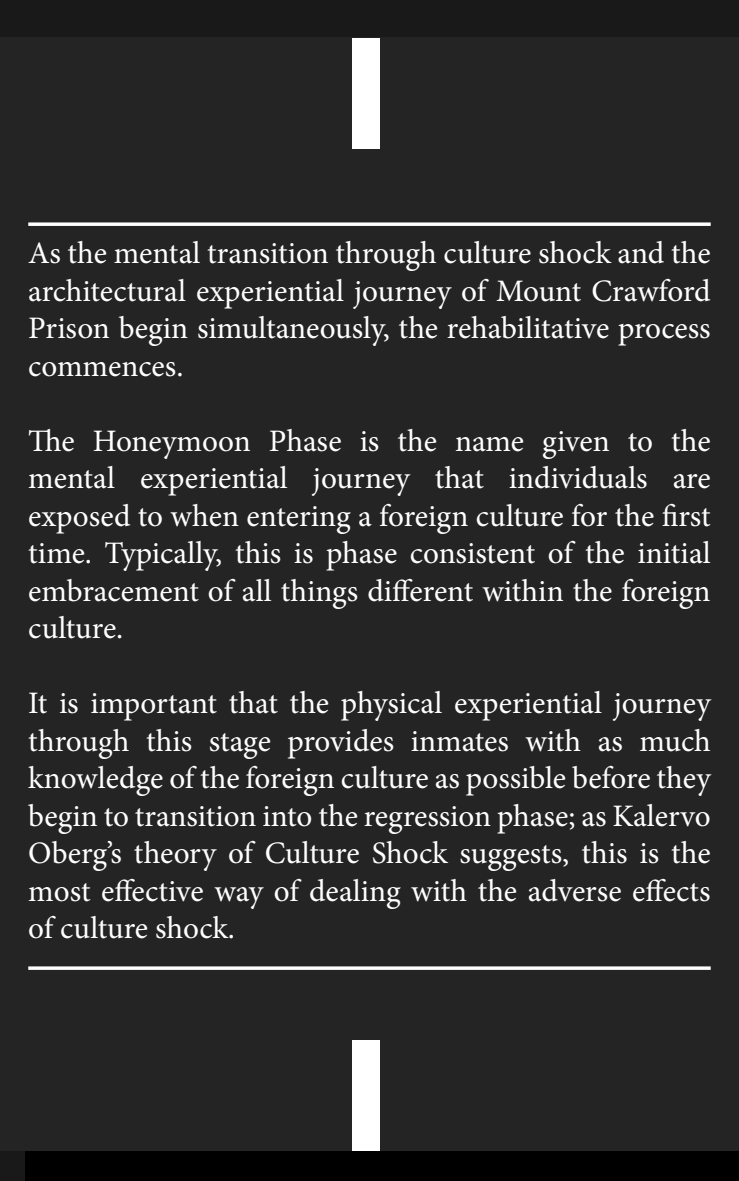

\section{Entrance}

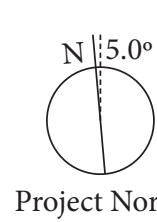

Project North
$0 \mathrm{~m}$

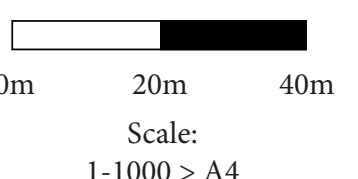

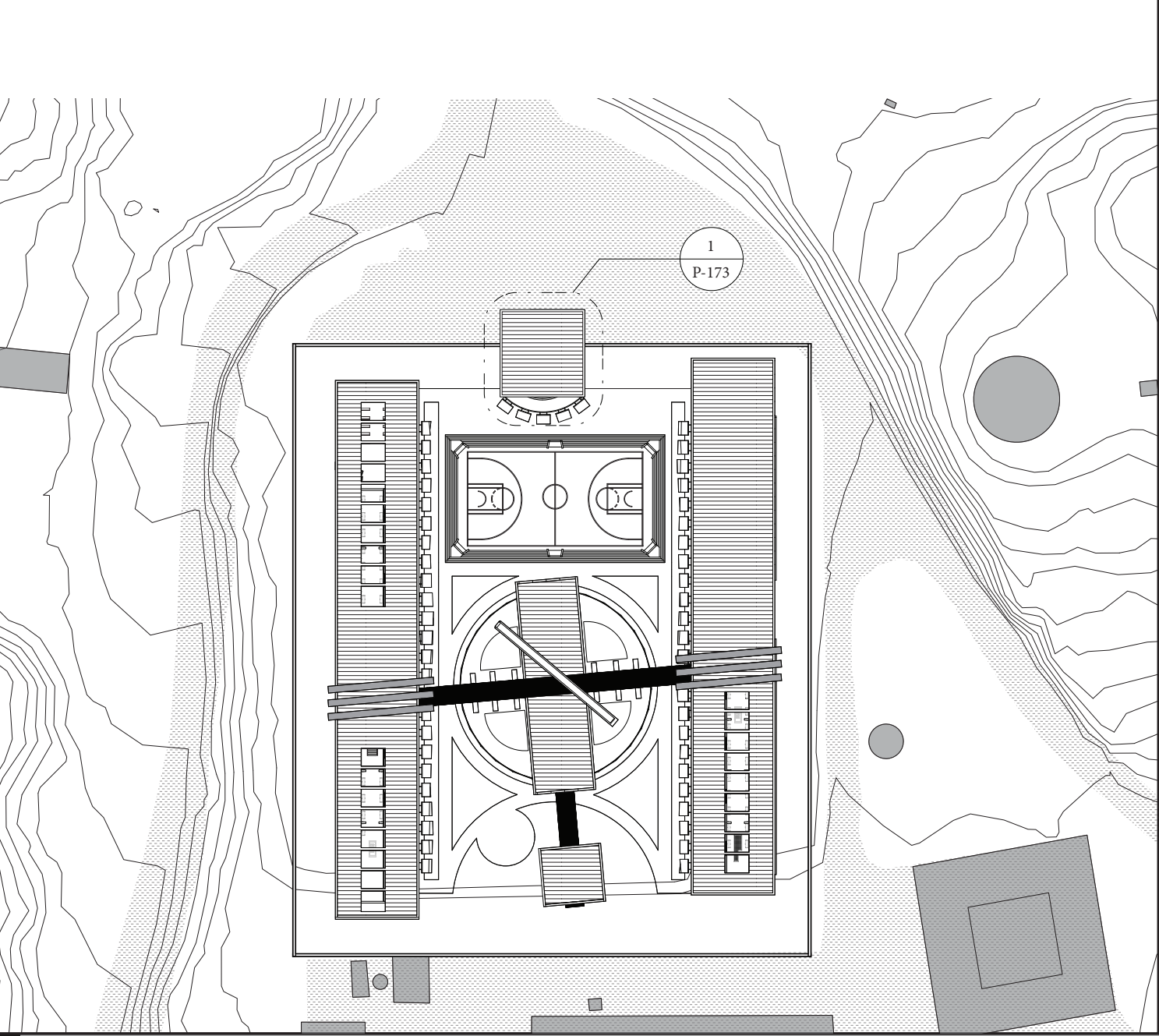



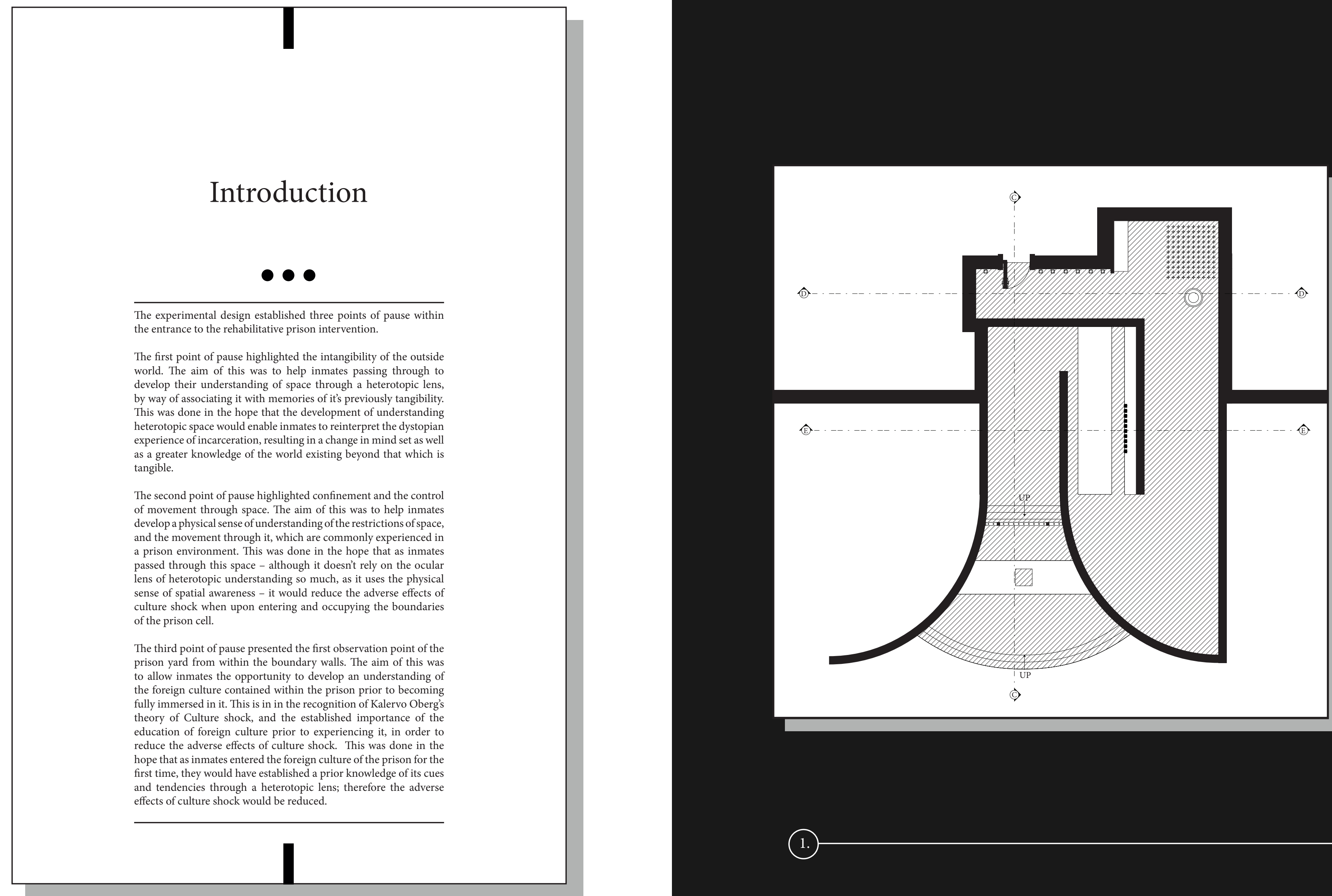

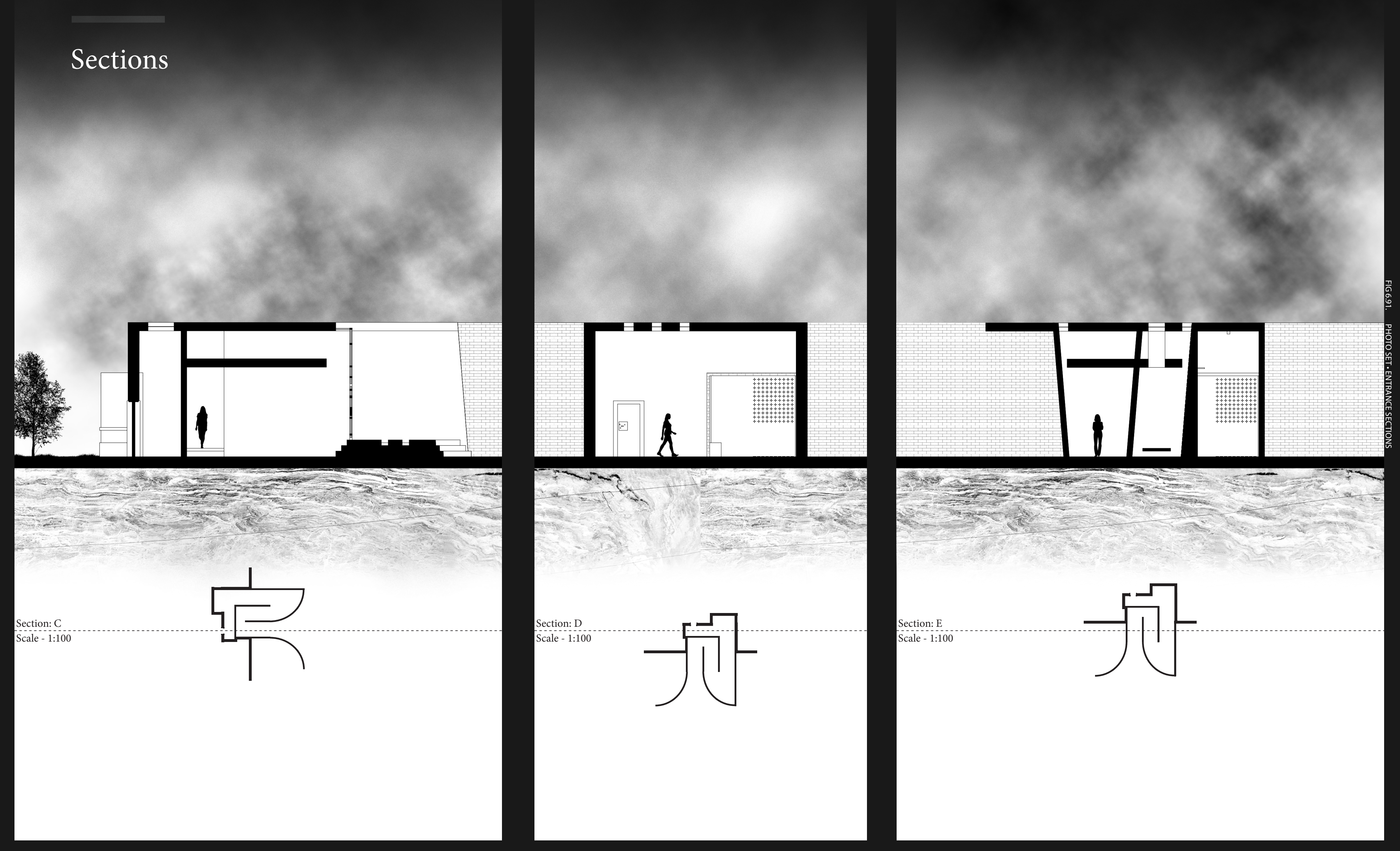


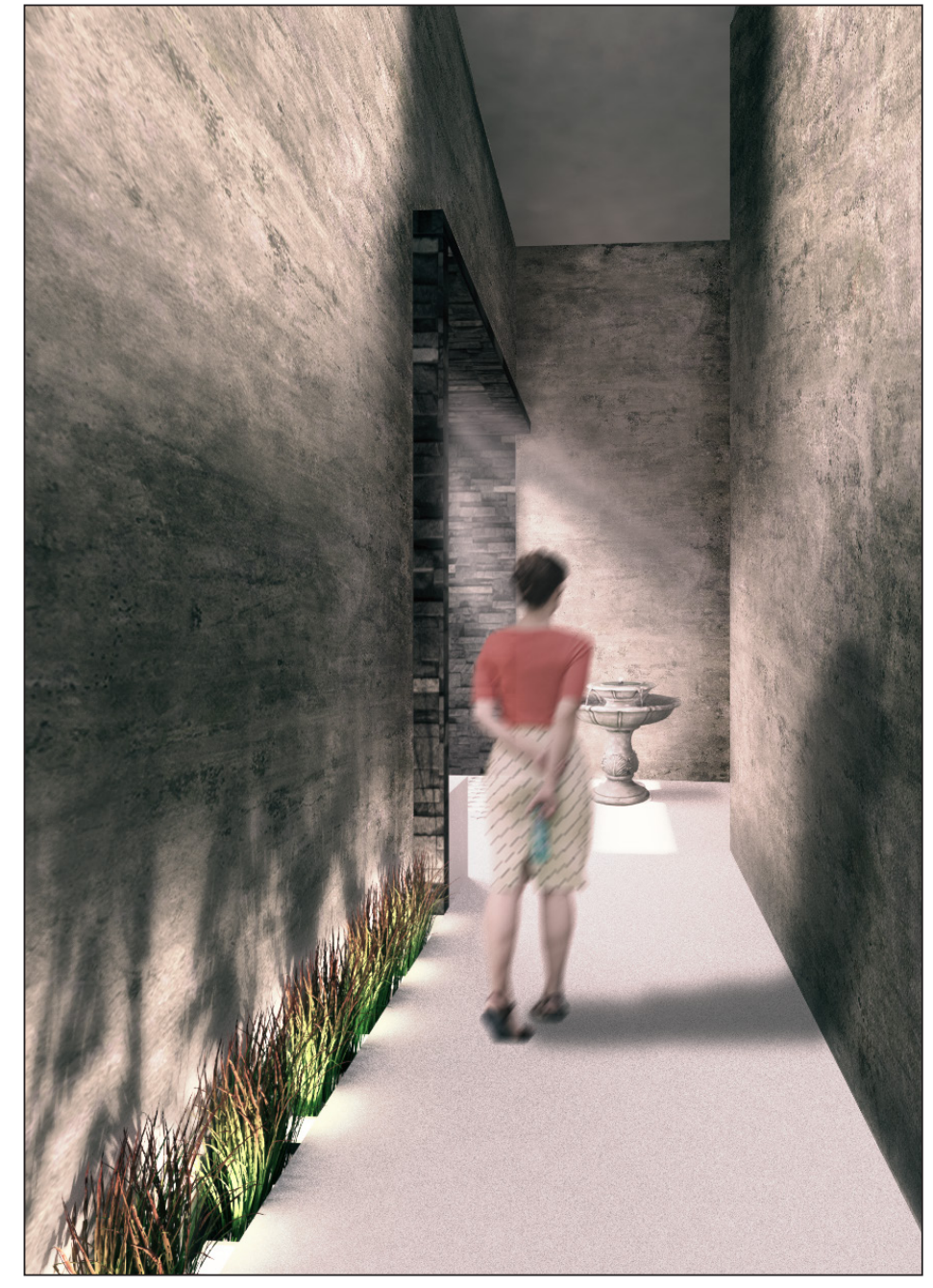

The developed design of the entrance to the rehabilitative of the material analysis, to emphasise the establishment of pause, as well as the themes

The development of the first point of pause along the spatial
experiential journey establishes a clear contrastinspatial orientation that is visible upon first entrance to the site (figure 6.92). The work of Wraight \& Associates Landscape Architecture in Wellington is wed as a preced in for establishing a contrast in material. This contrast in material however, is translated into the walls - as opposed to underfoot in order to draw the eye towards the desired focus of the world beyond the prison through the established in the experiment design. This establishes heightened sense of curiosity about the space and emphasises the act of pause in momentum, resulting in a more successful implementation of the theory developed in chapter two

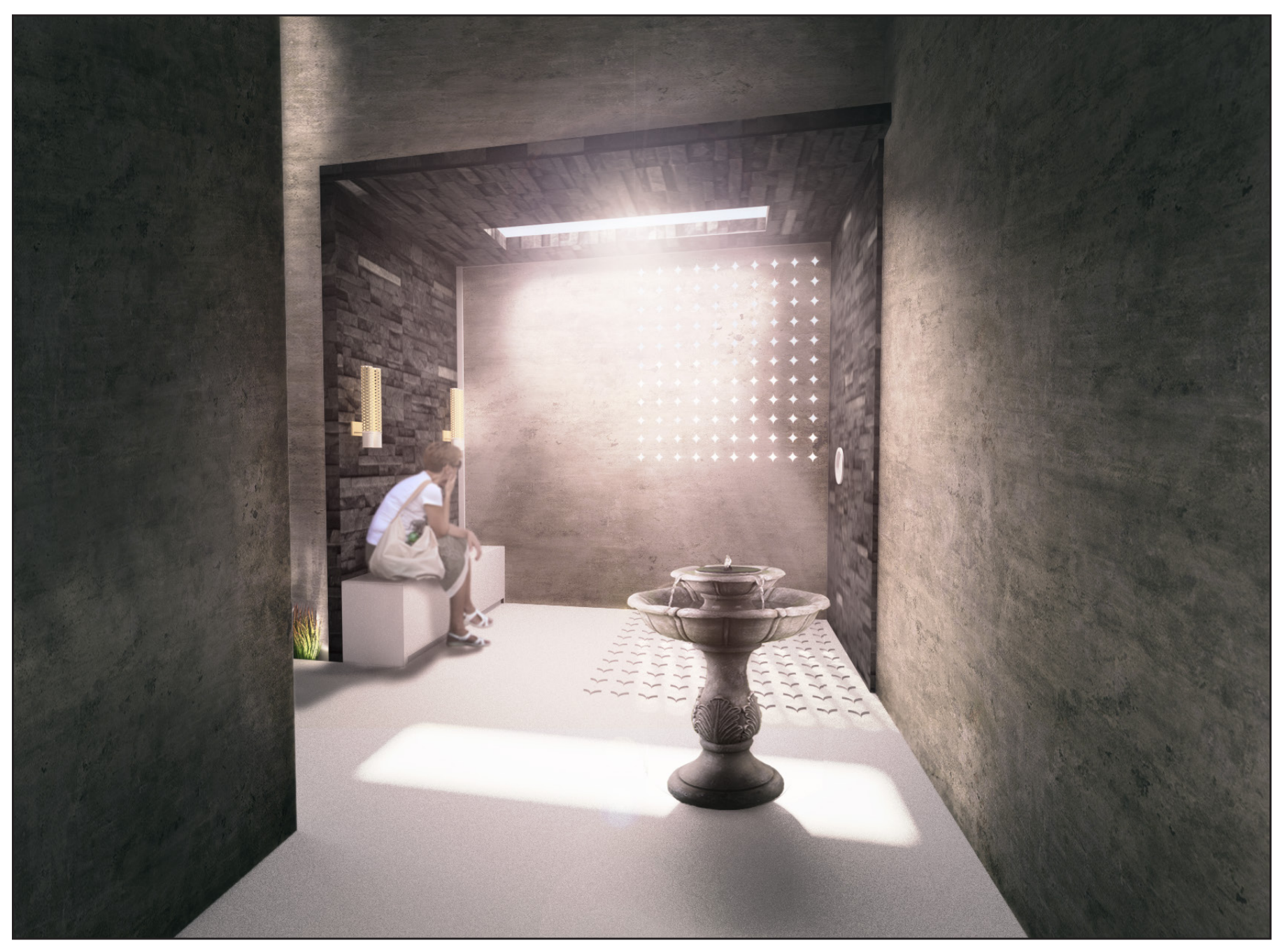




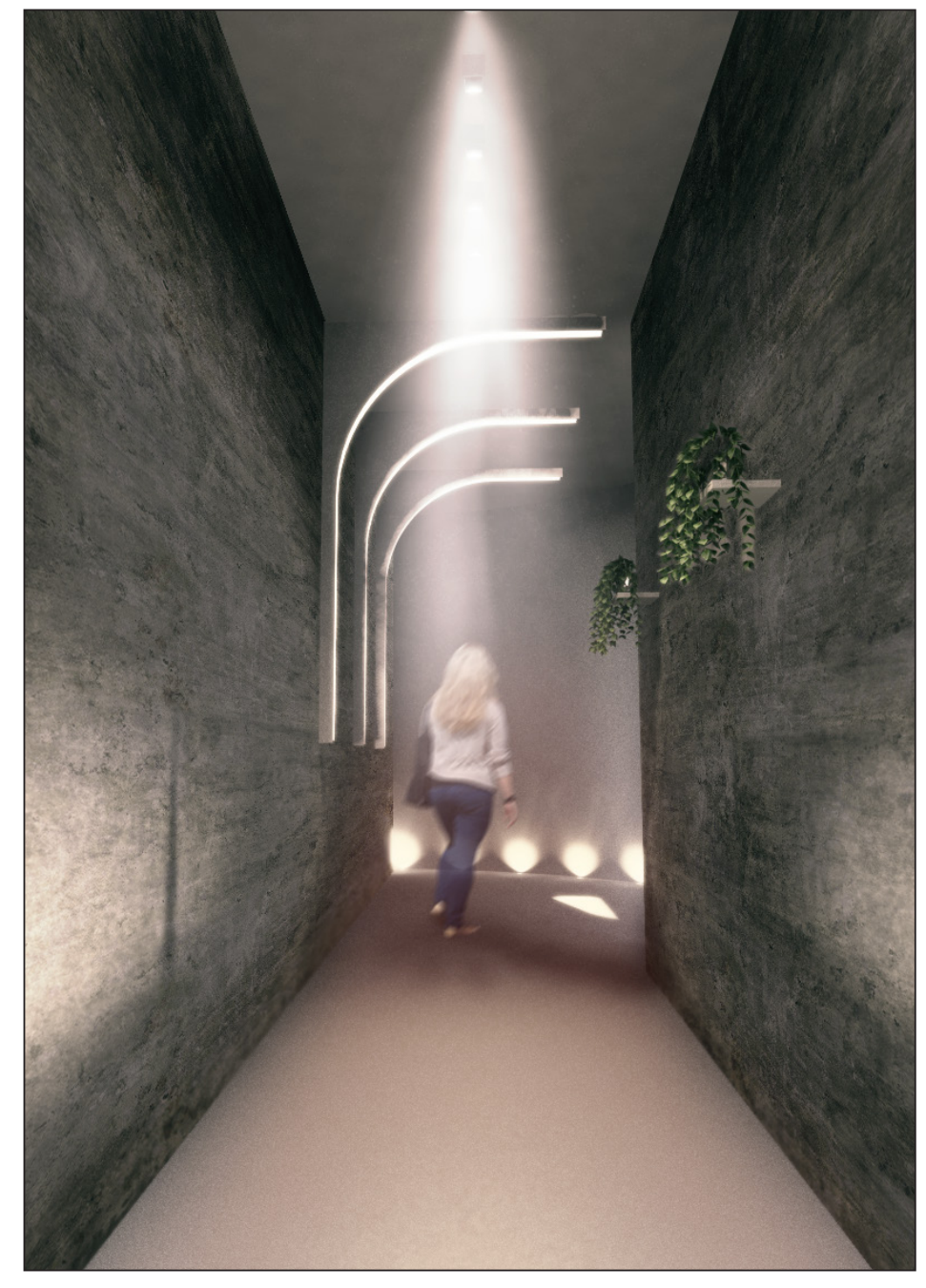

The development of the second

continuation of the establishment

of the dark slate walls in order

to maintain a theme throughout

the spatial experiential journey

of the entrance. The change in

the angled walls and reinforts

the sense of confinement. It

also incorporated the change in

material underfoot - influenced

by Wraight \& Associates in

their design of Waitangi Park

in Wellington - as the space

looks to encourage the pause in

momentum by way of altering

journey.

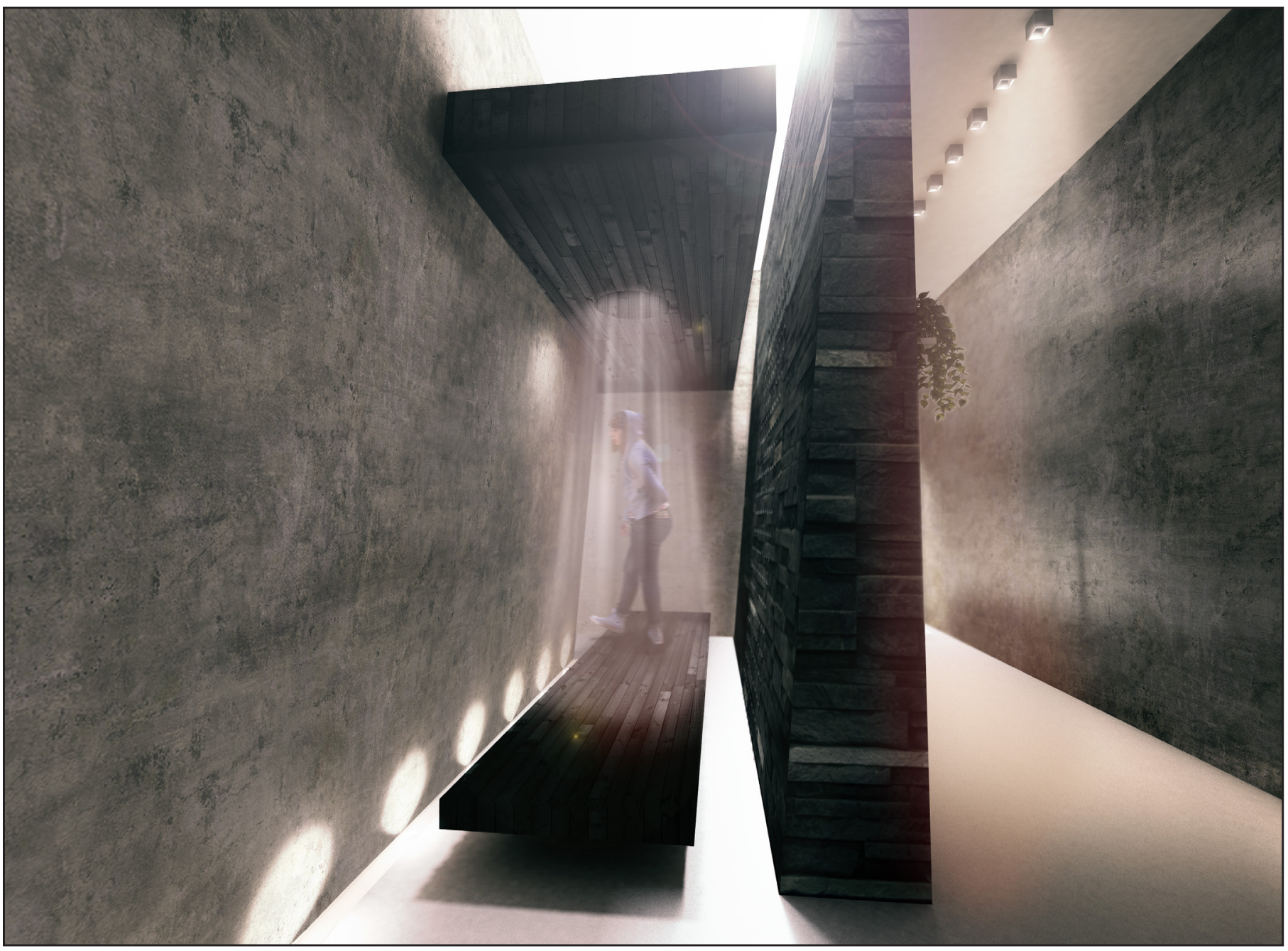


The development of the third point of pause (figure 6.96) looks to the prison environment through a heterotopic lens, as it establishes separation between the final stages of the honeymoon phase and the transitional experiences that follow. This is established through the design of the gate asitmimics the gates within historic maximum security corridor. The journey is guided by the continuation of the overhead cense of confinement that will be experienced in the next transition phase within prison cell Artifiel lighting along the left hond wall contrasts the natural lighting on the right as they meet in the middle to light the path to the first experience of the prison environment beyond the entrance. This contrast in light is representative of the Honeymoo phase drawing to an end, as the warm artificial lighting on the left cease to exist beyond the gates where it is replaced by the more harsh natural light of the outdoors.

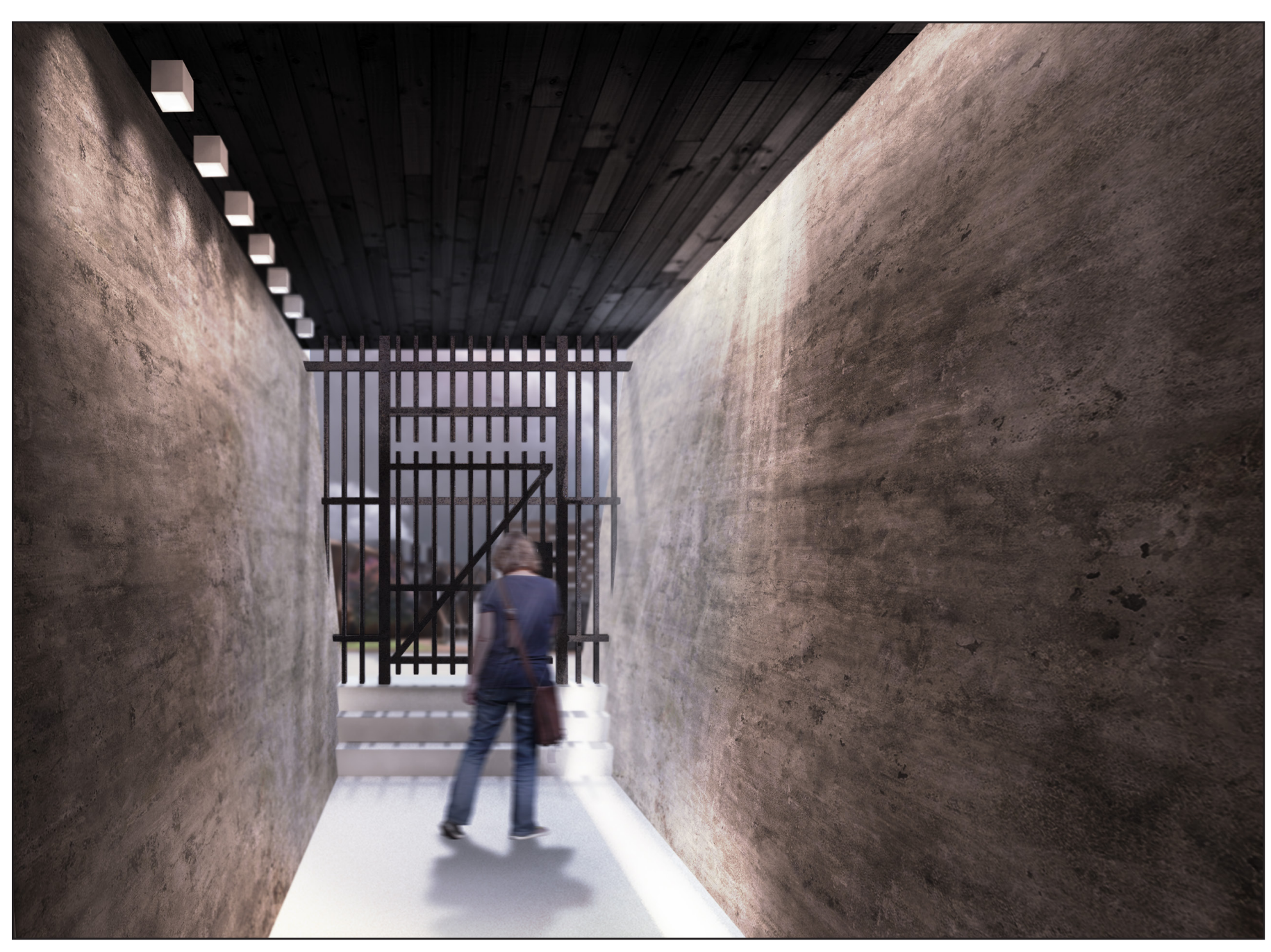




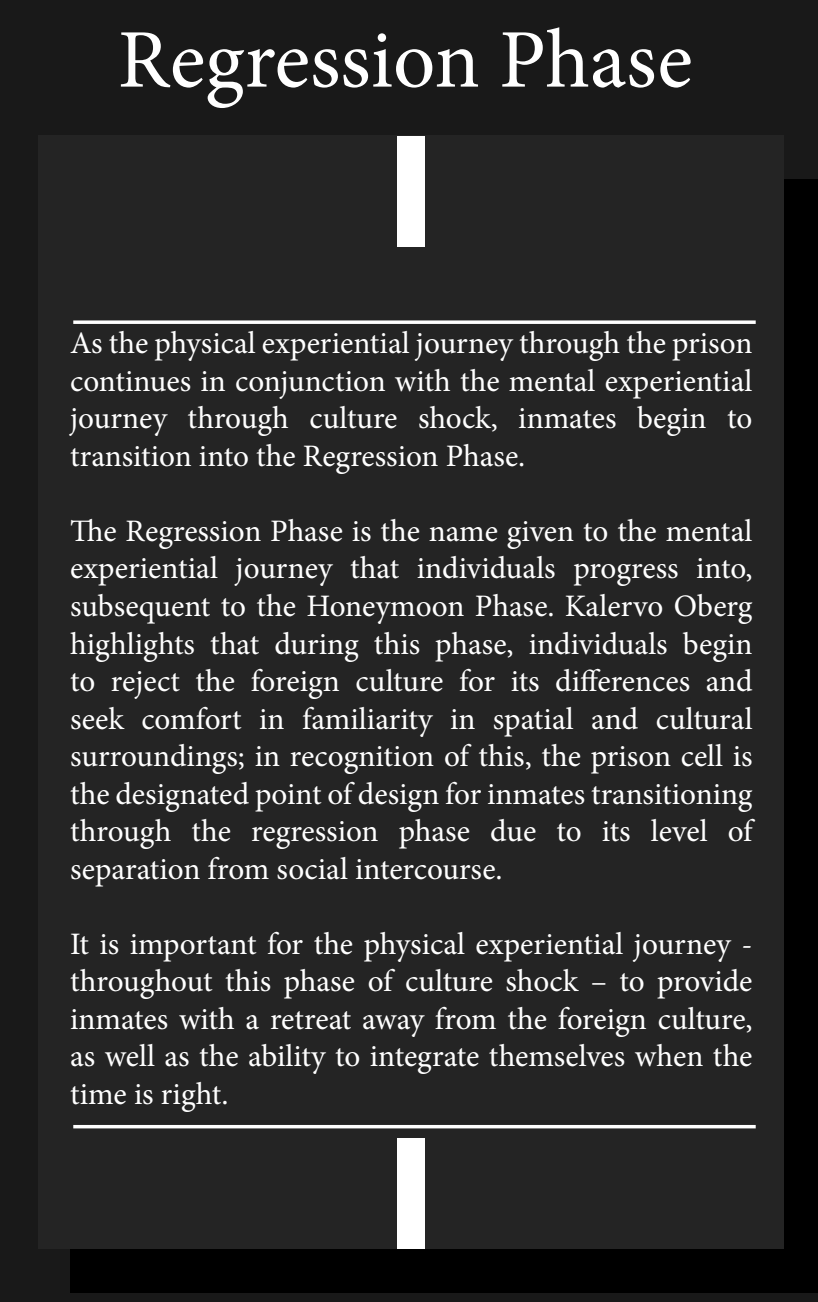

Prison Cell

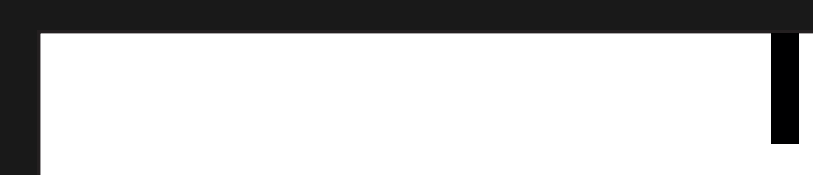

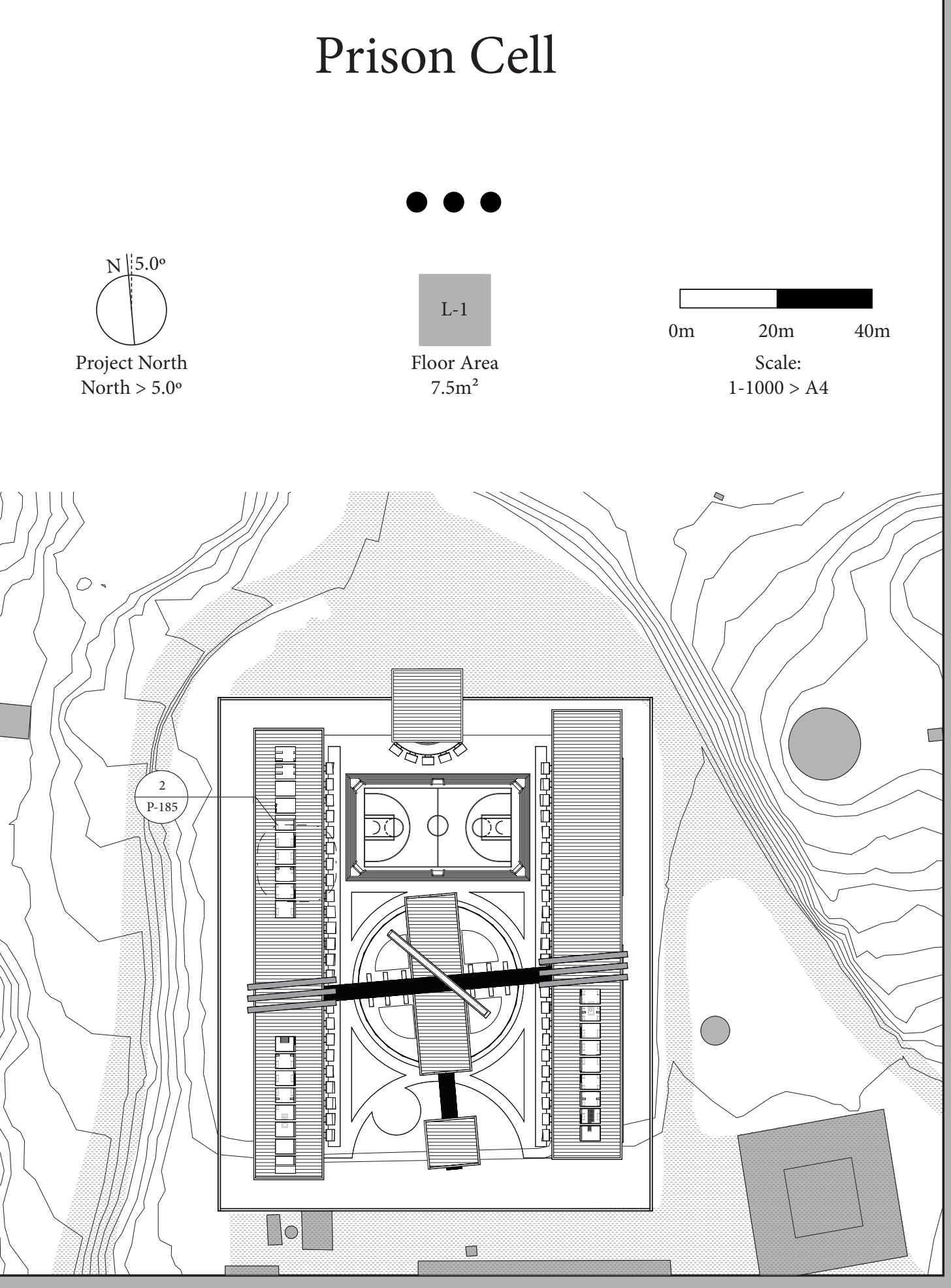



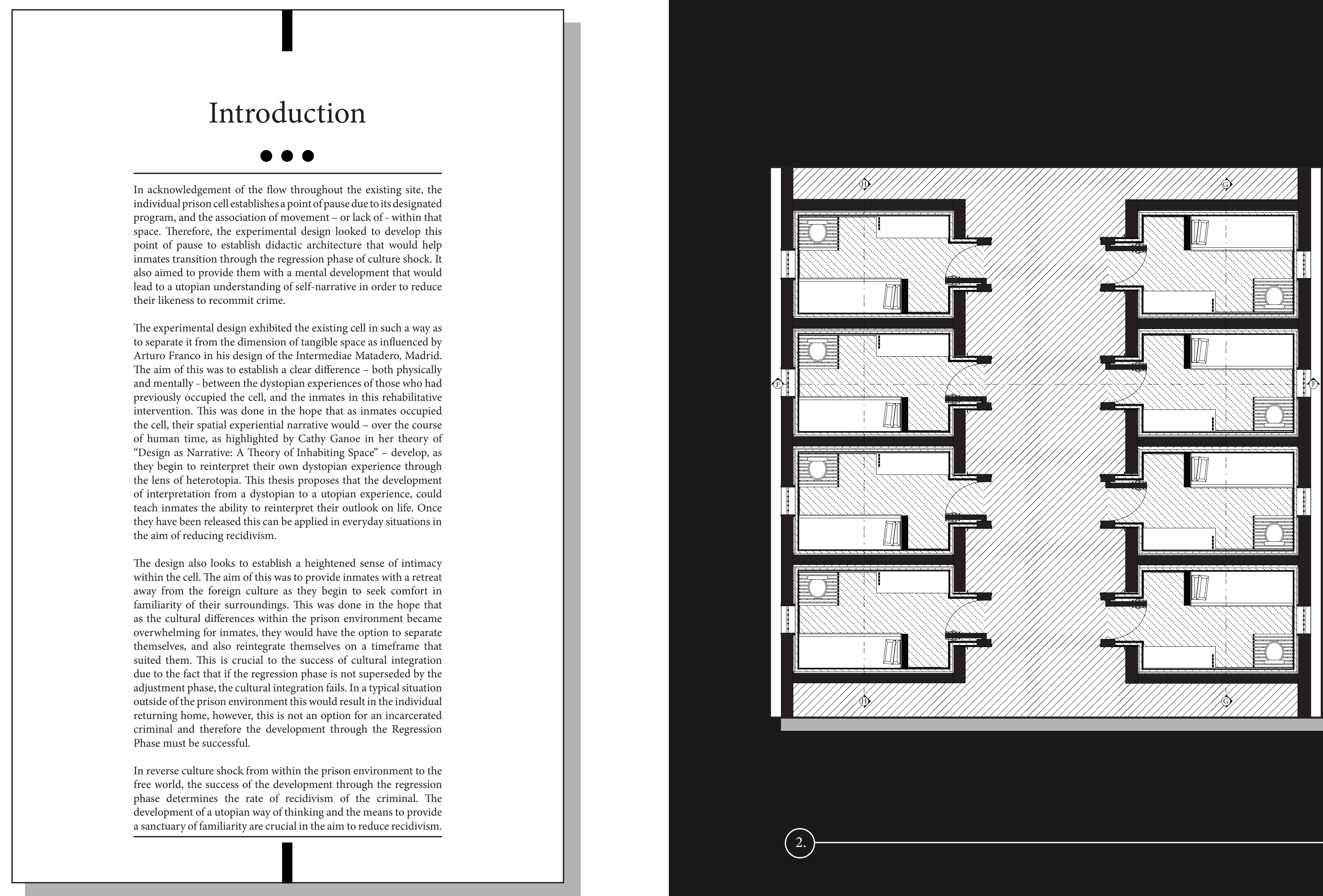

(2.) 
Sections
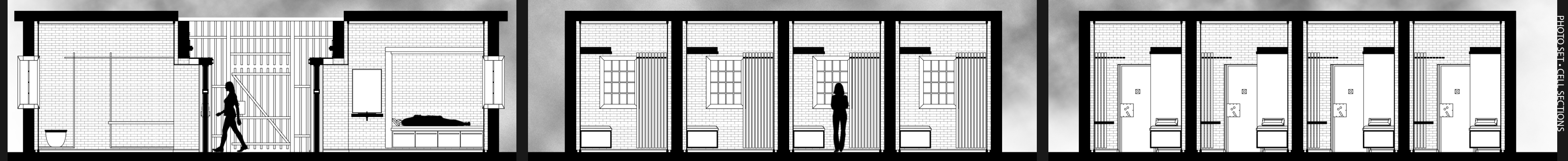

Section: $\mathrm{F}$
Scale - 1:100

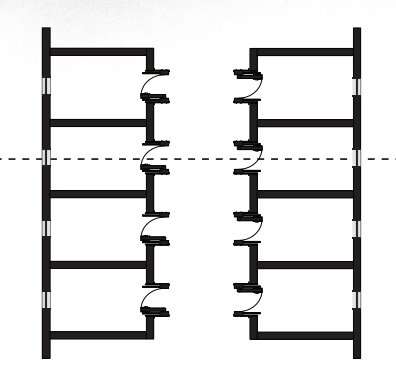

IIIIIT

红巧
IIIIIT

【โ'工ิ 
In a critical reflection of the experimental design, it was established that the separation of dystopian experience from in its ability to divide the cell physically - did not highlight the separation in experiential difference within the cell strongly enough. This was due to a lack of material contrast as a result of the design process techniques used in the experimental design.

The developed design establishes a clear contrast between spaces within the cell, and the experiential narrative within them. It does this through the use of digital rendering software and the application of materials as a tudy. Artificil lighting iterial manipulated to draw is also to this experiential difference as it follows the path around the perimeter of the existing cell, inhabiting the intangible space. As the graffiti, and the story of the existing walls is written through a of all places - the design now clearly depicts the experiential differences for their dystopian and utopian qualities.

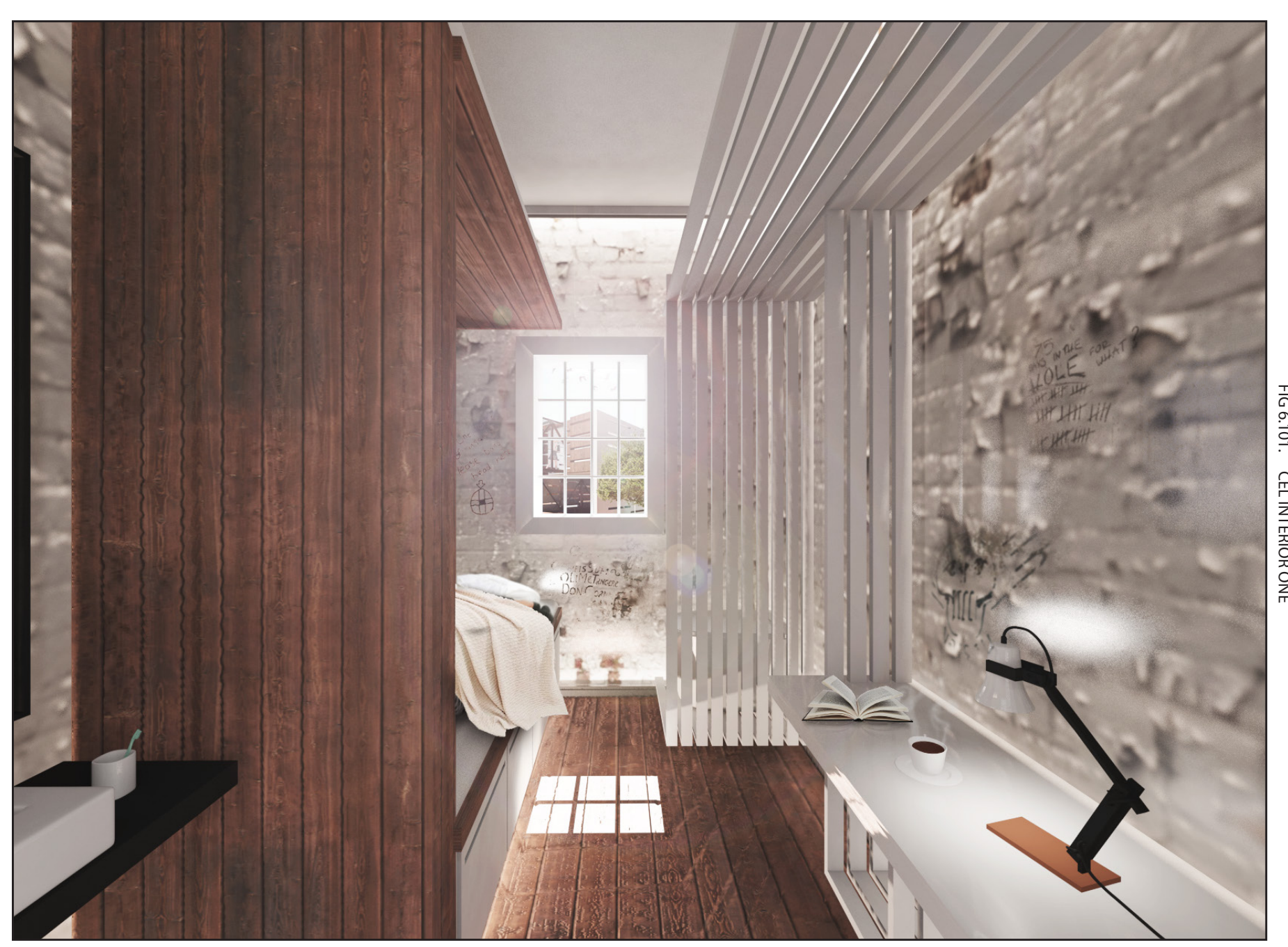



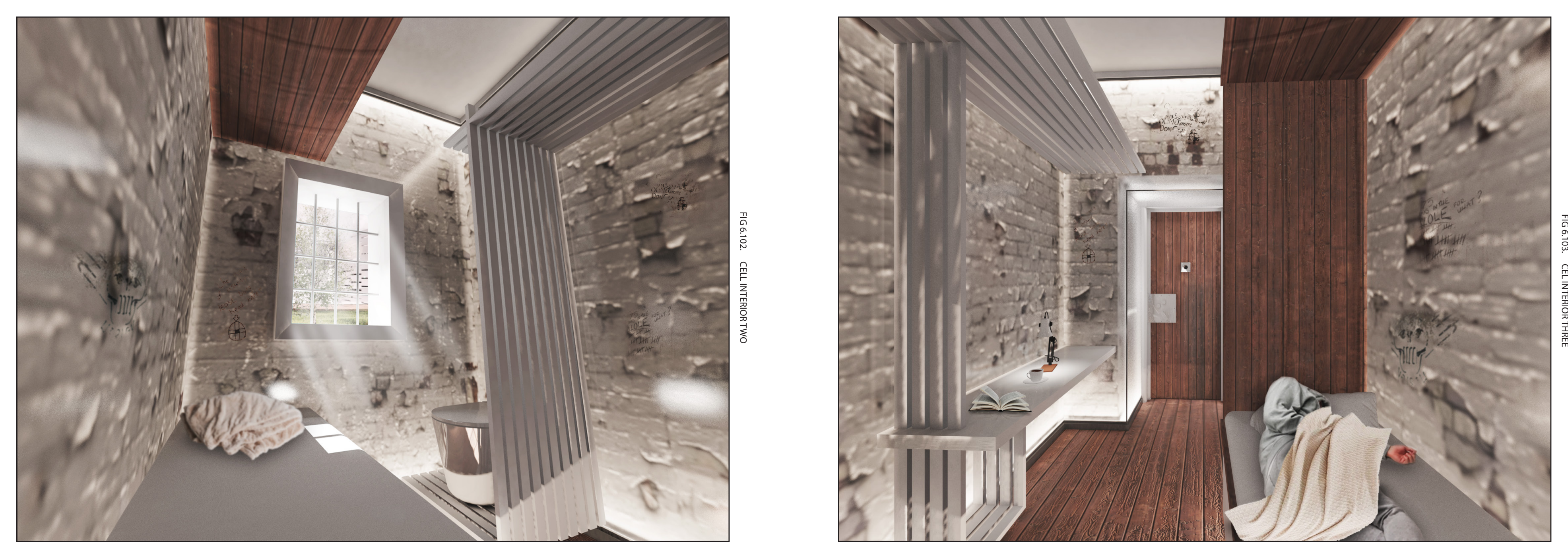
Adjustment Phase

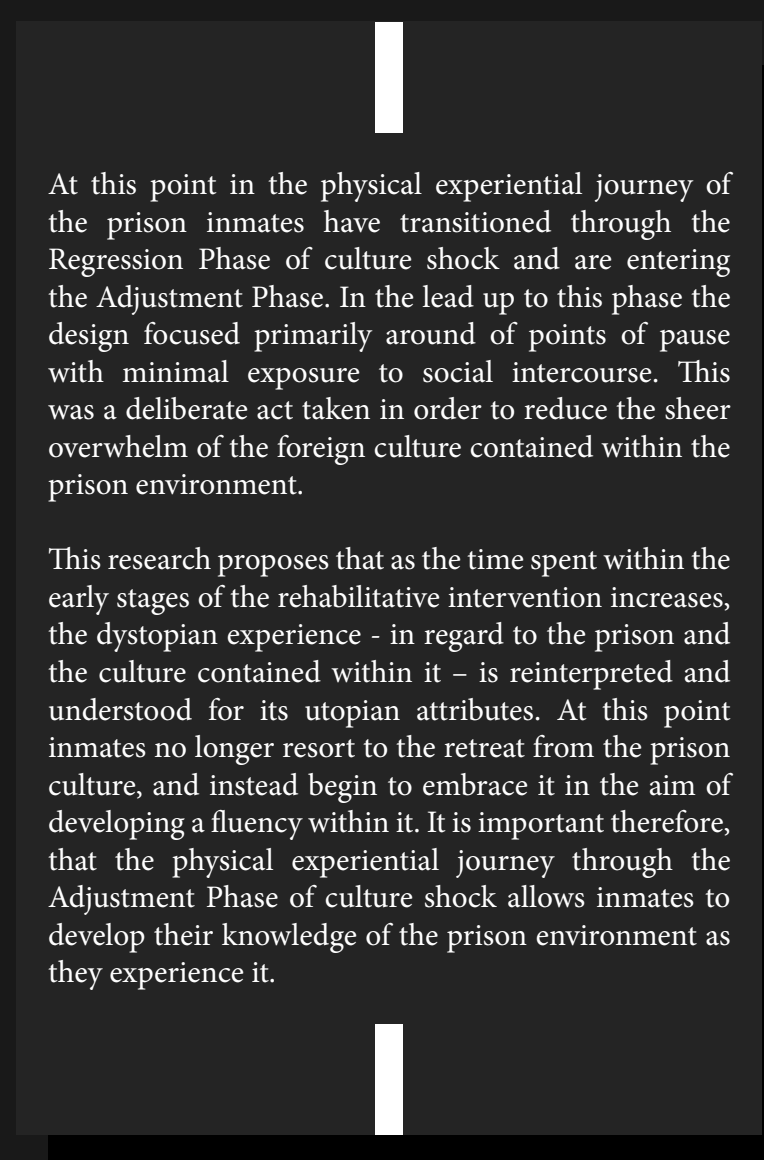

\section{Prison Circulation}

and are entering

design focused pringily arond of points of pause

exposure to social intercourse. This 政 prison environment.

This research proposes that as the time spent within the ges of the rehabilitative intervention increases, the dystopian experience - in regard to the prison and to 列 I

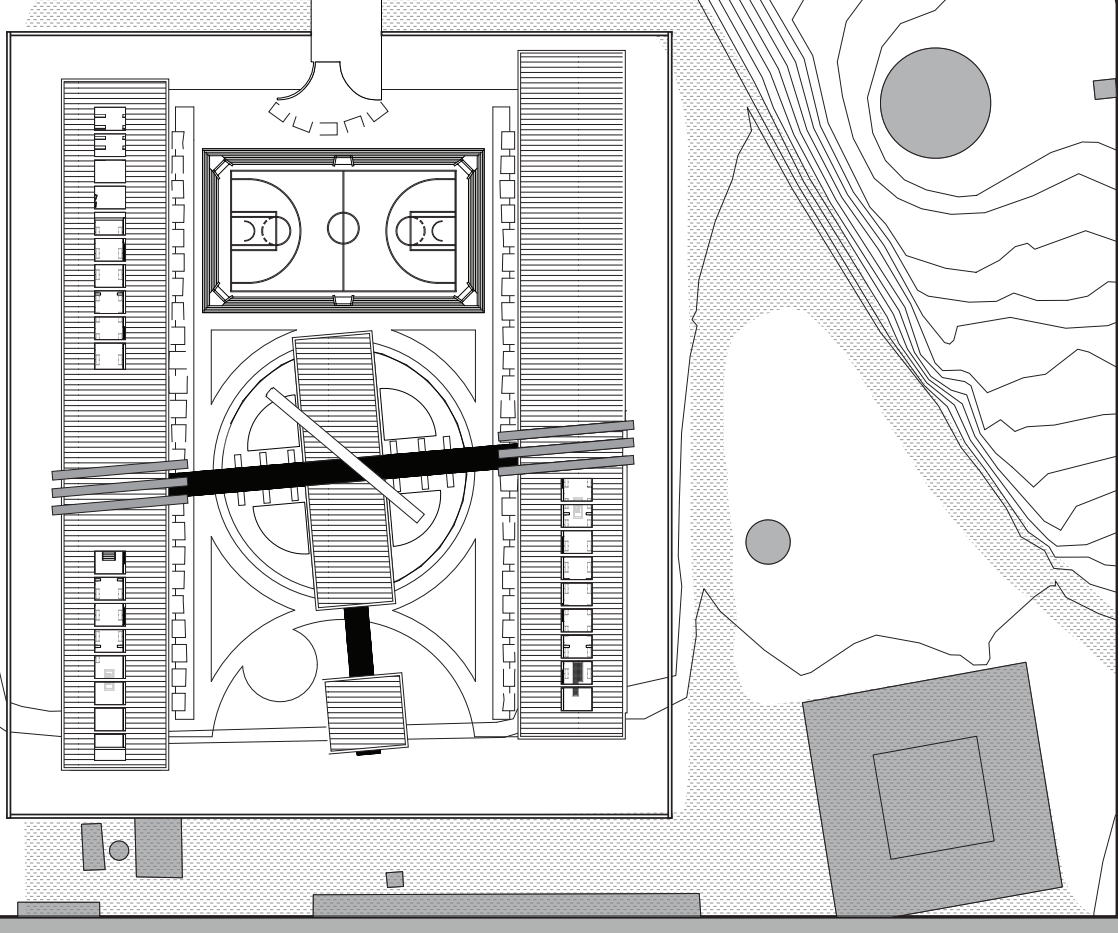



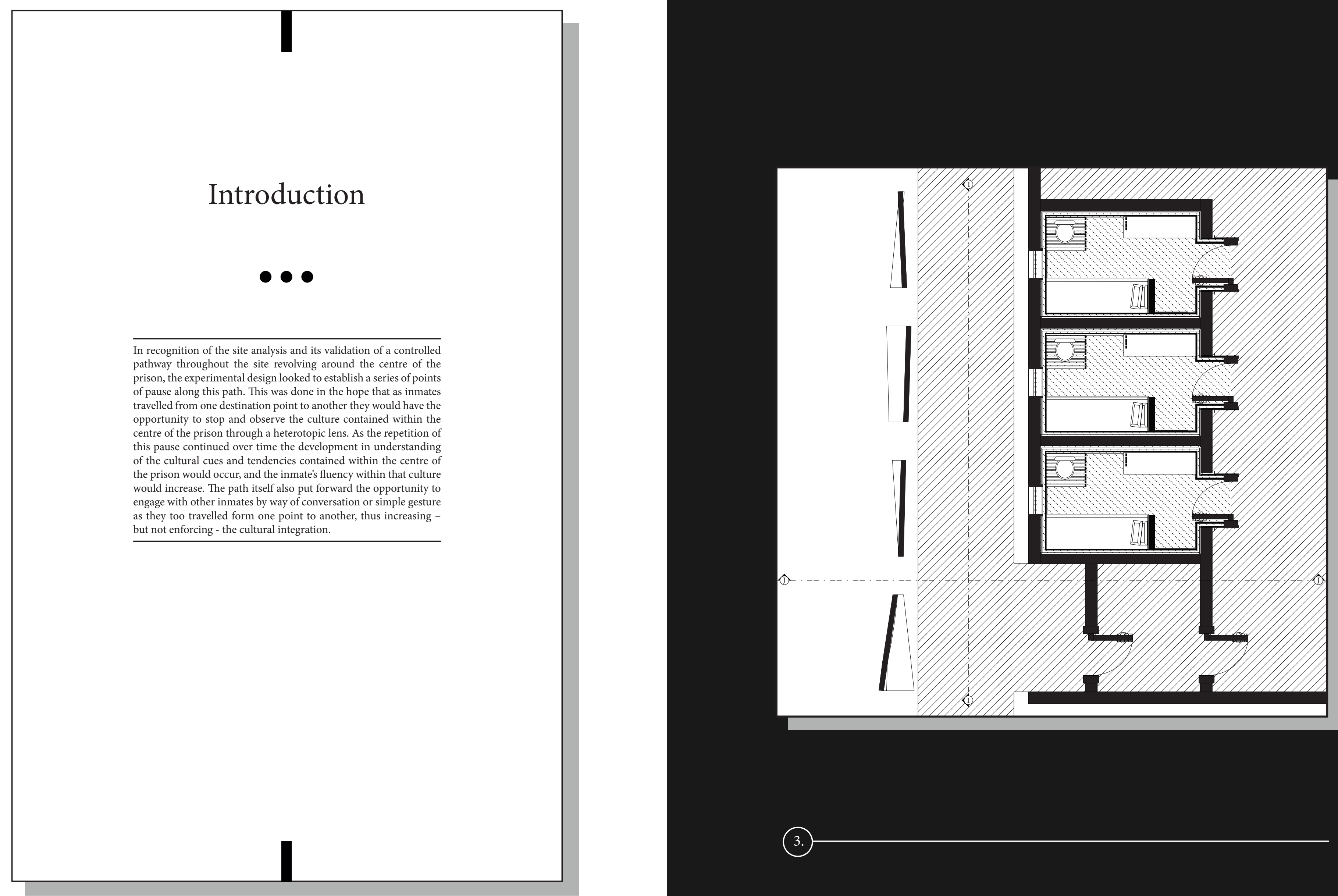
Sections
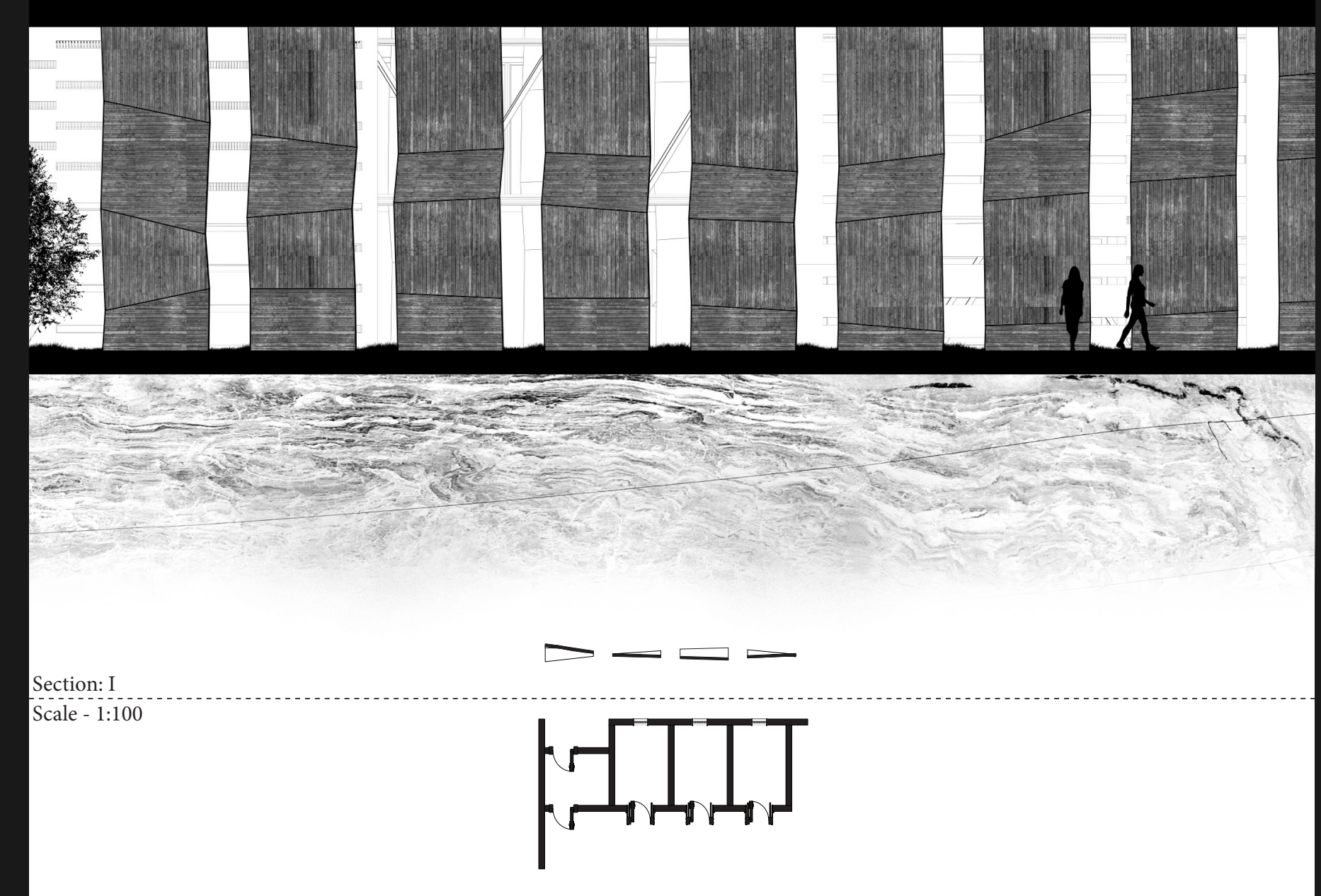
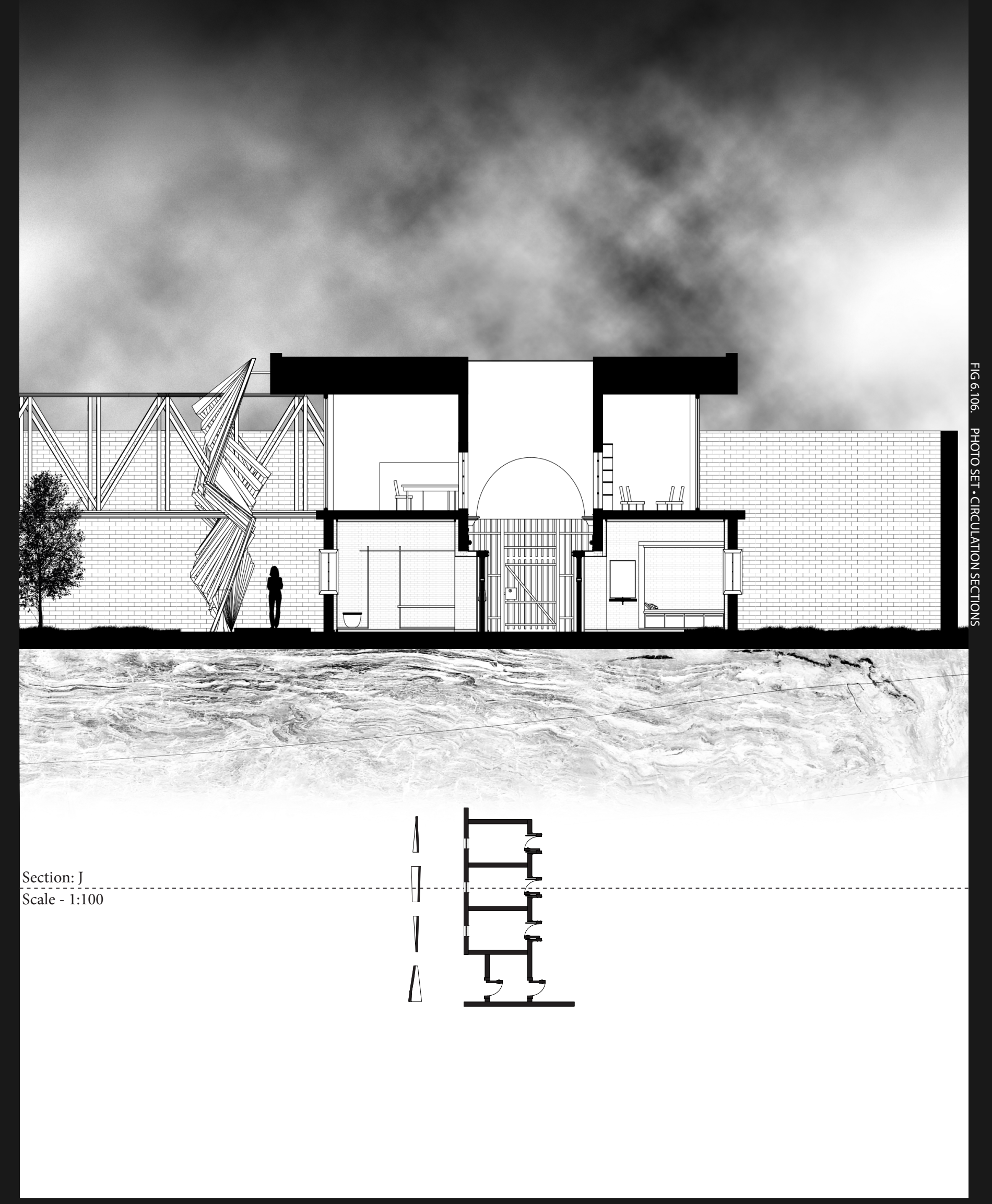


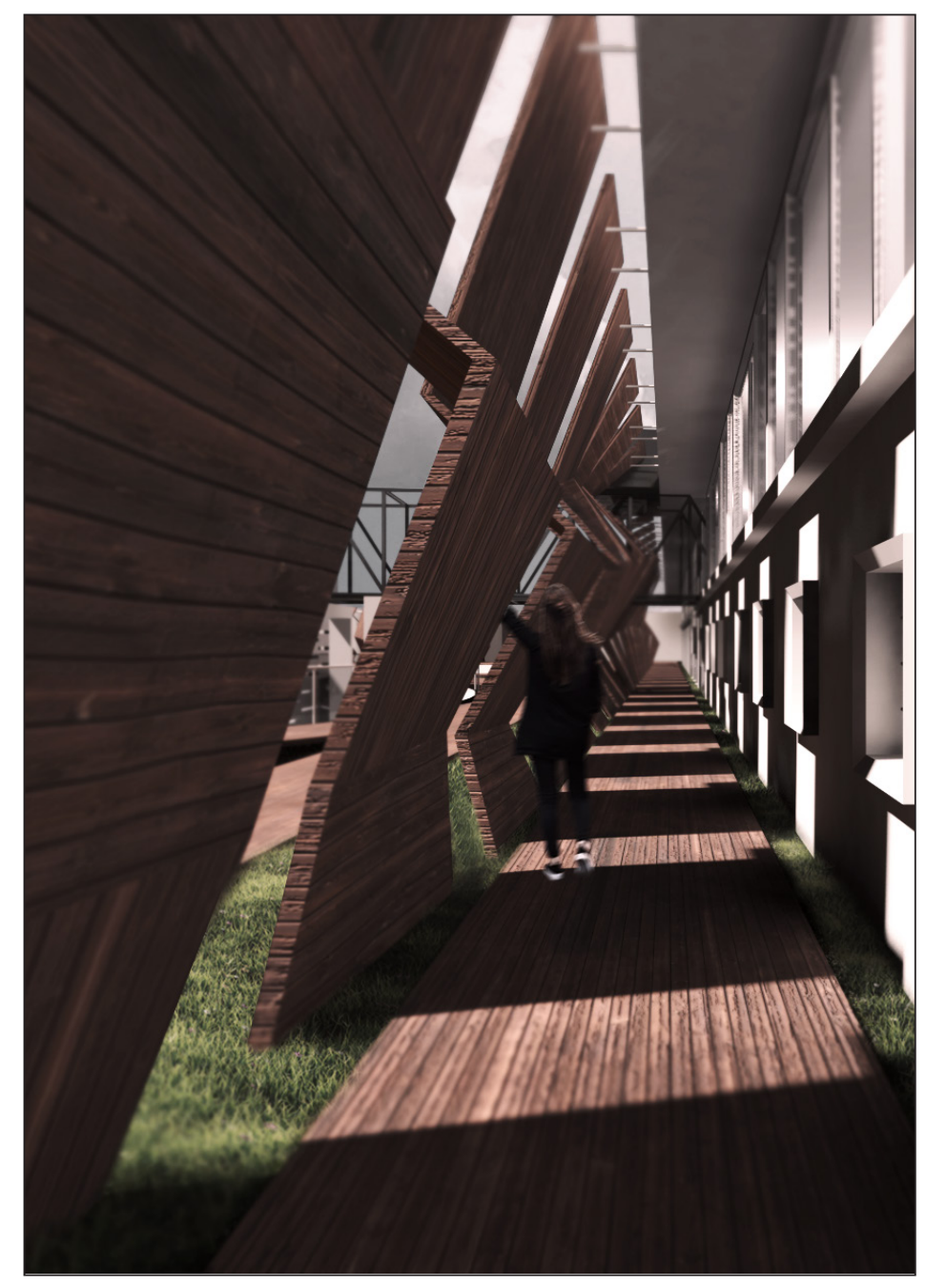

The developed design aims to encourage the inmates transition culture shock into the adjustment phase, as well as, provide them with the opportunity to learn more about he culture contained this by establishing a seamless transition in spatial experiential journey from the prison cell corridor into the outdoors, and the corresponding social intercourse. The wooden floorboards of the cell corridors continue on a path shielded from observation by the tall fragmented facade. It is from behind this facade that inmates can observe the culture within the prison centre from safety of the shadows. As inmates begin to venture into the prison centre, the pathways that guide the jouns altor in their material by Wraight \& Associates Landscape Architecture - in their design of Waitangi Park in Wellington - and symbolises the transition in mind set as inmates begin to further develop their fluency and acceptance of the the prison environment.

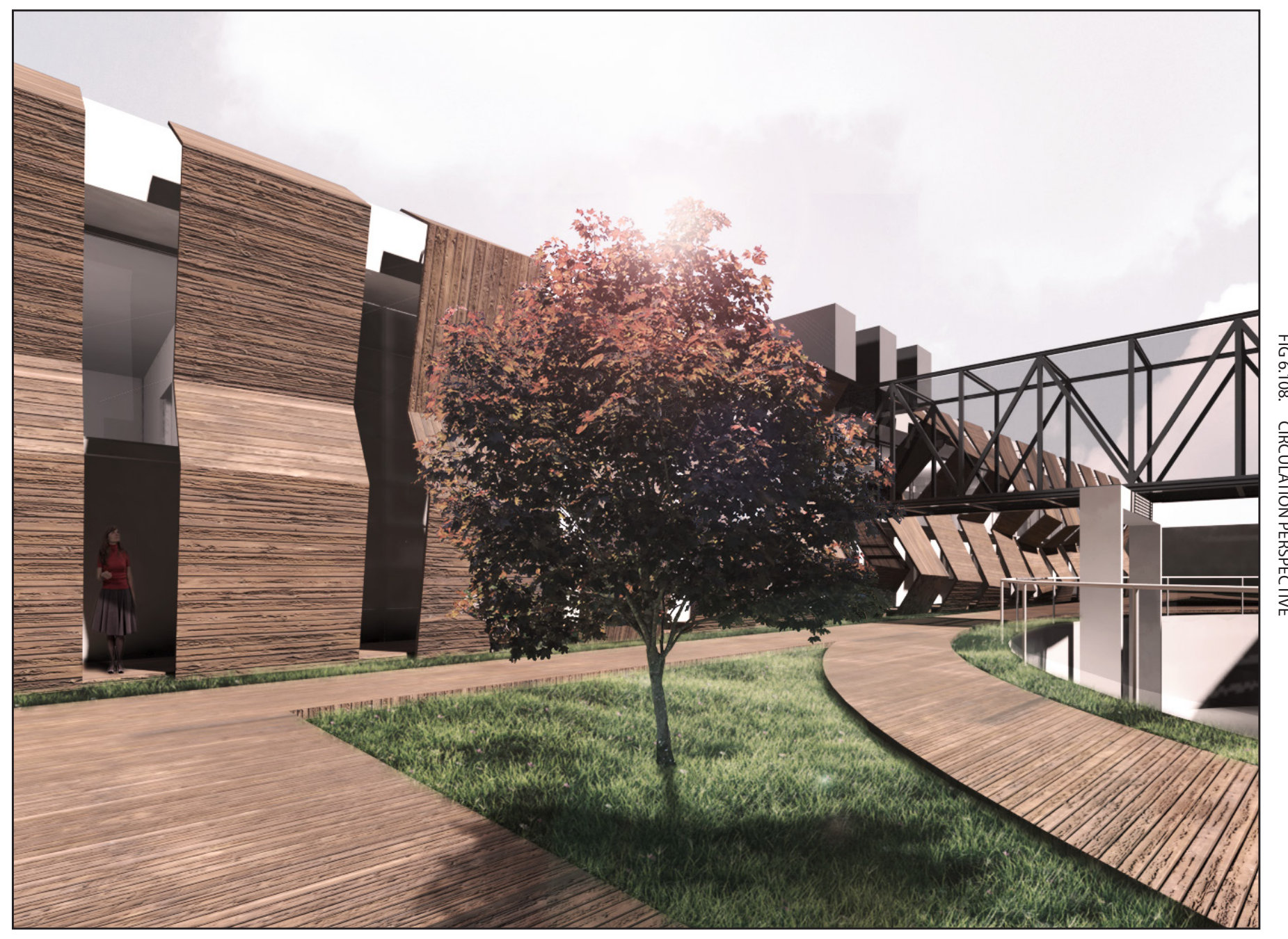




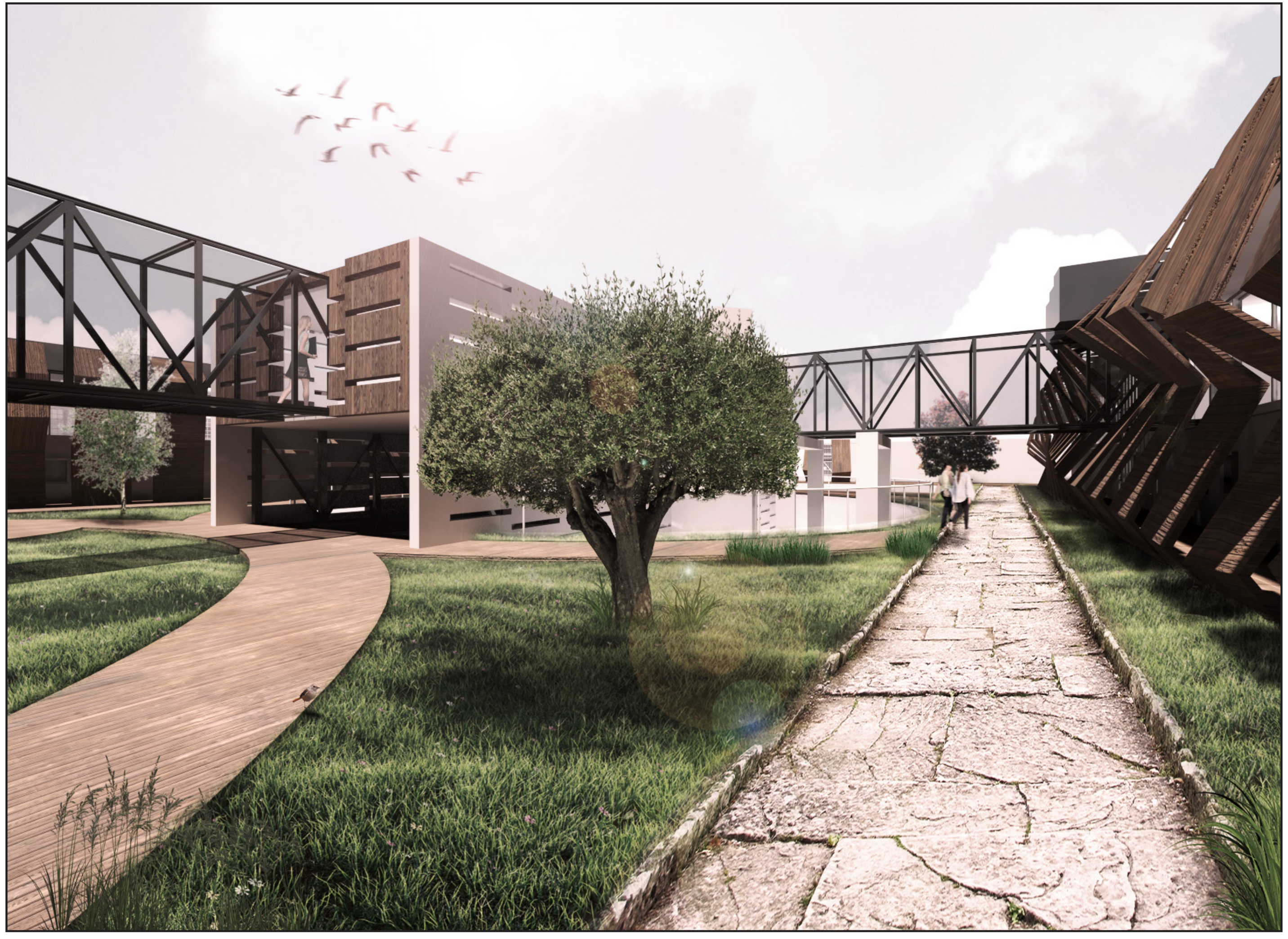




\section{Acceptance Phase}

\section{Prison Centre}

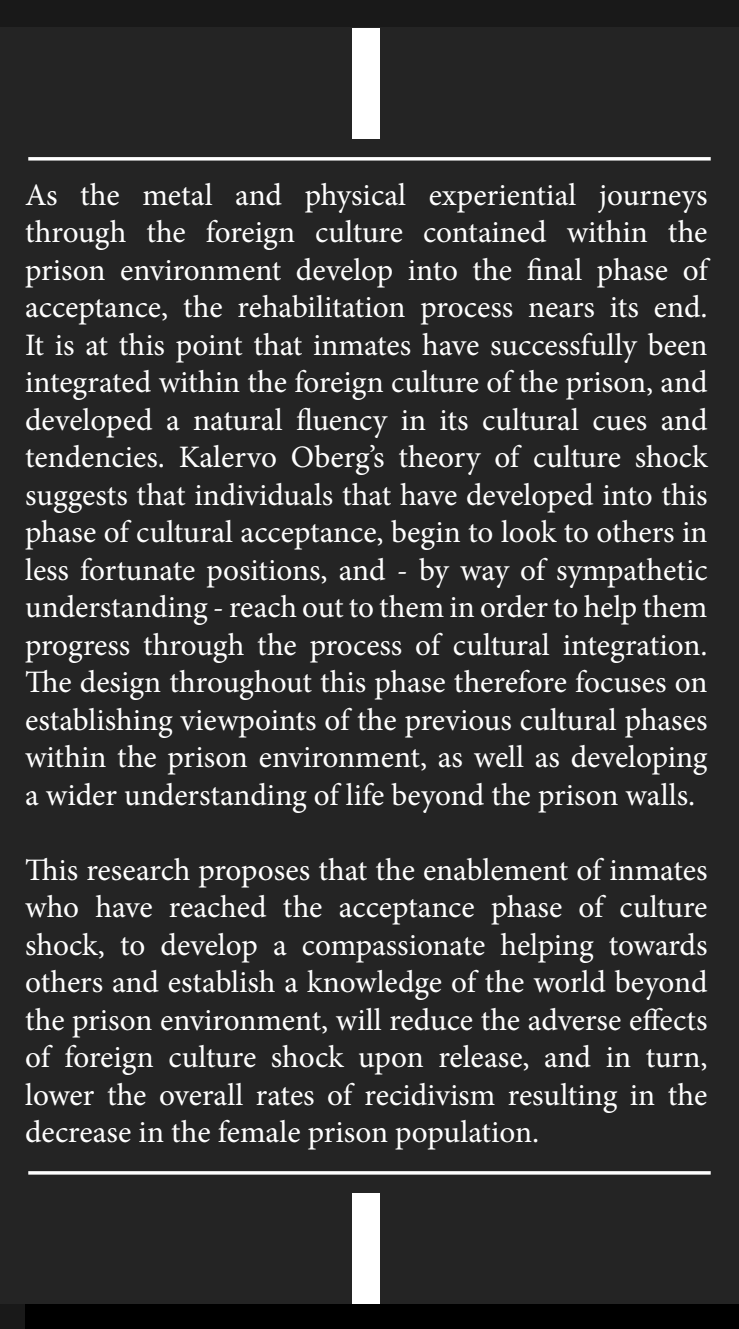

\section{-ys ,

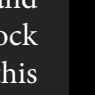

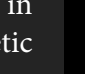 .

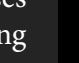

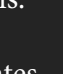 . . .} end. and .

the prison environment, will reduce the adverse effects
of foreign culture shock upon release, and in turn, lower the overall rates of recidivism resulting in the I

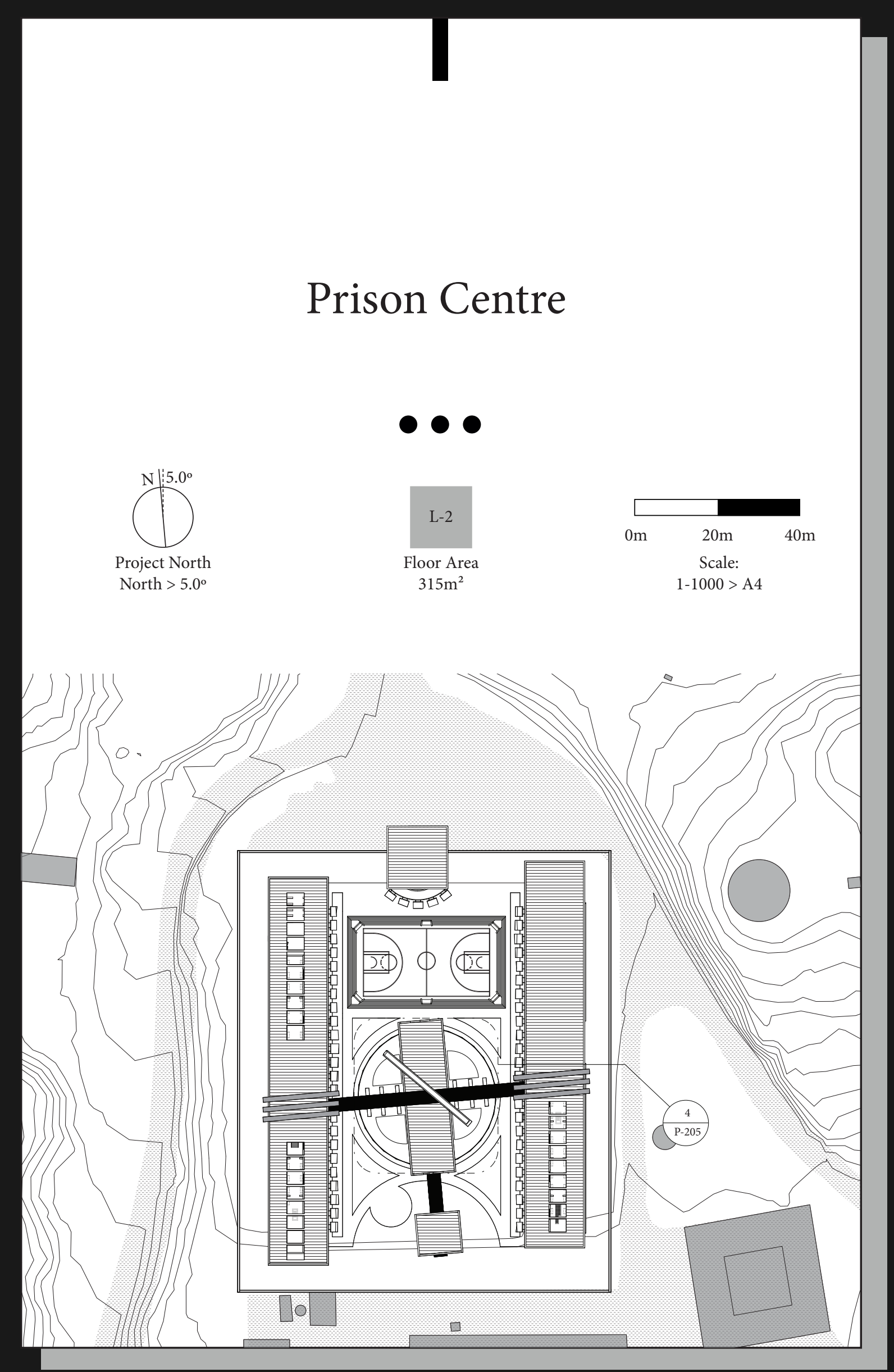



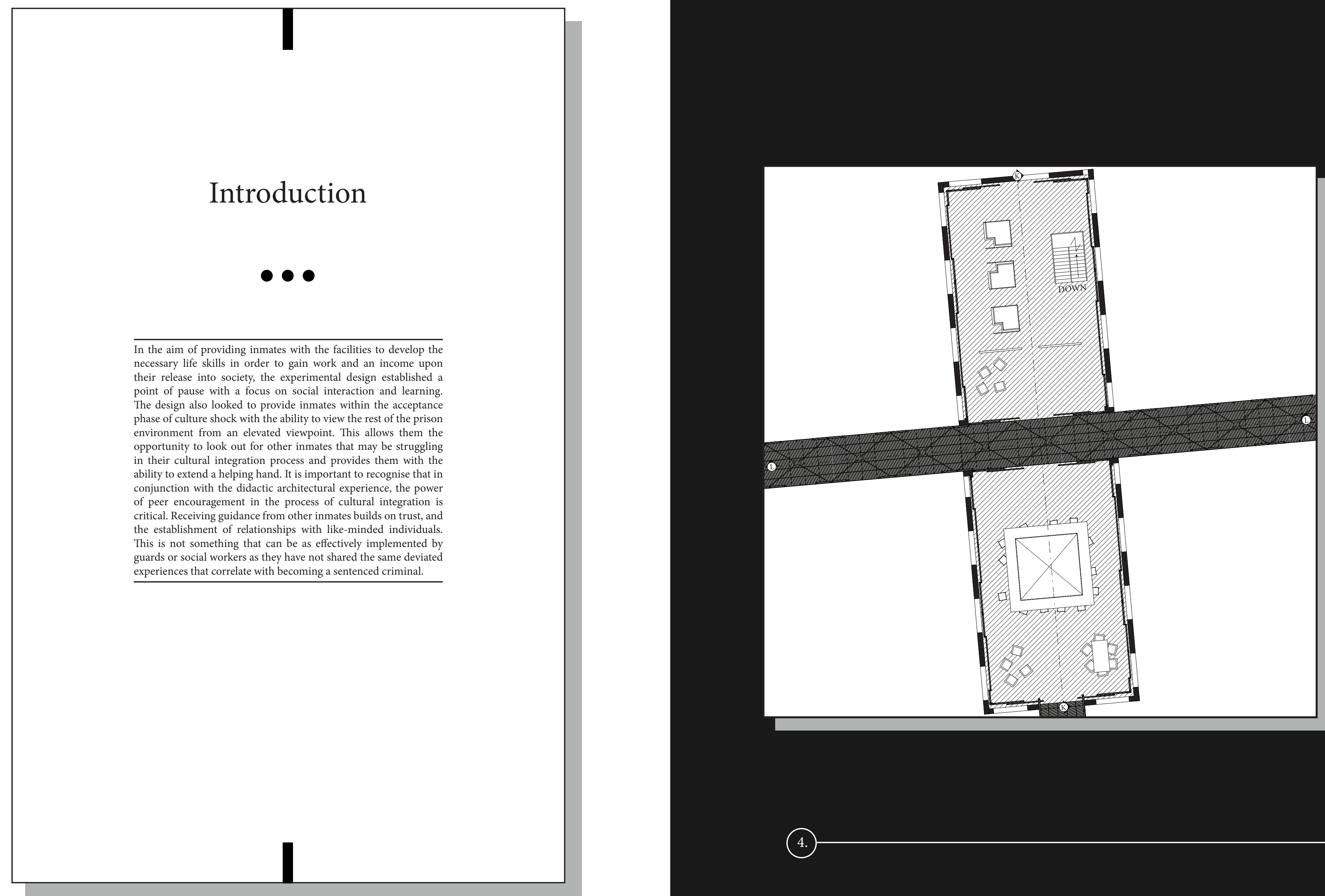

(4.) 
Sections

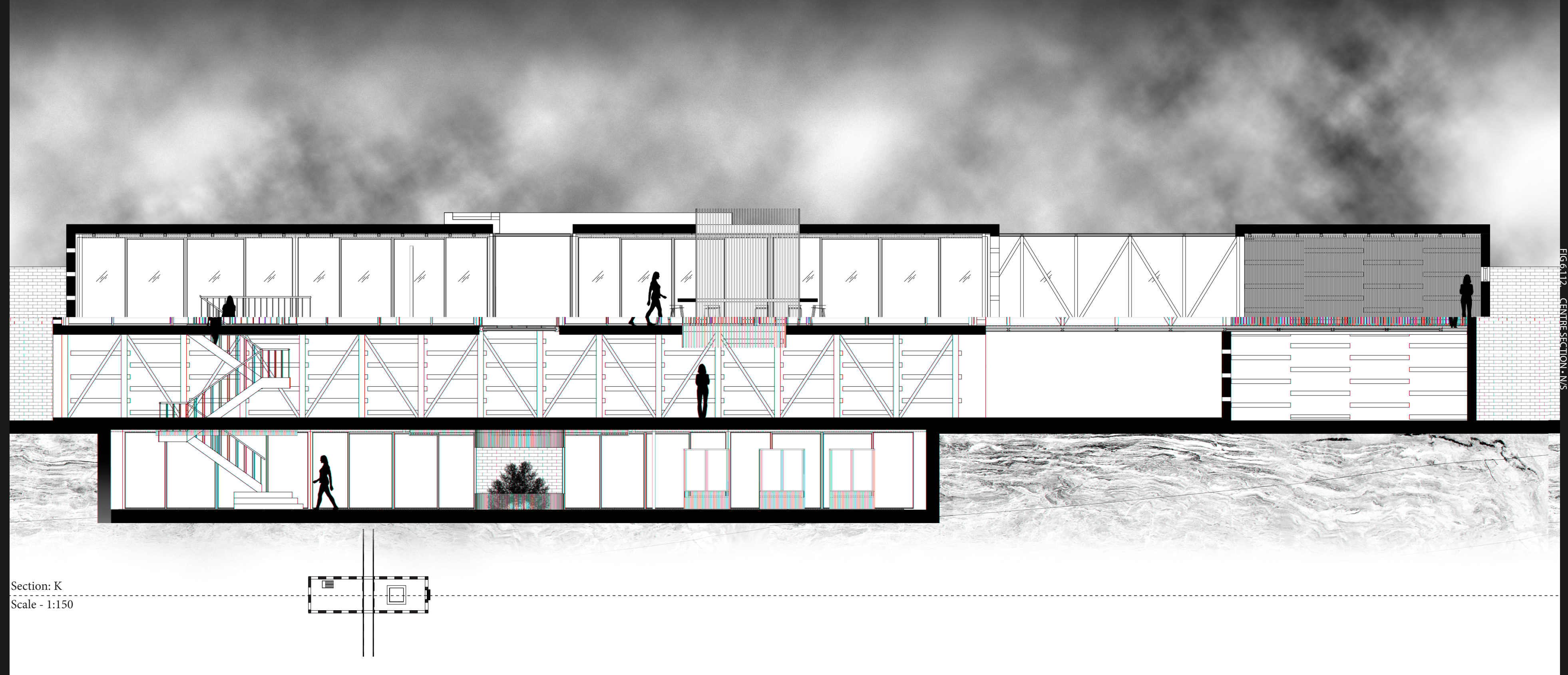


Sections

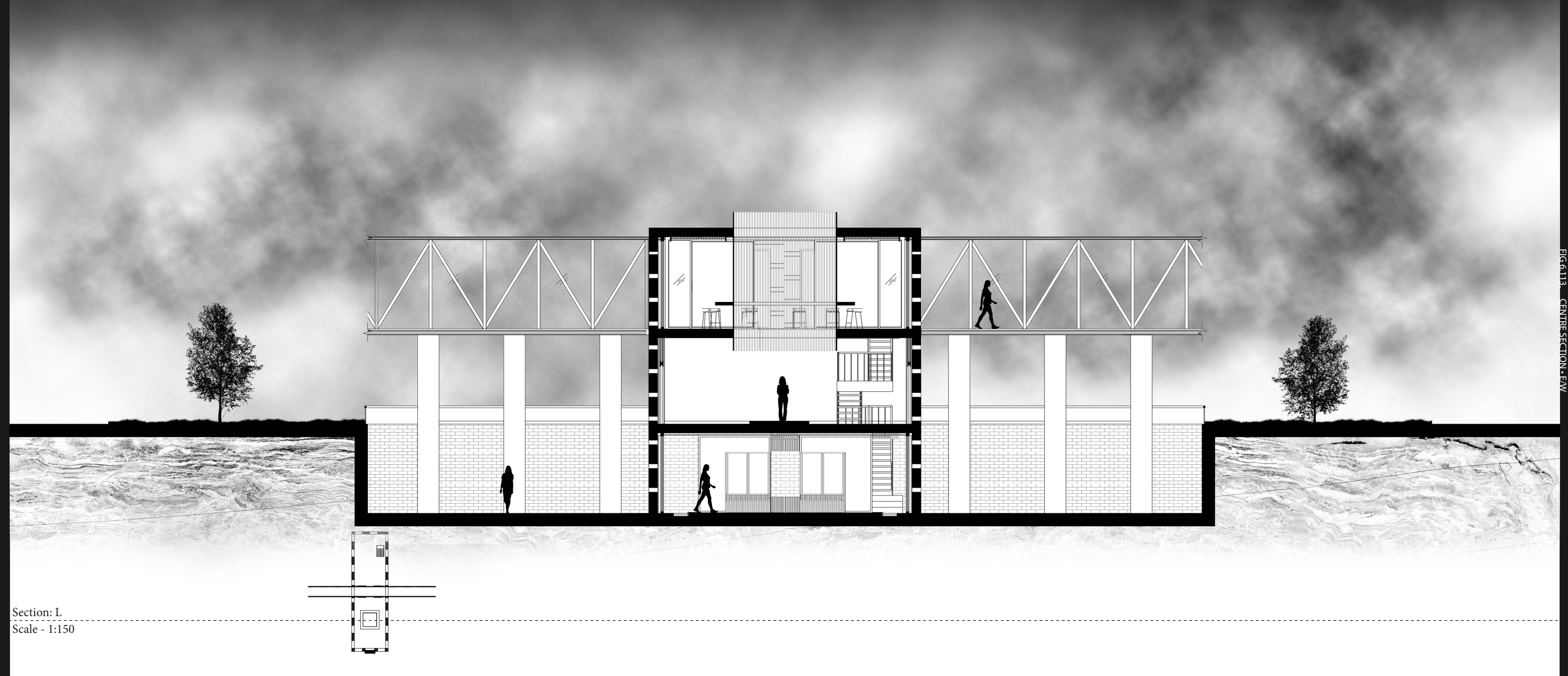




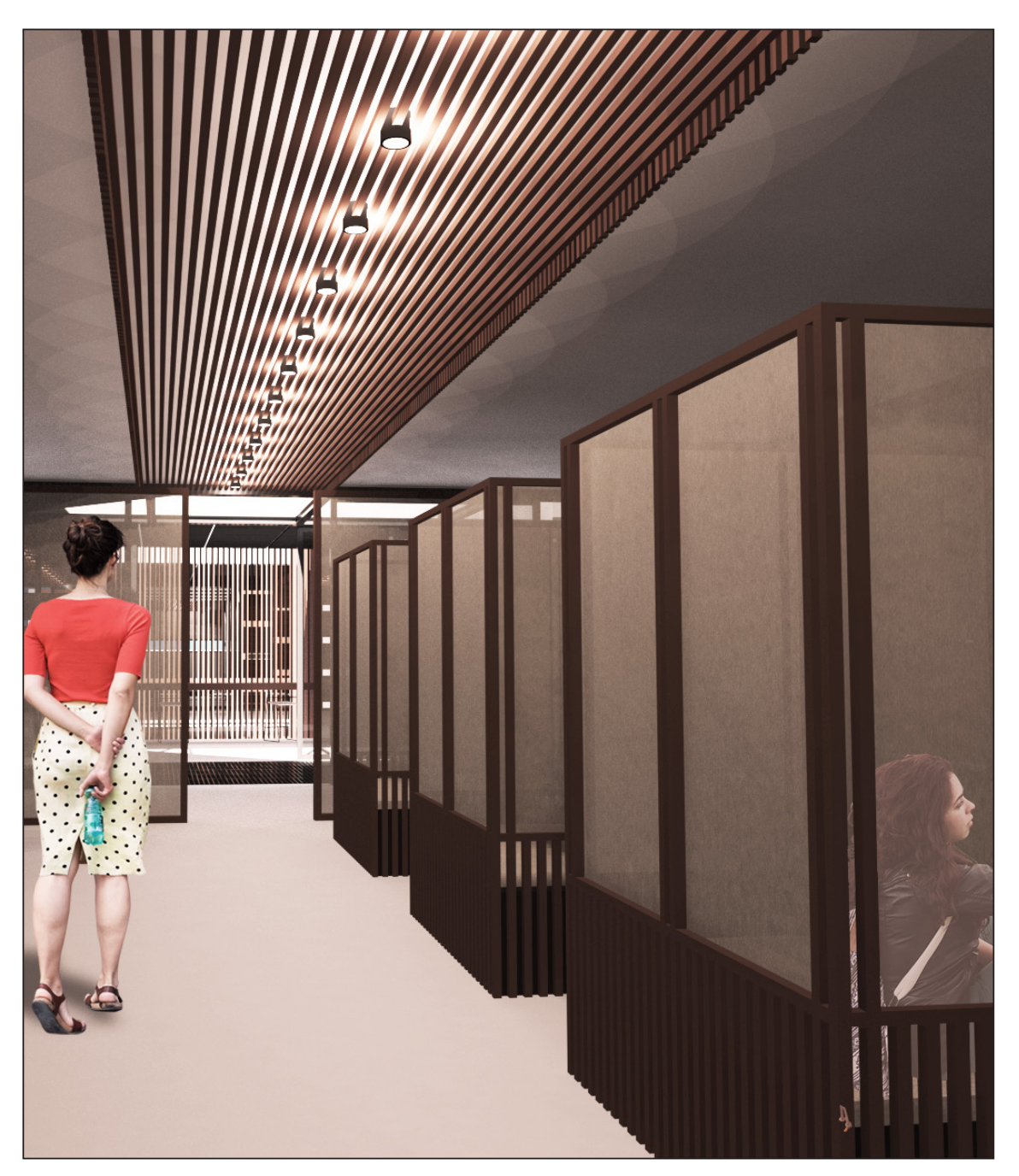

The development of the elevated level of the prison centre saw the establishment of adjacent features that aimed to guide inmates towards the intended point of pause. The space opens to a series of private booths that ace the exterior walls. These for women with children and it is here that the building of relationships with society begins. These spaces, while providing an levated sense of privacy, also allow for strict supervision as the open floor plan and mildly fransparent partitions maximise advances towards the point of pause aimed at establishing a learning environment for inmates, the crossing of paths occurs. This is influenced by Wraight \& Associates Landscape Architecture in their design of as the crossing of paths is used to identify alternative journeys. This spatial and experiential advancement is also emphasised by the change in ceiling material. The black ceiling tile is used to define the space of learning, as well as emphasise the views to both the sky above, and the view

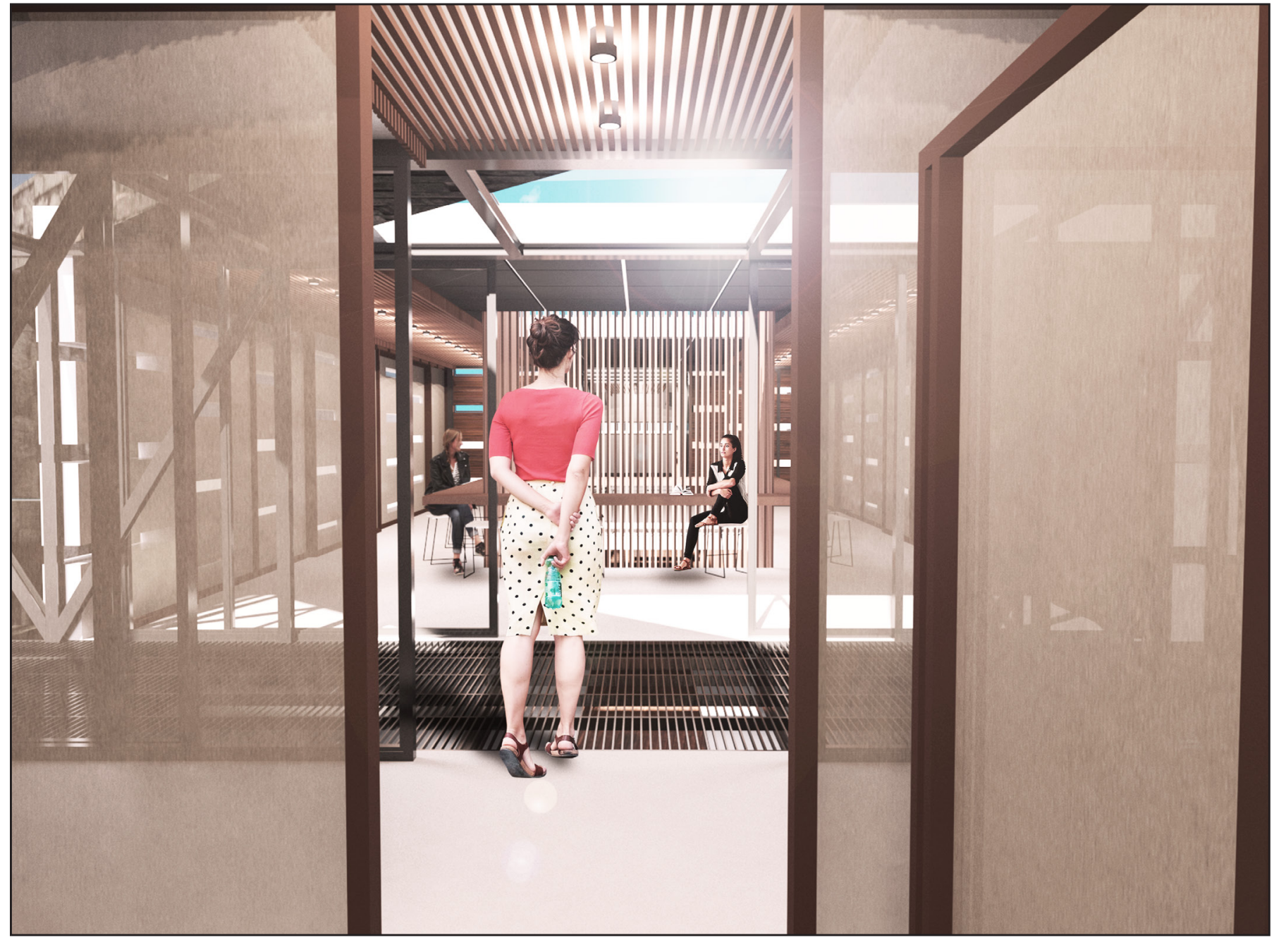

to the ground floor below. While the partitions that line the void in both the ceiling and the floor divide the tangible from the intangible space, they also draw attention to the exterior environment in the hope that inmates will observe the activities taking place below. This is done in the hope that as inmates in the final phase of culture shock observe their peers in the prior phases through a heterotopic lens, they can identify individuals that may be struggling to adapt to the prison culture, and look to assist them through the knowledge that they have acquired. As each inmate shares experiential similarthes in the process of cultural integration within the prison environment, hey are able to more strongly relate to each other, as opposed to social workers tasked with the aid of criminal rehabilitation. This research recognises the importance of the 

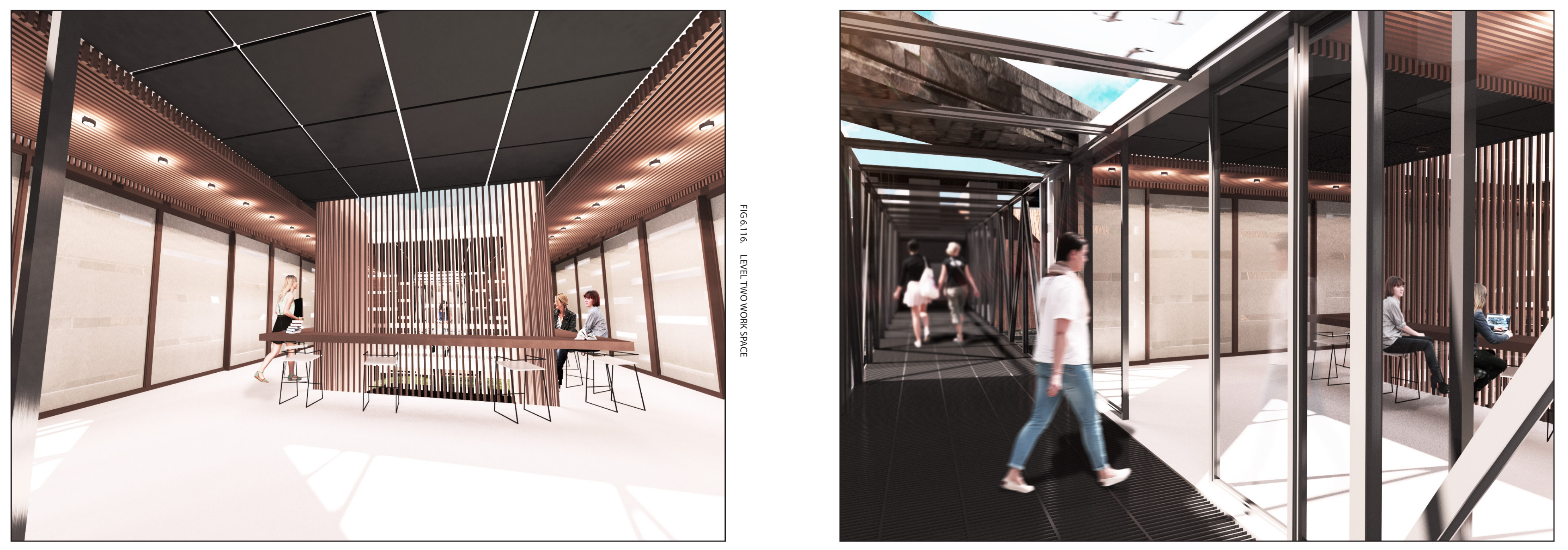


\section{Acceptance Phase}

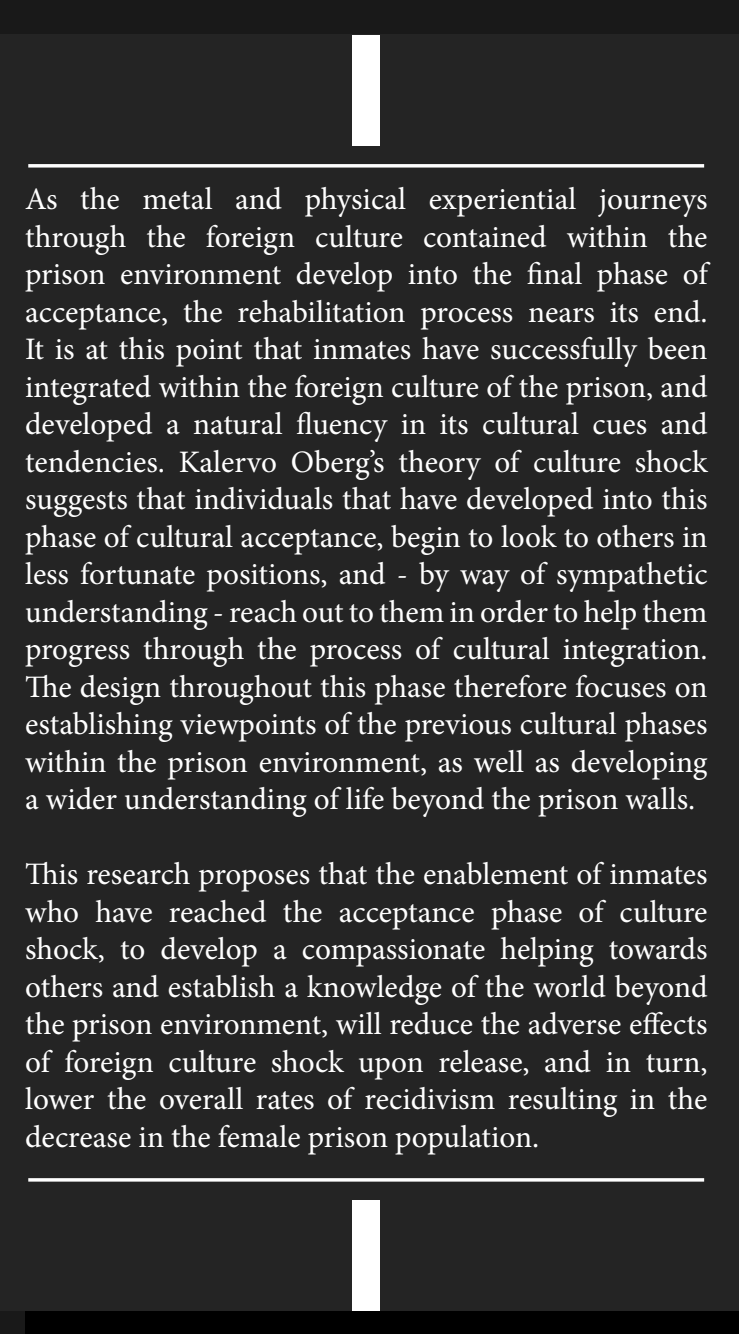

\section{Prison Centre}
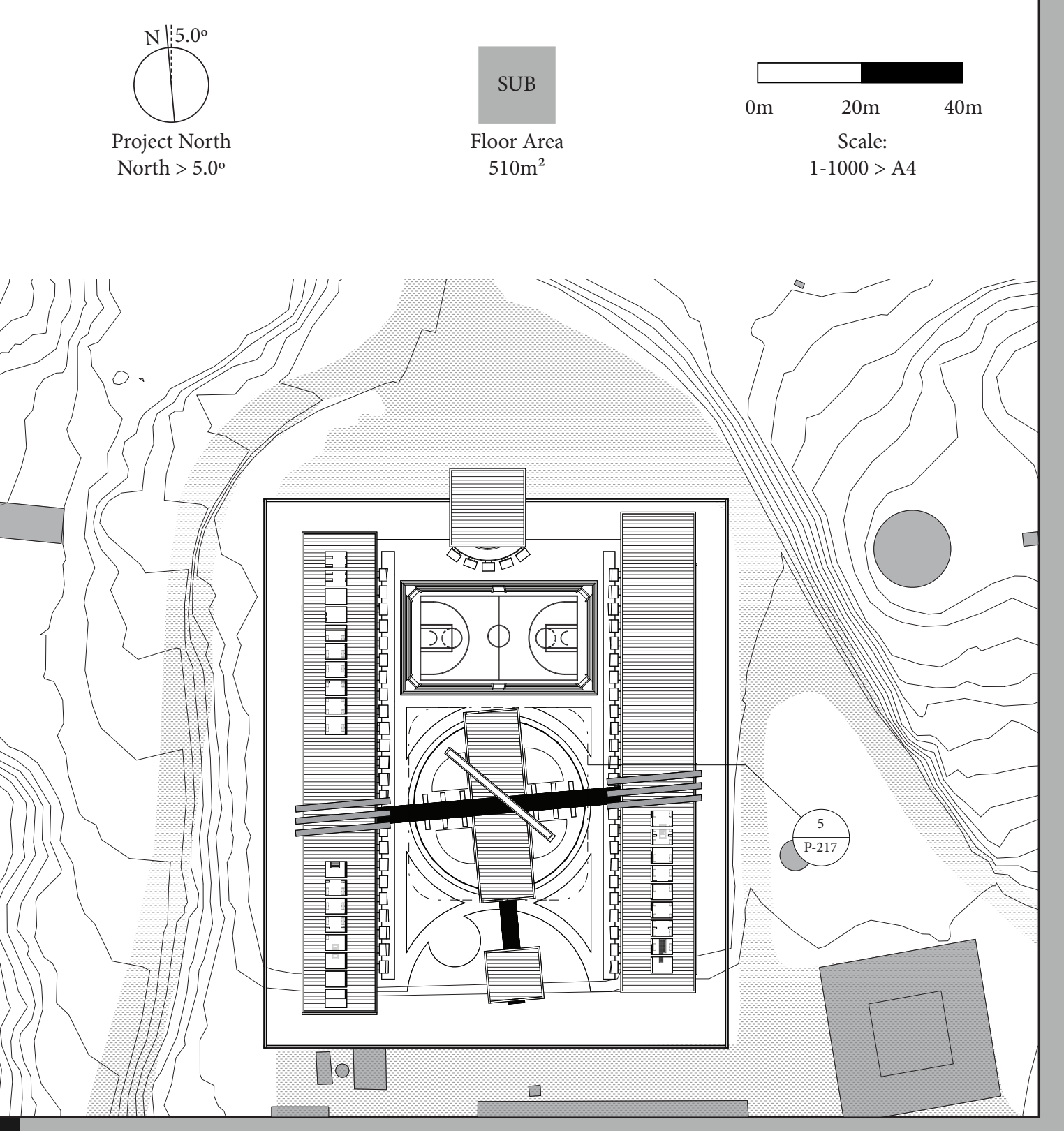

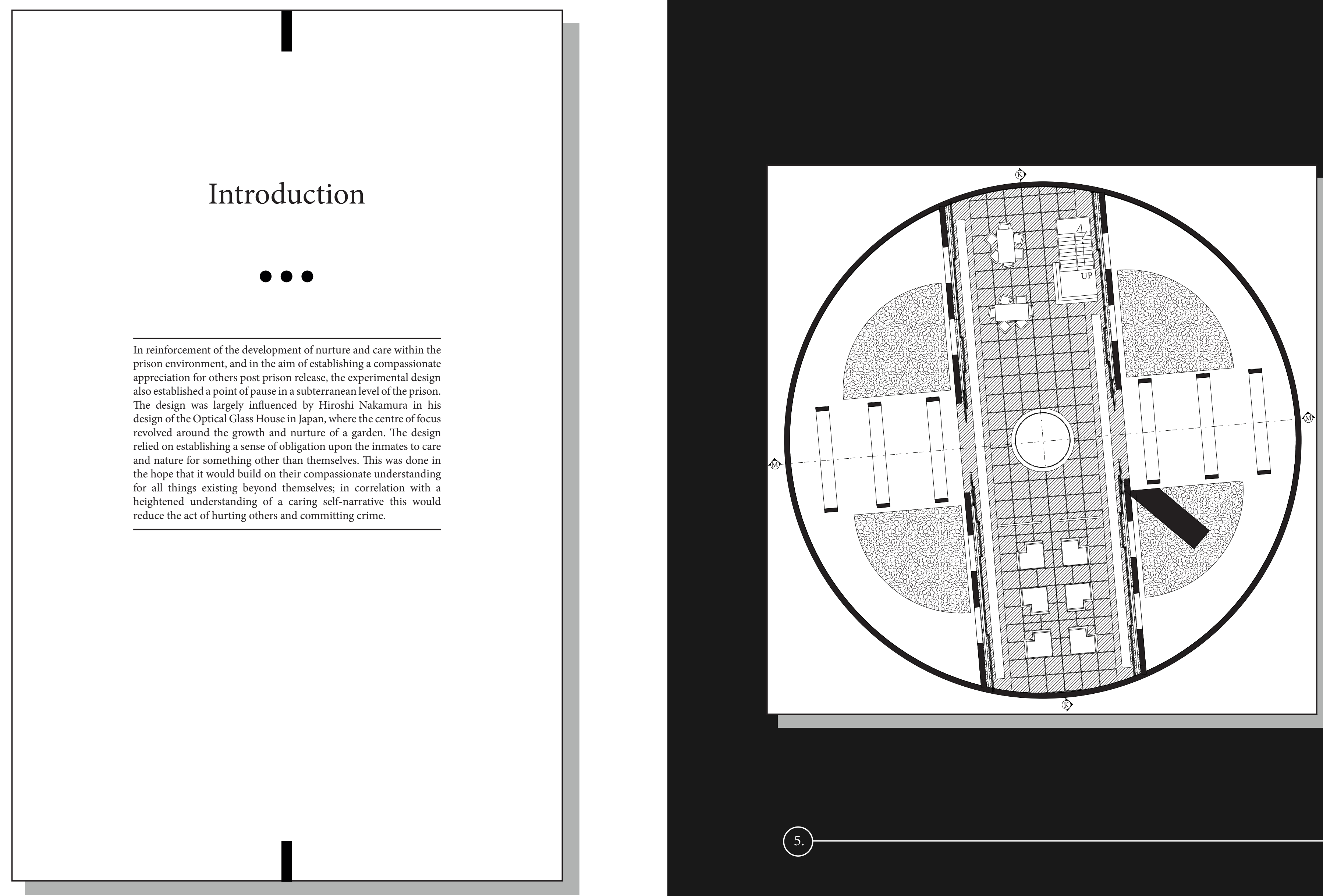

(5.) 
Sections

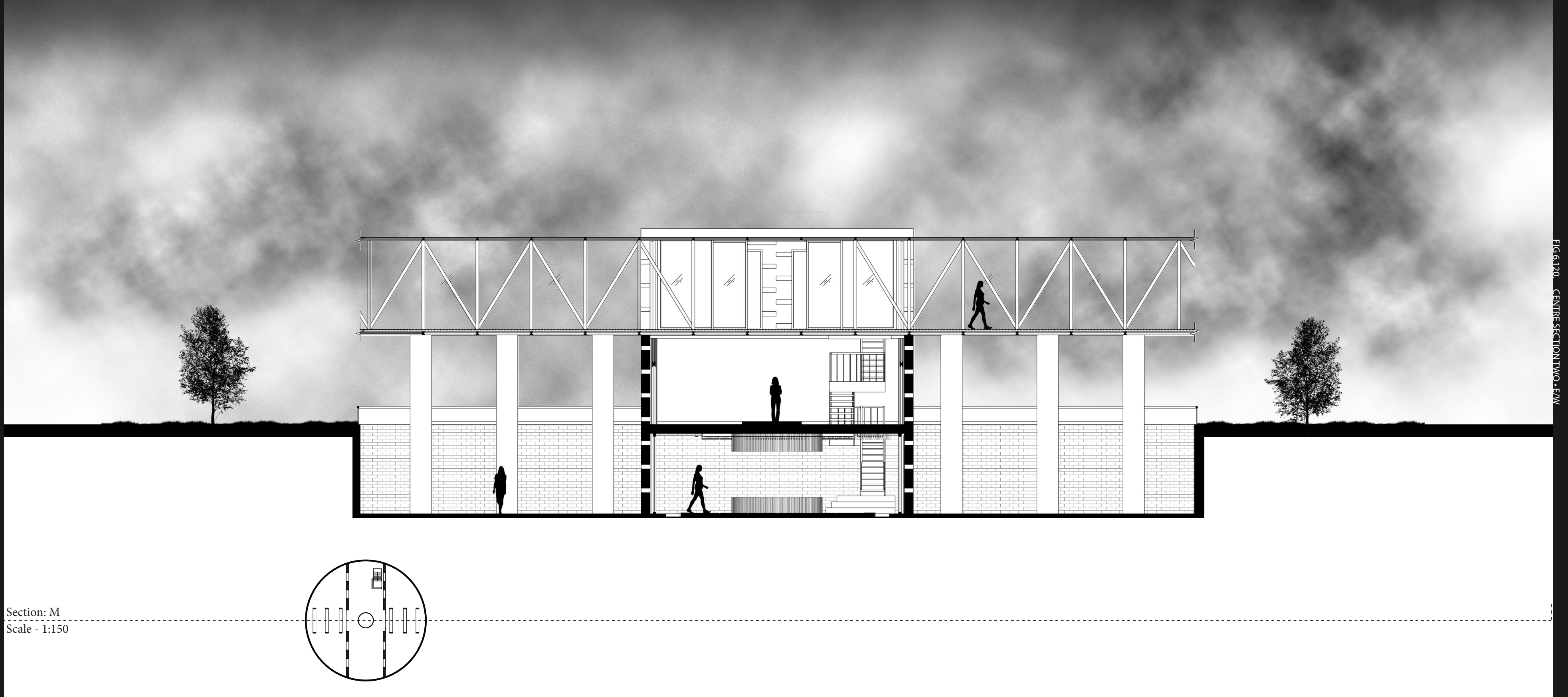




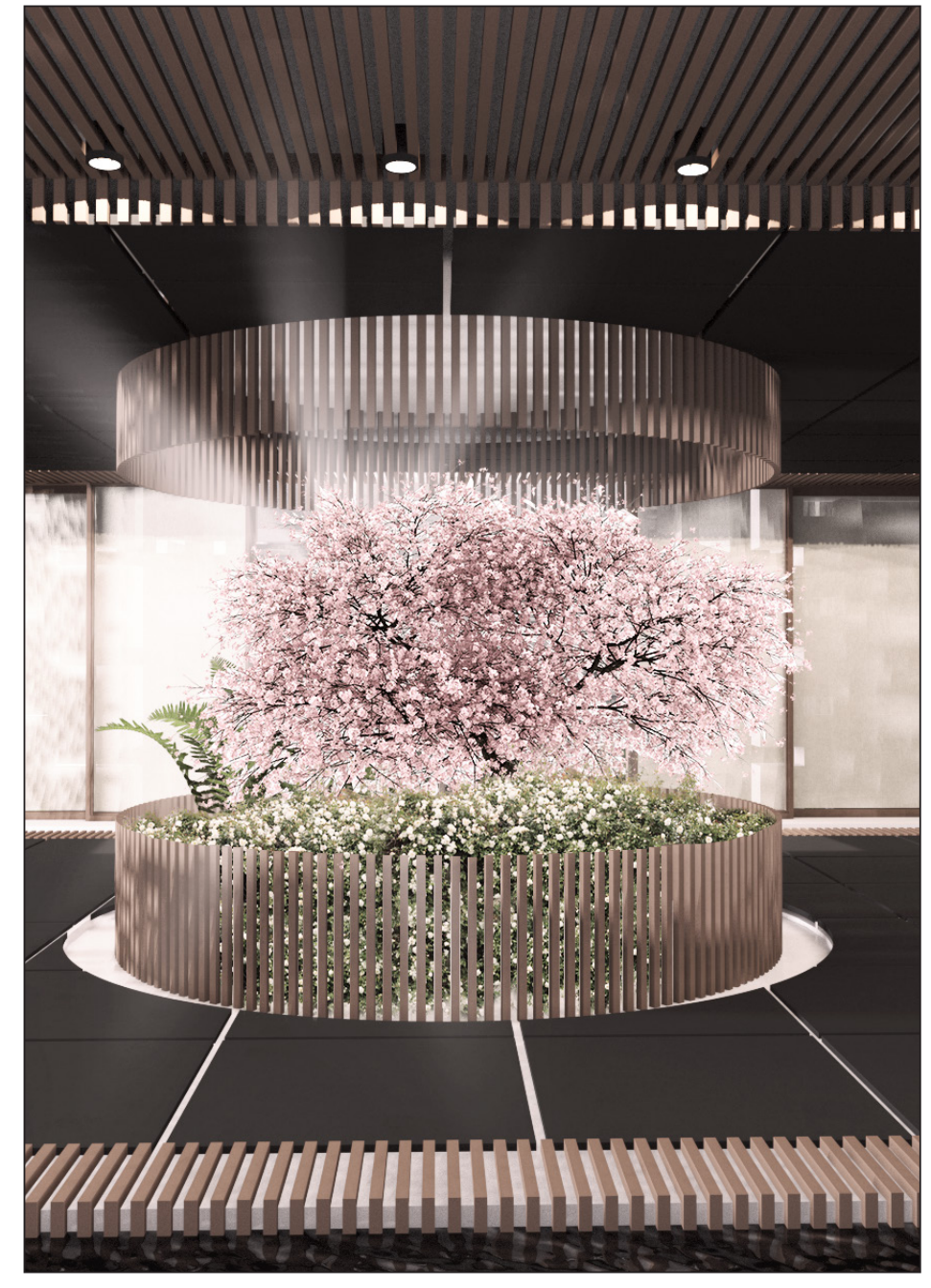

The development of the prison centre looked to further implement the theme of nurture and the compassionate understanding of others. In reflection of the experimental focal point astaut the garden, was not effective enough in the aim of encouraging care and nurture towards others; therefore, the developed design continues the theme of social interaction explored in the upper level, in conflemention implementation of elements nurture. The private visitation booths continue through the subterranean level and establish a delicacy throughout the space, as the care for inmates children and building on relationships occurs. A heightened sense of Intimacy is enphasised his on the use with flowing water and the warm colour pallet this is influenced by Peter Zumthor in his design of the Therme Vals in Switzerland. The flowing water also acts as a moat dividing the interior from the exterior as it emphasises the act of moving outside, by way of

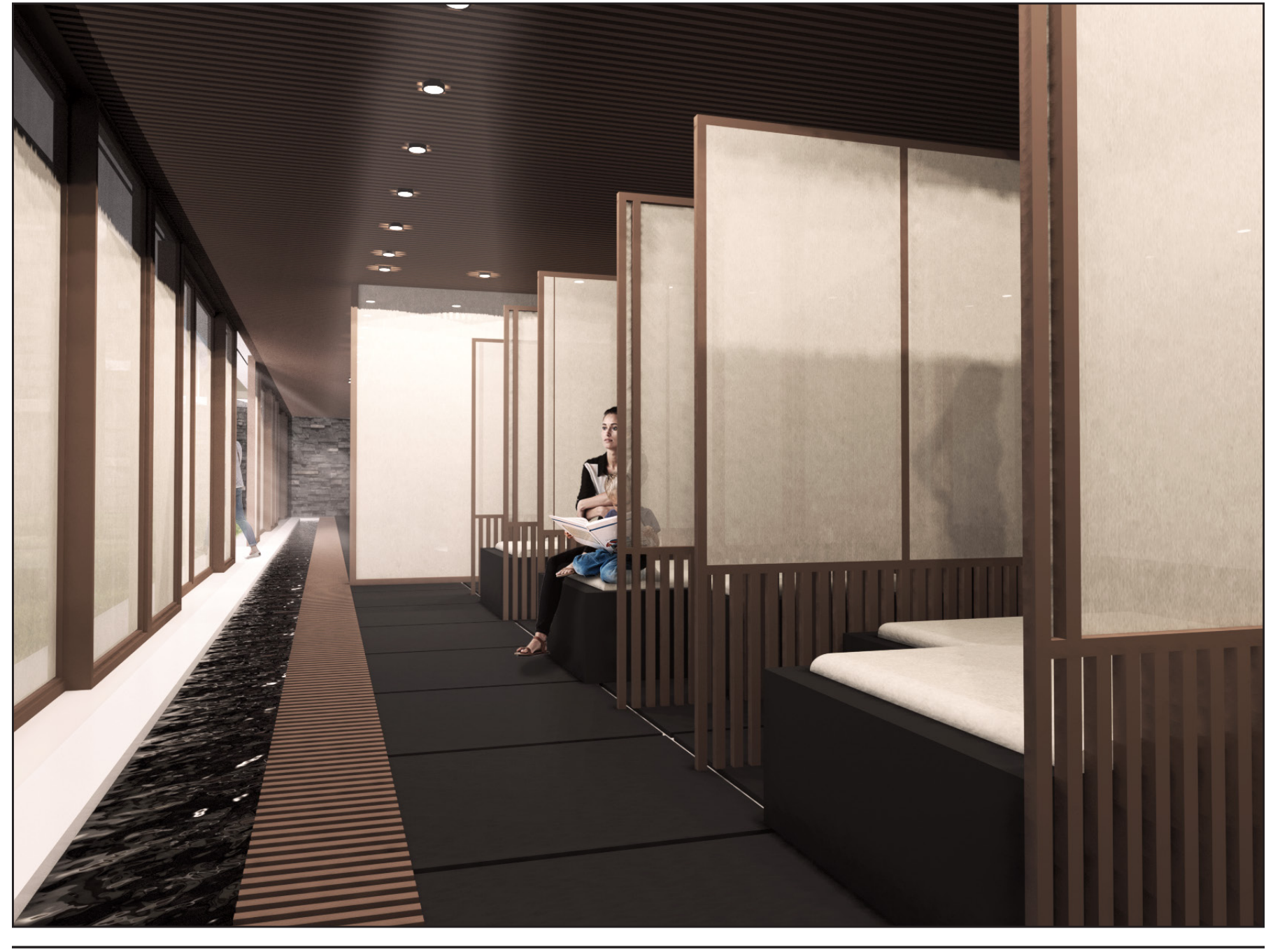

stepping over the water. The material study influenced the use of wood throughout the design as it further highlights the living plants and wooden textures; it is at this point in the design that inmates can begin to interact with utopia and life in their surrounding materials, and can experience the prison for its qualities of nurture as they develop their own interpretations of their surroundings. 

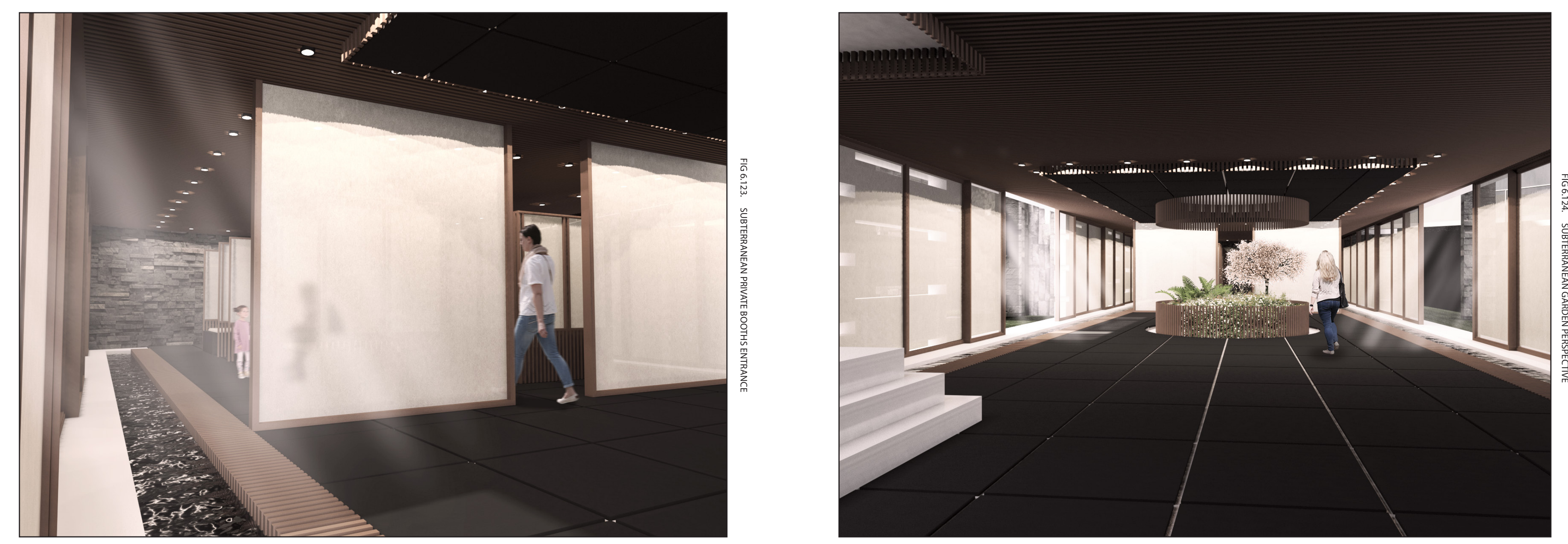

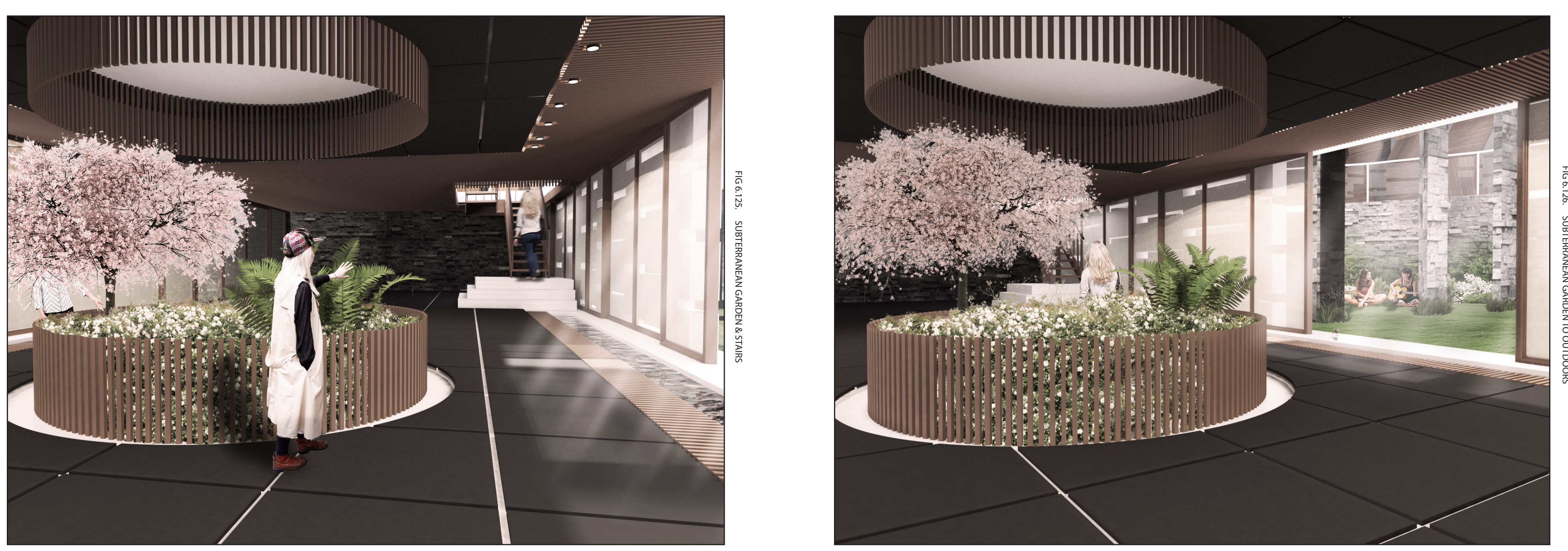


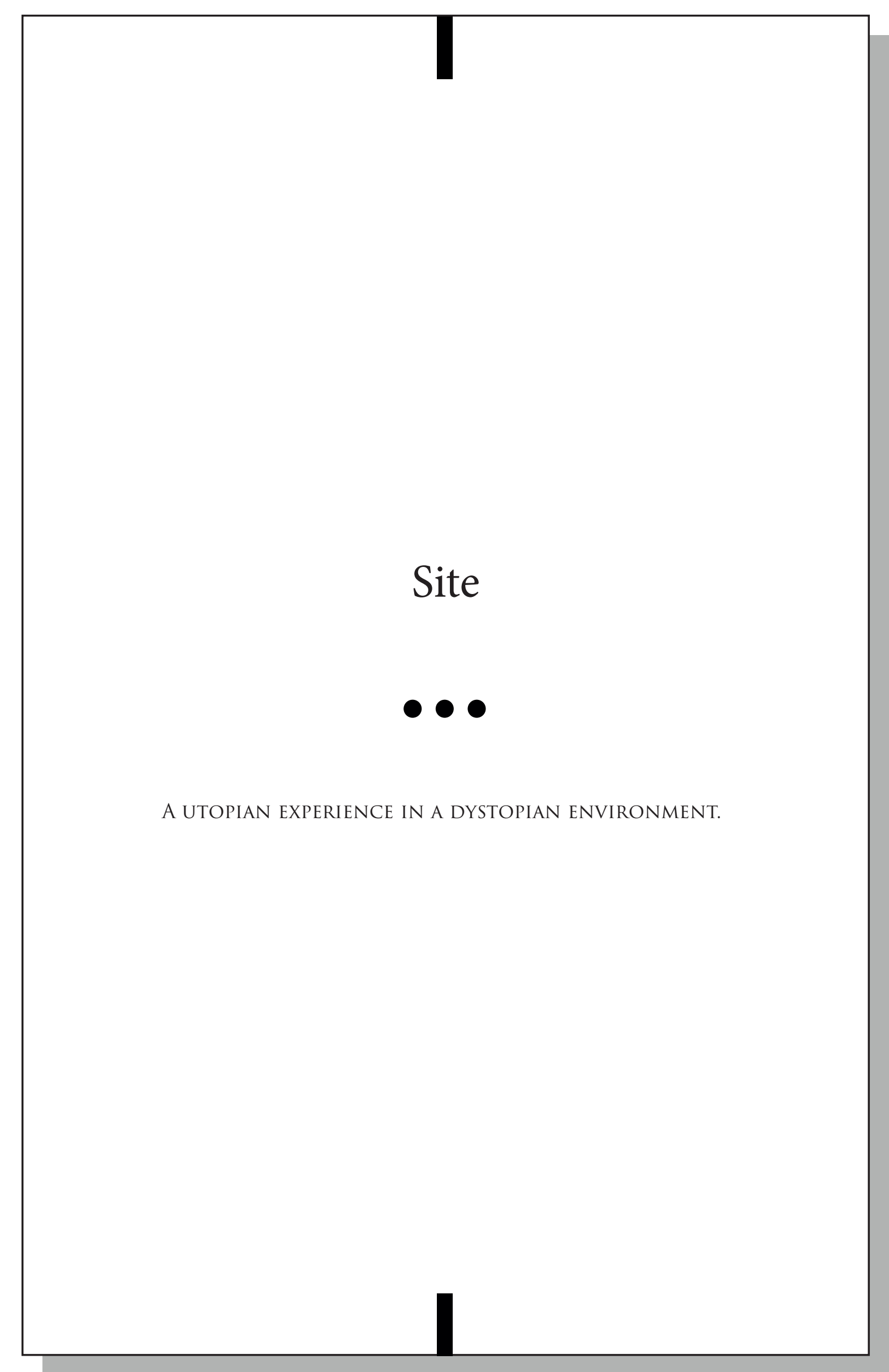




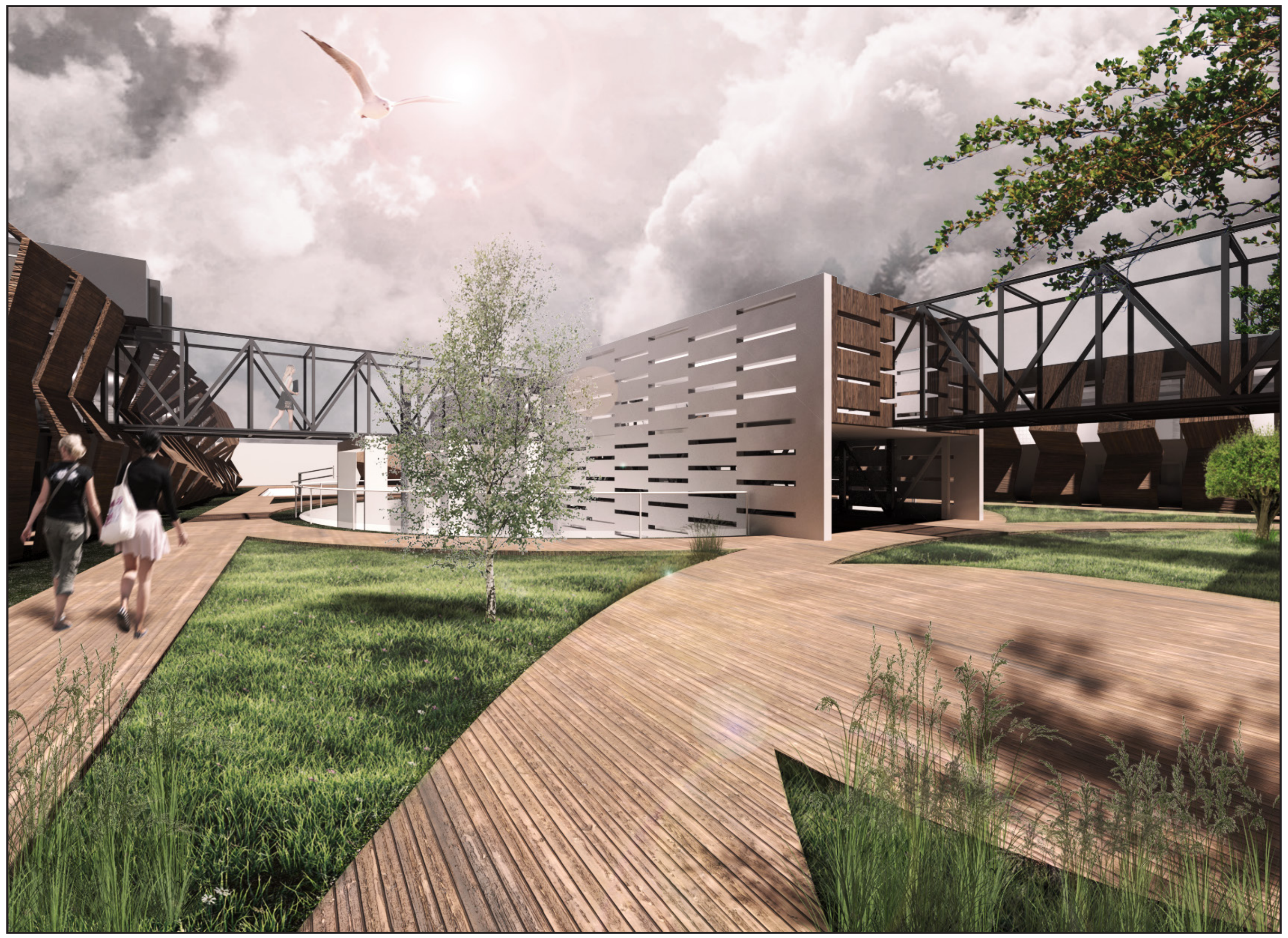




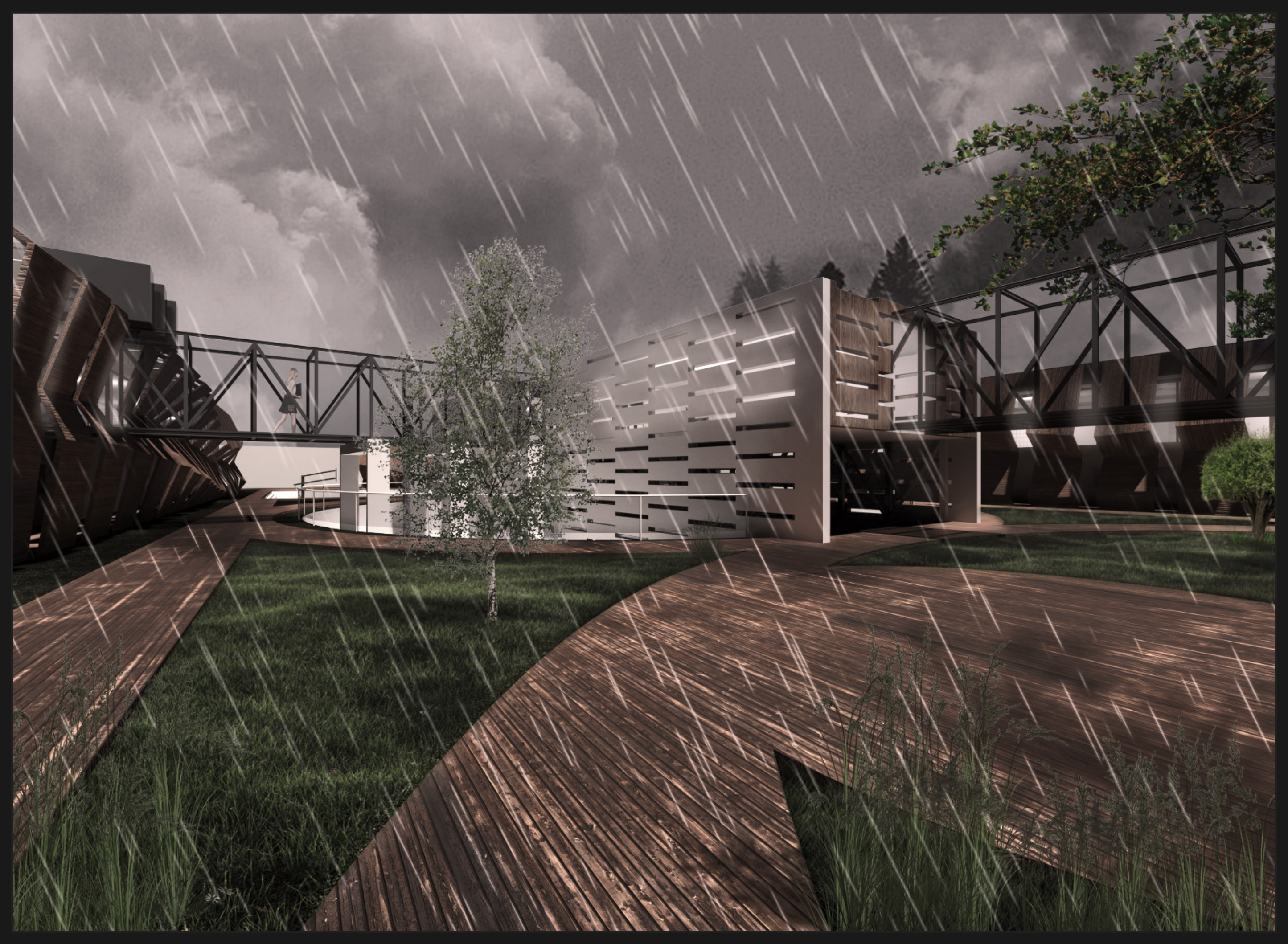




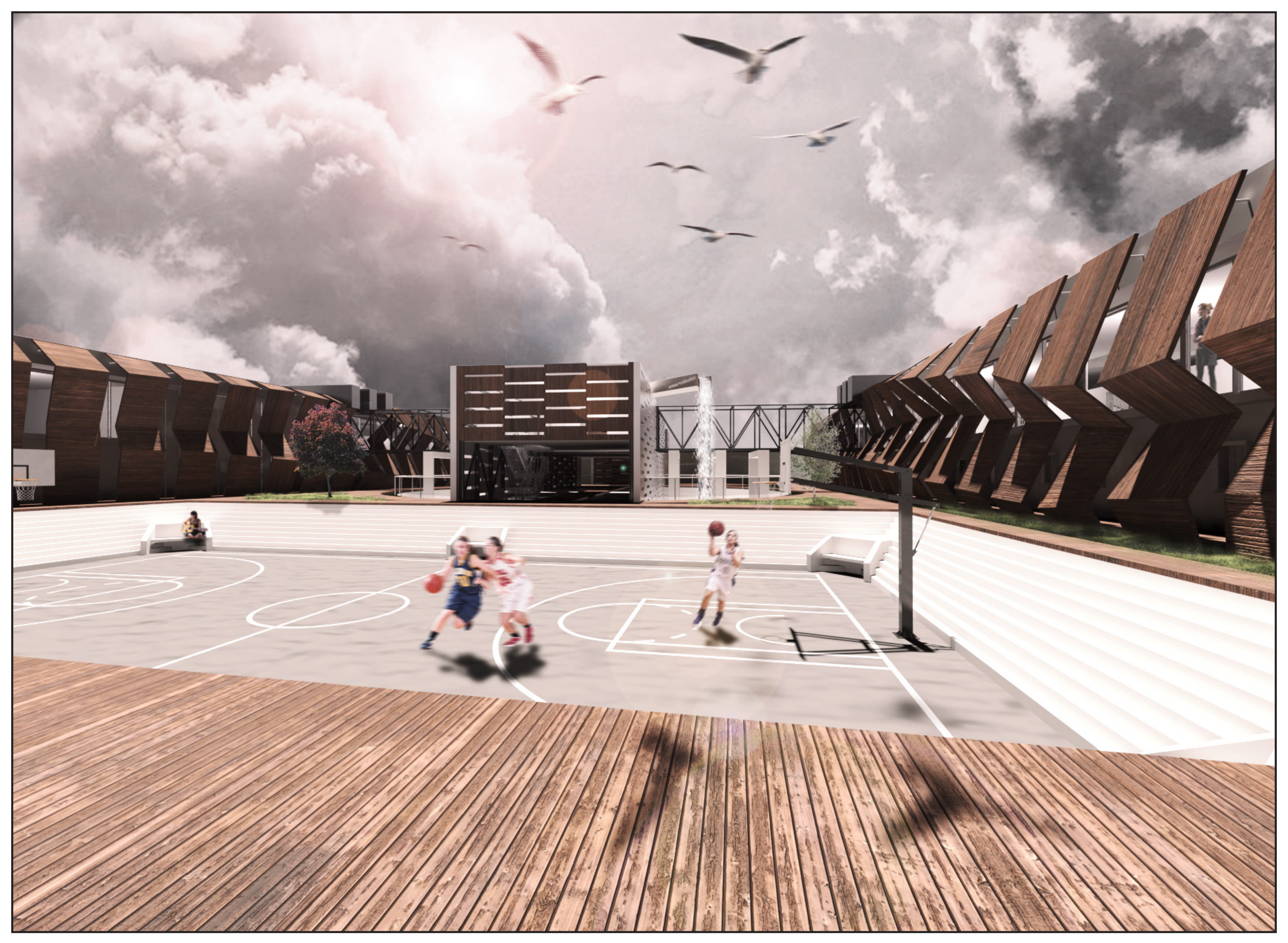




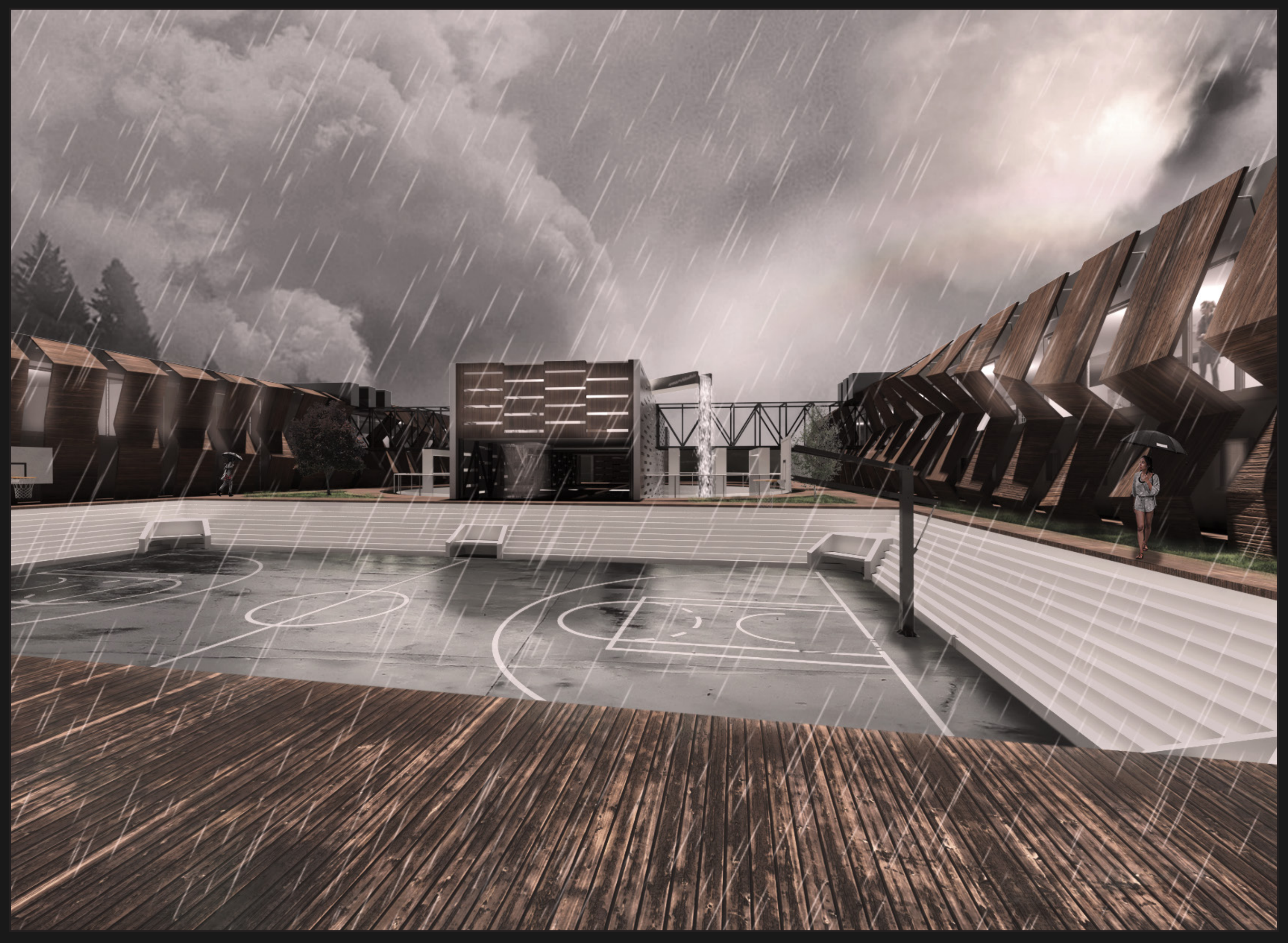



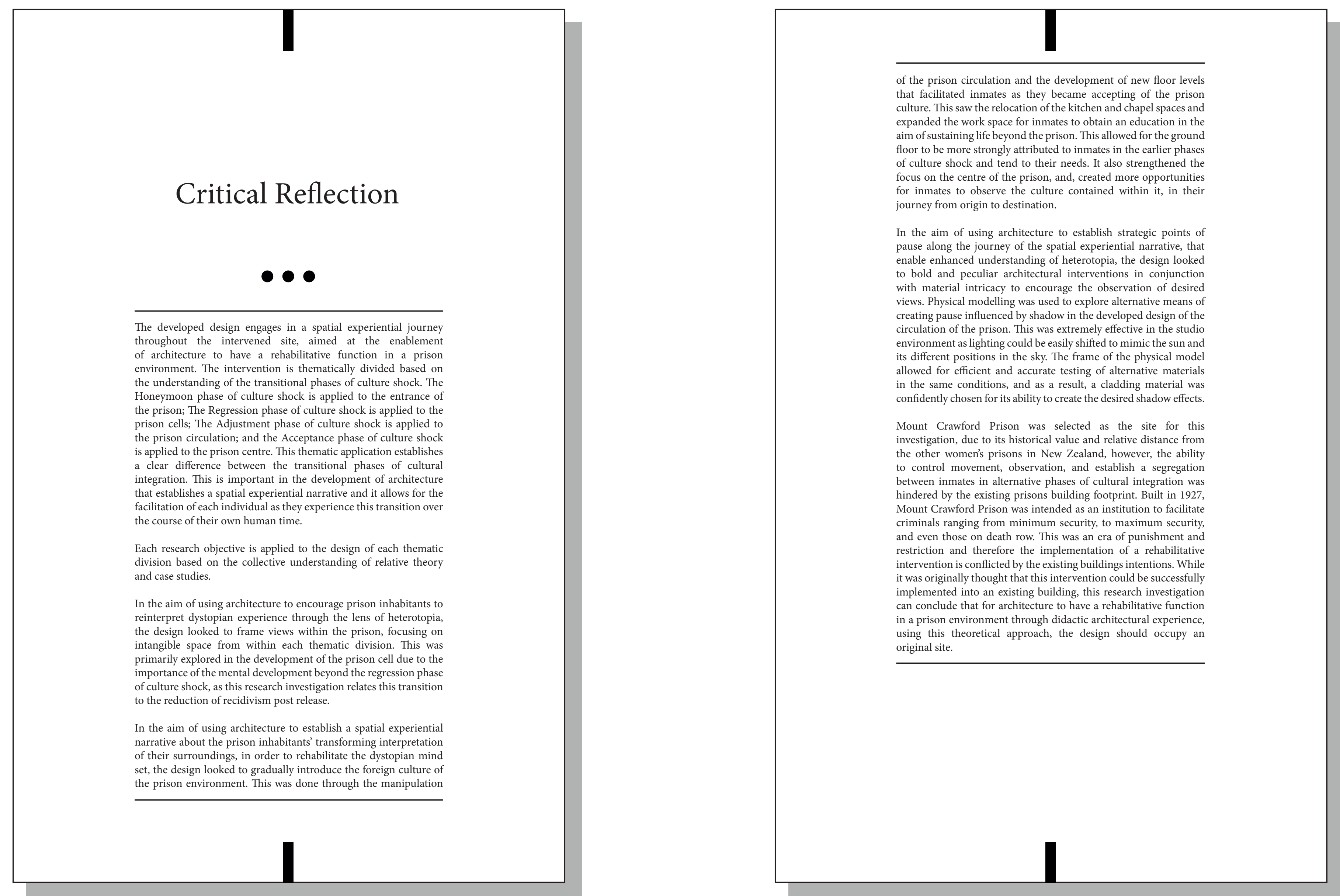


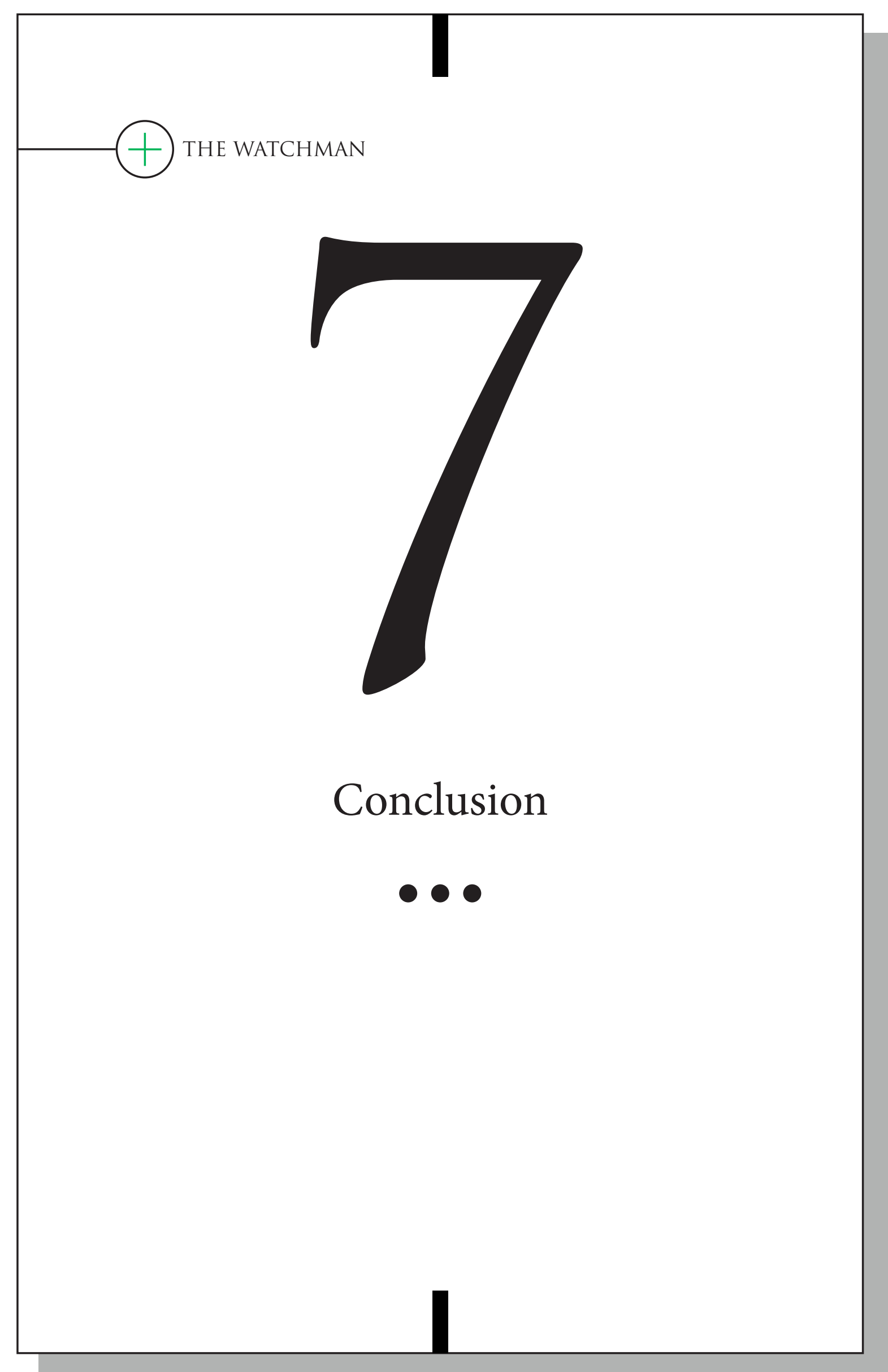





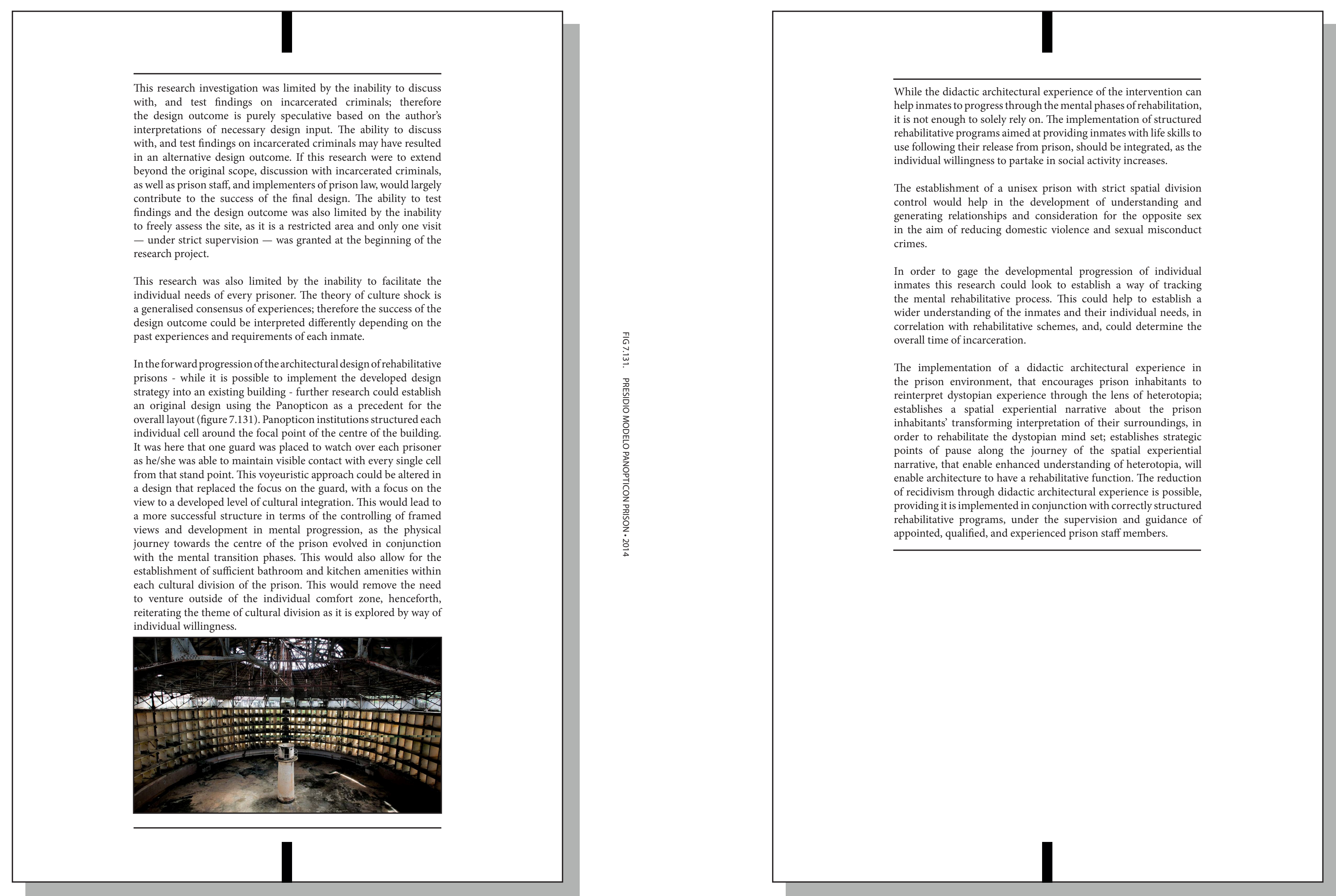


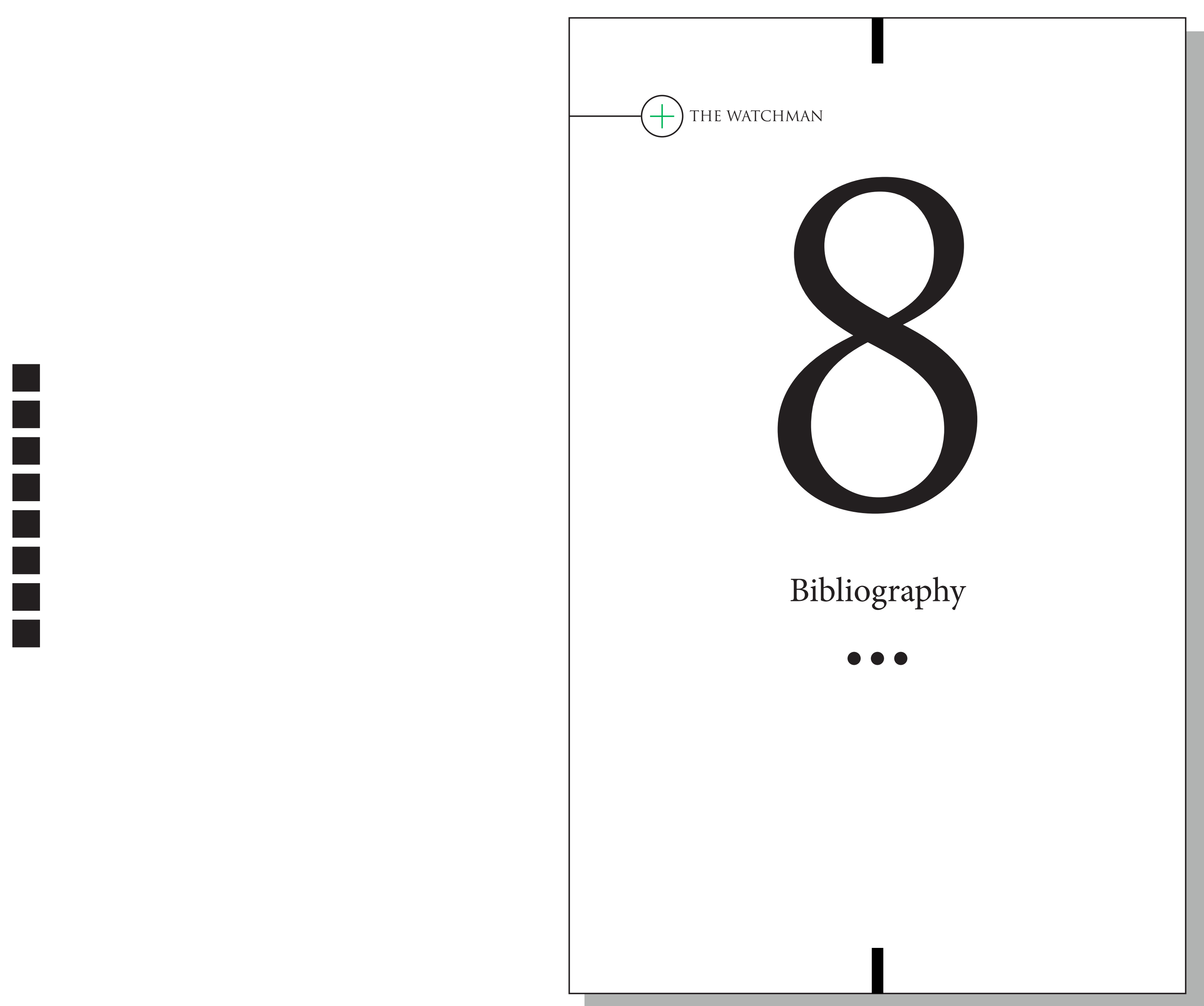




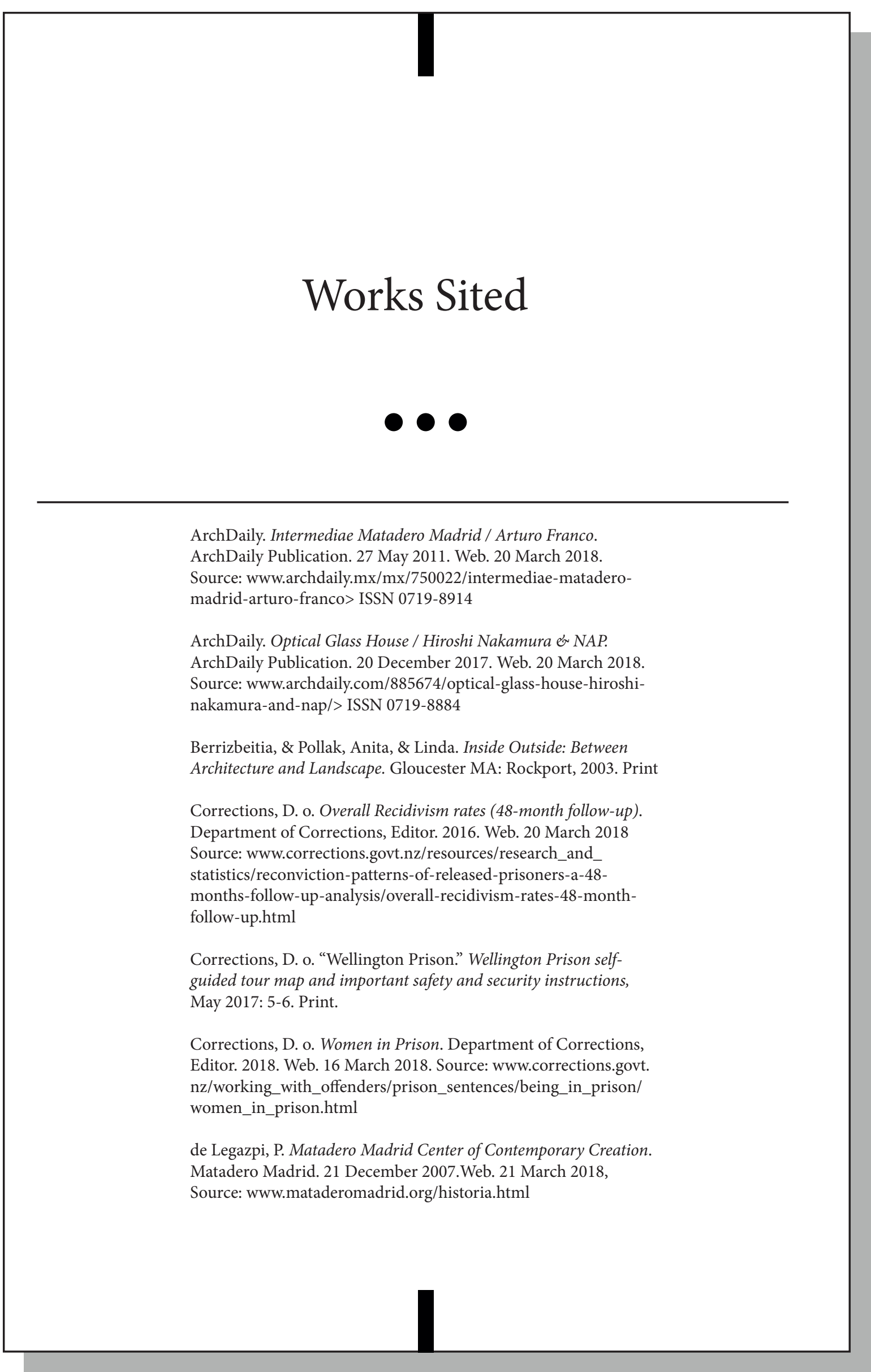

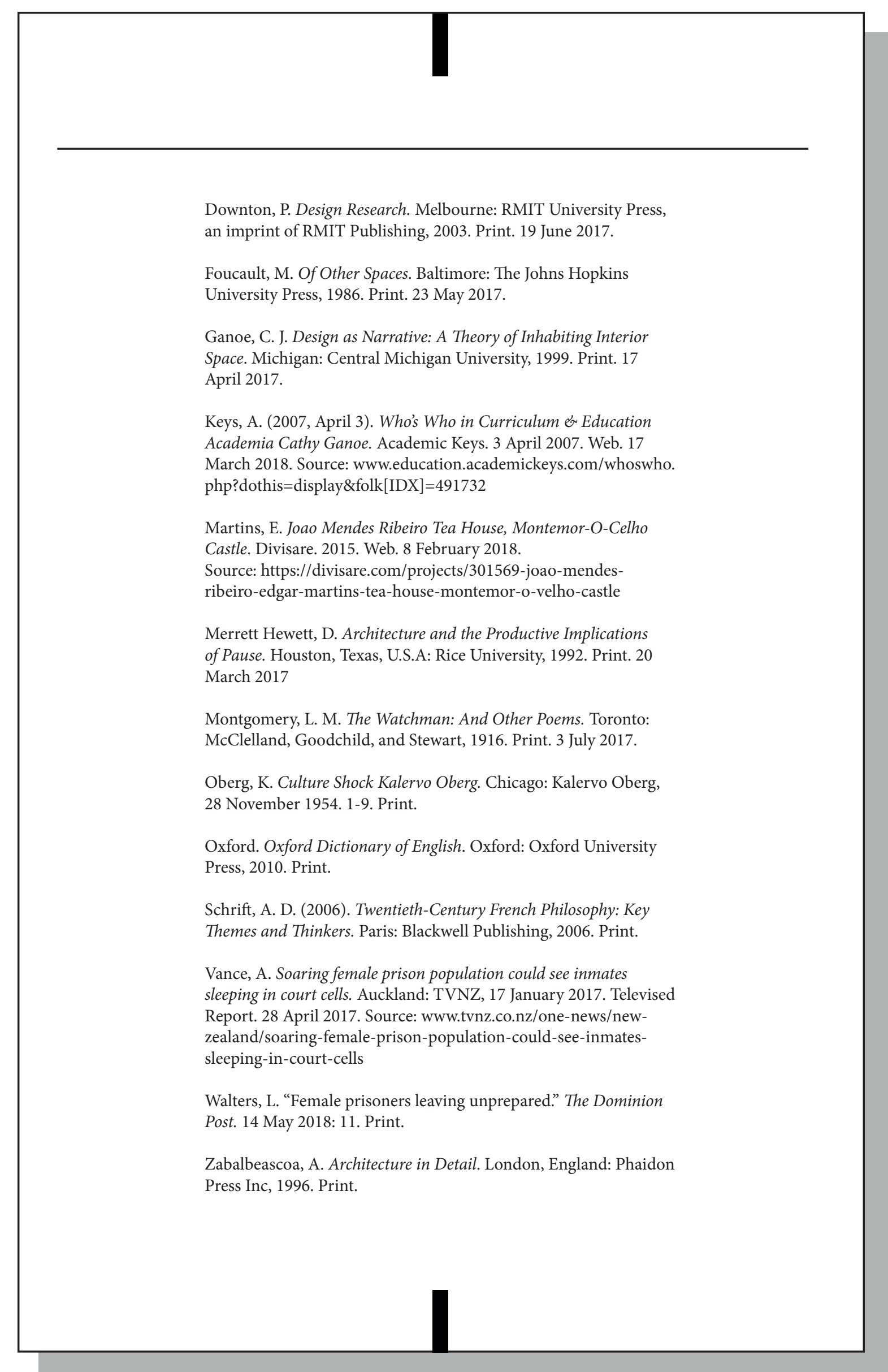




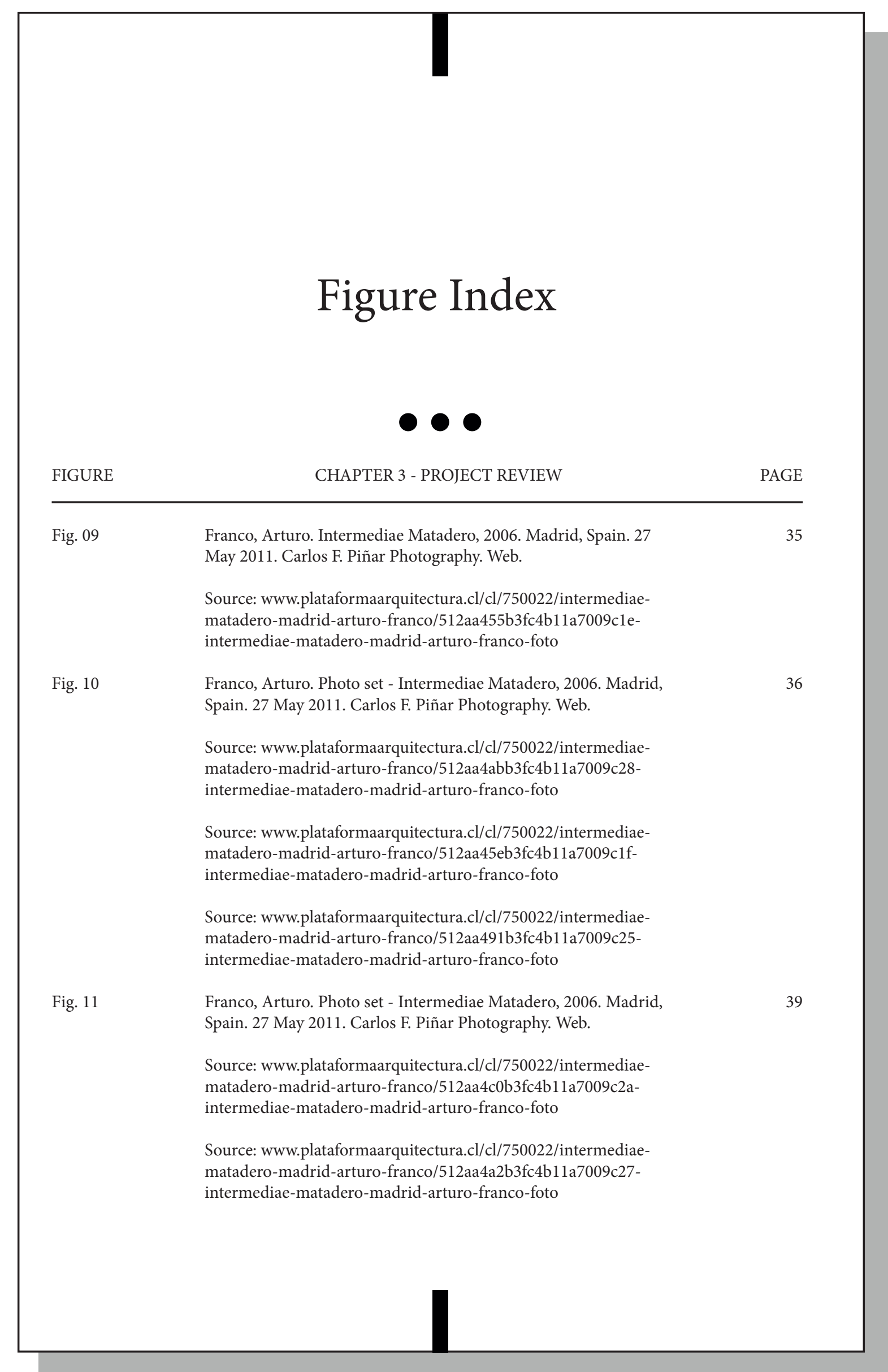

\begin{tabular}{|c|c|c|}
\hline FIGURE & CHAPTER 3 - PROJECT REVIEW & PAGE \\
\hline Fig. 12 & $\begin{array}{l}\text { Nakamura, Hiroshi. The Optical Glass House, 2012. Madrid, Spain. } \\
20 \text { December 2017. Koji Fuji Photography. Web. } \\
\text { Source: wwwwarchdaily.com/8856744/optical-glass-house-hiroshi- } \\
\text { nakamura-and-nap/5a386004b22ees8ef83000068-optical-glass- } \\
\text { house-hiroshi-nakamura-and-nap-photo }\end{array}$ & 41 \\
\hline Fig. 13 & $\begin{array}{l}\text { Nakamura, Hiroshi. Photo Set - The Optical Glass House, } 2012 . \\
\text { Madrid, Spain. } 20 \text { December 2017. Koji Fuji Photography. Web. } \\
\text { Source: www.archdaily.com/885674/optical-glass-house-hiroshi- } \\
\text { nakamura-and-nap/5a385fb9b22e38eff3000063-optical-glass- } \\
\text { house-hiroshi-nakamura-and-nap-photo } \\
\text { Source: www.archdaily.com/885674/optical-glass-house-hiroshi- } \\
\text { nakamura-and-nap/5a386009b22e3885f900001a-optical-glass- } \\
\text { house-hiroshi-nakamura-and-nap-photo } \\
\text { Source: www.archdaily.com/885674/optical-glass-house-hiroshi- } \\
\text { nakamura-and-nap/5a385fcbb22e38ef83000064-optical-glass- } \\
\text { house-hiroshi-nakamura-and-nap-photo }\end{array}$ & 42 \\
\hline Fig. 14 & $\begin{array}{l}\text { Nakamura, Hiroshi. Photo Set - The Optical Glass House, } 2012 . \\
\text { Madrid, Spain. } 20 \text { December 2017. Koji Fuji Photography. Web. } \\
\text { Source: www.archdaily.com/885674/optical-glass-house-hiroshi- } \\
\text { nakamura-and-nap/5a385fefb22e3885f9000018-optical-glass- } \\
\text { house-hiroshi-nakamura-and-nap-photo } \\
\text { Source: www.archdaily.com/885674/optical-glass-house-hiroshi- } \\
\text { nakamura-and-nap/5a385fbeb22e3885f9000014-optical-glass- } \\
\text { house-hiroshi-nakamura-and-nap-photo }\end{array}$ & 45 \\
\hline Fig. 15 & $\begin{array}{l}\text { Miralles, Enric and Carme Pinos. Igualada Cemetery, } 1994 . \\
\text { Igualada, Spain. } 13 \text { June 2013. Rasmus Hjortshøj Photography. } \\
\text { Web. } \\
\text { Source: www.nnmprrv.tumblr.com/post/53505415960/igualada- } \\
\text { cemetary-by-enric-miralles-photos-by }\end{array}$ & 47 \\
\hline Fig. 16 & $\begin{array}{l}\text { Miralles, Enric and Carme Pinos. Photo Set - Igualada Cemetery, } \\
\text { 1994. Igualada, Spain. } 13 \text { June 2013. Rasmus Hjortshøj } \\
\text { Photography. Web. } \\
\text { Source: www.nnmprv.tumblr.com/post/53505415960/igualada- } \\
\text { cemetary-by-enric-miralles-photos-by }\end{array}$ & 48 \\
\hline
\end{tabular}




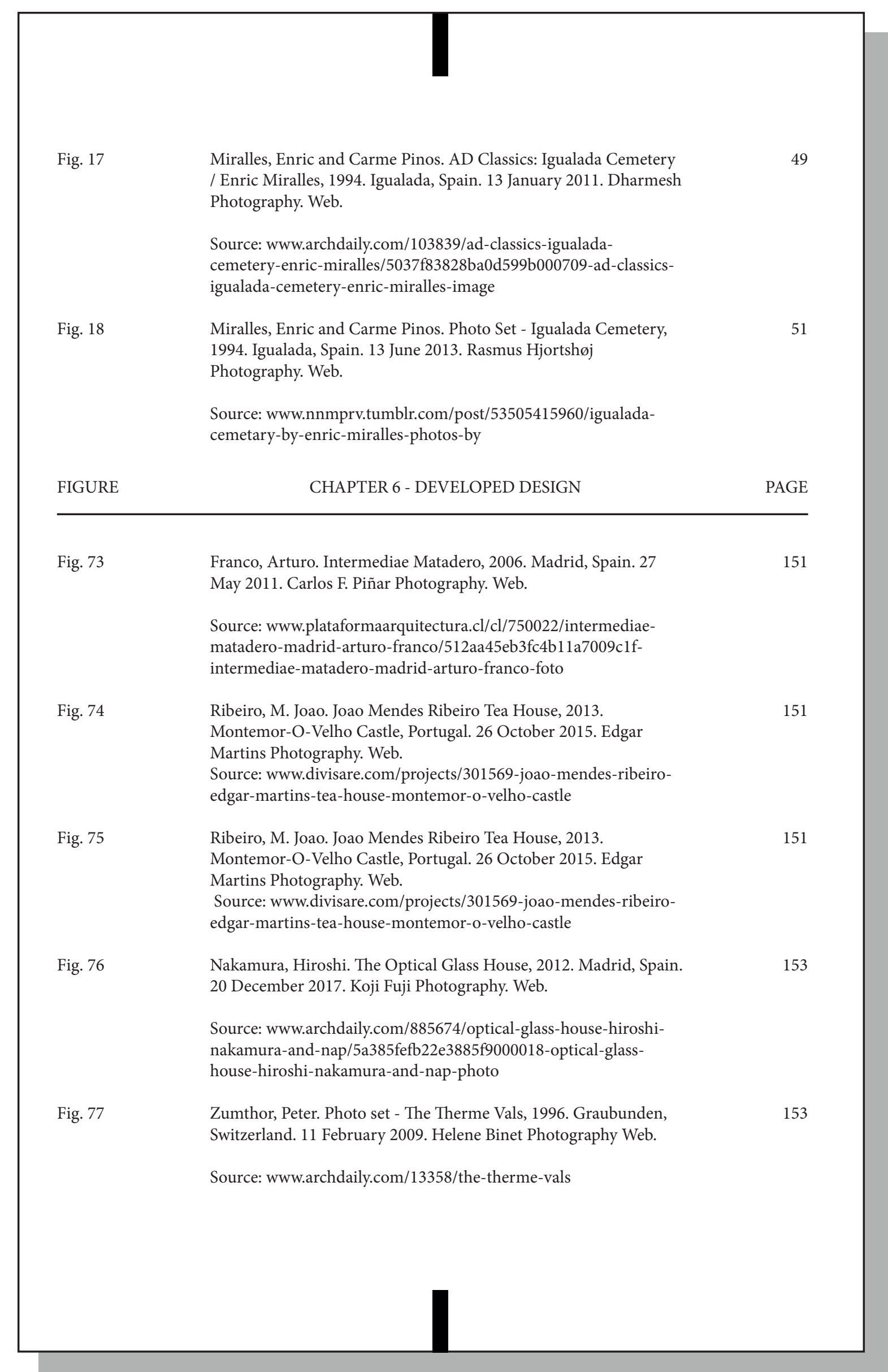

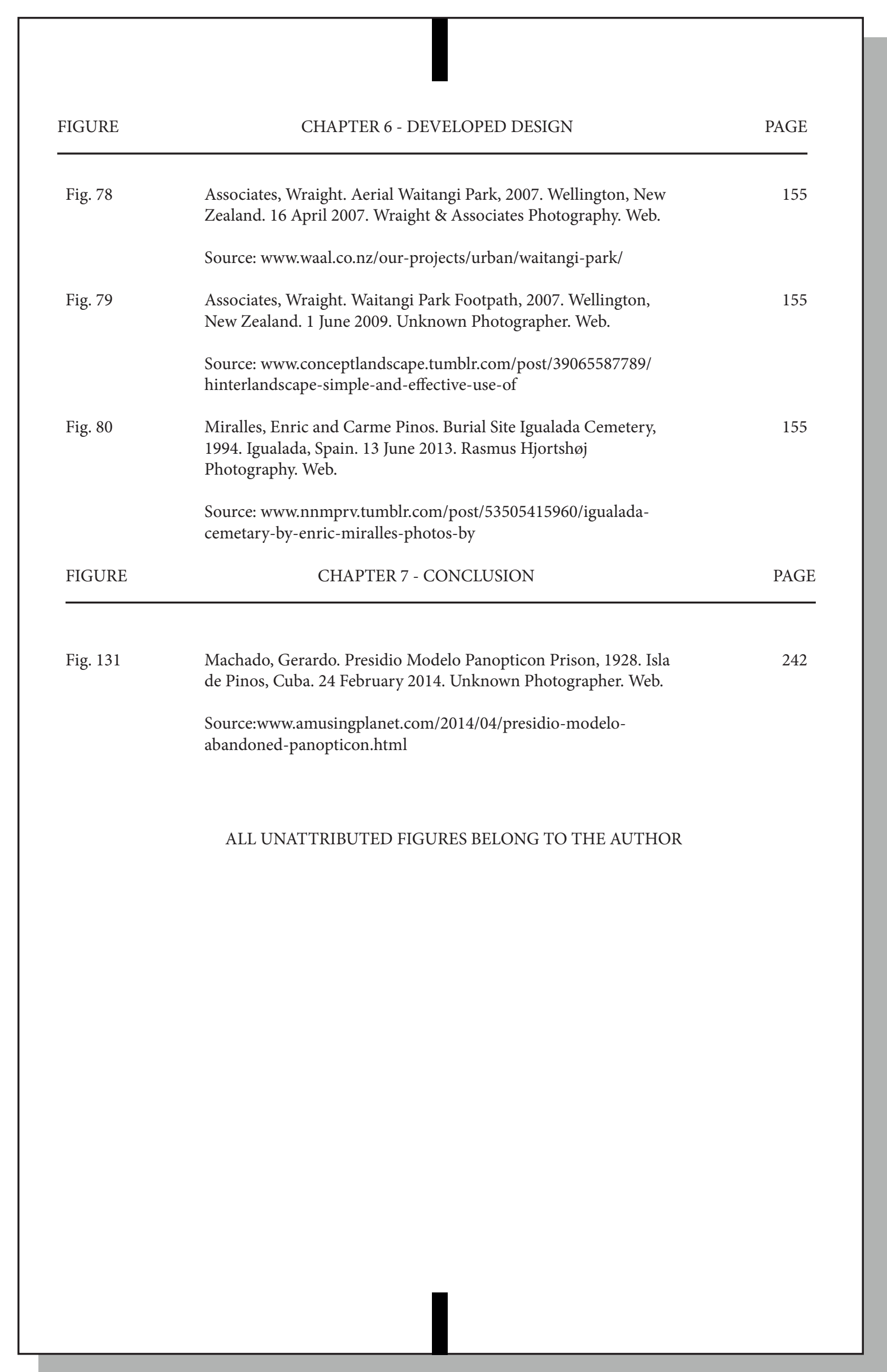




\section{THE WATCHMAN}

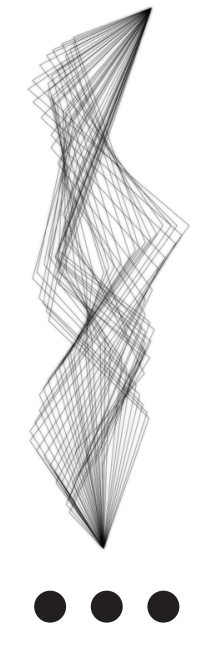

A DIDACTIC REHABILITATIVE ARCHITECTURE 